

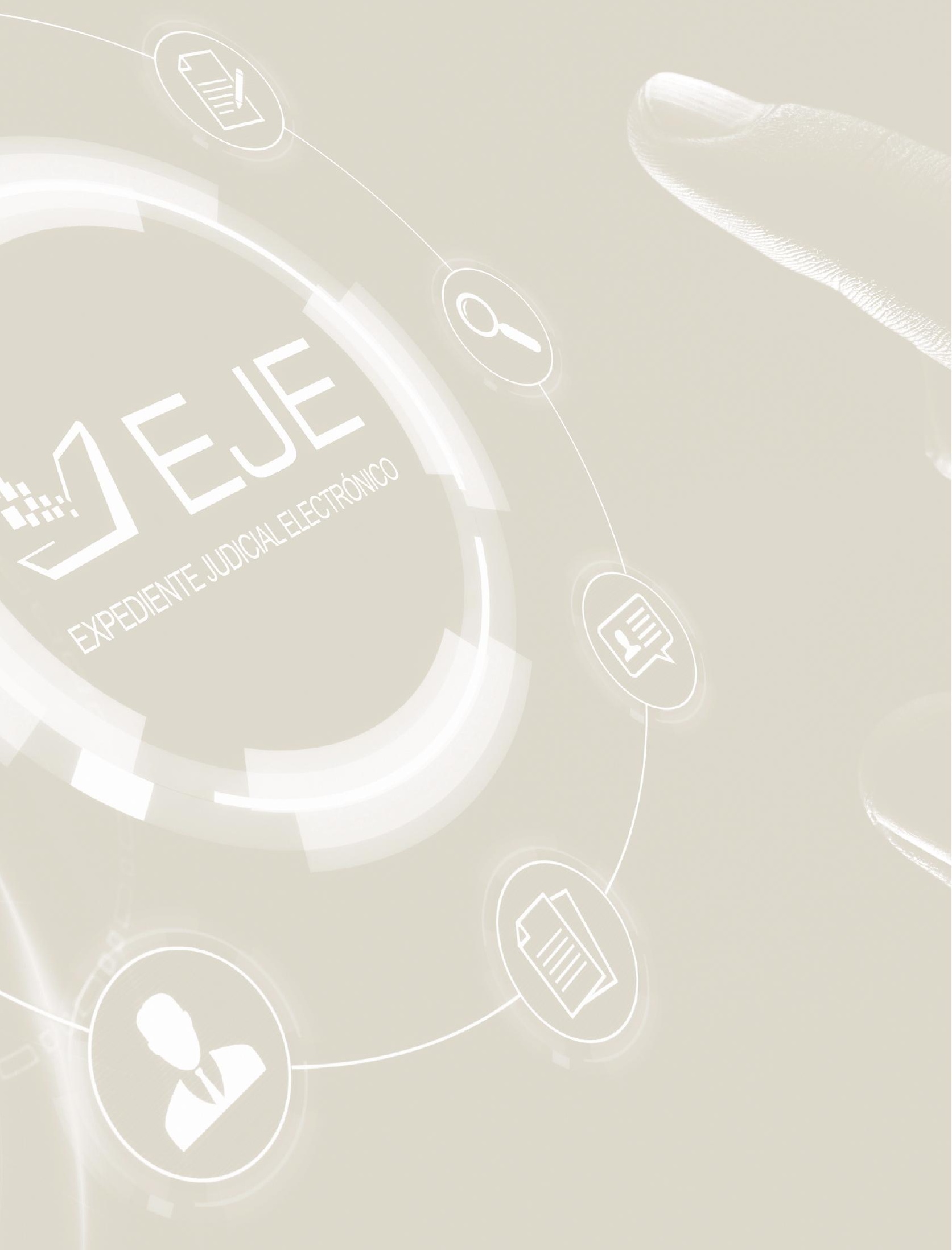




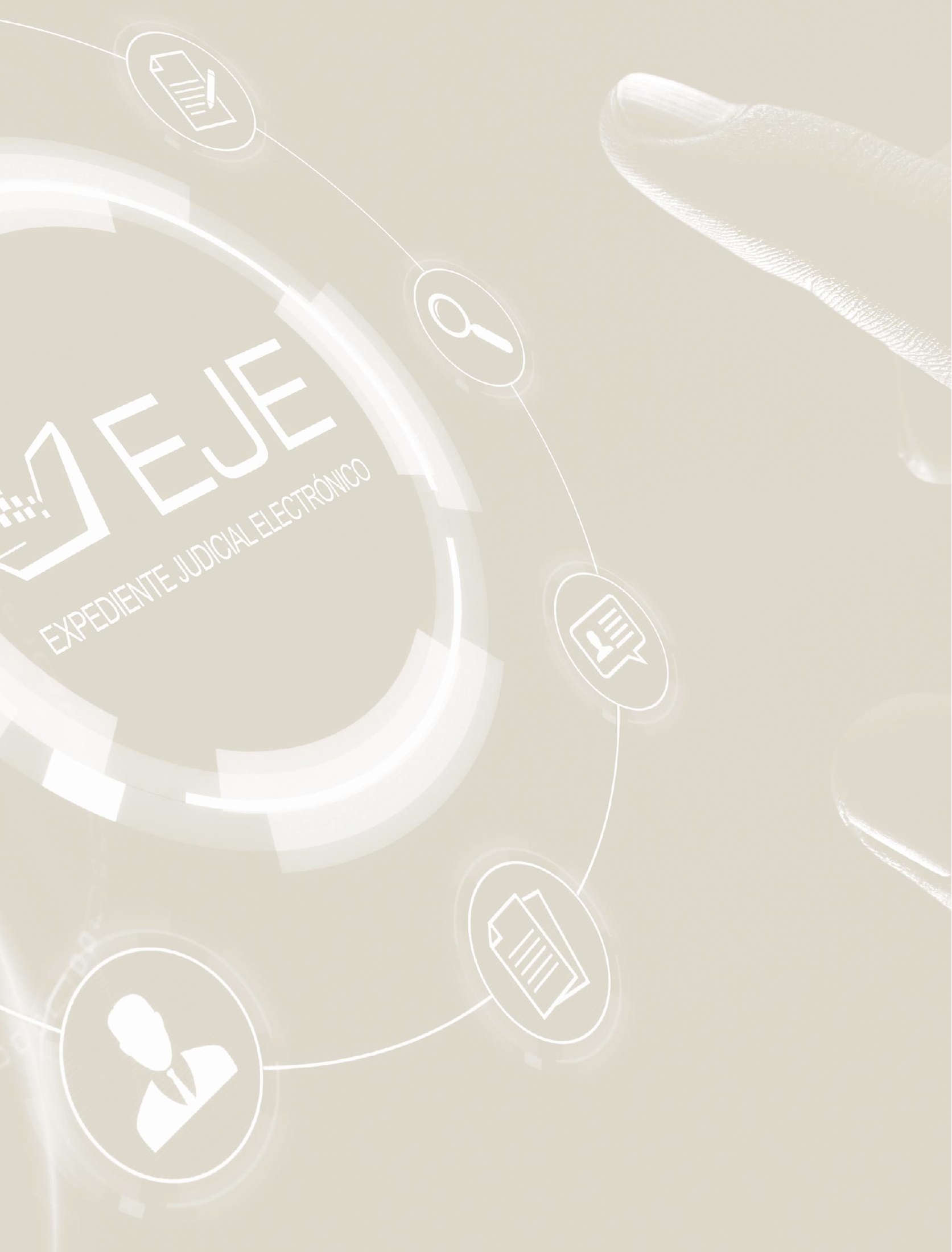




\title{
EXPEDIENTE JUDICIAL ELECTRÓNICO
}

\author{
므 poder Judicial del Perú \\ 므 FONDO EDITORIAL
}

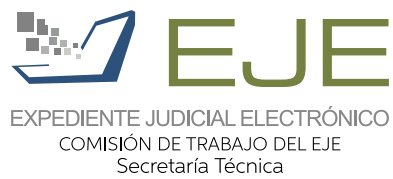


Expediente Judicial Electrónico

1. ${ }^{a}$ ed. Lima: Secretaría Técnica

de la Comisión de Trabajo del

Expediente Judicial Electrónico del

Poder Judicial/Fondo Editorial

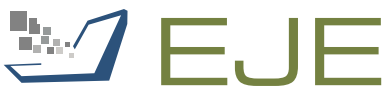

EXPEDIENTE JUDICIAL ELECTRÓNICO COMISIÓN DE TRABAJO DEL EJE Secretaría Técnica

del Poder Judicial del Perú, 2021.

172 pp., $17 \times 24.5 \mathrm{~cm}$

Este libro fue sometido a referato externo anónimo bajo el sistema doble ciego.

\section{Expediente Judicial Electrónico}

Primera edición: abril de 2021

Tiraje: 100 ejemplares

Hecho el Depósito Legal en la Biblioteca Nacional del Perú n. ${ }^{\circ}$ 2021-04331

ISBN: 978-612-4484-17-9

DOI:

Este libro se terminó de imprimir en abril de 2021 en Tarea Asociación Gráfica Educativa. Pasaje María Auxiliadora 156, Lima, Perú.
CC Poder Judicial del Perú

Secretaría Técnica de la Comisión de Trabajo del Expediente Judicial Electrónico del Poder Judicial

Palacio Nacional de Justicia, $2 .^{\circ}$ piso, oficina 244 Av. Paseo de la República cuadra 2 s/n, Lima, Perú Teléfono: (511) 410-1010, anexos: 11277 y 11297 Correo electrónico: secretariatecnicaeje1@pj.gob.pe

\section{Integrantes:}

Edith Elena Sicha Juárez, secretaria técnica Elizabeth Juana Abregú Meza

Fernando Juan Remuzgo Gamarra

Gloria Grande Gómez

Héctor Alberto Calcina Salcedo

Marcos Enrique Rojas Robles

Nataly Brunella Niquén Zárate

\section{(C) Poder Judicial del Perú}

Fondo Editorial del Poder Judicial

Palacio Nacional de Justicia, $4 .^{\circ}$ piso, oficina 421 Av. Paseo de la República cuadra 2 s/n, Lima, Perú Teléfono: (511) 410-1010, anexo: 11260

Correo electrónico: fondoeditorial@pj.gob.pe

Director: Francisco Távara Córdova

Coordinador: Helder Domínguez Haro

Editora responsable: Gladys Flores Heredia

Diseño gráfico: Rodolfo Loyola Mejía

Corrección de textos: Yuliana Padilla Elías

Diagramación: Miguel Condori Mamani

Asistente de edición: Silvia Ramos Romero 


\title{
COMISIÓN DE TRABAJO DEL EXPEDIENTE JUDICIAL ELECTRÓNICO DEL PODER JUDICIAL (AÑO 2020)
}

\author{
Héctor Enrique Lama More \\ Juez supremo titular
}

Presidente de la Comisión de Trabajo del Expediente Judicial Electrónico

Julio Martín Wong Abad

Juez supremo provisional de la Corte Suprema de Justicia

Miguel Ángel Benito Rivera Gamboa

Juez superior titular

Presidente de la Corte Superior de Justicia de Lima

Vicente Amador Pinedo Coa Juez superior titular

Presidente de la Corte Superior de Justicia de Lima Norte

Inés Felipa Villa Bonilla

Jueza superior titular

Presidenta de la Corte Superior Nacional de Justicia Penal Especializada

Sonia Bienvenida Torre Muñoz

Jueza superior titular

Coordinadora del Sistema Especializado en Crimen Organizado de la

Corte Superior Nacional de Justicia Penal Especializada

Ramiro Salinas Siccha

Juez superior titular

Coordinador del Sistema Especializado en Delitos de Corrupción de Funcionarios de la Corte Superior Nacional de Justicia Penal Especializada

\author{
Mariano Augusto Cucho Espinoza \\ Gerente general \\ Pedro Martín Chumpitaz Díaz \\ Gerente de Planificación \\ Rosmery Santos Magino \\ Gerente de Administración y Finanzas \\ Guillermo Pérez Silva \\ Gerente de Informática \\ Adler Horna Araujo
}

Gerente de Servicios Judiciales y Recaudación

Marco Antonio Sotomayor Vásquez

Subgerente de Desarrollo de Sistemas de Información

Antonio Vega Ventura

Jefe de la Oficina de Coordinación de Proyectos

Edith Elena Sicha Juárez

Secretaria técnica de la Comisión de Trabajo del Expediente Judicial Electrónico 



\section{ÍNDICE}

PRESENTACIÓN

Héctor Enrique Lama More

\section{CAPÍTULO I}

EXPEDIENTE JUDICIAL ELECTRÓNICO (EJE)

1.1. Antecedentes 15

1.2. Implementación del Expediente Judicial Electrónico (EJE) 24

1.2.1. Metodología de trabajo de la implementación 32

1.2.2. Componentes del EJE 38

1.3. Normatividad 40

1.3.1. Normatividad de gestión $\quad 40$

1.3.2. Normatividad de implementación 46

1.4. Acciones estratégicas y actividades operativas del Expediente Judicial Electrónico en desarrollo $\quad 55$

1.4.1. Acción estratégica 1

1.4.2. Acción estratégica 2

\section{CAPÍTULO II}

EL EJE EN CIFRAS

2.1. Ingresos a primera instancia $\quad 57$

2.1.1. Ingreso de demandas por tipo de órgano jurisdiccional $\quad 59$

2.1.2. Ingreso de demandas por corte superior de justicia 60

2.1.3. Ingreso de demandas por especialidad y tipo de órgano jurisdiccional 60

2.2. Salidas de primera instancia 64

2.3. Ingresos a segunda instancia 66

2.4. Salidas de segunda instancia 68

2.5. Elevaciones a las salas de la Corte Suprema de Justicia de la

República 


\section{CAPÍTULO III}

BENEFICIOS Y RESULTADOS DEL EJE 73

3.1. Beneficios 73

3.2. Resultados 76

3.2.1. Eficiencia del sistema 76

3.2.1.1. Impacto en los tiempos 76

a) Tiempo de calificación de la demanda 77

b) Tiempo de proveído de escritos 79

c) Tiempo de duración del proceso en primera instancia 82

d) Tiempo de duración del proceso en segunda instancia 84

3.2.1.2. Reducción de costos e impacto ecológico 87

3.2.2. Predictibilidad del sistema 88

3.2.2.1. Visor $\quad 89$

3.2.2.2. Videoconferencias $\quad 89$

3.2.2.3. Sistema de Notificaciones 91

a) Casillas electrónicas 92

b) Cédulas de notificación físicas y electrónicas 99

3.2.3. Equidad del sistema 106

3.2.3.1. Uso de la Mesa de Partes Electrónica para la presentación de demandas 106

3.2.3.2. Uso de la Mesa de Partes Electrónica para la presentación de escritos

3.2.3.3. Uso de la Mesa de Partes Electrónica en el marco de la Resolución Administrativa n. ${ }^{\circ}$ 133-2020-CE-PJ

\section{CAPÍTULO IV}

\section{EVENTOS Y CAPACITACIONES}

4.1. Congresos internacionales del EJE

4.1.1. I Congreso Internacional

4.1.2. II Congreso Internacional

4.2. Capacitaciones externas

4.2.1. Actividades de capacitación externa realizadas durante el año 2019

4.2.1.1. Talleres teórico-prácticos

4.2.1.2. Conferencias 
a) Conferencias para abogados

b) Conferencias para estudiantes de Derecho 130

4.2.1.3. Visitas guiadas

4.2.1.4. Charlas al público en general

4.2.1.5. Taller in-house

4.2.2. Actividades de capacitación externa realizadas durante el año 2020

4.2.2.1. Videoconferencias

a) Uso de la Mesa de Partes Electrónica (MPE) en el contexto del estado de emergencia nacional

b) Reactivación del Poder Judicial y uso de la Mesa de Partes Electrónica como herramienta preventiva ante la COVID-19

4.2.2.2. Capacitaciones virtuales

a) Capacitación antes de la implementación

b) Capacitación de reforzamiento

c) Capacitación a usuarios del Distrito Judicial de Huánuco

4.2.2.3. II Congreso Internacional

4.3.1. Actividades de capacitación interna realizadas durante el año 2019

4.3.1.1. Participación del EJE en charlas de inducción 138

4.3.1.2. Charla a personal del Poder Judicial 139

4.3.1.3. I Congreso Internacional

4.3.2. Actividades de capacitación interna realizadas durante el año 2020

4.3.2.1. Capacitaciones de reforzamiento

4.3.2.2. Capacitaciones antes de la implementación

a) Capacitación virtual en cinco nuevas cortes 140

b) Capacitación virtual en siete nuevas cortes 141

c) Capacitación virtual en la especialidad civil-litigación oral

d) Capacitación virtual en la especialidad penal-NCPP 
4.3.2.3. Personal del Poder Judicial fue capacitado en el uso de la Mesa de Partes Electrónica

4.3.2.4. II Congreso Internacional

\section{CAPÍTULO V}

PROYECCIONES

5.1. Desafíos y retos

LISTA DE ESQUEMAS

LISTA DE FIGURAS

LISTA DE TABLAS

REFERENCIAS 


\section{PReSENTACión}

El Expediente Judicial Electrónico (EJE), que se implementó desde el ańo 2017 en diversas cortes superiores de justicia del país, ha sido determinante en la iniciativa de modernización del Poder Judicial. Con este se busca dejar de lado el uso de papel, el archivamiento antiguo y las notificaciones tradicionales presenciales, para cambiarlos por procesos judiciales digitales, que brinden soluciones céleres y eficaces.

La presente publicación es un material óptimo — desarrollado por la Comisión de Trabajo, la cual presido, y la Secretaría Técnica del EJE - que muestra las ejecuciones de gestión y las cifras del uso de las herramientas tecnológicas que brinda el Poder Judicial, engranadas al Sistema Integrado de Justicia (SIJ), para el acceso y servicio de justicia de la ciudadanía.

Es importante mencionar cómo inició este proceso en los diversos distritos judiciales del país: la primera implementación del EJE se dio en la Corte Superior de Justicia de Lima, en el $4 .^{\circ}$ Juzgado Comercial, y luego en 60 órganos jurisdiccionales. En el 2018, se implementó en 7 órganos jurisdiccionales; en el 2019, en 21, haciendo un total de 88 órganos jurisdiccionales. A diciembre de 2020, está en ejecución en 193 órganos jurisdiccionales de 17 cortes superiores del país (Lima, Lima Norte, Cajamarca, Puente Piedra-Ventanilla, Tacna, Callao, Cusco, Arequipa, Junín, Lima Sur, La Libertad, Lambayeque, Lima Este, Piura, Puno, Santa e Ica); asimismo, la Corte Superior Nacional de Justicia Penal Especializada (Mesa de Partes Electrónica, etapa intermedia) está inserta en la dinámica de transformación digital.

La crisis generada por la pandemia ha resultado una oportunidad de mejora, pues se han redoblado los esfuerzos en la transformación digital del sistema de justicia. De forma particular, se ha promovido la 
planificación estratégica en la ejecución del despliegue del uso del EJE en las cortes superiores de justicia a nivel nacional.

Cabe señalar que en la etapa de reactivación de los servicios de justicia se dinamizan los beneficios en el avance del Expediente Judicial Electrónico (EJE), que viene acompañado de la implantación de la Mesa de Partes Electrónica (MPE), cuyo servicio se ha ampliado a las diversas especialidades, adecuándose a las necesidades de los justiciables que buscan acceder a la tutela de sus derechos.

El confinamiento por la COVID-19 representa un gran reto para el sistema de justicia. Ante ello, el Poder Judicial puso a disposición de la ciudadanía su plataforma digital para continuar brindando un servicio de justicia eficaz y célere, protegiendo la salud e integridad de juezas, jueces, auxiliares judiciales y litigantes. Así, fueron tramitados, desde el inicio de la cuarentena (en marzo) hasta finales de diciembre de 2020, 2227775 documentos a través de la MPE; 205153 de ellos mediante el EJE.

La MPE, habilitada durante la cuarentena para procesos con expedientes físicos en todas las especialidades, aprobada por Resolución Administrativa n. ${ }^{\circ}$ 133-2020-CE-PJ, permite a los usuarios presentar sus escritos, demandas o denuncias desde sus casas o estudios, de lunes a domingo, las 24 horas del día, sin acudir a las sedes judiciales.

Ello evidencia la capacidad de reacción del Poder Judicial para no detener la preservación de los derechos y simultáneamente asegurar el derecho a la vida y la salud de los ciudadanos que acceden al servicio de justicia. Las especialidades que emplearon este medio digital fueron laboral con el $27 \%$, familia civil $23 \%$, civil $19 \%$ y penal $16 \%$.

Por otra parte, capacitar a las juezas y los jueces y al personal auxiliar de los órganos jurisdiccionales donde se implementará el EJE también forma parte de nuestras diligencias, pues permite optimizar el uso de las herramientas tecnológicas del EJE en su aplicación, mediante capacitaciones en línea y difusión en forma virtual. Una acción similar se realizó con el reforzamiento de los conocimientos adquiridos respecto a las funcionalidades del EJE al personal de las cortes donde se implementó. 
Gestionar el cambio de accionar de los usuarios judiciales y litigantes para presentar demandas y escritos por la Mesa de Partes Electrónica permitió el aumento de ingresos electrónicos, pues mediante estrategias de difusión y capacitación se logró sensibilizar sobre la importancia del uso de las herramientas tecnológicas disponibles por el Poder Judicial y promover el uso de la MPE como eje de modernidad de la justicia peruana.

La transformación digital, prevista como objetivo estratégico institucional (OEI) en el Plan Estratégico Institucional 2021-2030 del Poder Judicial, supone la modernización del sistema de justicia, en lo referido a las facilidades de acceso del ciudadano de modo virtual o remoto, así como en el uso de la tecnología y plataformas informáticas en la tramitación misma de los procesos judiciales (EJE), en la fase de su escalamiento nacional; sin embargo, este OEI solo tendrá un éxito asegurado si se adoptan medidas urgentes:

a) La mejora de los procesos previstos en las propias normas procesales, como es el caso del uso de la oralidad —el abandono del trámite escrito- en los procesos civiles y la modernización del despacho judicial —Módulo Corporativo de Litigación Oral—.

b) El mapeo nacional de los procesos judiciales, con miras a la identificación y mejora de los procedimientos que se siguen al interior de cada uno de los despachos judiciales, logrando una eficiente uniformización y estandarización de estos.

c) Reorganización integral del sistema de administración del Poder Judicial, lo que implica una reorganización completa del sistema de gerencias existentes, dando lugar a una administración gerencial de gestión por procesos, acompañada de una inmediata adecuación de la administración a las nuevas reglas surgidas en los procesos judiciales, como consecuencia de su tramitación íntegramente electrónica.

Somos conscientes de que el camino hacia la transformación digital dentro del Poder Judicial está trazado y deberá realizarse indefectiblemente en los próximos años. La ejecución de la gestión se 
fortalece por la suscripción del préstamo internacional destinado a financiar la implementación de los expedientes judiciales electrónicos en materia no penal con el Banco Mundial (BM), y en materia penal con el Banco Interamericano de Desarrollo (BID).

\section{HÉCTOR ENRIQUE LAMA MORE}

Juez supremo titular de la Corte Suprema de Justicia de la República Presidente de la Comisión de Trabajo del Expediente Judicial Electrónico del Poder Judicial 


\section{EXPEDIENTE JUDICIAL ELECTRÓNICO (EJE)}

\subsection{Antecedentes}

A nivel institucional se han venido desarrollando a lo largo del tiempo diversas iniciativas para fortalecer y dinamizar el servicio de justicia, entre ellas, en los últimos diez años, destacan las que se muestran en el siguiente esquema:

Esquema n. ${ }^{\circ}$ 1. Antecedentes de iniciativas de transformación digital en el sistema de justicia en el Perú, previo al EJE

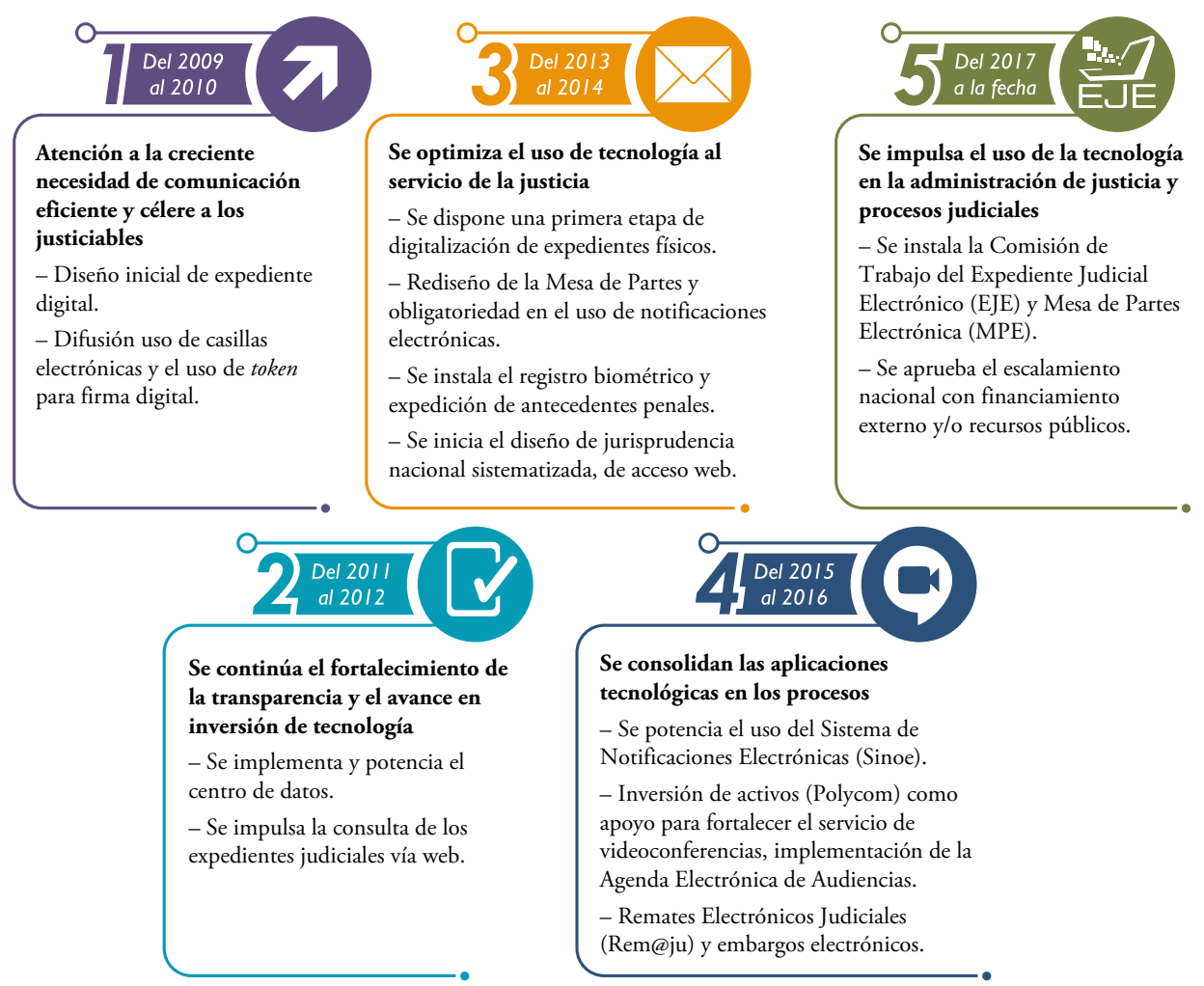

Elaboración: Secretaría Técnica de la Comisión de Trabajo del EJE. 
Cada una de estas iniciativas conducen a la mejora y apoyo en el funcionamiento general del sistema de justicia en el Poder Judicial, dentro del principio de la división entre las funciones jurisdiccionales y administrativas: lo jurisdiccional se desarrolla en la audiencia, mientras lo administrativo brinda el apoyo necesario a la administración de justicia y en consecuencia la asignación de funciones y responsabilidades para el trabajo y la instrumentalización de flujos y herramientas que permitan el control, la evaluación y la fijación de metas.

a) Durante el ańo 2009 hasta el 2010 se gestionaron diversas actividades cooperantes con la inclusión de las TIC (tecnologías de la información y la comunicación) en el sistema de justicia. De esta manera, al concluir el año 2009 se desarrolló la propuesta de solución tecnológica que representó el Expediente Digital con Cero Papel en el Nuevo Código Procesal Penal y en la Nueva Ley Procesal Laboral, con incorporación al «expediente virtual» del audio y video de audiencias. Así, se puso en servicio el Sistema Nacional de Videoconferencias, importante herramienta de soporte a la labor jurisdiccional que fue utilizada inicialmente por la Sala Penal Permanente de la Corte Suprema de Justicia y los juzgados de la selva central, Tumbes, Huancavelica, Lambayeque y Huánuco. Adicionalmente, se promovió la generación de certificados de antecedentes y el acceso al Registro Nacional de Identidad y Estado Civil (Reniec) en línea para todos los jueces con sistemas en red, cuyo piloto se inició en la Corte Superior de Justicia de Lima Norte.

De igual modo, comienza la implantación del Sistema de Notificación Electrónica en los juzgados contencioso administrativos y comerciales de la Corte Superior de Justicia de Lima, en los juzgados del nuevo Código Procesal Penal en La Libertad y en los juzgados con la Nueva Ley Procesal del Trabajo en Tacna, Cañete, La Libertad, Arequipa, Lambayeque y Cusco. Por otro lado, empieza el uso de la firma digital mediante token. 
b) En el periodo 2011-2012 el Poder Judicial, dentro de sus acciones para consolidar la transparencia de sus actuaciones y permitir el acceso de manera fácil y eficaz a la información que produce, continuó desarrollando un conjunto de productos tecnológicos que contribuirían a mejorar el servicio de impartición de justicia y a establecer un vínculo de acercamiento entre este poder del Estado y la comunidad en general. Destaca, entre estos, el Sistema de Consulta de Expedientes Judiciales, que permitió brindar a la ciudadanía un servicio integral y eficiente, proporcionando acceso al texto completo de las resoluciones expedidas por el juez en cada proceso. Este aplicativo, de alta disponibilidad para el usuario final, permite acceder a la información del expediente desde cualquier parte del mundo a través de internet; favorece, así, el ahorro de tiempo y dinero a los justiciables, quienes ya no tendrán que desplazarse a las sedes judiciales.

Dentro de estas iniciativas tecnológicas también se impulsó el trámite de certificados de antecedentes penales (SCAP). Esta medida concreta de gobierno electrónico por parte del Poder Judicial permite obtener el certificado de antecedentes penales a través de internet, de modo rápido, ágil y seguro; esto se da por medio del ingreso de datos por parte de los ciudadanos y la interconexión con otras instituciones como el Reniec y el Banco de la Nación.

Estas acciones consideraron también la optimización y ampliación del Sistema de Notificaciones Electrónicas (Sinoe), que permite la digitalización de las resoluciones y anexos, los cuales son notificados a través de una casilla electrónica proporcionada por el Poder Judicial, con la misma efectividad que las notificaciones con cédulas de papel. Por ello se logró establecer mecanismos de funcionamiento que permitan el ahorro de costos y que también impliquen aspectos que hagan más fácil su uso, a fin de difundir esta moderna y ágil forma de emitir notificaciones en todo el país.

De otro lado, en la Corte Superior de Justicia de Lima, se inició el uso, en el área penal, del sistema de Control Biométrico de Procesados y Condenados Libres con reglas de conducta, el cual se extendió en los siguientes años al resto de las cortes superiores del país. 
c) Durante el 2013 hasta el 2014 el Poder Judicial continuó gestionando resultados orientados a una consolidación tecnológica. De esta manera, el proyecto del Expediente Digital lanzado en el 2010 tenía por intención ir concretando la evolución digital, es decir, pasar del papel al formato digital en los expedientes judiciales, convirtiendo los escritos (legajos físicos) en archivos electrónicos mediante el uso de un sistema digital seguro e interactivo. Adicionalmente, se impulsó el proceso de digitalización de documentos: la transformación de los legajos físicos al formato electrónico implicó el despliegue de una «línea de producción digital», la cual trabaja con un software especial y con un hardware compuesto por tres escáneres, computadoras de escritorio, servidor de alta capacidad y una red de área de almacenamiento, entre otros equipos. Por otro lado, se potenció el Servicio de Jurisprudencia Nacional Sistematizada en el que se difunde la jurisprudencia de la Corte Suprema y las cortes superiores de justicia. Tuvo como fuente al Sistema Integrado Judicial (SIJ), el gran núcleo informático con la base de datos del Poder Judicial, que es alimentado permanentemente por los órganos jurisdiccionales del país.

Se desarrolló el aplicativo de remates judiciales en línea, el sistema Rem@ju (Remate Electrónico Judicial), mecanismo que regula los remates judiciales por la vía electrónica y permite la libre participación de los postores individuales. Fue creado mediante el proyecto que se presentó al Congreso en abril de 2013 y se convirtió en ley en junio de 2014. El sistema permite una subasta imparcial, efectiva y transparente, gracias a la cual los postores pueden participar en línea en el remate, desde cualquier lugar con acceso a internet. En el 2014 se concluyeron las labores previas a la operatividad del sistema, y este comenzó a implementarse progresivamente en los distritos judiciales del país.

El Rem@ju promueve la transparencia de las operaciones comerciales, pues ya no se necesitan terceras partes que manejen una subasta. Además, elimina la necesidad de realizar la subasta en un espacio físico y con intermediarios, situación que se prestaba para que algunas personas recurran a actos ilícitos en provecho 
propio. Ahora, al alentar la participación de un número mayor de postores, estos podrán conseguir mejores precios en los remates.

En septiembre de 2013 el Poder Judicial inició la ejecución, a nivel nacional, del proyecto Depósitos Judiciales Electrónicos, mediante el cual

el Banco de la Nación notifica por la vía electrónica al órgano respectivo del Poder Judicial, sobre los depósitos bancarios hechos en el día por las partes en un proceso judicial (los depósitos son una garantía dineraria que se hacen para cumplir con alguna obligación dispuesta por el juez) (Consejo Ejecutivo del Poder Judicial, 2018a, p. 17).

El uso del canal electrónico elimina el riesgo de extravío, pérdida o uso indebido (fraude por falsificación) de los antiguos certificados (físicos) de depósitos judiciales, en especial cuando los expedientes se trasladan de un órgano jurisdiccional a otro. Con el antiguo sistema, el litigante, luego de hacer el depósito en el banco, recibía como constancia un documento impreso, que debía entregar después, en forma presencial, al órgano jurisdiccional que se encargaba de su custodia física. Con este sistema, a la culminación del proceso judicial, el juez autoriza al Banco de la Nación, por la vía electrónica, hacer efectiva la garantía y pagarle a la persona correspondiente. La duración de los procesos judiciales, en consecuencia, se ha acortado, pues los juzgados ahora tienen en forma inmediata la información de los depósitos para la respectiva autorización de pago.

Un elemento tecnológico adicional fue el inicio del escalamiento nacional del Registro Biométrico Digital, otra de las innovaciones en los servicios judiciales que se utiliza con los procesados y sentenciados en libertad, quienes, por mandato judicial, deben reportarse periódicamente y registrar su presencia en la Corte Superior correspondiente. El registro es ahora muy rápido gracias a un equipo lector de huellas digitales instalado en las cortes que verifica la identidad de la persona. Este sustituye a los antiguos cuadernos judiciales en los que, hasta hace poco tiempo, tales personas daban cuenta de su asistencia con una firma. 
De otro lado, un elemento que se integrará en estas iniciativas de avance tecnológico es el software para firmas digitales, programa informático propio que se diseñó a fin de no depender de terceras empresas para las firmas en documentos digitales. Cumpliendo con las normas que rigen la firma electrónica en el país, el software - que lleva el nombre de PJSigner- fue presentado para su evaluación a Indecopi. Esta entidad verificó que el programa cumpliera con todos los requisitos de la Infraestructura Oficial de Firma Electrónica del país (IOFE) y lo acreditó en noviembre de 2014. La acreditación recibida garantiza que los documentos electrónicos firmados digitalmente son auténticos y tienen el mismo valor e implicancias legales que los documentos que llevan una firma manuscrita. Con este software todos los documentos transmitidos desde el Poder Judicial por medios electrónicos llevan las firmas digitales, con valor probatorio en los procesos judiciales y/o procedimientos administrativos (por ejemplo, notificaciones electrónicas, remates judiciales electrónicos, embargos judiciales electrónicos, trámite documentario).

d) En el periodo 2015 a 2016 se procedió a extender la aplicación de la notificación electrónica a los órganos jurisdiccionales de todos los distritos judiciales del país. Dicho cometido se cumplió a plenitud e incluso se ha ido más allá de lo previsto, puesto que también se incluyó a la Sala Penal Nacional y la Corte Suprema de Justicia.

En esta etapa se lanzó oficialmente el sistema de videoconferencias, cuya aplicación garantiza el pleno respeto de los principios que amparan el debido proceso, tales como la eficacia, la celeridad, la economía, la inmediación y la oportunidad. Se inauguró en 31 cortes superiores de justicia y 11 centros penitenciarios del país, a los cuales se proveyó de 150 equipos de última generación del sistema Polycom, que permite la interconexión entre los magistrados y los imputados que se encuentran en condición de internos, superando las dificultades geográficas, demográficas y culturales del país.

De este modo, se evitan los traslados de jueces, internos, testigos, peritos $\mathrm{u}$ otras partes procesales, incluso a un distrito 
judicial diferente, lo cual implica demoras innecesarias y la exposición a situaciones de riesgo, como la fuga de los reclusos, la frustración de las audiencias o la pérdida de expedientes, afectando así el desarrollo de los procesos.

Ofrecer soluciones tecnológicas a determinados problemas que se presentan en la administración de justicia ha sido una constante para el Poder Judicial. Muestra de ello es la aplicación de la Agenda Judicial Electrónica para optimizar la programación de audiencias y evitar que estas se frustren debido al cruce de horarios.

El decidido avance de la modernización de los servicios judiciales también se ha visto reflejado en el procedimiento de embargos bancarios, una operación importante que ordenan los jueces para asegurar el cumplimiento de las obligaciones contraídas por un deudor, lo que redunda en la seguridad jurídica del país. Esta herramienta elimina varios trámites respecto del procedimiento tradicional, imprimiéndole celeridad, transparencia y eficacia a esta operación. Faculta a los juzgados de la especialidad comercial a ejecutar retenciones de dinero de forma inmediata y, además, posibilita que las entidades financieras respondan de manera instantánea a lo requerido por los juzgados, a través del uso del sistema.

e) A partir del ańo 2017 se analizaron y articularon las iniciativas tecnológicas y los resultados obtenidos por cada una de ellas, que cooperan en la transformación digital y en su momento surgieron de la planificación en la atención de brechas para brindar un adecuado servicio de administración de justicia, procurando obtener eficiencia en el uso de los recursos financieros y asignación de inversiones en infraestructura, equipamiento y modernización tecnológica.

Actualmente, la combinación del uso de la tecnología en la administración de justicia, cuyo resultado objetivo es el diseño del Expediente Judicial Electrónico, la oralidad en los procesos y la dinámica y diseño del despacho corporativo, representan en su conjunto los componentes de la modernización del Poder Judicial. 
Esquema n. ${ }^{\circ}$ 2. Componentes de la modernización del despacho judicial

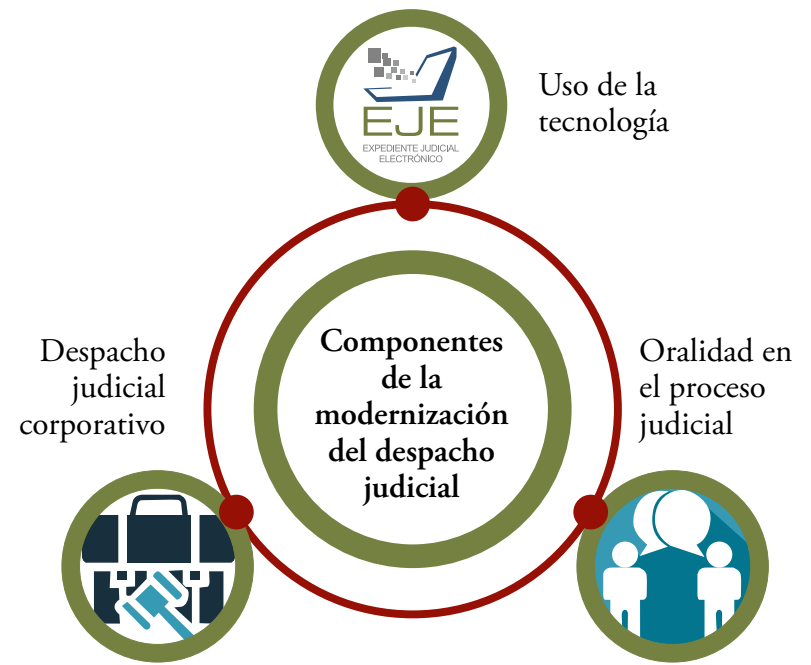

El despacho judicial representa la unidad orgánica que brinda el servicio de administración de justicia a favor de la población en el distrito judicial y materia de su competencia.

Elaboración: Secretaría Técnica de la Comisión de Trabajo del EJE.

El proceso de transformación digital en el Poder Judicial es impostergable y terminará por incorporar la tecnología en el flujo de los procesos judiciales con la aplicación de herramientas informáticas emergentes y la modernización de los marcos legales.

La experiencia y los resultados que vienen dándose en la introducción de las tecnologías de la información y la comunicación en la administración de la justicia representan soluciones de mejora en su funcionamiento y son un aporte para racionalizar procedimientos y reducir los gastos, optimizando el acceso a la justicia, la cooperación entre autoridades judiciales y la eficacia de la justicia misma. Este modelo comprende un gran número de soluciones tecnológicas que se utilizan en el ámbito judicial mediante propuestas de eficaces sistemas de gestión y control de informaciones judiciales; procurando promover un servicio eficiente de las tecnologías de la información y la comunicación aplicadas a la justicia (Aspis, 2010, p. 327).

El avance tecnológico enfocado a la mejora del servicio de justicia permitió obtener diversos productos que se consolidaron como componentes del Expediente Judicial Electrónico, permitiendo afianzar el modelo de gestión enfocado en procesos por resultados dentro de las 
actividades conducentes a la obtención del objetivo estratégico institucional (OEI) de transformación digital del Poder Judicial.

Las actividades y los resultados desplegados por el Expediente Judicial Electrónico le han permitido consolidarse como una iniciativa de modernización promotora de cambios favorables para el acceso a la justicia.

En el desarrollo de esta dinámica se han desarrollado importantes herramientas, tales como la Consulta de Expedientes Judiciales, que permite, a la fecha, efectuar el seguimiento resumido de los actuados en el proceso judicial; herramientas como el Sistema de Grabación de Audiencias (Sigra), que permite la grabación y archivo en medios magnéticos de las audiencias; y el Sistema de Notificación Electrónica (Sinoe). Componentes de apoyo como el control biométrico, la emisión de certificados de depósitos judiciales, el sistema de remates judiciales electrónicos (Rem@ju), el embargo electrónico, el certificado de antecedentes penales (CAPe) y los edictos electrónicos (Edictos-e) y la Jurisprudencia Nacional Sistematizada. Cada uno de estos se incorpora funcionalmente al Expediente Judicial Electrónico (EJE).

Esquema n. ${ }^{\circ}$ 3. Tecnología en los procesos judiciales

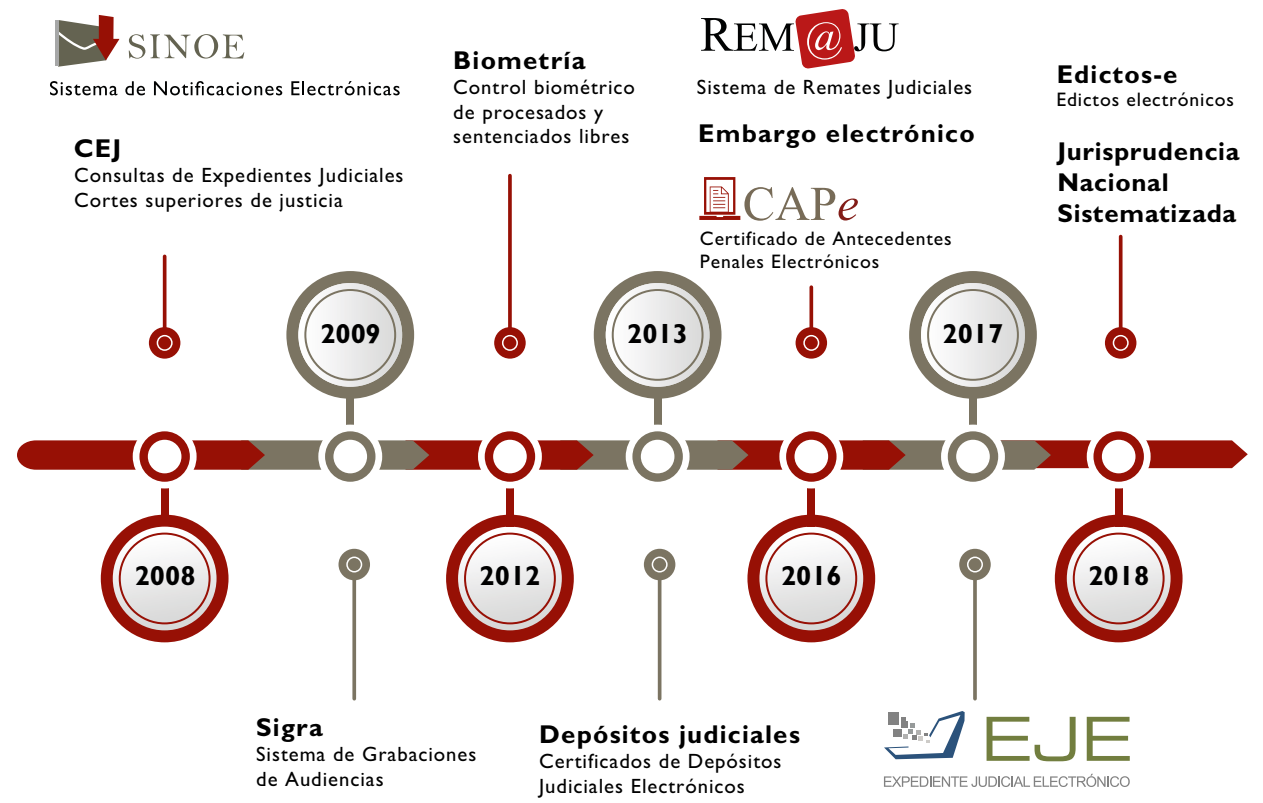

Elaboración: Secretaría Técnica de la Comisión de Trabajo del EJE. 


\subsection{Implementación del Expediente Judicial Electrónico (EJE)}

El Expediente Judicial Electrónico es parte de la transformación digital. Uno de sus objetivos es cambiar el método tradicional de trabajo, en el cual se utiliza mucho tiempo en la recepción de documentos (escritos y demandas) en la mesa de partes e implica costos de traslado del expediente a la sede judicial correspondiente; asimismo, a nivel del trámite en despacho, se realizan tareas que generan una extensión mayor de tiempo, con el consiguiente impacto negativo en el proceso. Todo ello se transformaría a un método más eficaz, ordenado y seguro a través de los medios digitales.

Esta herramienta, desde su lanzamiento en el 2017 hasta la fecha, ha establecido las bases que permiten abandonar en el corto plazo los obsoletos legajos de papel y tramitología innecesaria, permitiendo alcanzar el proceso digital completo, transmitiendo digitalmente los datos y conservándolos en bases de datos electrónicas, sustituyendo los viejos archivos judiciales y las notificaciones tradicionales.

Los principales componentes del Expediente Judicial Electrónico son los siguientes:

- Mesa de Partes Electrónica, la cual hace posible el acceso al sistema de justicia en medios digitales y remotos.

- Visor de expediente, que permite el análisis integral de los actuados.

- Firma electrónica, la cual brinda la seguridad a los documentos.

- Sistema de Notificación Electrónica, que permite la adecuada y oportuna comunicación de las decisiones judiciales. 
Esquema n. ${ }^{0}$ 4. Componentes del Expediente Judicial Electrónico (EJE)

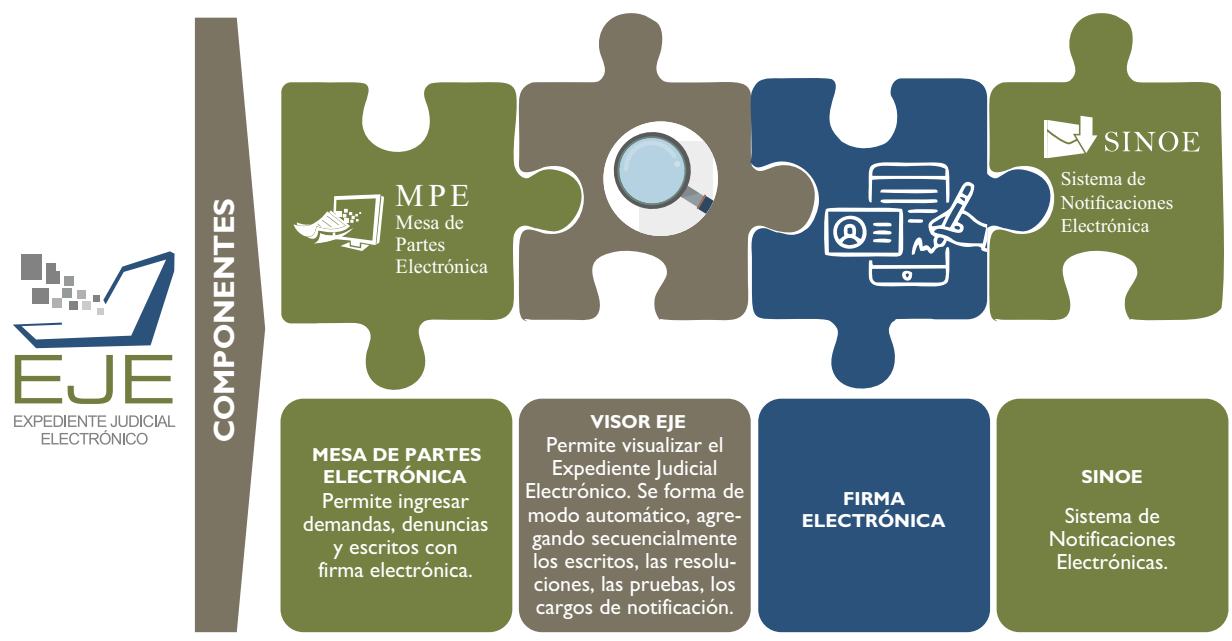

Elaboración: Secretaría Técnica de la Comisión de Trabajo del EJE.

Antes de la iniciativa del Expediente Judicial Electrónico, del 2017, cada expediente judicial, formado por un conjunto de papeles, debía trasladarse físicamente de un sitio a otro, durante la tramitación del proceso, a fin de conseguir una respuesta a la pretensión ejercitada, así como para la resolución del procedimiento. En la actualidad, el expediente se tramita mediante la Mesa de Partes Electrónica (MPE), a través de la cual se pueden digitalizar los documentos, creando un conjunto de información contenida en metadatos en formato digital accesible a todos los operadores jurídicos intervinientes.

Así, puede indicarse que el avance cronológico del Expediente Judicial Electrónico se resume de la siguiente manera:

El Expediente Judicial Electrónico inició sus actividades en el 2017. Esta innovadora herramienta tecnológica entró en funcionamiento en la Corte Superior de Justicia de Lima en el 4. Juzgado Comercial y en ese mismo ańo se extendieron sus beneficios a un total de 60 órganos jurisdiccionales en la citada corte superior.

En el año siguiente, 2018, se implementaron 7 órganos jurisdiccionales adicionales en la Corte Superior de Justicia de Lima.

En el año 2019, las actividades realizadas permitieron fortalecer y dinamizar las metas, impulsando el despliegue a 21 órganos jurisdiccionales, haciendo un total de 88 . Es relevante señalar que durante 
ese año las actividades de la Comisión de Trabajo del Expediente Judicial Electrónico empezaron a descentralizarse, este proceso se llevó a cabo primero en la Corte Superior de Justicia de Lima Norte y continuó con Cajamarca, Puente Piedra-Ventanilla y Tacna; así comenzó el avance del EJE en las regiones.

Asimismo, se iniciaron las actividades para la implementación del Expediente Judicial Electrónico y Mesa de Partes Electrónica en la especialidad penal en la Corte Superior de Justicia Penal Especializada en Delitos de Crimen Organizado y Corrupción de Funcionarios. Coincidentemente, ese año los avances del Expediente Judicial Electrónico promovieron que este fuera considerado como parte del Plan de Competitividad y Productividad del Estado Peruano.

Esquema n. ${ }^{\circ}$ 5. Evolución del proceso de implementación del EJE en las cortes superiores de justicia

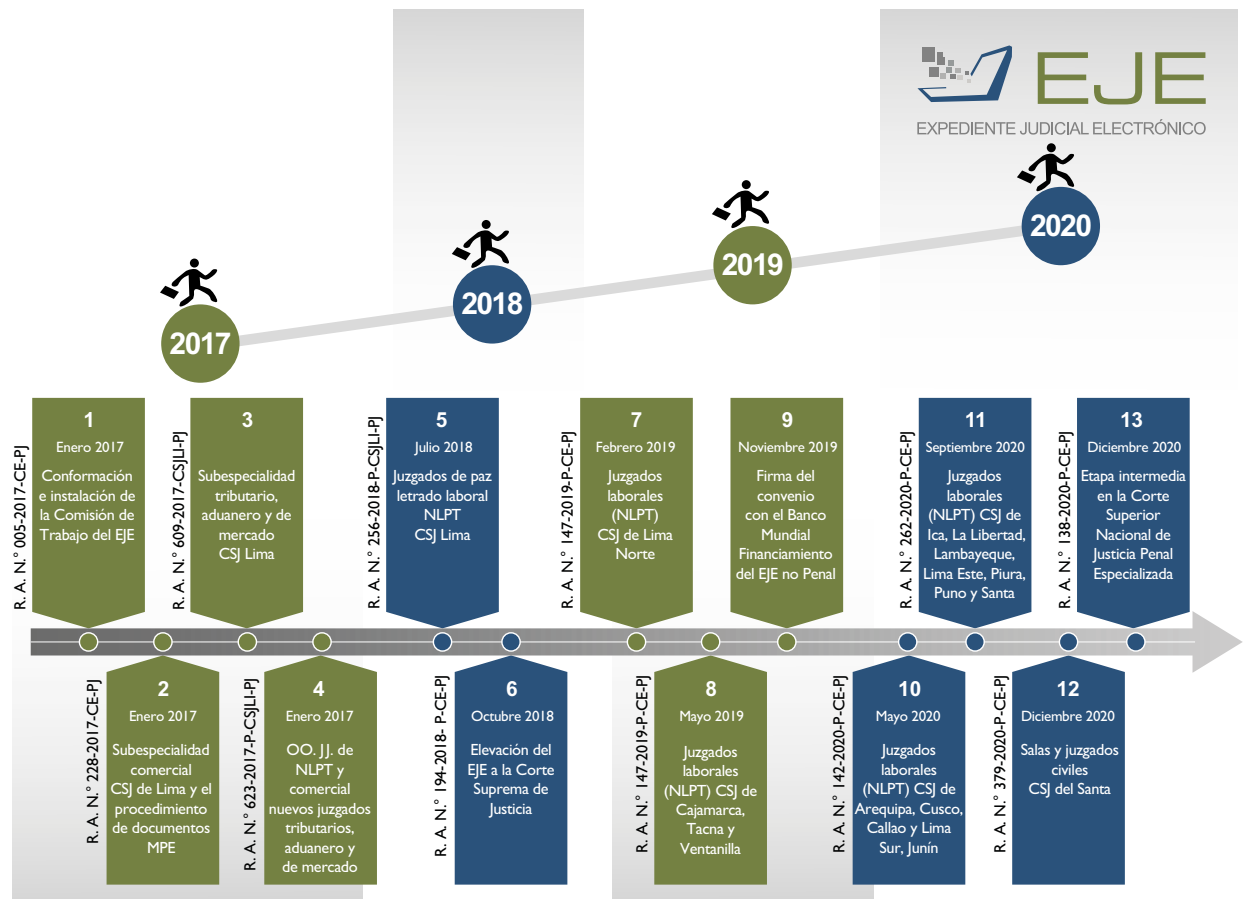

Elaboración: Secretaría Técnica de la Comisión de Trabajo del EJE. 
Durante el año 2020, la dinámica de los trabajos que vino ejecutando el Expediente Judicial Electrónico permitió la implementación de sus beneficios en 105 órganos jurisdiccionales más, que considera 18 salas superiores, 53 juzgados especializados y 34 juzgados de paz letrados.

En resumen, al 31 de diciembre de 2020, son 17 cortes superiores de justicia las que cuentan con órganos jurisdiccionales que trabajan con el Expediente Judicial Electrónico. En total son 32 salas superiores de justicia, que representan el $17 \%$; 111 juzgados especializados, que representan el $57 \%$; y 50 juzgados de paz letrados, que representan el $26 \%$, haciendo un total de 193 órganos jurisdiccionales a nivel nacional, los que incluyen los 7 órganos jurisdiccionales de la Corte Superior de Justicia del Santa de la especialidad civil-litigación oral.

Figura n. ${ }^{\circ}$ 1. Órganos jurisdiccionales implementados con el EJE por tipo de órgano jurisdiccional

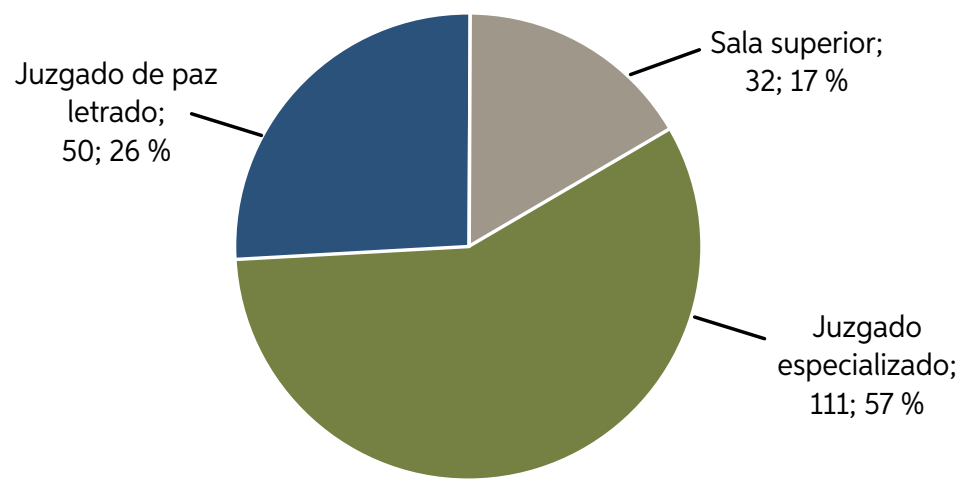

Fecha de actualización: 31 de diciembre de 2020.

Elaboración: Secretaría Técnica de la Comisión de Trabajo del EJE.

Es preciso mencionar que, al 31 de diciembre de 2020, mediante la Resolución Administrativa n. ${ }^{\circ}$ 000138-2020-P-CE-PJ, de fecha 28 de diciembre de 2020, se dispuso la implementación del Expediente Judicial Electrónico (EJE) y la Mesa de Partes Electrónica (MPE) (etapa intermedia), a partir del 29 de diciembre de 2020, en la Corte Superior Nacional de Justicia Penal Especializada.

La cantidad de órganos jurisdiccionales implementados con el EJE se detalla en la siguiente tabla: 
Tabla n. ${ }^{0}$ 1. Órganos jurisdiccionales implementados con el EJE

\begin{tabular}{|c|c|c|c|c|c|c|c|c|}
\hline \multirow[b]{2}{*}{ N.o } & \multirow[b]{2}{*}{ Año } & \multirow[b]{2}{*}{ CSJ } & \multirow[b]{2}{*}{ Especialidad } & \multicolumn{3}{|c|}{ Tipo de OOJJ } & \multirow{2}{*}{\multicolumn{2}{|c|}{$\begin{array}{l}\text { Cantidad } \\
\text { de OOJJ }\end{array}$}} \\
\hline & & & & $\begin{array}{c}\text { Sala } \\
\text { superior }\end{array}$ & $\begin{array}{c}\text { Juzgado } \\
\text { especializado }\end{array}$ & $\begin{array}{l}\text { Juzgado de } \\
\text { paz letrado }\end{array}$ & & \\
\hline \multirow{5}{*}{1} & \multirow{4}{*}{2017} & \multirow{5}{*}{ Lima } & $\begin{array}{l}\text { Civil } \\
\text { subespecialidad } \\
\text { comercial }\end{array}$ & 2 & 17 & & 19 & \\
\hline & & & $\begin{array}{l}\text { Cont. adm. } \\
\text { subespecialidad } \\
\text { tributaria y } \\
\text { aduanera }\end{array}$ & 2 & 5 & & 7 & \\
\hline & & & $\begin{array}{l}\text { Cont. adm. } \\
\text { subespecialidad } \\
\text { en temas de } \\
\text { mercado }\end{array}$ & 1 & 4 & & 5 & \\
\hline & & & Laboral-NLPT & 5 & 24 & & 29 & \\
\hline & 2018 & & Laboral-NLPT & & & 7 & 7 & \\
\hline 2 & 2019 & Lima Norte & Laboral-NLPT & 1 & 3 & 5 & 9 & \\
\hline 3 & 2019 & Cajamarca & Laboral-NLPT & 1 & 2 & 2 & 5 & \\
\hline 4 & 2019 & $\begin{array}{l}\text { Puente } \\
\text { Piedra- } \\
\text { Ventanilla }\end{array}$ & Laboral-NLPT & 1 & 1 & 1 & 3 & \\
\hline 5 & 2019 & Tacna & Laboral-NLPT & 1 & 2 & 1 & 4 & \\
\hline 6 & 2020 & Callao & Laboral-NLPT & 1 & 4 & 2 & 7 & \\
\hline 7 & 2020 & Cusco & Laboral-NLPT & 1 & 3 & 2 & 6 & \\
\hline 8 & 2020 & Arequipa & Laboral-NLPT & 2 & 5 & 2 & 9 & \\
\hline 9 & 2020 & Junín & Laboral-NLPT & 1 & 2 & 1 & 4 & \\
\hline 10 & 2020 & Lima Sur & Laboral-NLPT & 2 & 2 & 4 & 8 & \\
\hline 11 & 2020 & La Libertad & Laboral-NLPT & 2 & 7 & 3 & 12 & \\
\hline 12 & 2020 & Lambayeque & Laboral-NLPT & 1 & 5 & 2 & 8 & \\
\hline 13 & 2020 & Lima Este & Laboral-NLPT & 1 & 5 & 9 & 15 & \\
\hline 14 & 2020 & Puno & Laboral-NLPT & 1 & 2 & 2 & 5 & \\
\hline 15 & 2020 & Piura & Laboral-NLPT & 1 & 4 & 2 & 7 & \\
\hline \multirow[b]{2}{*}{16} & \multirow[b]{2}{*}{2020} & \multirow[b]{2}{*}{ Santa } & Laboral-NLPT & 2 & 7 & 3 & 12 & \\
\hline & & & $\begin{array}{l}\text { Civil-litigación } \\
\text { oral }\end{array}$ & 2 & 5 & & 7 & \\
\hline 17 & 2020 & Ica & Laboral-NLPT & 1 & 2 & 2 & 5 & \\
\hline \multicolumn{4}{|c|}{ Total de órganos jurisdiccionales con el EJE } & 32 & 111 & 50 & 193 & \\
\hline
\end{tabular}

Fecha de actualización: 31 de diciembre de 2020.

Elaboración: Secretaría Técnica de la Comisión de Trabajo del EJE.

Leyenda: CSJ: Corte Superior de Justicia, OOJJ: Órgano jurisdiccional, NLPT: Nueva Ley Procesal del Trabajo. 
Figura n. ${ }^{0}$ 2. Órganos jurisdiccionales implementados con el EJE por año

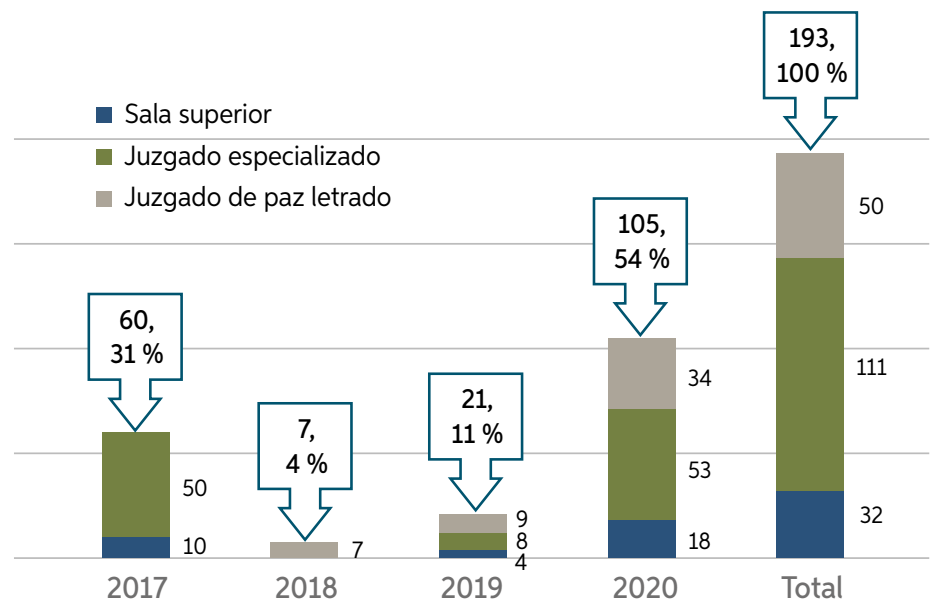

Fecha de actualización: 31 de diciembre de 2020.

Elaboración: Secretaría Técnica de la Comisión de Trabajo del EJE.

Al 31 de diciembre de 2020, del total de los órganos jurisdiccionales que trabajan con el EJE, el $31 \%$ fue implementado en el año 2017, el $4 \%$ en el ańo 2018, el $11 \%$ en el año 2019 y el $54 \%$ en el año 2020, destacando que más del $50 \%$ se ha realizado durante la emergencia sanitaria.

Esquema n. ${ }^{\circ}$ 6. Órganos jurisdiccionales implementados con el EJE

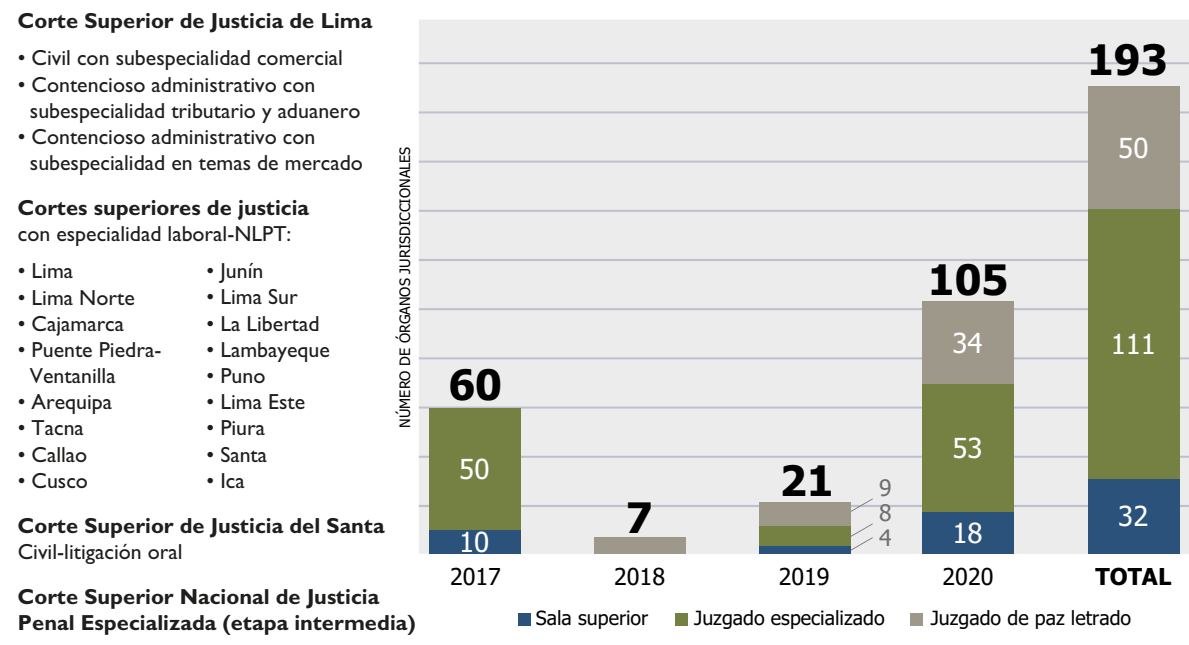

Elaboración: Secretaría Técnica de la Comisión de Trabajo del EJE. 
Esquema n. ${ }^{\circ}$ 7. Especialidad de los órganos jurisdiccionales implementados con el EJE
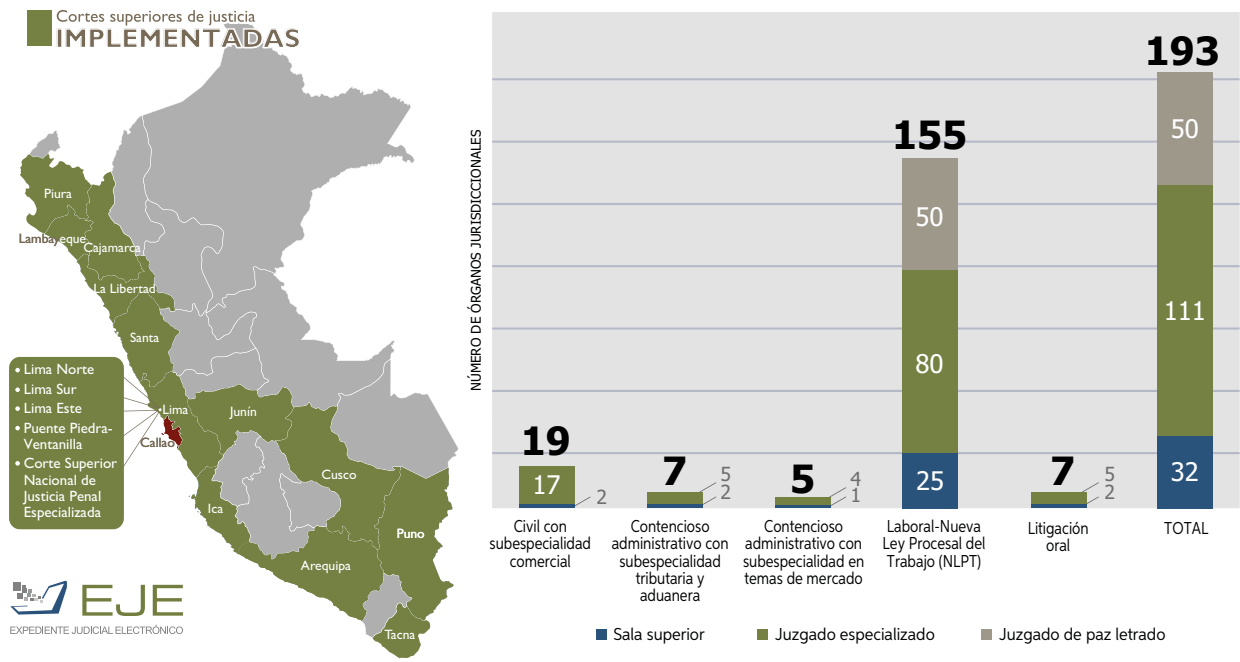

Elaboración: Secretaría Técnica de la Comisión de Trabajo del EJE.

La distribución de los órganos jurisdiccionales por especialidad se muestra de la siguiente manera: el $80 \%$ corresponde a la especialidad NLPT laboral, el $10 \%$ pertenece a la especialidad civil subespecialidad comercial, el $4 \%$ corresponde a la especialidad contencioso administrativo subespecialidad tributario y aduanero, el $4 \%$ pertenece a la especialidad civil-litigación oral y el $2 \%$ corresponde a contencioso administrativo subespecialidad en temas de mercado.

Figura n. ${ }^{\circ}$ 3. Órganos jurisdiccionales implementados con el EJE por especialidad

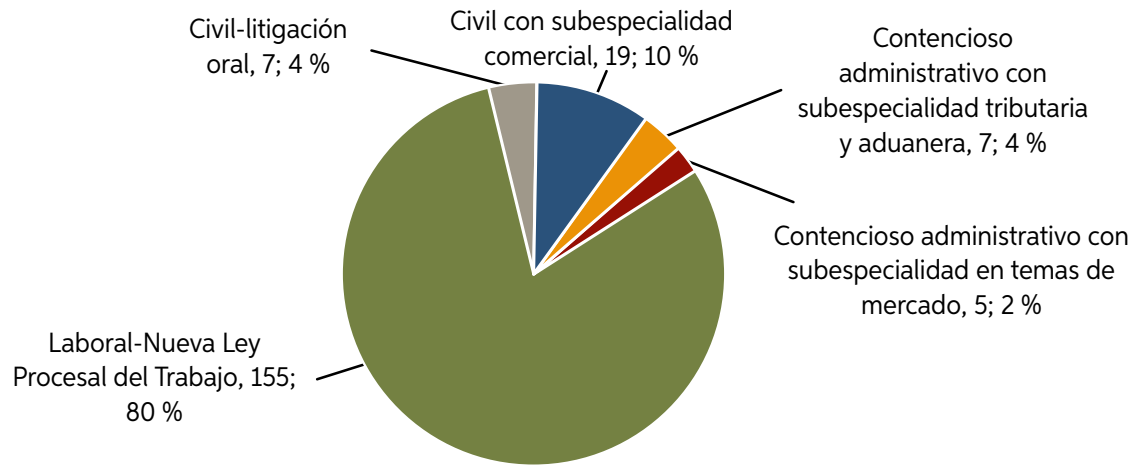

Fecha de actualización: 31 de diciembre de 2020.

Elaboración: Secretaría Técnica de la Comisión de Trabajo del EJE. 
Igualmente, a este número de órganos jurisdiccionales se añadirán los correspondientes a la Corte Superior Nacional de Justicia Penal Especializada Penal en Delitos de Corrupción de Funcionarios y Crimen Organizado (R. A. n. ${ }^{\circ}$ 138-2020-P-CE-PJ).

De otro lado, a causa de la declaración de emergencia sanitaria a nivel nacional, por el plazo de noventa días calendario, a fin de evitar la propagación de la COVID-19, realizada por medio del Decreto Supremo n. ${ }^{\circ}$ 008-2020-SA y prorrogada a través de los Decretos Supremos n. ${ }^{\text {os }}$ 020-2020- SA y 027-2020, el Poder Judicial tomó medidas para replantear el desarrollo de actividades presenciales por el trabajo remoto, empleando recursos virtuales: «En ese contexto, el Consejo Ejecutivo del Poder Judicial dispuso diversas medidas administrativas en concordancia con el Decreto Supremo N. ${ }^{\circ}$ 116-2020-PCM, modificado por Decretos Supremos N.o 129-2020-PCM, N.o 135-2020-PCM y N. ${ }^{\circ}$ 139-2020-PCM y N.o 146-2020-PCM» (Consejo Ejecutivo del Poder Judicial, 2020, considerando segundo).

En relación con el avance del despliegue del Expediente Judicial Electrónico en las cortes superiores de justicia que gestionan procesos en la Nueva Ley Procesal del Trabajo, desde el inicio del proyecto este ha evolucionado anualmente hasta llegar al $63 \%$.

Figura n. ${ }^{\circ} 4$. Avance del EJE respecto a las 27 cortes superiores de justicia que aplican la NLPT

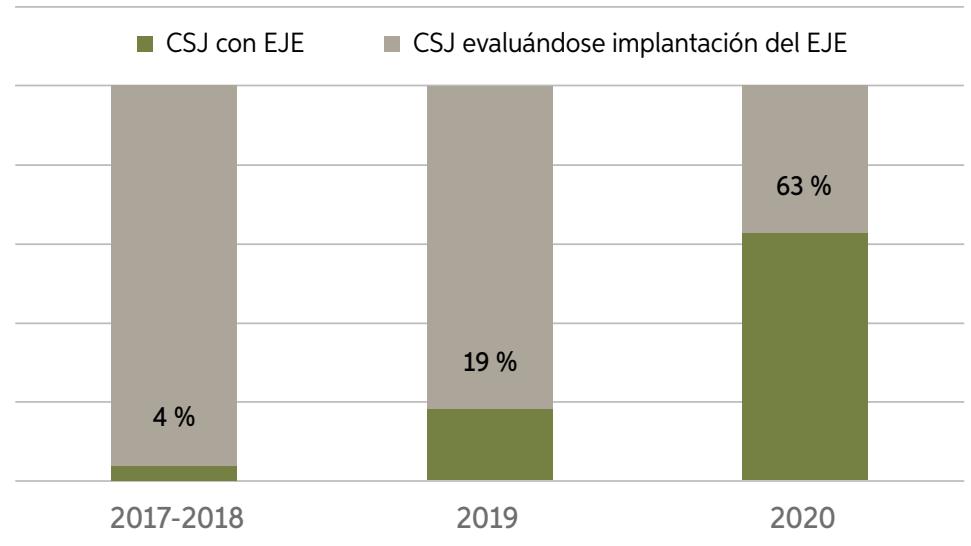

Fecha de actualización: 31 de diciembre de 2020.

Elaboración: Secretaría Técnica de la Comisión de Trabajo del EJE. 
Adicionalmente, desde el 2019, la Secretaría Técnica de la Comisión de Trabajo del Expediente Judicial Electrónico innovó la metodología de trabajo en el proceso, diseño y optimización de recursos y tiempos, elementos necesarios para su implementación. Esta labor se inició en el área penal en la Corte Superior Nacional de Justicia Penal Especializada en Delitos de Crimen Organizado y Corrupción de Funcionarios, donde se efectuó el diseño participativo, consensuado y compartido de las actividades, las tareas y el proceso para el ingreso de documentos y su indexación, con los magistrados de la especialidad, el personal jurisdiccional y administrativo. El resultado de ello permitirá la generación del expediente digital con los requerimientos de los jueces de la especialidad y se obtendrá el diseño macro de los flujos propios a la operatividad general en la etapa intermedia.

El resultado obtenido permitió concretar un avance importante en las coordinaciones con el Ministerio Público para la interoperabilidad con esta instancia del sistema de justicia; por ello se llevaron a cabo reuniones técnicas de coordinación para la presentación de la Carpeta Fiscal Electrónica en compatibilidad con el Expediente Judicial Electrónico que opera en el Poder Judicial.

\subsubsection{Metodología de trabajo de la implementación}

Cuando identificamos los impactos potenciales positivos no puede dejar de mencionarse la eficiencia del sistema judicial y la transparencia relacionada directamente con los problemas de celeridad procesal, sobrecarga, seguridad de la información, comunicaciones en medios electrónicos y el impacto en los costes relacionados con el inicio de un proceso tanto para el justiciable como para el Poder Judicial.

Durante los procesos de reformas judiciales siempre se concibió que las tecnologías de la información y la comunicación (TIC) podrían cambiar y ayudar a reforzar la eficacia del sistema de justicia. De este modo podemos referirnos al surgimiento de importantes iniciativas, entre ellas el Expediente Judicial Electrónico, la Mesa de Partes Electrónica, las Notificaciones Electrónicas, entre otras, que buscan atender las necesidades cada vez más específicas del sistema de justicia. Para tal efecto se esbozó preliminarmente durante la concepción macro 
del Expediente Judicial Electrónico, un flujo de líneas maestras para la posterior planificación, y se tuvo como reto principal garantizar los derechos fundamentales en un contexto de modernización y transformación digital.

Esquema n. ${ }^{\circ}$ 8. Flujo del proceso de modernización de los servicios de justicia

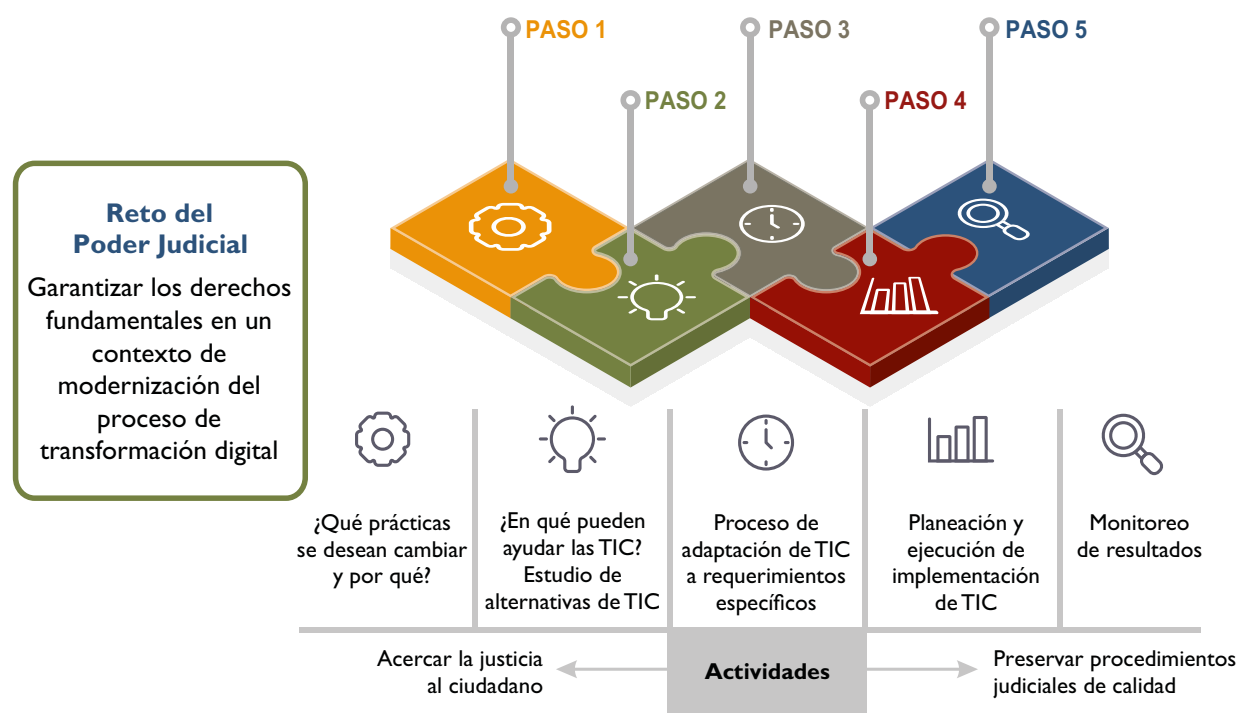

Elaboración: Secretaría Técnica de la Comisión de Trabajo del EJE.

La mayoría de usuarios esperan lograr que la administración de justicia sea accesible, rápida y predecible. Las TIC tienen el suficiente potencial para conseguir estos objetivos, no circunscritos al incremento de inversión en tecnología, sino en políticas judiciales que logren equilibrar las posibilidades y la creatividad de estas con el marco legal existente (Pozobón, 2012, párr. 8).

En la esfera de transformación digital que representan el Expediente Judicial Electrónico y la Mesa de la Partes Electrónica, estos se vienen apoyando de herramientas provenientes de otras disciplinas que aseguran su adecuado avance; de este modo, la administración y la gestión permiten que se obtenga un impacto positivo en la medida en que se empleen coordinadamente. 
Resulta fundamental indicar que la herramienta que le da sentido, coherencia e integridad al uso de otras herramientas de gestión es una adecuada planificación estratégica. A tal efecto, el uso de cualquier herramienta de gestión debe hacer referencia a cuál es su vinculación con el plan estratégico de la institución, situación que se concretó en el actual Plan Estratégico Institucional.

Esquema n. ${ }^{\circ}$ 9. Plan Estratégico Institucional (PEI) del Poder Judicial para el periodo $2020-2030$

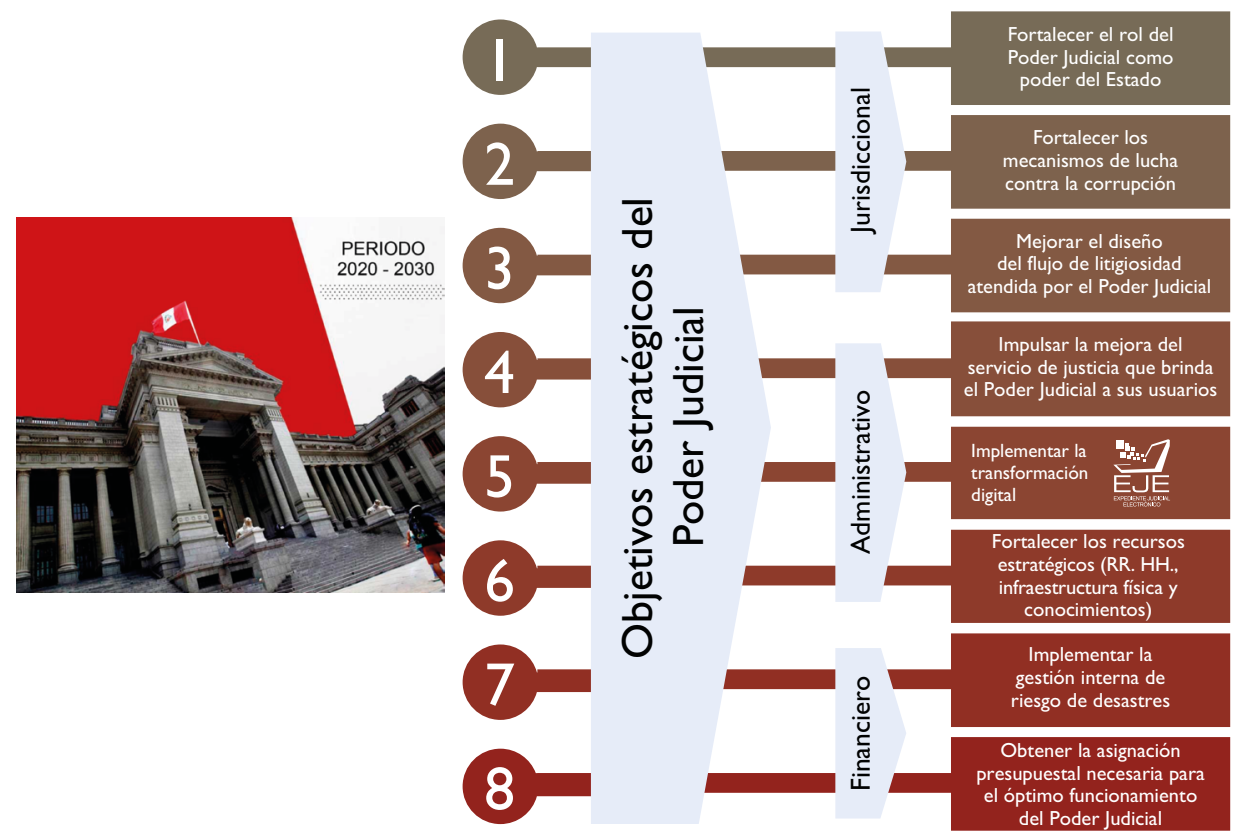

Elaboración: Secretaría Técnica de la Comisión de Trabajo del EJE.

Dentro de las herramientas de gestión, cabe mencionar el liderazgo desarrollado por la Presidencia de la Comisión de Trabajo del Expediente Judicial Electrónico y de la Secretaría Técnica de la Comisión de Trabajo del Expediente Judicial Electrónico, integrados por un equipo profesional multidisciplinario, que diseñaron planes prospectivos y fijaron metas, objetivos estratégicos, determinaron controles cronológicos del avance de las metas específicas y medios de validación, incluyendo programas de capacitación y entrenamiento del personal, y propuesta de los rediseños organizacionales, en articulación con las 
gerencias coadyuvantes de Informática y Servicios Judiciales y Recaudación de la Gerencia General. Todas estas acciones se ejecutaron y vienen desarrollándose de acuerdo con los Planes Anuales de Actividades y Plan Operativo Institucional del Expediente Judicial Electrónico, ligado al Plan Estratégico Institucional.

Al respecto, por encargo de la Presidencia de la Comisión de Trabajo del EJE, la Secretaría Técnica ha venido desarrollando una metodología de planificación estratégica de trabajo para la obtención de resultados concretos, que pueden resumirse en el presente esquema:

Esquema n. ${ }^{\circ}$ 10. Resumen de la metodología de las tareas de implementación del Expediente Judicial Electrónico en la justicia peruana

1

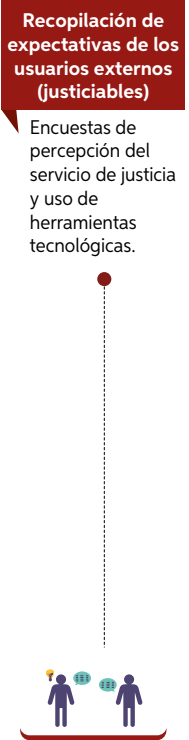

2

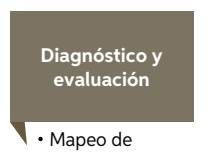

- Mapeo de

perfiles.

- Interoperabilidad con otras

instituciones.

- Identificación y evaluación de las soluciones tecnológicas disponibles.

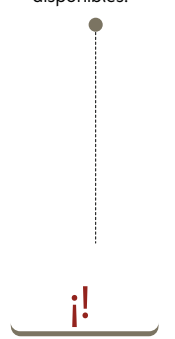

3

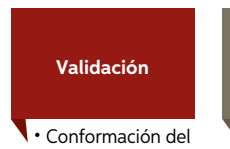

Comité de Usuarios por Especialidad
(integrado por magistrados, personal jurisdiccional y administrativo). Valida documentos de gestión administrativa.

- Conformación del Comité de Implantación. Advierte incidencias y requerimientos durante el proceso de implementación del EJE (capacitación, puesta en producción y monitoreo).

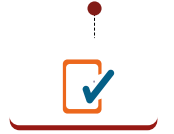

4

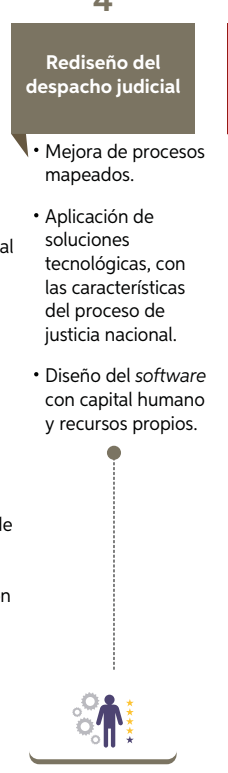

5

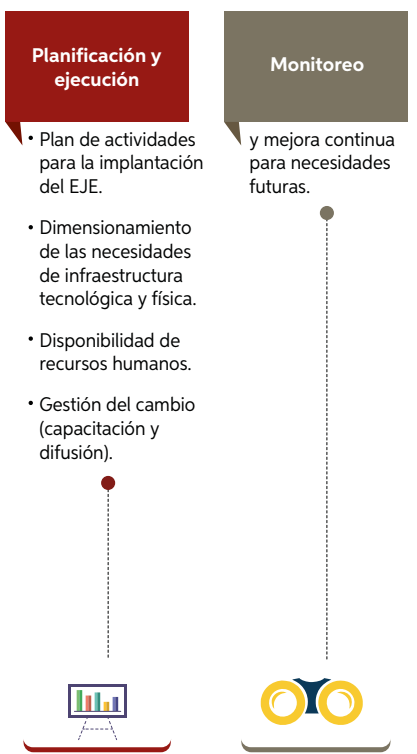

Elaboración: Secretaría Técnica de la Comisión de Trabajo del EJE.

Por otro lado, puede indicarse que existen diversos elementos que promovieron la elección de esta solución tecnológica con la finalidad de enfrentar las particularidades de los procesos tradicionales de la administración de justicia, centrada fuertemente aún en la lógica del expediente escrito y que se señalan a continuación: 
Esquema n. ${ }^{\circ}$ 11. Elementos de motivación del uso del Expediente Judicial Electrónico como elemento de transformación digital en el Poder Judicial

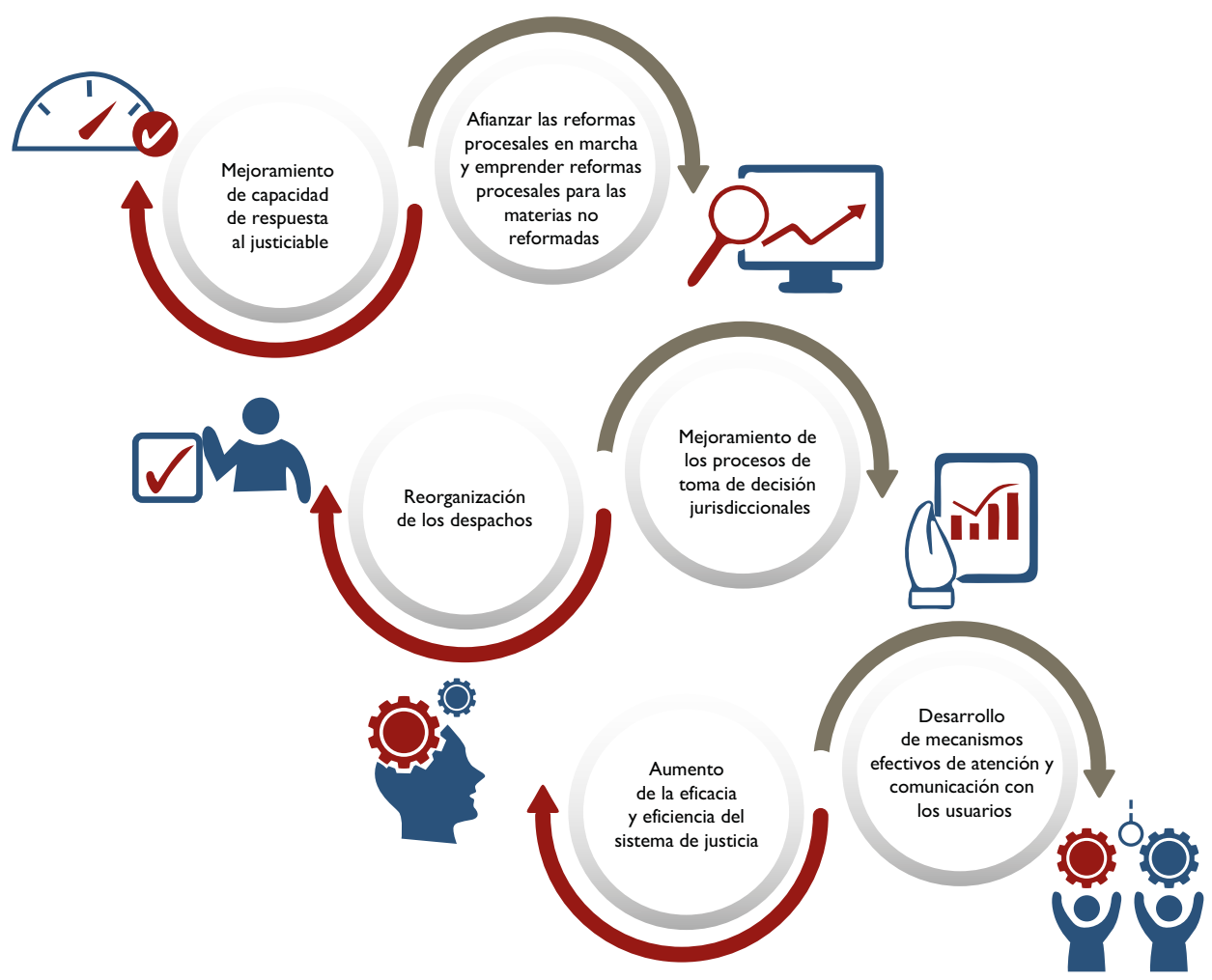

Elaboración: Secretaría Técnica de la Comisión de Trabajo del EJE.

Según puede advertirse, el Expediente Judicial Electrónico es una iniciativa tecnológica institucional que ha venido consolidándose en sus actividades como proyecto desde el 2017.

Si bien existen iniciativas similares en países de la región, el Expediente Judicial Electrónico no ha sido diseñado sobre la base de alguno de ellos. Esto es una ventaja diferenciada o fortaleza, pues se ha diseńado de manera interna, autogestionaria, en la que se identifican como elementos favorables los siguientes:

- Mayor know-how. Desde el inicio del proyecto los integrantes de la Comisión de Trabajo del Expediente Judicial Electrónico, la 
Secretaría Técnica, la Gerencia de Informática y la Gerencia de Servicios Judiciales y Recaudación, así como los magistrados y el personal jurisdiccional y administrativo de las sedes judiciales donde se ha implementado el Expediente Judicial Electrónico, han aportado la metodología y los conocimientos en función de su experiencia y de las necesidades observadas a diario, y las han integrado adecuadamente al diseño del sistema, evolucionando en sus procesos de implementación.

- Mayor capacidad de mantenimiento y soporte. Una vez concretada la implementación, la retroalimentación que resulta de la solución de errores y la modificación o adaptación se hace más dinámica, puesto que la programación la realizan técnicos propios.

- Compromiso con el proyecto. Un valor agregado importante lo representa el empeño o vínculo entre los participantes del desarrollo del proyecto Expediente Judicial Electrónico en comparación con el control de la ejecución de un contrato.

- Oportunidad. La posibilidad de desarrollar un sistema de gestión que comprende el acceso a la administración de justicia optimizando los recursos asignados, analizando los procesos, las actividades y tareas, los sistemas de registro, asignación y seguimiento de causas.

Adicionalmente, en estos tiempos de aislamiento social, la pandemia de la COVID-19 ha dinamizado el uso de tecnologías digitales impulsando así el Expediente Judicial Electrónico y la Mesa de Partes Electrónica, ha potenciado el modo de atención y acceso a la justicia más adecuado y eficiente, a fin de preservar la salud de los justiciables y los administradores de justicia. Al respecto, el Poder Judicial, como muestra de su capacidad de respuesta, para asegurar la continuidad del servicio de justicia dispuso una serie de medidas que se aprecian en la siguiente infografía. 
Esquema n. ${ }^{\circ}$ 12. Medidas del Poder Judicial para enfrentar la pandemia y brindar acceso a la justicia

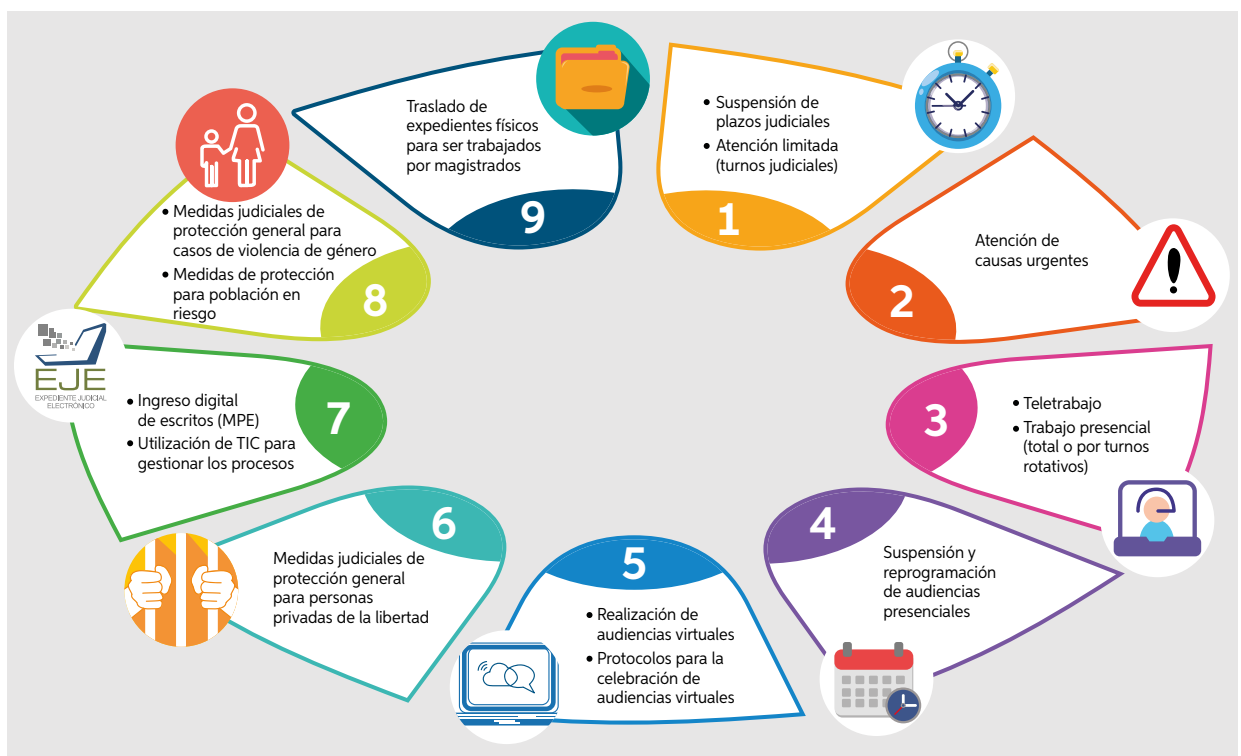

Elaboración: Secretaría Técnica de la Comisión de Trabajo del EJE.

\subsubsection{Componentes del EJE}

- Mesa de Partes Electrónica, a través de la cual se accede al sistema de justicia en medios digitales y remotos; brinda un mecanismo de acceso y registro de demandas y escritos de los usuarios del Poder Judicial a través de medios virtuales, al digitalizar los expedientes y documentos que ingresen a mesa de partes. Estos podrán ser visualizados de manera inmediata por el órgano jurisdiccional correspondiente para su trámite respectivo, desde cualquier ubicación y con una atención ininterrumpida durante todos los días del año. De este modo se brinda un acceso eficaz e irrestricto a la justicia y se facilita el trabajo remoto de los jueces y los auxiliares jurisdiccionales para atender la tutela de derechos requerida por los justiciables.

Así, puede decirse que la Mesa de Partes Electrónica (MPE) es un componente esencial del EJE que permite a los usuarios externos presentar documentos desde cualquier computadora que tenga acceso a internet (desde sus hogares, centros de trabajo, cabinas de internet), 
a través de la casilla electrónica Sinoe, que el Poder Judicial otorga a los abogados de manera gratuita.

La Mesa de Partes Electrónica viene funcionando para la presentación de escritos a partir del 2018. Los usuarios pueden presentar a través de esta no solo escritos necesarios para el desarrollo del proceso, sino además demandas, medidas cautelares fuera del proceso y otros. Permite la reducción de costos para el justiciable y la administración de justicia (ahorro de papel e impresiones, así como gastos de movilidad y disminución del uso de espacios para archivo físico); así como mejoras de tiempo en el proceso de presentación, pues el justiciable no tiene que hacer cola, lo que asegura la accesibilidad desde cualquier lugar que cuente con internet y un sistema con mecanismos de control y seguimiento, y permite el uso de firmas electrónicas.

Este componente está disponible las 24 horas del día, los 7 días de la semana y se puede acceder a través de la casilla electrónica del Sinoe.

- Visor de expediente, que permite el análisis integral de los actuados. No solo apoya de manera ágil a la labor jurisdiccional mediante un sistema de bandejas por las cuales se accede a los documentos que forman parte de los actuados en medios digitales, sino que también pueden acceder a la integridad de esa información los justiciables, eliminando la necesidad de acceder a la sala de lectura en las sedes judiciales.

- Firma electrónica, la cual brinda seguridad a los documentos. Es una expresión genérica y mucho más amplia en cuanto a los datos electrónicos; dentro de este concepto, se encuentra la firma digital, con criptografía y basada en clave pública. Así, la firma digital que dispone el Poder Judicial evita la suplantación de identidad y hace posible la autenticación y la identificación en los distintos procesos.

- Sistema de Notificación Electrónica, que permite la adecuada y oportuna comunicación de las decisiones judiciales. 
La notificación electrónica diseñada en el Poder Judicial nos ofrece la posibilidad de ganar en eficiencia y en eficacia respecto a la notificación tradicional en medios físicos (papel).

\subsection{Normatividad}

\subsubsection{Normatividad de gestión}

- Resolución Administrativa n. ${ }^{\circ}$ 228-2017-CE-PJ. Que aprueba el Reglamento del Expediente Judicial Electrónico, «que será de obligatorio cumplimiento para todos los órganos jurisdiccionales del Poder Judicial y partes intervinientes en un proceso; con excepción de aquellos órganos jurisdiccionales donde no se encuentra implementado el Expediente Judicial Electrónico (EJE)» (Consejo Ejecutivo del Poder Judicial, 2017a, art. tercero).

- Resolución Administrativa n. ${ }^{\circ}$ 228-2017-CE-PJ. Que aprueba

el «Procedimiento de Ingreso de Documentos - Mesa de Partes» y los procedimientos macro del Expediente Judicial Electrónico (EJE), denominados:

a) «Calificación de la demanda».

b) «Proveer escritos».

c) «Elaboración de resolución».

d) «Notificación de resolución».

e) «Agenda diaria».

f) «Elevación a instancia superior».

g) «Tramitación de expedientes» (Consejo Ejecutivo del Poder Judicial, 2017a, art. cuarto).

- Resolución Administrativa n. ${ }^{\circ}$ 345-2017-CE-PJ. Que aprueba los siguientes documentos de gestión denominados:

a) «Procedimiento ingreso de documentos - Mesa Partes»,

b) «Procedimiento gestión de documentos en custodia», y

c) «Procedimiento notificaciones físicas - demandas y escritos». 
Los cuales serán de obligatorio cumplimiento para todos los órganos jurisdiccionales del Poder Judicial y las partes intervinientes en un proceso; con excepción de aquellos órganos jurisdiccionales donde no se encuentra implementado el Expediente Judicial Electrónico (EJE) (Consejo Ejecutivo del Poder Judicial, 2017b, art. primero).

Y deja «sin efecto el "Procedimiento de Ingreso de Documentos - Mesa de Partes", aprobado por la Resolución Administrativa n. ${ }^{\circ} 228$ 2017-CE-PJ» (Consejo Ejecutivo del Poder Judicial, 2017b, art. tercero).

- Resolución Administrativa n. ${ }^{\circ}$ 198-2018-CE-PJ. Que aprueba los documentos de gestión denominados:

i) «Procedimiento de remisión automatizada del Expediente Judicial Electrónico (EJE) al Ministerio Público - especialidad Contencioso Administrativo"; y, ii) Protocolo para la remisión automatizada del Expediente Judicial Electrónico (EJE) al Ministerio Público Dictamen Fiscal», que serán de obligatorio cumplimiento para todos los órganos jurisdiccionales del Poder Judicial de la especialidad Contencioso Administrativo, donde se encuentra implementado el Expediente Judicial Electrónico (EJE) (Consejo Ejecutivo del Poder Judicial, 2018b, art. primero).

- Resolución Administrativa de Presidencia n. ${ }^{\circ}$ 194-2018-P-CE-PJ. Que aprueba

el documento normativo de gestión administrativa denominado Procedimiento de Elevación y Devolución del Expediente Judicial Electrónico - EJE en las Salas de la Corte Suprema de Justicia de la República [...] el cual será de obligatorio cumplimiento para todos los órganos jurisdiccionales del Poder Judicial y partes intervinientes en un proceso que cuente con las condiciones técnicas necesarias.

[...] Dispone la elevación del Expediente Judicial Electrónico a las siguientes Salas de la Corte Suprema de Justicia de la República: i) Sala de Derecho Constitucional y Social Permanente, ii) Segunda Sala de Derecho Constitucional y Social Transitoria, iii) Tercera Sala de Derecho Constitucional y Social Transitoria, iv) Sala Civil 
Permanente; y v) Sala Civil Transitoria; a partir del 29 de octubre de 2018, de acuerdo al procedimiento citado en el artículo primero [...] (Consejo Ejecutivo del Poder Judicial, 2018b, arts. primero y segundo).

También dispuso la devolución de la ejecutoria suprema del Expediente Judicial Electrónico a los órganos jurisdiccionales correspondientes, a través del citado procedimiento.

- Resolución Administrativa n. ${ }^{\circ}$ 328-2018-CE-PJ. Que aprueba los documentos normativos de gestión administrativa denominados:

i) Procedimiento de Presentación de Documentos a través de la Mesa de Partes Electrónica (MPE); y,

ii) Protocolo para la Presentación de Documentos a través de la Mesa de Partes Electrónica (MPE); el cual detalla los lineamientos para el adecuado uso y presentación de documentos a través de la Mesa de Partes Electrónica.

Documentos que serán de aplicación en todos los órganos jurisdiccionales del Poder Judicial donde se encuentra implementado el Expediente Judicial Electrónico (EJE) (Consejo Ejecutivo del Poder Judicial, 2018c, art. primero).

También «dispone que, a partir del 27 de diciembre de 2018, la presentación de la demanda, medida cautelar fuera de proceso y otros, se pueda realizar a través de la Mesa de Partes Electrónica-MPE; de acuerdo al procedimiento y protocolo citados» (Consejo Ejecutivo del Poder Judicial, 2018c, art. segundo).

- Resolución Administrativa n. ${ }^{\circ}$ 070-2019-CE-PJ. Que aprueba

los procedimientos específicos de las Especialidades Civil - Sub Especialidad Comercial y Contencioso Administrativo - Sub Especialidad Tributario y de Mercado, que serán de obligatorio cumplimiento para todos los órganos jurisdiccionales del Poder Judicial y las partes intervinientes en un proceso en donde se encuentre implementado el Expediente Judicial Electrónico (EJE); según el detalle siguiente: 
1. «Procedimientos Específicos para Juzgados de la Sub Especialidad Comercial con Expediente Judicial Electrónico-EJE»:

a) Apelación y queja.

b) Calificación de demandas.

c) Calificación de escritos.

d) Cuestiones probatorias.

e) Proceso sumarísimo.

f) Proceso único de ejecución (bienes muebles o inmuebles afectados - judicial o extrajudicialmente - opción 1).

g) Proceso único de ejecución (bienes muebles o inmuebles afectados - judicial o extrajudicialmente - opción 2).

h) Pericia de liquidación.

i) Proceso abreviado (contestación de demanda).

j) Proceso abreviado - Reconvención.

k) Medida cautelar.

l) Proceso de conocimiento (contestación de demanda).

m) Proceso de conocimiento - Reconvención.

n) Proceso de ejecución de laudo arbitral.

o) Proceso de obligación de hacer / No hacer / Dar bien mueble.

p) Proceso no contencioso.

q) Proceso único de ejecución (trámite).

r) Procedimiento de incautación judicial.

s) Trámite del recurso de queja (revisión en primera instancia).

t) Proceso único de ejecución (etapa de ejecución) - Embargo en forma de retención.

u) Proceso único de ejecución (etapa de ejecución) - Embargo en forma de administración de bienes.

v) Proceso único de ejecución (etapa de ejecución) - Embargo en forma de intervención en recaudación.

w) Proceso de obligación de dar bien mueble (etapa de ejecución); y,

x) Proceso no contencioso - Convocatoria judicial.

2. «Procedimientos Específicos para Salas de la Sub Especialidad Comercial con Expediente Judicial Electrónico-EJE» para primera instancia:

a) Anulación de laudo arbitral; $y$,

b) Reconocimiento de laudo extranjero. 
3. «Procedimientos Específicos para Salas de la Sub Especialidad Comercial con Expediente Judicial Electrónico-EJE» para segunda instancia:

a) Apelación de autos con efecto suspensivo-Apelación de sentencia en el proceso sumarísimo.

b) Apelación de autos sin efecto suspensivo.

c) Apelación de sentencias (conocimiento y abreviado).

d) Consulta por inhibición.

e) Procedimiento de consulta; y,

f) Trámite del recurso de queja (revisión en segunda instancia).

Para la Especialidad Contencioso Administrativo-Sub Especialidad Tributario, Aduanero y en Temas de Mercado.

4. «Procedimientos Específicos para Juzgados de la Sub Especialidad Tributario, Aduanero y en Temas de Mercado con Expediente Judicial Electrónico-EJE»:

a) Calificación de demandas.

b) Calificación de escritos.

c) Proceso de apelación y queja.

d) Proceso cautelar en temas de mercado (admitida).

e) Proceso cautelar tributario y aduanero (admitida).

f) Proceso especial; y,

g) Proceso urgente.

5. «Procedimiento Específico para Salas de la Sub Especialidad Tributario, Aduanero y en Temas de Mercado con Expediente Judicial Electrónico-EJE» para primera instancia:

a) Proceso de revisión judicial.

6. «Procedimientos Específicos para Salas de la Sub Especialidad Tributario, Aduanero y en Temas de Mercado con Expediente Judicial Electrónico-EJE» para segunda instancia:

a) Apelación de autos con efecto suspensivo.

b) Apelación de autos sin efecto suspensivo.

c) Apelación de sentencia-tributario y aduanero.

d) Apelación de sentencia-temas de mercado.

e) Procedimiento de consulta.

f) Proceso de inhibición en la calificación; y,

g) Recurso de queja (Consejo Ejecutivo del Poder Judicial, 2019a, art. primero). 
los procedimientos específicos de la Especialidad Laboral-Nueva Ley Procesal del Trabajo, que serán de obligatorio cumplimiento para todos los órganos jurisdiccionales del Poder Judicial y las partes intervinientes en un proceso en donde se encuentre implementado el Expediente Judicial Electrónico (EJE); según el detalle siguiente:

1. «Procedimientos específicos para Juzgados de Paz Letrado de la Especialidad Laboral-Nueva Ley Procesal de Trabajo (JPL-NLPT) con Expediente Judicial Electrónico-EJE»:

a) Calificación de demanda.

b) Apelación y queja.

c) Proceso abreviado.

d) Proceso de ejecución.

e) Proceso de inhibición en la calificación.

f) Proceso no contencioso-ofrecimiento de pago y consignación; y,

g) Medida cautelar.

2. «Procedimientos específicos para Juzgados de la Especialidad Laboral-Nueva Ley Procesal de Trabajo (NLPT) con Expediente Judicial Electrónico-EJE» para primera instancia:

a) Calificación de demanda (abreviado y ordinario).

b) Proceso ordinario laboral.

c) Calificación de contestación de demanda.

d) Proceso abreviado - Juzgado especializado laboral.

e) Proceso de inhibición en la calificación.

f) Trámite del recurso de apelación y queja; $y$,

g) Medida cautelar.

3. «Procedimientos específicos para Juzgados de la Especialidad Laboral-Nueva Ley Procesal de Trabajo (NLPT) con Expediente Judicial Electrónico-EJE» para segunda instancia:

a) Apelación de autos con efecto suspensivo.

b) Apelación de autos sin efecto suspensivo.

c) Apelación de sentencia; $y$,

d) Recurso de queja.

4. «Procedimientos específicos para Salas de la Especialidad Laboral -Nueva Ley Procesal de Trabajo (NLPT) con Expediente Judicial Electrónico-EJE» para segunda instancia: 
a) Apelación de autos con efecto suspensivo.

b) Apelación de autos sin efecto suspensivo; y,

c) Apelación de sentencia.

5. Procedimientos específicos para Salas de la Especialidad Laboral -Nueva Ley Procesal de Trabajo (NLPT) con Expediente Judicial Electrónico-EJE» para primera instancia:

a) Anulación de laudo arbitral; $y$,

b) Impugnación de laudos arbitrales económicos (Consejo Ejecutivo del Poder Judicial, 2019b, art. primero).

\subsubsection{Normatividad de implementación}

- Resolución Administrativa n. ${ }^{\circ}$ 228-2017-CE-PJ. Que dispone la implementación del Cuarto Juzgado Comercial de la Corte Superior de Justicia de Lima, con las demandas que se interpongan a partir del 31 de julio de 2017.

- Resolución Administrativa n. ${ }^{\circ}$ 609-2017-P-CSJLI/PJ. Que dispone la implementación del Expediente Judicial Electrónico en órganos jurisdiccionales de la Corte Superior de Justicia de Lima: del 9. , $10 .^{\circ}, 11 .^{\circ}$ y $12 .^{\circ}$ Juzgado Laboral-Nueva Ley Procesal de Trabajo.

- Resolución Administrativa n. ${ }^{\circ}$ 623-2017-P-CSJLI/PJ. Que dispone la implementación del Expediente Judicial Electrónico en diversos órganos jurisdiccionales de la Corte Superior de Justicia de Lima: 1) de la especialidad laboral Nueva Ley Procesal de Trabajo (Juzgados $13 .^{\circ}, 14 .^{\circ}, 15 .^{\circ}$ y $\left.16 .^{\circ}\right), 2$ ), de la subespecialidad comercial (Juzgados $14 .^{\circ}, 15 .^{\circ}$ y $16 .^{\circ}$ y $\left.17 .^{\circ}\right)$ y 3$)$ de la subespecialidad tributario y de mercado (Juzgados $21 .^{\circ}$ y $25 .^{\circ}$ ).

- Resolución Administrativa n. ${ }^{\circ}$ 644-2017-P-CSJLI/PJ. Que dispone la implementación del Expediente Judicial Electrónico en diversos órganos jurisdiccionales de la Corte Superior de Justicia de Lima: 5..$^{a}$ 6. ${ }^{a}$ y 7. ${ }^{a}$ Salas Superiores de la Especialidad Contencioso Administrativo con subespecialidad Tributario y de Mercado; y $1 .^{\circ}$, 2. $.^{\circ} 3 .^{\circ}$ y $4 .^{\circ}$ Juzgados de la Nueva Ley Procesal del Trabajo. 
- Resolución Administrativa n. ${ }^{\circ}$ 673-2017-P-CSJLI/PJ. Que dispone la implementación del Expediente Judicial Electrónico en diversos órganos jurisdiccionales de la Corte Superior de Justicia de Lima: cuatro de la especialidad laboral-NLPT (Juzgados $5 .^{\circ}, 6 .^{\circ}, 7 .^{\circ}$ y $8 .^{\circ}$ ), y siete de la subespecialidad comercial (Juzgados $7 .^{\circ}, 8 .^{\circ}, 9 .^{\circ}, 10 .^{\circ}$, $11 .^{\circ}, 12 .^{\circ}$ y $13 .^{\circ}$.

- Resolución Administrativa n. ${ }^{\circ}$ 678-2017-P-CSJLI/PJ. Que dispone la implementación del Expediente Judicial Electrónico en diversos órganos jurisdiccionales de la Corte Superior de Justicia de Lima: $17 .^{\circ}, 18 .^{\circ}, 19 .^{\circ}$ y $20 .^{\circ}$ Juzgados Laborales-Nueva Ley Procesal del Trabajo.

- Resolución Administrativa n. ${ }^{\circ}$ 687-2017-P-CSJLI/PJ. Que dispone la implementación del Expediente Judicial Electrónico en diversos órganos jurisdiccionales de la Corte Superior de Justicia de Lima: cuatro juzgados laborales $\operatorname{NLPT}\left(21 .^{\circ}, 22 .^{\circ}, 38 .^{\circ}\right.$ y $\left.39 .^{\circ}\right)$, y cinco salas laborales $\operatorname{NLPT}\left(1 .^{a}, 3 .^{a}, 4 .^{a}, 7 .^{a}\right.$ y $\left.8 .^{a}\right)$.

- Resolución Administrativa n. ${ }^{\circ}$ 256-2018-P-CSJLI/PJ. Que dispone la implementación del Expediente Judicial Electrónico en diversos órganos jurisdiccionales de la Corte Superior de Justicia de Lima: se determina la entrada en vigencia de siete juzgados de paz letrado del distrito de Lima que aplican la Nueva Ley Procesal de Trabajo (NLPT) para la implementación del Expediente Judicial Electrónico: $1 .^{\circ}, 2 .^{\circ}, 3 .^{\circ}, 4 .^{\circ}, 5 .^{\circ}, 6 .^{\circ}$ y $7 .^{\circ}$.

- Resolución Administrativa n. ${ }^{\circ}$ 147-2019-P-CSJLIMANORTE/PJ. Que autoriza «la implementación del Expediente Judicial Electrónico (EJE) y la Mesa de Partes Electrónica (MPE) en el Módulo Corporativo Laboral de la Corte Superior de Justicia de Lima Norte, esto es en 5 Juzgados de Paz Letrado, 2 Juzgados Especializados de Trabajo y en la Sala Laboral Permanente» (Corte Superior de Justicia de Lima Norte, 2019, art. primero). 
- Resolución Administrativa n. ${ }^{\circ}$ 230-2019-CE-PJ. Que dispone la implementación del Expediente Judicial Electrónico (EJE) y la Mesa de Partes Electrónica (MPE) en las Cortes Superiores de Justicia de Cajamarca, Tacna y Ventanilla.

- Resolución Administrativa n. ${ }^{\circ}$ 282-2019-CE-PJ. Que aprueba el Plan de Actividades para la Implementación del Expediente Judicial Electrónico (EJE) en el Módulo Corporativo Laboral (NLPT) y en la Sala Laboral Permanente de la Corte Superior de Justicia de Cajamarca.

También dispone la implementación del Expediente Judicial Electrónico (EJE) y la Mesa de Partes Electrónica (MPE) en los órganos jurisdiccionales de la especialidad laboral (NLPT) de la Corte Superior de Justicia de Cajamarca, de la siguiente forma: 2 juzgados de paz letrados laboral, 2 juzgados especializados de trabajo y 1 Sala Laboral Permanente.

- Resolución Administrativa n. ${ }^{\circ}$ 470-2019-CE-PJ. Que aprueba el Plan de Actividades para la Implementación del Expediente Judicial Electrónico (EJE) en el Módulo Corporativo Laboral (NLPT) y en la Sala Laboral Permanente de las Cortes Superiores de Justicia de Ventanilla y Tacna.

Dispone, asimismo:

la implementación del Expediente Judicial Electrónico (EJE) y la Mesa de Partes Electrónica (MPE) en los órganos jurisdiccionales de la especialidad laboral (NLPT) de la Corte Superior de Justicia de Ventanilla, conforme al siguiente detalle: 1 Juzgado de Paz Letrado Laboral, 1 Juzgado Especializado Laboral y 1 Sala Laboral Permanente (Consejo Ejecutivo del Poder Judicial, 2019c, art. segundo).

Igualmente dispone:

la implementación del Expediente Judicial Electrónico (EJE) y la Mesa de Partes Electrónica (MPE) en los órganos jurisdiccionales de la especialidad laboral (NLPT) de la Corte Superior de Justicia 
de Tacna, conforme al siguiente detalle: 1 Juzgado de Paz Letrado Laboral, 2 Juzgados de Trabajo y 1 Sala Laboral Permanente (Consejo Ejecutivo del Poder Judicial, 2019c, art. tercero).

- Resolución Administrativa n. ${ }^{\circ}$ 142-2020-CE-PJ. Que aprueba:

la ampliación del proyecto Expediente Judicial Electrónico-EJE Piloto en el área laboral, a las Cortes Superiores de Justicia de Arequipa, Cusco, Callao, Junín y Lima Sur, por tener mayor volumen de atención al público; conforme a la segunda propuesta presentada por la Gerencia de Informática de la Gerencia General del Poder Judicial (Consejo Ejecutivo del Poder Judicial, 2020a, art. primero).

- Resolución Administrativa n. ${ }^{\circ}$ 206-2020-CE-PJ. Que dispone:

la implementación del Expediente Judicial Electrónico (EJE) y la Mesa de Partes Electrónica (MPE) [...] en los órganos jurisdiccionales de la especialidad laboral (NLPT) de la Corte Superior de Justicia del Callao, conforme al detalle siguiente:

- Sala Laboral,

- $1^{\circ}$ Juzgado Especializado de Trabajo,

- $2^{\circ}$ Juzgado Especializado de Trabajo,

- $3^{\circ}$ Juzgado Especializado de Trabajo,

- $5^{\circ}$ Juzgado Especializado de Trabajo,

- $1^{\circ}$ Juzgado de Paz Letrado Laboral, y

- $2^{\circ}$ Juzgado de Paz Letrado Laboral (Consejo Ejecutivo del Poder Judicial, 2020b, art. primero).

También dispone:

la implementación del Expediente Judicial Electrónico (EJE) y la Mesa de Partes Electrónica (MPE) [...] en los órganos jurisdiccionales de la especialidad laboral (NLPT) de la Corte Superior de Justicia de Cusco, conforme al detalle siguiente:

- $1^{\circ}$ Sala Laboral,

- $1^{\circ}$ Juzgado Especializado de Trabajo,

- $4^{\circ}$ Juzgado Especializado de Trabajo,

- $6^{\circ}$ Juzgado Especializado de Trabajo, 
- $1^{\circ}$ Juzgado de Paz Letrado Laboral, y

- $2^{\circ}$ Juzgado de Paz Letrado Laboral (Consejo Ejecutivo del Poder Judicial, 2020b, art. segundo).

- Resolución Administrativa n. ${ }^{\circ}$ 235-2020-CE-PJ. Que dispone:

la implementación del Expediente Judicial Electrónico (EJE) y la Mesa de Partes Electrónica (MPE) [...] en los órganos jurisdiccionales de la especialidad laboral (NLPT) de la Corte Superior de Justicia de Arequipa, conforme al detalle siguiente:

- $1^{\circ}$ Sala Laboral.

- $3^{\circ}$ Sala Laboral.

- $1^{\circ}$ Juzgado de Trabajo.

- $2^{\circ}$ Juzgado de Trabajo.

- $7^{\circ}$ Juzgado de Trabajo.

- $8^{\circ}$ Juzgado de Trabajo.

- $9^{\circ}$ Juzgado de Trabajo.

- $4^{\circ}$ Juzgado de Paz Letrado - Especialidad Laboral.

- $9^{\circ}$ Juzgado de Paz Letrado - Especialidad Laboral (Consejo Ejecutivo del Poder Judicial, 2020c, art. primero).

También dispone:

la implementación del Expediente Judicial Electrónico (EJE) y la Mesa de Partes Electrónica (MPE) [...] en los órganos jurisdiccionales de la especialidad laboral (NLPT) de la Corte Superior de Justicia de Junín, conforme al detalle siguiente:

- $1^{\circ}$ Sala Laboral de Huancayo.

- $2^{\circ}$ Juzgado Especializado de Trabajo de Huancayo.

- $3^{\circ}$ Juzgado Especializado de Trabajo de Huancayo.

- Juzgado de Paz Letrado con especialidad Laboral de Huancayo (Consejo Ejecutivo del Poder Judicial, 2020c, art. segundo).

- Resolución Administrativa n. . 251-2020-CE-PJ. Que dispone

la implementación del Expediente Judicial Electrónico (EJE) y la Mesa de Partes Electrónica (MPE) [...] en los siguientes órganos jurisdiccionales de la Corte Superior de Justicia de Lima Sur, para la atención de la especialidad laboral (NLPT), conforme al detalle siguiente: 
- Sala Civil Permanente de Villa María del Triunfo.

- Sala Civil Transitoria Descentralizada.

- $1^{\circ}$ Juzgado Especializado de Trabajo.

- $2^{\circ}$ Juzgado Especializado de Trabajo.

- $1^{\circ}$ Juzgado de Paz Letrado Laboral.

- $2^{\circ}$ Juzgado de Paz Letrado Laboral.

- $3^{\circ}$ Juzgado de Paz Letrado Laboral.

- $1^{\circ}$ Juzgado de Paz Letrado Laboral Transitorio (Consejo Ejecutivo del Poder Judicial, 2020d, art. primero).

- Resolución Administrativa n. ${ }^{\circ}$ 262-2020-CE-PJ. Que amplía «la implantación del Expediente Judicial Electrónico-EJE Piloto en la especialidad laboral-Nueva Ley Procesal del Trabajo, en las Cortes Superiores de Justicia de La Libertad, Puno, Lambayeque, Lima Este, Piura, Santa e Ica» (Consejo Ejecutivo del Poder Judicial, 2020e, art. primero).

- Resolución Administrativa n. 309-2020-CE-PJ. Que dispone

la implantación del Expediente Judicial Electrónico (EJE) y la Mesa de Partes Electrónica (MPE) [...] en los siguientes órganos jurisdiccionales de la Corte Superior de Justicia de La Libertad, para la atención de la especialidad laboral (Nueva Ley Procesal del Trabajo-NLPT), conforme al detalle siguiente:

- $1^{\circ}$ Sala Especializada Laboral Permanente de La Libertad.

- $2^{\circ}$ Sala Especializada Laboral Permanente de La Libertad.

- $3^{\circ}$ Juzgado Especializado de Trabajo Permanente de Trujillo.

- $4^{\circ}$ Juzgado Especializado de Trabajo Permanente de Trujillo

- $6^{\circ}$ Juzgado Especializado de Trabajo Permanente de Trujillo.

- $7^{\circ}$ Juzgado Especializado de Trabajo Permanente de Trujillo.

- $8^{\circ}$ Juzgado Especializado de Trabajo Permanente de Trujillo.

- $9^{\circ}$ Juzgado Especializado de Trabajo Permanente de Trujillo.

- $10^{\circ}$ Juzgado Especializado de Trabajo Permanente de Trujillo.

- $1^{\circ}$ Juzgado de Paz Letrado Laboral Permanente de Trujillo.

- $10^{\circ}$ Juzgado de Paz Letrado Laboral Permanente de Trujillo.

- $2^{\circ}$ Juzgado de Paz Letrado Laboral Transitorio de Trujillo (Consejo Ejecutivo del Poder Judicial, 2020f, art. primero). 
- Resolución Administrativa n. 320-2020-CE-PJ. Que dispone

la implantación del Expediente Judicial Electrónico (EJE) y la Mesa de Partes Electrónica (MPE) [...] en los siguientes órganos jurisdiccionales de la Corte Superior de Justicia de Lambayeque, para la atención de la especialidad laboral (NLPT), conforme al detalle siguiente:

- Segunda Sala Laboral Permanente de Chiclayo.

- $1^{\circ}$ Juzgado de Trabajo Permanente de Chiclayo.

- $2^{\circ}$ Juzgado de Trabajo Permanente de Chiclayo.

- $7^{\circ}$ Juzgado de Trabajo Permanente de Chiclayo.

- $8^{\circ}$ Juzgado de Trabajo Permanente de Chiclayo.

- Juzgado de Trabajo Transitorio de Chiclayo.

- $1^{\circ}$ Juzgado de Paz Letrado Laboral de Chiclayo.

- $2^{\circ}$ Juzgado de Paz Letrado Laboral de Chiclayo (Consejo Ejecutivo del Poder Judicial, 2020g, art. primero).

- Resolución Administrativa n. ${ }^{\circ}$ 326-2020-CE-PJ. Que dispone

la implantación del Expediente Judicial Electrónico (EJE) y la Mesa de Partes Electrónica (MPE) [...] en los siguientes órganos jurisdiccionales de la Corte Superior de Justicia de Lima Este, para la atención de la especialidad laboral (NLPT), conforme al detalle siguiente:

- $2^{\circ}$ Juzgado de Trabajo Permanente - Zona 01.

- $3^{\circ}$ Juzgado de Trabajo Permanente - Zona 01.

- $1^{\circ}$ Juzgado de Paz Letrado Laboral Permanente - Zona 01.

- $2^{\circ}$ Juzgado de Paz Letrado Laboral Permanente - Zona 01.

- Juzgado de Trabajo Permanente - Zona 02.

- $1^{\circ}$ Juzgado de Paz Letrado Laboral Permanente - Zona 02.

- $2^{\circ}$ Juzgado de Paz Letrado Laboral Permanente - Zona 02.

- $3^{\circ}$ Juzgado de Paz Letrado Laboral Permanente - Zona 02.

- $4^{\circ}$ Juzgado de Paz Letrado Laboral Permanente - Zona 02.

- Juzgado de Trabajo Transitorio de Descarga - Zona 02.

- Sala Laboral Permanente.

- Juzgado de Trabajo Permanente - Zona 03.

- $1^{\circ}$ Juzgado de Paz Letrado Laboral Permanente - Zona 03.

- $2^{\circ}$ Juzgado de Paz Letrado Laboral Permanente - Zona 03.

- $3^{\circ}$ Juzgado de Paz Letrado Laboral Permanente - Zona 03 (Consejo Ejecutivo del Poder Judicial, 2020h, art. primero). 


\section{También dispone}

la implantación del Expediente Judicial Electrónico (EJE) y la Mesa de Partes Electrónica (MPE) [...] en los siguientes órganos jurisdiccionales de la Corte Superior de Justicia de Puno, para la atención de la especialidad laboral (NLPT), conforme al detalle siguiente:

- Sala Laboral de Puno.

- Juzgado de Trabajo Transitorio - Zona Sur.

- Juzgado de Paz Letrado Laboral - Zona Sur.

- Juzgado de Trabajo - Zona Norte.

- Juzgado de Paz Letrado Laboral - Zona Norte (Consejo Ejecutivo del Poder Judicial, 2020h, art. segundo).

- Resolución Administrativa n. ${ }^{\circ}$ 338-2020-CE-PJ. Que dispone

la implantación del Expediente Judicial Electrónico (EJE) y la Mesa de Partes Electrónica (MPE) [...] en los siguientes órganos jurisdiccionales de la Corte Superior de Justicia de Piura, para la atención de la especialidad laboral (NLPT), conforme al detalle siguiente:

- Sala Laboral Permanente de Piura

- $1^{\circ}$ Juzgado de Trabajo de Piura

- $5^{\circ}$ Juzgado de Trabajo Transitorio de Piura

- $6^{\circ}$ Juzgado de Trabajo Transitorio de Piura

- $8^{\circ}$ Juzgado de Trabajo Transitorio de Piura

- $5^{\circ}$ Juzgado de Paz Letrado Laboral de Piura

- $8^{\circ}$ Juzgado de Paz Letrado Laboral de Piura (Consejo Ejecutivo del Poder Judicial, 2020i, art. primero).

- Resolución Administrativa n. 3 343-2020-CE-PJ. Que dispone

la implantación del Expediente Judicial Electrónico (EJE) y la Mesa de Partes Electrónica (MPE) [...] en los siguientes órganos jurisdiccionales de la Corte Superior de Justicia del Santa, para la atención de la especialidad laboral (NLPT), conforme al detalle siguiente:

- Sala Laboral Permanente.

- Sala Laboral Transitoria.

- $1^{\circ}$ Juzgado Especializado Laboral. 
- $2^{\circ}$ Juzgado Especializado Laboral.

- $3^{\circ}$ Juzgado Especializado Laboral.

- $5^{\circ}$ Juzgado Especializado Laboral.

- $6^{\circ}$ Juzgado Especializado Laboral.

- $8^{\circ}$ Juzgado Especializado Laboral.

- $9^{\circ}$ Juzgado Especializado Laboral.

- $1^{\circ}$ Juzgado de Paz Letrado Laboral-NLPT.

- $2^{\circ}$ Juzgado de Paz Letrado Laboral-NLPT.

- $3^{\circ}$ Juzgado de Paz Letrado Laboral-NLPT (Consejo Ejecutivo del Poder Judicial, 2020j, art. primero).

- Resolución Administrativa n. ${ }^{\circ}$ 355-2020-CE-PJ. Que dispone

la implantación del Expediente Judicial Electrónico (EJE) y la Mesa de Partes Electrónica (MPE) [...] en los siguientes órganos jurisdiccionales de la Corte Superior de Justicia de Ica, para la atención de la especialidad laboral (NLPT), conforme al detalle siguiente:

- Sala Laboral de Ica.

- $1^{\circ}$ Juzgado de Trabajo de Ica.

- $2^{\circ}$ Juzgado de Trabajo de Ica.

- $1^{\circ}$ Juzgado de Paz Letrado Laboral de Ica.

- $2^{\circ}$ Juzgado de Paz Letrado Laboral de Ica (Consejo Ejecutivo del Poder Judicial, 2020k, art. primero).

- Resolución Administrativa n. ${ }^{\circ}$ 379-2020-CE-PJ. Que dispone

la implementación del Expediente Judicial Electrónico (EJE) y la Mesa de Partes Electrónica (MPE) [...] en los siguientes órganos jurisdiccionales del Módulo Civil Corporativo de Litigación Oral y Salas Civiles de la Corte Superior de Justicia del Santa, que atienden procesos de la Especialidad Civil Subespecialidad Civil, conforme al detalle siguiente:

- $1^{\circ}$ Sala Superior Civil Permanente.

- $2^{\circ}$ Sala Superior Civil Permanente.

- $1^{\circ}$ Juzgado Especializado Civil Permanente.

- $2^{\circ}$ Juzgado Especializado Civil Permanente

- $3^{\circ}$ Juzgado Especializado Civil Permanente.

- $4^{\circ}$ Juzgado Especializado Civil Permanente.

- $5^{\circ}$ Juzgado Especializado Civil Permanente (Consejo Ejecutivo del Poder Judicial, 20201, art. primero). 
- Resolución Administrativa n. ${ }^{\circ}$ 138-2020-P-CE-PJ. Que dispone «la implementación del Expediente Judicial Electrónico-EJE y la Mesa de Partes Electrónica-MPE (Etapa Intermedia) [...] en la Corte Superior Nacional de Justicia Penal Especializada» (Consejo Ejecutivo del Poder Judicial, 2020m, art. primero).

\subsection{Acciones estratégicas y actividades operativas del Expediente Judicial Electrónico en desarrollo}

Las actividades que viene desplegando la Secretaría Técnica de la Comisión de Trabajo del Expediente Judicial Electrónico se han dinamizado en los tiempos actuales, en los cuales la pandemia ha sido el catalizador positivo de la aceleración del proceso de modernización de los servicios de justicia. De este modo, como herramienta tecnológica, se ha hecho posible el acceso a la justicia preservando la calidad de los procedimientos judiciales, pues se permite un flujo constante de retroalimentación con una evolución positiva de la propuesta tecnológica, para ello se dispone de acciones estratégicas concretas que se desarrollarán.

\subsubsection{Acción estratégica 1}

Procesos optimizados de gestión. Los procesos jurisdiccionales se ejecutan en medios virtuales y con menor desplazamiento de usuarios y elevada disposición al uso de las TIC en los procesos jurisdiccionales y administrativos.

Actividades operativas:

- Infraestructura tecnológica moderna (hardware y software, equipamiento e instalaciones) en los servicios judiciales donde opera el Expediente Judicial Electrónico (EJE). Esta actividad permite asegurar la sostenibilidad y mejoramiento de las condiciones de operatividad e implementación.

Las actividades de esta dimensión consideran la planificación, la ejecución, el monitoreo y la evaluación de los planes anuales, los 
cuales están interrelacionados por procesos de retroalimentación permanentes en la gestión de la operatividad del Expediente Judicial Electrónico, inmerso en un proceso de mejora continua con miras a optimizar los servicios que brinda.

- Personal jurisdiccional y administrativo mejor capacitado en el uso de las TIC-Expediente Judicial Electrónico. Se promueve de manera virtual la capacitación en la operatividad del Expediente Judicial Electrónico como herramienta tecnológica dirigida a los usuarios internos y externos; se fomenta, igualmente, la difusión de buenas prácticas. Se promueve, asimismo, los aspectos favorables y el impulso de su implementación en las diversas cortes superiores de justicia a nivel nacional. De esta manera, se permite incorporar la gestión del cambio en el concepto de mejora continua.

- Procesos judiciales y administrativos estandarizados. Los procedimientos estandarizados permiten generar valor público y eficiencia en el uso de recursos.

\subsubsection{Acción estratégica 2}

Procesos optimizados de gestión. Eficaz soporte de los procesos de decisión e información para los servicios judiciales que brinda el Poder Judicial.

Actividades operativas:

- Óptimo sistema estadístico. Disponer de información estratégica permite adoptar medidas conducentes a la eficiencia en la entrega del servicio de administración de justicia.

- Adecuado desarrollo de instrumentos de monitoreo y control de procesos. El monitoreo de un proyecto implica controlar todos sus procesos: se hace el seguimiento, se revisa y se informa sobre el avance para cumplir los objetivos de desempeño definidos en el plan para la dirección de proyecto. Se evalúan los procedimientos y las tendencias que permitan mejoras y su eficiente sostenibilidad en el tiempo. 


\section{Capítulo II}

\section{EL EJE EN CIFRAS}

\subsection{Ingresos a primera instancia}

La implementación del Expediente Judicial Electrónico genera el efecto de sustitución del expediente judicial físico a partir del 2017. Este se evidencia en la evolución del número de demandas electrónicas, que al 31 de diciembre de 2020 sumaban 185286 ingresadas a los órganos jurisdiccionales implementados, información que incluye lo migrado del Expediente Judicial Digital para la Corte Superior de Justicia de Lima Norte, como se observa en la siguiente tabla, detallada por distrito judicial y especialidad:

Tabla n. ${ }^{\circ}$ 2. Cantidad de demandas EJE ingresadas al Poder Judicial

\begin{tabular}{|c|c|c|c|c|c|c|}
\hline N. ${ }^{\circ}$ & CSJ & Especialidad & $\begin{array}{l}\text { Juzgados de } \\
\text { paz letrado }\end{array}$ & $\begin{array}{c}\text { Juzgados } \\
\text { especializados }\end{array}$ & $\begin{array}{c}\text { Salas } \\
\text { superiores }\end{array}$ & $\begin{array}{l}\text { Total de } \\
\text { ingresos }\end{array}$ \\
\hline \multirow{4}{*}{1} & \multirow{4}{*}{ Lima } & $\begin{array}{l}\text { Civil con } \\
\text { subespecialidad } \\
\text { comercial }\end{array}$ & & 48289 & 1520 & 49809 \\
\hline & & $\begin{array}{l}\text { Cont. adm. con } \\
\text { subespecialidad } \\
\text { tributaria y } \\
\text { aduanera }\end{array}$ & & 3065 & 29 & 3094 \\
\hline & & $\begin{array}{l}\text { Cont. adm. con } \\
\text { subespecialidad en } \\
\text { temas de mercado }\end{array}$ & & 4547 & 282 & 4829 \\
\hline & & Laboral-NLPT & 15466 & 39261 & 304 & 55031 \\
\hline \multirow[t]{2}{*}{2} & \multirow{2}{*}{ Lima Norte } & $\begin{array}{l}\text { Laboral-NLPT- } \\
\text { migrados }\end{array}$ & 33436 & 4738 & 5 & 38179 \\
\hline & & Laboral-NLPT-EJE & 12150 & 3268 & 175 & 15593 \\
\hline
\end{tabular}




\begin{tabular}{|c|l|l|c|c|c|c|}
\hline 3 & Cajamarca & Laboral-NLPT & 1505 & 906 & 1 & 2412 \\
\hline 4 & $\begin{array}{l}\text { Puente } \\
\text { Piedra- } \\
\text { Ventanilla }\end{array}$ & Laboral-NLPT & 608 & 513 & 0 & 1121 \\
\hline 5 & Tacna & Laboral-NLPT & 563 & 367 & 0 & 930 \\
\hline 6 & Callao & Laboral-NLPT & 1012 & 869 & 0 & 1881 \\
\hline 7 & Cusco & Laboral-NLPT & 469 & 400 & 0 & 869 \\
\hline 8 & Arequipa & Laboral-NLPT & 1678 & 665 & 2 & 2345 \\
\hline 9 & Junín & Laboral-NLPT & 321 & 256 & 1 & 578 \\
\hline 10 & Lima Sur & Laboral-NLPT & 1557 & 357 & 0 & 1914 \\
\hline 11 & La Libertad & Laboral-NLPT & 1157 & 652 & 0 & 1809 \\
\hline 12 & Lambayeque & Laboral-NLPT & 375 & 431 & 0 & 806 \\
\hline 13 & Lima Este & Laboral-NLPT & 2366 & 303 & 0 & 2669 \\
\hline 14 & Puno & Laboral-NLPT & 202 & 46 & 0 & 248 \\
\hline 15 & Piura & Laboral-NLPT & 472 & 163 & 0 & 1835 \\
\hline \multirow{2}{*}{ Total } & Santa & Laboral-NLPT & 104 & 230 & 283 \\
\cline { 2 - 7 } & Civil-litigación oral & 0 & 171 & 0 & 17 \\
\hline
\end{tabular}

Fecha de actualización: 31 de diciembre de 2020.

Fuente: Gerencia de Informática.

Elaboración: Secretaría Técnica de la Comisión de Trabajo del EJE.

Leyenda: CSJ: Corte Superior de Justicia, NLPT: Nueva Ley Procesal del Trabajo.

En la figura siguiente se observa la distribución de las demandas EJE ingresadas por especialidad y tipo de órgano jurisdiccional: 
Figura n. ${ }^{\circ}$ 5. Cantidad de demandas EJE ingresadas por especialidad y tipo de órgano jurisdiccional

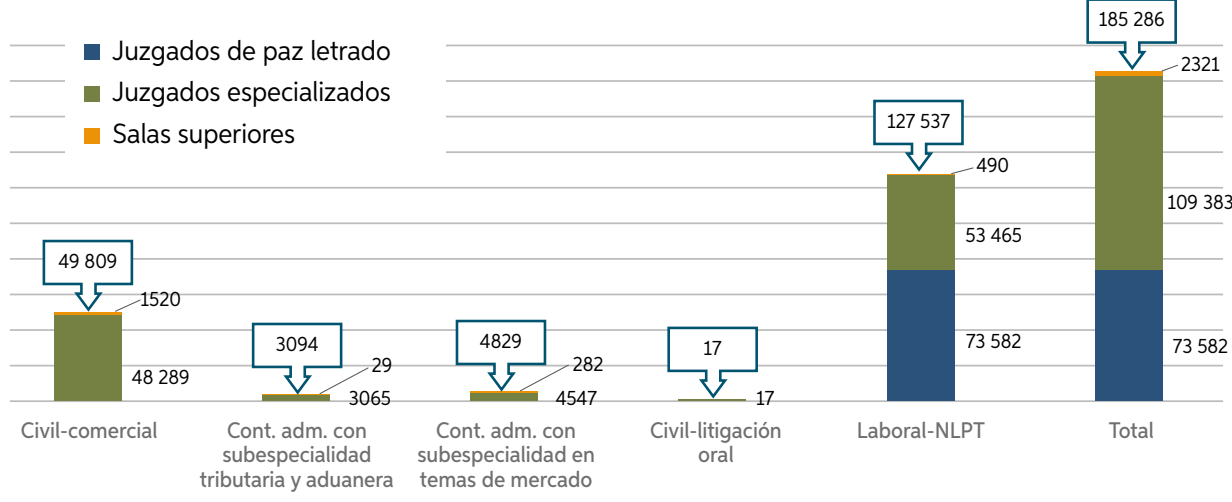

Fecha de actualización: 31 de diciembre de 2020.

Fuente: Gerencia de Informática.

Elaboración: Secretaría Técnica de la Comisión de Trabajo del EJE.

\subsubsection{Ingreso de demandas por tipo de órgano jurisdiccional}

De la información mostrada en la figura n. ${ }^{\circ} 5$ se observa que 73582 demandas ingresaron a través de los juzgados de paz letrados, lo que representa el $40 \%$; 109383 demandas ingresaron en los juzgados especializados, lo que corresponde al $59 \%$; y 2321 demandas fueron ingresadas en las salas superiores, lo que representa el $1 \%$ del total. Esto se muestra en la siguiente figura:

Figura n. ${ }^{\circ}$ 6. Cantidad de demandas EJE ingresadas por tipo de órgano jurisdiccional

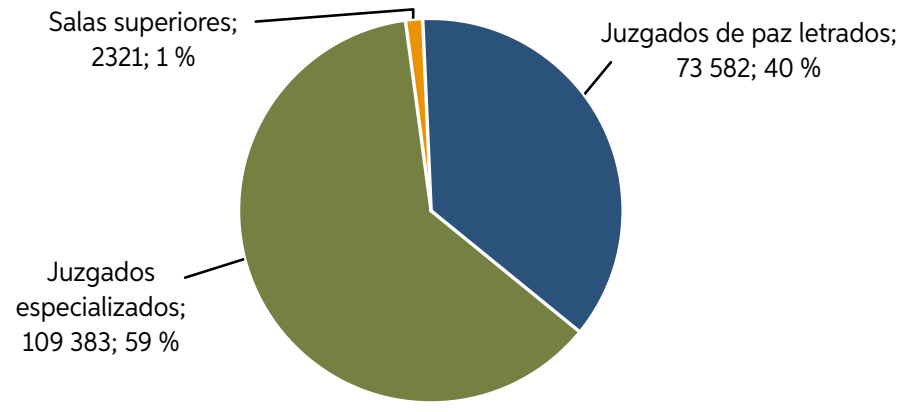

Fecha de actualización: 31 de diciembre de 2020.

Fuente: Gerencia de Informática.

Elaboración: Secretaría Técnica de la Comisión de Trabajo del EJE. 


\subsubsection{Ingreso de demandas por corte superior de justicia}

Del total de las demandas ingresadas el $60.9 \%$ son de la Corte Superior de Justicia de Lima, el 29 \% son de la Corte Superior de Justicia de Lima Norte y el $10.1 \%$ restante han ingresado en las demás cortes superiores de justicia implementadas, lo que se puede observar en la siguiente figura.

Figura n. ${ }^{\circ}$ 7. Cantidad de demandas EJE ingresadas por tipo de órgano jurisdiccional

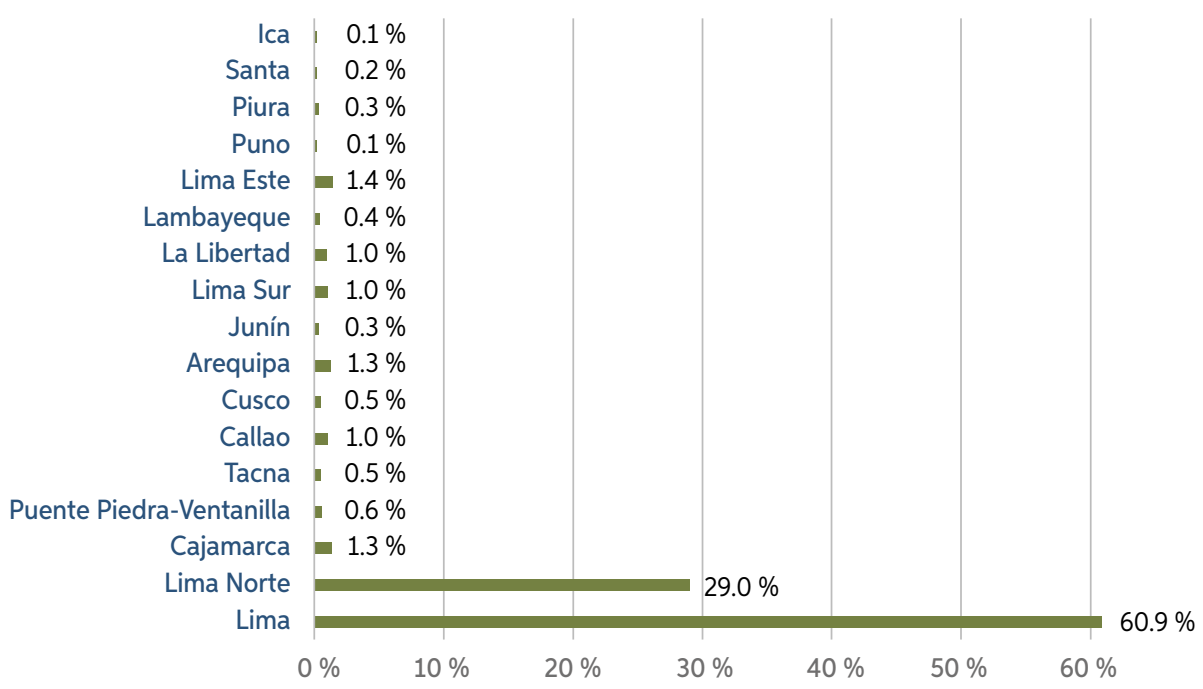

Fecha de actualización: 31 de diciembre de 2020.

Fuente: Gerencia de Informática.

Elaboración: Secretaría Técnica de la Comisión de Trabajo del EJE.

\subsubsection{Ingreso de demandas por especialidad y tipo de órgano jurisdiccional}

Al realizar un análisis por especialidad y según el tipo de órgano jurisdiccional al que se presentan las demandas ante el Poder Judicial, se obtiene que para el caso de las especialidades civil, subespecialidad comercial y contencioso administrativo, subespecialidades tributario y en temas de mercado de la Corte Superior de Justicia de Lima, así como civil-litigación oral, casi el $100 \%$ de las demandas son ingresadas en los juzgados especializados. Como se muestra en la tabla y la figura siguientes: 
Tabla n. ${ }^{\circ}$ 3. Demandas EJE ingresadas por especialidad y tipo de órgano jurisdiccional

\begin{tabular}{|c|c|c|c|c|c|c|c|}
\hline \multirow{2}{*}{ N. ${ }^{\circ}$} & \multirow{2}{*}{ CSJ } & \multirow{2}{*}{ Especialidad } & \multicolumn{2}{|c|}{ Juzgados especializados } & \multicolumn{2}{|c|}{ Salas superiores } & \multirow{2}{*}{ Total } \\
\hline & & & Demanda & Porcentaje & Demanda & Porcentaje & \\
\hline \multirow{3}{*}{1} & \multirow{3}{*}{ Lima } & $\begin{array}{l}\text { Civil con } \\
\text { subespecialidad } \\
\text { comercial }\end{array}$ & 48289 & $96.9 \%$ & 1520 & $3.1 \%$ & 49809 \\
\hline & & $\begin{array}{l}\text { Cont. adm. con } \\
\text { subespecialidad } \\
\text { tributaria y } \\
\text { aduanera }\end{array}$ & 3065 & $99.1 \%$ & 29 & $0.9 \%$ & 3094 \\
\hline & & $\begin{array}{l}\text { Cont. adm. con } \\
\text { subespecialidad } \\
\text { en temas de } \\
\text { mercado }\end{array}$ & 4547 & $94.2 \%$ & 282 & $5.8 \%$ & 4829 \\
\hline 2 & Santa & $\begin{array}{l}\text { Civil-litigación } \\
\text { oral }\end{array}$ & 17 & $100 \%$ & 0 & $0 \%$ & 17 \\
\hline \multicolumn{3}{|c|}{ Total } & 55918 & $96.8 \%$ & 1831 & $3.2 \%$ & 57749 \\
\hline
\end{tabular}

Fecha de actualización: 31 de diciembre de 2020.

Fuente: Gerencia de Informática.

Elaboración: Secretaría Técnica de la Comisión de Trabajo del EJE.

Leyenda: CSJ: Corte Superior de Justicia.

Figura n. ${ }^{\circ}$ 8. Demandas EJE ingresadas por especialidad y tipo de órgano jurisdiccional

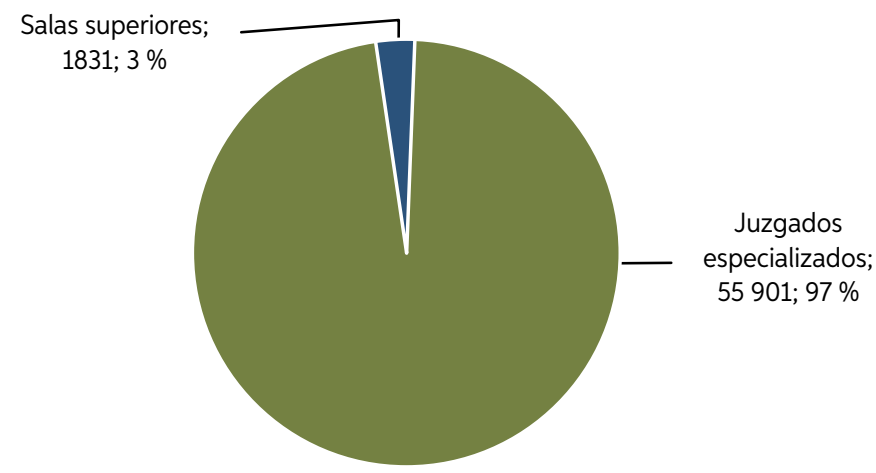

Fecha de actualización: 31 de diciembre de 2020.

Fuente: Gerencia de Informática.

Elaboración: Secretaría Técnica de la Comisión de Trabajo del EJE. 
Para el caso de la especialidad laboral-Nueva Ley Procesal del Trabajo (NLPT), el mayor porcentaje de demandas son presentadas en los juzgados de paz letrados a nivel nacional. Sin embargo, observando en detalle cada corte superior de justicia, se evidencia que en las Cortes Superiores de Justicia de Lima, Lambayeque y del Santa, el mayor porcentaje de demandas son presentadas en los juzgados especializados, como se observa en la siguiente tabla.

Tabla n. ${ }^{\circ}$ 4. Demandas EJE ingresadas por tipo de órgano jurisdiccional en la especialidad laboral-NLPT

\begin{tabular}{|c|c|c|c|c|c|c|c|c|c|}
\hline \multirow{2}{*}{ N. ${ }^{\circ}$} & \multirow{2}{*}{ CSJ } & \multirow{2}{*}{ Especialidad } & \multicolumn{2}{|c|}{$\begin{array}{l}\text { Juzgados de paz } \\
\text { letrado }\end{array}$} & \multicolumn{2}{|c|}{$\begin{array}{c}\text { Juzgados } \\
\text { especializados }\end{array}$} & \multicolumn{2}{|c|}{ Salas superiores } & \multirow{2}{*}{ Total } \\
\hline & & & Demanda & $\%$ & Demanda & $\%$ & Demanda & $\%$ & \\
\hline 1 & Lima & $\begin{array}{l}\text { Laboral- } \\
\text { NLPT }\end{array}$ & 15466 & $28.1 \%$ & 39261 & $71.3 \%$ & 304 & $0.6 \%$ & 55031 \\
\hline \multirow[t]{2}{*}{2} & \multirow{2}{*}{ Lima Norte } & $\begin{array}{l}\text { Laboral- } \\
\text { NLPT- } \\
\text { migrados }\end{array}$ & 33436 & $87.6 \%$ & 4738 & $12.4 \%$ & 5 & $0 \%$ & 38179 \\
\hline & & $\begin{array}{l}\text { Laboral- } \\
\text { NLPT-EJE }\end{array}$ & 12150 & $77.9 \%$ & 3268 & $21 \%$ & 175 & $1.1 \%$ & 15593 \\
\hline 3 & Cajamarca & $\begin{array}{l}\text { Laboral- } \\
\text { NLPT }\end{array}$ & 1505 & $62.4 \%$ & 906 & $37.6 \%$ & 1 & $0 \%$ & 2412 \\
\hline 4 & $\begin{array}{l}\text { Puente } \\
\text { Piedra- } \\
\text { Ventanilla }\end{array}$ & $\begin{array}{l}\text { Laboral- } \\
\text { NLPT }\end{array}$ & 608 & $54.2 \%$ & 513 & $45.8 \%$ & 0 & $0 \%$ & 1121 \\
\hline 5 & Tacna & $\begin{array}{l}\text { Laboral- } \\
\text { NLPT }\end{array}$ & 563 & $60.5 \%$ & 367 & $39.5 \%$ & 0 & $0 \%$ & 930 \\
\hline 6 & Callao & $\begin{array}{l}\text { Laboral- } \\
\text { NLPT }\end{array}$ & 1012 & $53.8 \%$ & 869 & $46.2 \%$ & 0 & $0 \%$ & 1881 \\
\hline 7 & Cusco & $\begin{array}{l}\text { Laboral- } \\
\text { NLPT }\end{array}$ & 469 & $54 \%$ & 400 & $46 \%$ & 0 & $0 \%$ & 869 \\
\hline 8 & Arequipa & $\begin{array}{l}\text { Laboral- } \\
\text { NLPT }\end{array}$ & 1678 & $71.6 \%$ & 665 & $28.4 \%$ & 2 & $0.1 \%$ & 2345 \\
\hline 9 & Junín & $\begin{array}{l}\text { Laboral- } \\
\text { NLPT }\end{array}$ & 321 & $55.5 \%$ & 256 & $44.3 \%$ & 1 & $0.2 \%$ & 578 \\
\hline 10 & Lima Sur & $\begin{array}{l}\text { Laboral- } \\
\text { NLPT }\end{array}$ & 1557 & $81.3 \%$ & 357 & $18.7 \%$ & 0 & $0 \%$ & 1914 \\
\hline
\end{tabular}




\begin{tabular}{|l|l|l|c|c|c|c|c|c|c|}
\hline 11 & La Libertad & $\begin{array}{l}\text { Laboral- } \\
\text { NLPT }\end{array}$ & 1157 & $64 \%$ & 652 & $36 \%$ & 0 & $0 \%$ & 1809 \\
\hline 12 & Lambayeque & $\begin{array}{l}\text { Laboral- } \\
\text { NLPT }\end{array}$ & 375 & $46.5 \%$ & 431 & $53.5 \%$ & 0 & $0 \%$ & 806 \\
\hline 13 & Lima Este & $\begin{array}{l}\text { Laboral- } \\
\text { NLPT }\end{array}$ & 2366 & $88.6 \%$ & 303 & $11.4 \%$ & 0 & $0 \%$ & 2669 \\
\hline 14 & Puno & $\begin{array}{l}\text { Laboral- } \\
\text { NLPT }\end{array}$ & 202 & $81.5 \%$ & 46 & $18.5 \%$ & 0 & $0 \%$ & 248 \\
\hline 15 & Piura & $\begin{array}{l}\text { Laboral- } \\
\text { NLPT }\end{array}$ & 472 & $74.3 \%$ & 163 & $25.7 \%$ & 0 & $0 \%$ & 635 \\
\hline 16 & Santa & $\begin{array}{l}\text { Laboral- } \\
\text { NLPT }\end{array}$ & 104 & $31 \%$ & 230 & $68.5 \%$ & 2 & $0.6 \%$ & 336 \\
\hline 17 & Ica & $\begin{array}{l}\text { Laboral- } \\
\text { NLPT }\end{array}$ & 141 & $77.9 \%$ & 40 & $22.1 \%$ & 0 & $0 \%$ & 181 \\
\hline Subtotal & & 7358 & $57.7 \%$ & 53465 & $41.9 \%$ & 490 & $0.4 \%$ & 127537 \\
\hline
\end{tabular}

Fecha de actualización: 31 de diciembre de 2020.

Fuente: Gerencia de Informática.

Elaboración: Secretaría Técnica de la Comisión de Trabajo del EJE.

Leyenda: CSJ: Corte Superior de Justicia.

Figura n. ${ }^{\circ}$ 9. Demandas EJE ingresadas por tipo de órgano jurisdiccional en la especialidad laboral-NLPT

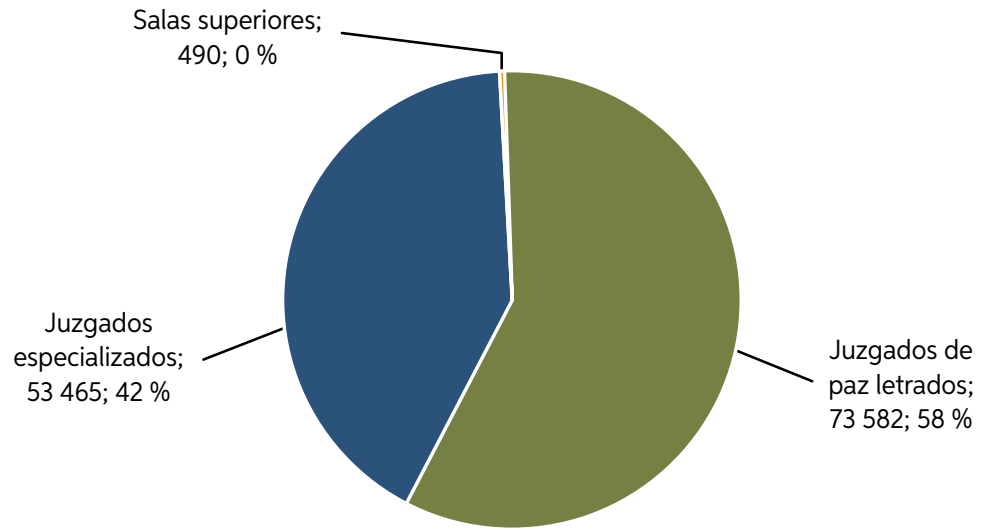

Fecha de actualización: 31 de diciembre de 2020.

Fuente: Gerencia de Informática.

Elaboración: Secretaría Técnica de la Comisión de Trabajo del EJE. 


\subsection{Salidas de primera instancia}

Al 31 de diciembre de 2020 han terminado el proceso de primera instancia 72162 expedientes judiciales electrónicos, como se observa en la siguiente tabla.

Tabla n. ${ }^{\circ}$ 5. Cantidad de EJE que terminaron su proceso de primera instancia

\begin{tabular}{|c|c|c|c|c|c|c|c|c|c|c|c|}
\hline \multirow[t]{2}{*}{ N. ${ }^{\circ}$} & \multirow[t]{2}{*}{ CSJ } & \multirow[t]{2}{*}{ Especialidad } & \multicolumn{2}{|c|}{$\begin{array}{c}\text { Juzgados de paz } \\
\text { letrado }\end{array}$} & \multicolumn{2}{|c|}{$\begin{array}{c}\text { Juzgados } \\
\text { especializados }\end{array}$} & \multicolumn{2}{|c|}{ Salas superiores } & \multicolumn{2}{|c|}{ Subtotal } & \multirow[t]{2}{*}{ Total } \\
\hline & & & Auto & Sentencia & Auto & Sentencia & Auto & Sentencia & Auto & Sentencia & \\
\hline \multirow{4}{*}{1} & \multirow{4}{*}{ Lima } & $\begin{array}{l}\text { Civil con } \\
\text { subespe- } \\
\text { cialidad } \\
\text { comercial }\end{array}$ & & & 19916 & 201 & 0 & 722 & 19916 & 923 & 20839 \\
\hline & & $\begin{array}{l}\text { Cont. adm. } \\
\text { con subes- } \\
\text { pecialidad } \\
\text { tributaria y } \\
\text { aduanera } \\
\end{array}$ & & & 94 & 1044 & 0 & 0 & 94 & 1044 & 1138 \\
\hline & & $\begin{array}{l}\text { Cont. adm. } \\
\text { con subes- } \\
\text { pecialidad } \\
\text { en temas } \\
\text { de mercado } \\
\end{array}$ & & & 185 & 869 & 11 & 111 & 196 & 980 & 1176 \\
\hline & & $\begin{array}{l}\text { Laboral- } \\
\text { NLPT }\end{array}$ & 9304 & 6035 & 1510 & 12666 & 65 & 125 & 10879 & 18826 & 29705 \\
\hline 2 & $\begin{array}{l}\text { Lima } \\
\text { Norte }\end{array}$ & $\begin{array}{l}\text { Laboral- } \\
\text { NLPT-EJE }\end{array}$ & 7175 & 8018 & 82 & 702 & 0 & 0 & 7257 & 8720 & 15977 \\
\hline 3 & Cajamarca & $\begin{array}{l}\text { Laboral- } \\
\text { NLPT }\end{array}$ & 498 & 733 & 44 & 259 & 0 & 0 & 542 & 992 & 1534 \\
\hline 4 & $\begin{array}{l}\text { Puente } \\
\text { Piedra- } \\
\text { Ventanilla }\end{array}$ & $\begin{array}{l}\text { Laboral- } \\
\text { NLPT }\end{array}$ & 200 & 48 & 0 & 44 & 0 & 0 & 200 & 92 & 292 \\
\hline 5 & Tacna & $\begin{array}{l}\text { Laboral- } \\
\text { NLPT }\end{array}$ & 560 & 86 & 6 & 140 & 0 & 0 & 566 & 226 & 792 \\
\hline 6 & Callao & $\begin{array}{l}\text { Laboral- } \\
\text { NLPT }\end{array}$ & 263 & 84 & 10 & 0 & 0 & 0 & 273 & 84 & 357 \\
\hline 7 & Cusco & $\begin{array}{l}\text { Laboral- } \\
\text { NLPT }\end{array}$ & 4 & 92 & 1 & 8 & 0 & 0 & 5 & 100 & 105 \\
\hline 8 & Arequipa & $\begin{array}{l}\text { Laboral- } \\
\text { NLPT }\end{array}$ & 4 & 0 & 0 & 4 & 0 & 0 & 4 & 4 & 8 \\
\hline 9 & Junín & $\begin{array}{l}\text { Laboral- } \\
\text { NLPT }\end{array}$ & 5 & 64 & 0 & 6 & 0 & 0 & 5 & 70 & 75 \\
\hline
\end{tabular}




\begin{tabular}{|c|c|c|c|c|c|c|c|c|c|c|c|}
\hline 10 & $\begin{array}{l}\text { Lima } \\
\text { Sur }\end{array}$ & $\begin{array}{l}\text { Laboral- } \\
\text { NLPT }\end{array}$ & 0 & 2 & 0 & 0 & 0 & 0 & 0 & 2 & 2 \\
\hline 11 & $\begin{array}{l}\text { La } \\
\text { Libertad }\end{array}$ & $\begin{array}{l}\text { Laboral- } \\
\text { NLPT }\end{array}$ & 0 & 39 & 0 & 0 & 0 & 0 & 0 & 39 & 39 \\
\hline 12 & $\begin{array}{l}\text { Lima } \\
\text { Este }\end{array}$ & $\begin{array}{l}\text { Laboral- } \\
\text { NLPT }\end{array}$ & 95 & 13 & 0 & 0 & 0 & 0 & 95 & 13 & 108 \\
\hline 13 & Puno & $\begin{array}{l}\text { Laboral- } \\
\text { NLPT }\end{array}$ & 0 & 7 & 0 & 2 & 0 & 0 & 0 & 9 & 9 \\
\hline 14 & Piura & $\begin{array}{l}\text { Laboral- } \\
\text { NLPT }\end{array}$ & 6 & 0 & 0 & 0 & 0 & 0 & 6 & 0 & 6 \\
\hline \multicolumn{3}{|c|}{ Total } & 18114 & 15221 & 21848 & 15945 & 76 & 958 & 40038 & 32124 & 72162 \\
\hline \multicolumn{9}{|c|}{ Porcentaje } & $55.5 \%$ & $44.5 \%$ & \\
\hline
\end{tabular}

Fecha de actualización: 31 de diciembre de 2020.

Fuente: Gerencia de Informática.

Elaboración: Secretaría Técnica de la Comisión de Trabajo del EJE.

Leyenda: CSJ: Corte Superior de Justicia.

En la tabla anterior se observa que el $44.5 \%$ concluye su proceso en primera instancia con la emisión de una sentencia y el $55.5 \%$ termina la citada instancia con un auto.

En la siguiente figura se observa que del total de expedientes judiciales electrónicos que terminaron su proceso de primera instancia, el $2 \%$ lo hizo en una sala superior, el $52 \%$ en un juzgado especializado y el $46 \%$ en un juzgado de paz letrado.

Figura n. ${ }^{\circ}$ 10. Cantidad de EJE que terminaron su proceso de primera instancia por tipo de órgano jurisdiccional

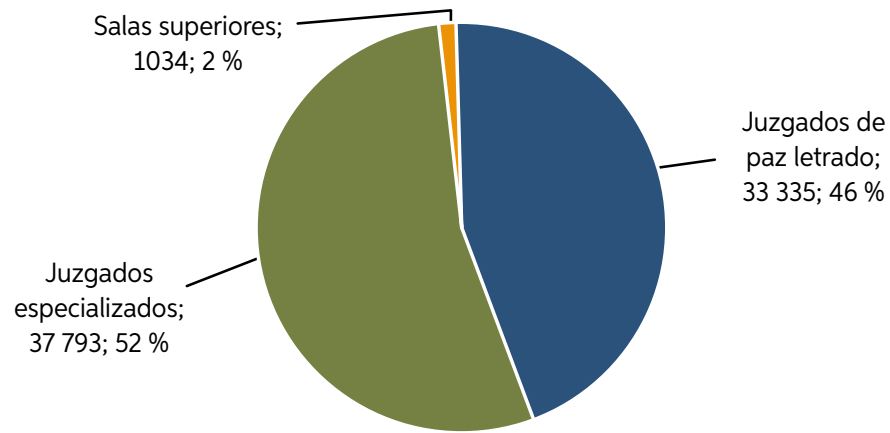

Fecha de actualización: 31 de diciembre de 2020.

Fuente: Gerencia de Informática.

Elaboración: Secretaría Técnica de la Comisión de Trabajo del EJE. 


\subsection{Ingresos a segunda instancia}

Al 31 de diciembre de 2020 se han registrado 2762 ingresos a los órganos jurisdiccionales de segunda instancia. De estos 1394 representan el $50.5 \%$ de apelaciones sobre el principal; los restantes son ingresos, en su mayoría apelaciones sobre incidentes, como se observa en la siguiente tabla, detallada por distrito judicial y especialidad:

Tabla n. ${ }^{\circ}$. Cantidad de expedientes judiciales electrónicos apelados

\begin{tabular}{|c|c|c|c|c|c|c|c|c|c|}
\hline \multirow{2}{*}{$\mathrm{N} .^{\circ}$} & \multirow{2}{*}{ CSJ } & \multirow{2}{*}{ Especialidad } & \multicolumn{2}{|c|}{$\begin{array}{c}\text { Juzgados } \\
\text { especializados }\end{array}$} & \multicolumn{2}{|c|}{ Salas superiores } & \multicolumn{2}{|c|}{$\begin{array}{l}\text { Total de } \\
\text { ingresos }\end{array}$} & \multirow[b]{2}{*}{ Total } \\
\hline & & & $\begin{array}{c}\text { Apelación } \\
\text { del } \\
\text { principal }\end{array}$ & Otros & $\begin{array}{c}\text { Apelación } \\
\text { del } \\
\text { principal }\end{array}$ & Otros & $\begin{array}{c}\text { Apelación } \\
\text { del } \\
\text { principal }\end{array}$ & Otros & \\
\hline \multirow{4}{*}{1} & \multirow{4}{*}{ Lima } & $\begin{array}{l}\text { Civil con } \\
\text { subespecialidad } \\
\text { comercial }\end{array}$ & & & 144 & 481 & 144 & 481 & 625 \\
\hline & & $\begin{array}{l}\text { Cont. } \\
\text { adm. con } \\
\text { subespecialidad } \\
\text { tributaria y } \\
\text { aduanera }\end{array}$ & & & 55 & 73 & 55 & 73 & 128 \\
\hline & & $\begin{array}{l}\text { Cont. } \\
\text { adm. con } \\
\text { subespecialidad } \\
\text { en temas de } \\
\text { mercado }\end{array}$ & & & 7 & 67 & 7 & 67 & 74 \\
\hline & & Laboral-NLPT & 226 & 31 & 178 & 226 & 404 & 257 & 661 \\
\hline \multirow{2}{*}{2} & \multirow{2}{*}{$\begin{array}{l}\text { Lima } \\
\text { Norte }\end{array}$} & $\begin{array}{l}\text { Laboral-NLPT- } \\
\text { migrados }\end{array}$ & 62 & 29 & 275 & 77 & 337 & 106 & 443 \\
\hline & & $\begin{array}{l}\text { Laboral-NLPT- } \\
\text { EJE }\end{array}$ & 141 & 60 & 121 & 287 & 262 & 347 & 609 \\
\hline 3 & Cajamarca & Laboral-NLPT & 9 & 0 & 78 & 28 & 87 & 28 & 115 \\
\hline 4 & $\begin{array}{l}\text { Puente } \\
\text { Piedra- } \\
\text { Ventanilla }\end{array}$ & Laboral-NLPT & 4 & 0 & 3 & 0 & 7 & 0 & 7 \\
\hline 5 & Tacna & Laboral-NLPT & 11 & 0 & 64 & 3 & 75 & 3 & 78 \\
\hline 6 & Callao & Laboral-NLPT & 3 & 0 & 0 & 1 & 3 & 1 & 4 \\
\hline
\end{tabular}




\begin{tabular}{|l|l|l|c|c|c|c|c|c|c|}
\hline 7 & Cusco & Laboral-NLPT & 2 & 0 & 4 & 1 & 6 & 1 & 7 \\
\hline 8 & Arequipa & Laboral-NLPT & 0 & 0 & 2 & 1 & 2 & 1 & 3 \\
\hline 9 & Junín & Laboral-NLPT & 0 & 0 & 5 & 1 & 5 & 1 & 6 \\
\hline 10 & $\begin{array}{l}\text { La } \\
\text { Libertad }\end{array}$ & Laboral-NLPT & 0 & 0 & 0 & 1 & 0 & 1 & 1 \\
\hline 11 & Lima Este & Laboral-NLPT & 0 & 1 & 0 & 0 & 0 & 1 & 1 \\
\hline \multicolumn{2}{l|}{ Total } & 458 & 121 & 936 & 1247 & 1394 & 1368 & 2762 \\
\hline \multicolumn{2}{l|}{ Porcentaje }
\end{tabular}

Fecha de actualización: 31 de diciembre de 2020.

Fuente: Gerencia de Informática.

Elaboración: Secretaría Técnica de la Comisión de Trabajo del EJE.

Leyenda: CSJ: Corte Superior de Justicia.

En la siguiente figura se observa que del total de expedientes judiciales electrónicos apelados, el $21 \%$ ingresó a un juzgado especializado y el $79 \%$ a una sala superior.

Figura n. ${ }^{\circ}$ 11. Cantidad de expedientes judiciales electrónicos apelados por tipo de órgano jurisdiccional

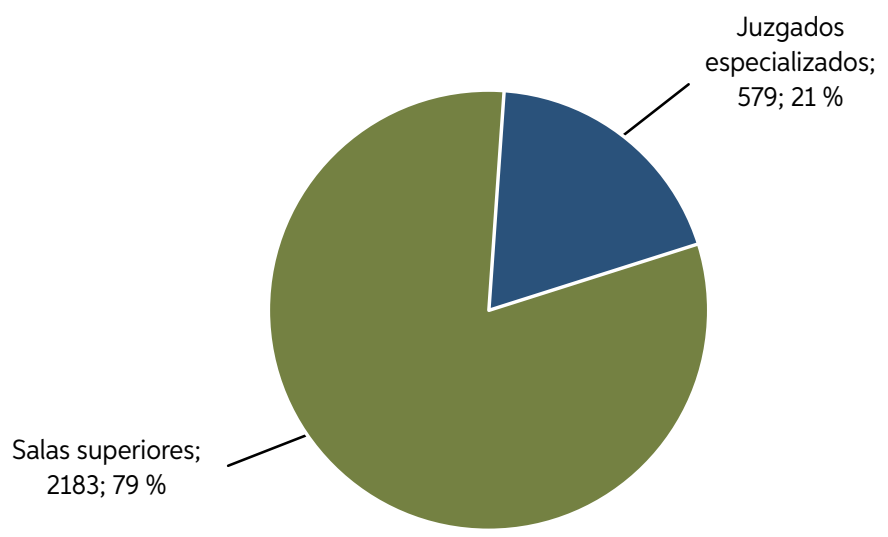

Fecha de actualización: 31 de diciembre de 2020.

Fuente: Gerencia de Informática.

Elaboración: Secretaría Técnica de la Comisión de Trabajo del EJE. 


\subsection{Salidas de segunda instancia}

Al 31 de diciembre de 2020 han terminado el proceso de segunda instancia 6236 expedientes judiciales electrónicos, como se observa en la siguiente tabla.

Tabla n. ${ }^{\circ}$ 7. Cantidad de EJE que terminaron su proceso de segunda instancia

\begin{tabular}{|c|c|c|c|c|c|c|c|c|c|}
\hline \multirow[t]{2}{*}{ N. ${ }^{\circ}$} & \multirow[t]{2}{*}{ CSJ } & \multirow[t]{2}{*}{ Especialidad } & \multicolumn{2}{|c|}{$\begin{array}{c}\text { Juzgados } \\
\text { especializados }\end{array}$} & \multicolumn{2}{|c|}{ Salas superiores } & \multicolumn{2}{|c|}{ Subtotal } & \multirow[t]{2}{*}{ Total } \\
\hline & & & Auto & Sentencia & Auto & Sentencia & Auto & Sentencia & \\
\hline \multirow{4}{*}{1} & \multirow{4}{*}{ Lima } & $\begin{array}{l}\text { Civil con } \\
\text { subespecialidad } \\
\text { comercial }\end{array}$ & & & 944 & 9 & 944 & 9 & 953 \\
\hline & & $\begin{array}{l}\text { Cont. } \\
\text { adm. con } \\
\text { subespecialidad } \\
\text { tributaria y } \\
\text { aduanera }\end{array}$ & & & 71 & 408 & 71 & 408 & 479 \\
\hline & & $\begin{array}{l}\text { Cont. } \\
\text { adm. con } \\
\text { subespecialidad } \\
\text { en temas de } \\
\text { mercado }\end{array}$ & & & 52 & 73 & 52 & 73 & 125 \\
\hline & & Laboral-NLPT & 9 & 137 & 220 & 3926 & 229 & 4063 & 4292 \\
\hline 2 & $\begin{array}{l}\text { Lima } \\
\text { Norte }\end{array}$ & $\begin{array}{l}\text { Laboral-NLPT- } \\
\text { EJE }\end{array}$ & 29 & 10 & 167 & 106 & 196 & 116 & 312 \\
\hline 3 & Cajamarca & Laboral-NLPT & 0 & 1 & 9 & 32 & 9 & 33 & 42 \\
\hline 4 & $\begin{array}{l}\text { Puente } \\
\text { Piedra- } \\
\text { Ventanilla }\end{array}$ & Laboral-NLPT & 0 & 1 & 0 & 0 & 0 & 1 & 1 \\
\hline 5 & Tacna & Laboral-NLPT & 0 & 1 & 2 & 29 & 2 & 30 & 32 \\
\hline \multicolumn{3}{|c|}{ Total } & 38 & 150 & 1465 & 4583 & 1503 & 4733 & 6236 \\
\hline \multicolumn{7}{|c|}{ Porcentaje } & $24.1 \%$ & $75.9 \%$ & \\
\hline
\end{tabular}

Fecha de actualización: 31 de diciembre de 2020.

Fuente: Gerencia de Informática.

Elaboración: Secretaría Técnica de la Comisión de Trabajo del EJE.

Leyenda: CSJ: Corte Superior de Justicia. 
En la tabla anterior se observa que el $75.9 \%$ concluye su proceso en segunda instancia con la emisión de una sentencia y el $24.1 \%$ termina la citada instancia con un auto.

En la siguiente figura se observa que del total de expedientes judiciales electrónicos que terminaron su proceso de segunda instancia, el $97 \%$ lo hizo en una sala superior y el $3 \%$ en un juzgado especializado.

Figura n. ${ }^{\circ}$ 12. Cantidad de EJE que terminaron su proceso de segunda instancia por tipo de órgano jurisdiccional

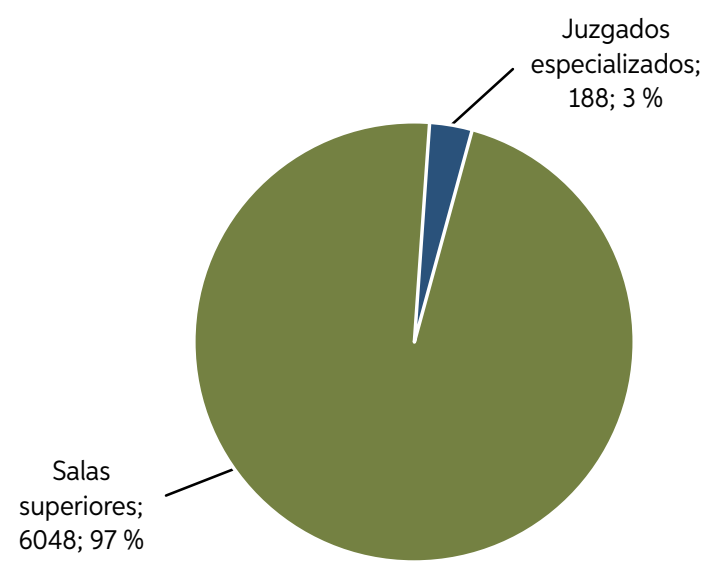

Fecha de actualización: 31 de diciembre de 2020.

Fuente: Gerencia de Informática.

Elaboración: Secretaría Técnica de la Comisión de Trabajo del EJE.

\subsection{Elevaciones a las salas de la Corte Suprema de Justicia de la República}

Al 31 de diciembre de 2020 se han registrado 4303 elevaciones de expedientes judiciales electrónicos a las salas de la Corte Suprema, desde los Distritos Judiciales de Lima, Lima Norte, Cajamarca y Tacna, como se observa en la siguiente tabla detallada por especialidad. 
Tabla n. ${ }^{\circ}$ 8. Cantidad de elevaciones a las salas de la Corte Suprema de Justicia de la República

\begin{tabular}{|c|c|c|c|c|c|c|c|}
\hline N. ${ }^{\circ}$ & CSJ & Especialidad & Casación & Apelación & Queja & Consulta & Total \\
\hline \multirow{4}{*}{1} & \multirow{4}{*}{ Lima } & $\begin{array}{l}\text { Civil con subespecialidad } \\
\text { comercial }\end{array}$ & 303 & 1 & 1 & 0 & 305 \\
\hline & & $\begin{array}{l}\text { Cont. adm. con } \\
\text { subespecialidad tributaria } \\
\text { y aduanera }\end{array}$ & 366 & 2 & 0 & 0 & 368 \\
\hline & & $\begin{array}{l}\text { Cont. adm. con } \\
\text { subespecialidad en temas } \\
\text { de mercado }\end{array}$ & 59 & 87 & 0 & 0 & 146 \\
\hline & & Laboral-NLPT & 2764 & 77 & 0 & 6 & 2847 \\
\hline 2 & $\begin{array}{l}\text { Lima } \\
\text { Norte }\end{array}$ & Laboral-NLPT & 627 & 0 & 0 & 0 & 627 \\
\hline 3 & Cajamarca & Laboral-NLPT & 1 & 0 & 0 & 0 & 1 \\
\hline 4 & Tacna & Laboral-NLPT & 9 & 0 & 0 & 0 & 9 \\
\hline \multicolumn{3}{|c|}{ Total } & 4129 & 167 & 1 & 6 & 4303 \\
\hline \multicolumn{3}{|c|}{ Porcentaje } & $96 \%$ & $3.9 \%$ & $0 \%$ & $0.1 \%$ & $100 \%$ \\
\hline
\end{tabular}

Fecha de actualización: 31 de diciembre de 2020.

Fuente: Gerencia de Informática.

Elaboración: Secretaría Técnica de la Comisión de Trabajo del EJE.

Leyenda: CSJ: Corte Superior de Justicia, NLPT: Nueva Ley Procesal del Trabajo.

En la figura siguiente se observa que el $96 \%$ son elevaciones por casación. El 3.9 \% son elevaciones por apelación y las restantes son consultas y quejas elevadas a las salas de la Corte Suprema. 
Figura n. ${ }^{\circ}$ 13. EJE elevados a la Corte Suprema de Justicia de la República por tipo de órgano jurisdiccional

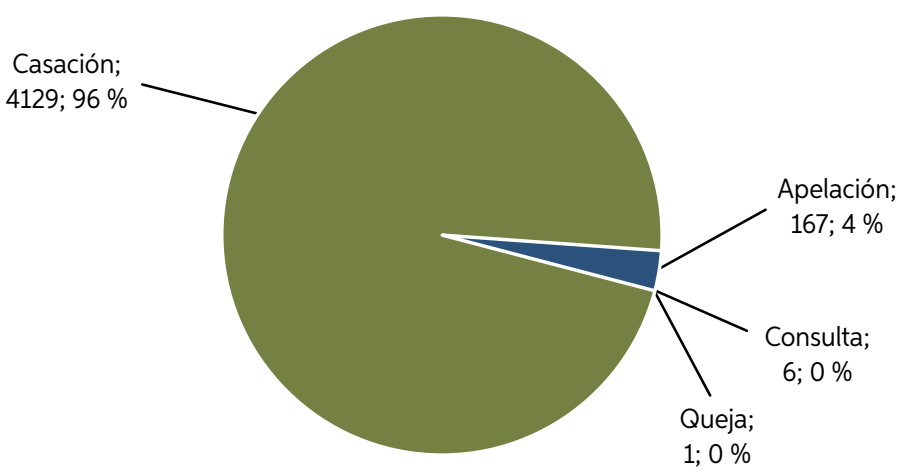

Fecha de actualización: 31 de diciembre de 2020.

Fuente: Gerencia de Informática.

Elaboración: Secretaría Técnica de la Comisión de Trabajo del EJE. 



\section{BENEFICIOS Y RESULTADOS DEL EJE}

\subsection{Beneficios}

Los beneficios del Expediente Judicial Electrónico que explican la aceptación y demanda de su implementación a nivel nacional se verifican en dos dimensiones: por un lado, acercan la justicia a la ciudadanía - en particular a los grupos vulnerables — para que pueda, de manera más eficiente, acceder a ella y preservar sus derechos; y, por el otro, se optimizan los procesos que apoyan las decisiones judiciales para continuar ofreciendo respuestas de calidad.

\section{Esquema n. ${ }^{\circ}$ 13. Aporte de la introducción de las TIC en la administración de justicia}

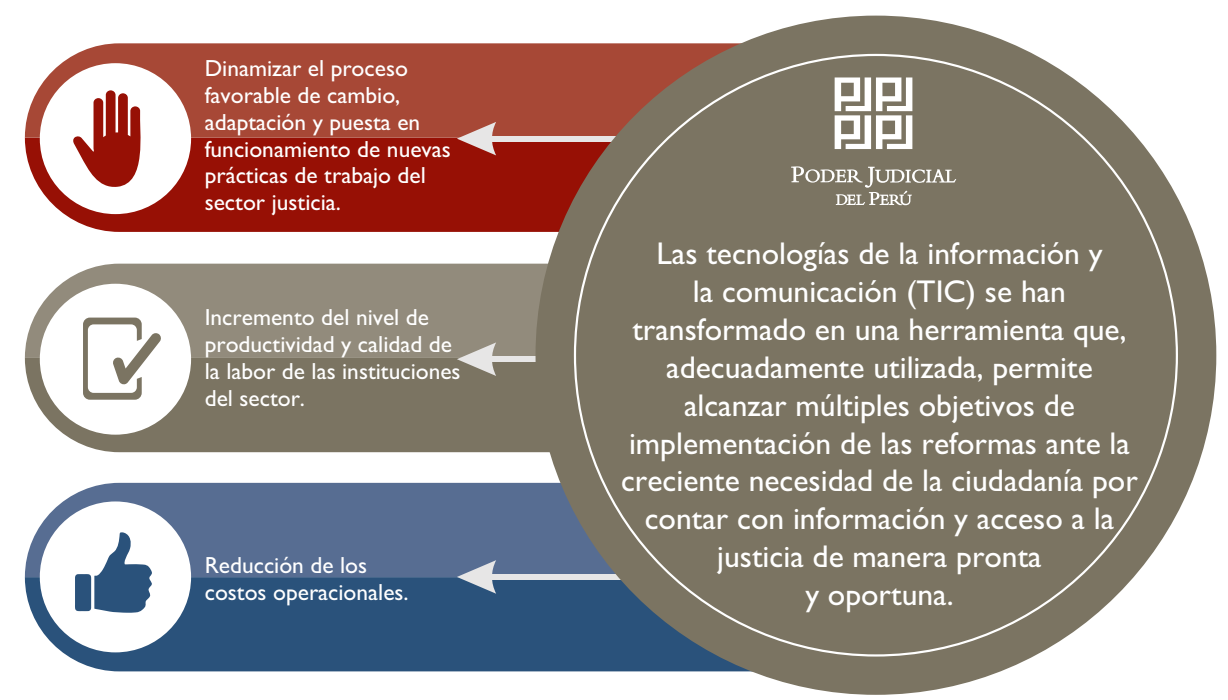

Elaboración: Secretaría Técnica de la Comisión de Trabajo del EJE. 
El Expediente Judicial Electrónico nos obligará a repensar y reformular todos nuestros procesos claves. El perfil del magistrado ha evolucionado al trabajar en un entorno digital, ello fortalece nuestro modelo de integridad institucional.

Del mismo modo, el EJE nos permite repensar los tiempos en etapas de un proceso, las que deberán responder a la lógica digital. Esto repercurtirá a favor del usuario, pues podrá contar con mayor predictibilidad y unidad de criterio, sumado a una mejora significativa en la duración de un proceso.

Asimismo, permite generar beneficios tanto para el justiciable como para la labor jurisdiccional, puesto que se encarga de enlazar, concentrar y diseñar la articulación de diversos esfuerzos de modernización e introducción de la tecnología en apoyo a los procesos judiciales. Ello desde el 2008, en que fueron analizados productos previos, lo cual les brinda carácter orgánico y los hace adquirir la calidad de componentes, fruto de la visión de constante modernización del Poder Judicial.

Los beneficios se articulan en la tendencia a la automatización de procesos; de esta manera pueden verificarse en la gestión de la mesa de partes, el sistema de notificación, el uso de repositorios de jurisprudencia, los sistemas de información en línea y todo aquello que permita al usuario acceder al servicio judicial sin necesidad de recurrir personalmente a la entidad. Con esto se impulsan nuevas competencias tanto en el justiciable como en el personal jurisdiccional y administrativo.

El ahorro de recursos para la administración de justicia es medible en la menor asignación presupuestal para consumibles de oficina propios de la impresión y papel, así como en el uso de ambientes físicos destinados a los archivos físicos, que irán disminuyendo en volumen al evolucionar a la digitalización. Por su parte, el justiciable reduce no solo los costes financieros derivados de los generados por la movilización a la sede judicial para entregar documentos a la sala de lectura, sino también los derivados de los tiempos de espera y traslado.

$\mathrm{El}$ acceso sin restricciones a la integridad de los actuados (expediente y escritos en medios digitales) al incorporar este nuevo acceso a la justicia vía web, así como la comunicación inmediata (vía Sinoe) de las decisiones jurisdiccionales que brindan impulso al proceso son 
elementos que aseguran la transparencia y la celeridad, permitiendo el seguimiento y la gestión de solución de conflictos y atención de las pretensiones de los justiciables de forma eficaz.

Esquema n. ${ }^{\circ}$ 14. Beneficios para la labor jurisdiccional y el justiciable

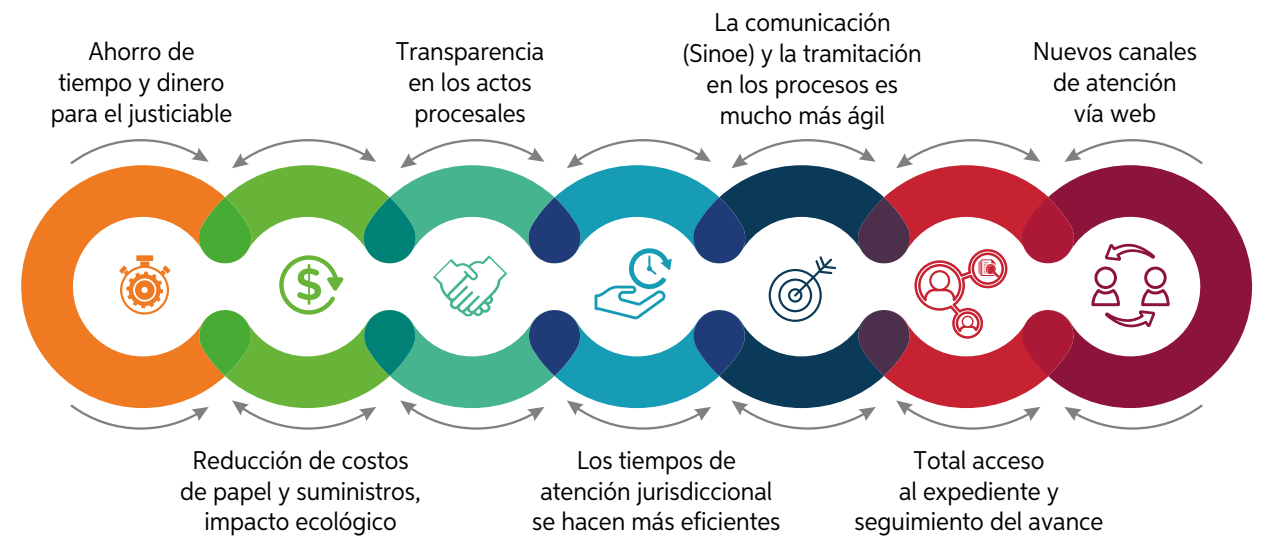

Elaboración: Secretaría Técnica de la Comisión de Trabajo del EJE.

Adicionalmente, el avance tecnológico ha permitido en su operatividad establecer buenas prácticas en el despacho judicial. En resumen, pueden considerarse las siguientes:

Esquema n. ${ }^{\circ}$ 15. Buenas prácticas en el uso del Expediente Judicial Electrónico en el despacho judicial

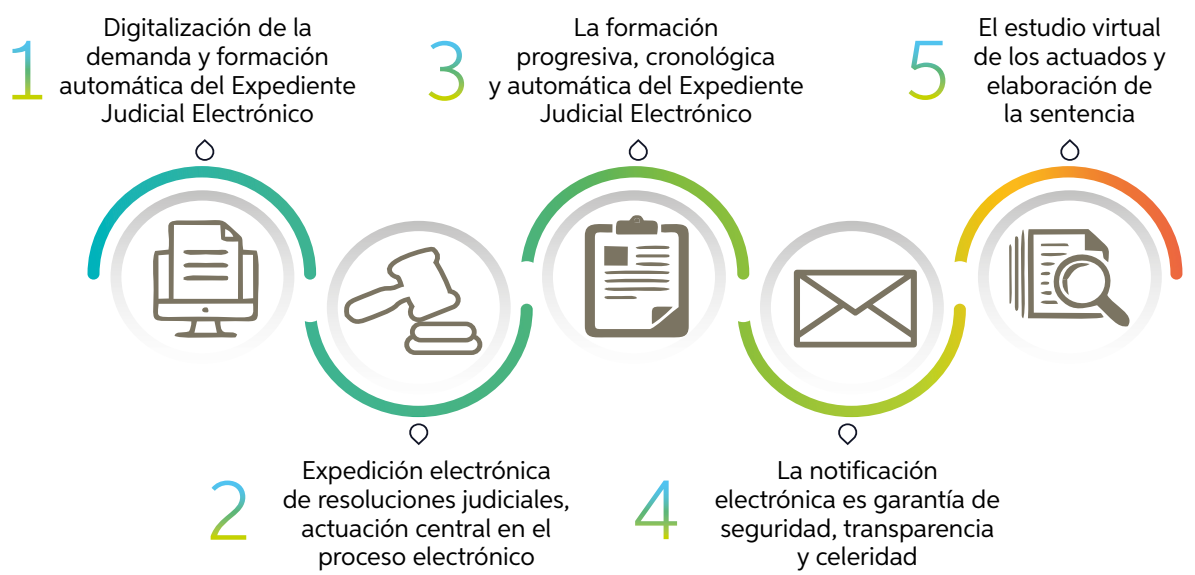

Elaboración: Secretaría Técnica de la Comisión de Trabajo del EJE. 


\subsection{Resultados}

Los resultados obtenidos con el Expediente Judicial Electrónico son los siguientes:

Esquema n. ${ }^{\circ}$ 16. Resultado del Expediente Judicial Electrónico

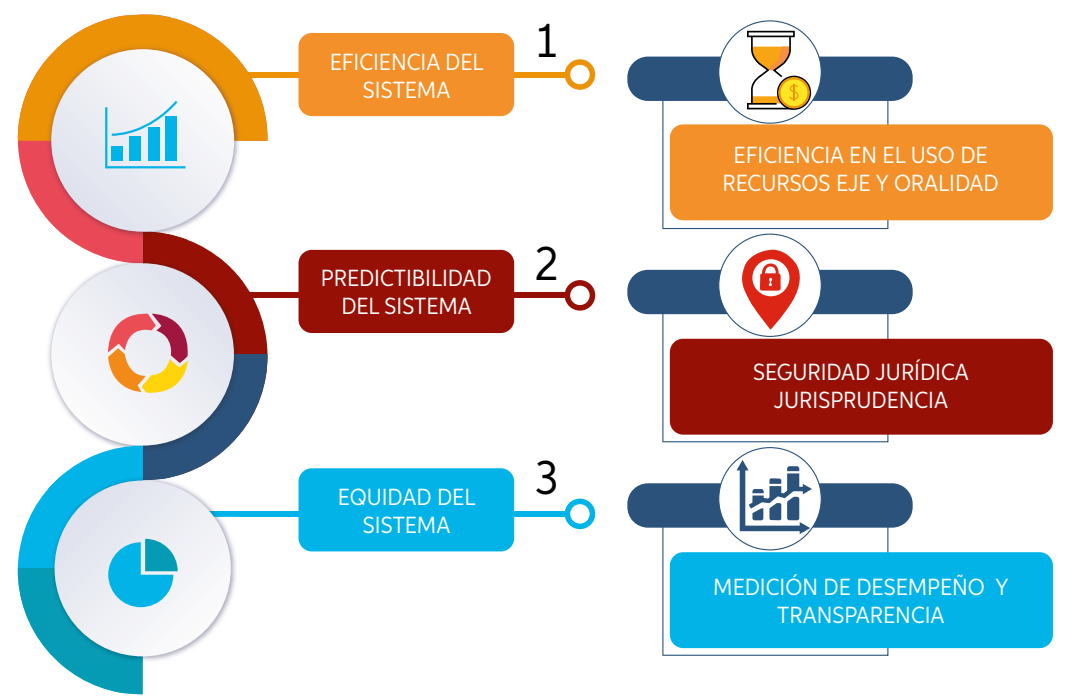

Elaboración: Secretaría Técnica de la Comisión de Trabajo del EJE.

\subsubsection{Eficiencia del sistema}

Medida en términos de beneficios tales como la celeridad en la tramitación de los procesos y los costos, se optimiza el uso de los recursos disponibles, se potencia la productividad y mejora del servicio de atención al justiciable.

\subsubsection{Impacto en los tiempos}

Desde el inicio de la implementación del Expediente Judicial Electrónico hasta el 31 de diciembre de 2020, las cifras se han ido consolidando. De modo que se ha obtenido la siguiente información, que muestra la mejora en los tiempos de atención a los documentos que ingresan, así como en los tiempos que dura un proceso en primera y segunda instancia. 


\section{a) Tiempo de calificación de la demanda}

Este tiempo se considera desde que ingresa la demanda por la mesa de partes hasta que se hace el descargo de la resolución de calificación. La digitalización de los documentos en el Expediente Judicial Electrónico permite ahorrar tiempos de procesos manuales que antes se realizaban en el expediente físico, como la búsqueda y el traslado de documentos para su atención.

\section{Para la Corte Superior de Justicia de Lima}

Este ahorro de tiempo en la calificación de la demanda se observa en la siguiente tabla:

Tabla n. ${ }^{\circ}$ 9. Disminución del tiempo de calificación de la demanda (días hábiles) CSJ de Lima

\begin{tabular}{|c|c|c|c|c|c|}
\hline Tipo de & \multicolumn{2}{|c|}{ Físico } & \multicolumn{2}{|c|}{ Electrónico } & \multirow{2}{*}{$\begin{array}{c}\text { Tasa de } \\
\text { variación } \\
\text { promedio }\end{array}$} \\
\hline CSJ & $\begin{array}{l}\text { Demandas } \\
\text { calificadas } \\
\text { promediadas }\end{array}$ & $\begin{array}{l}\text { Días prom. } \\
\text { para descargo }\end{array}$ & $\begin{array}{l}\text { Demandas } \\
\text { calificadas } \\
\text { promediadas }\end{array}$ & $\begin{array}{l}\text { Días prom. } \\
\text { para descargo }\end{array}$ & \\
\hline Lima & 59648 & 28.4 & 108029 & 23.2 & $-18 \%$ \\
\hline
\end{tabular}

Fecha de actualización: 31 de diciembre de 2020.

Fuente: Gerencia de Informática.

Elaboración: Secretaría Técnica de la Comisión de Trabajo del EJE.

Leyenda: CSJ: Corte Superior de Justicia.

En la tabla anterior se observa que en la Corte Superior de Justicia de Lima, en el caso de las demandas físicas ingresadas en los órganos jurisdiccionales, demoraron en promedio 28.4 días para descargar la resolución de calificación. Mientras que, luego de implementarse el Expediente Judicial Electrónico, los mismos órganos jurisdiccionales demoraron en promedio 23.2 días para descargar la citada resolución. Ello muestra una disminución del $18 \%$ en el tiempo de calificación de la demanda, como se puede observar en la siguiente figura: 
Figura n. ${ }^{0}$ 14. Comparación del tiempo de calificación de la demanda (días hábiles) CSJ de Lima

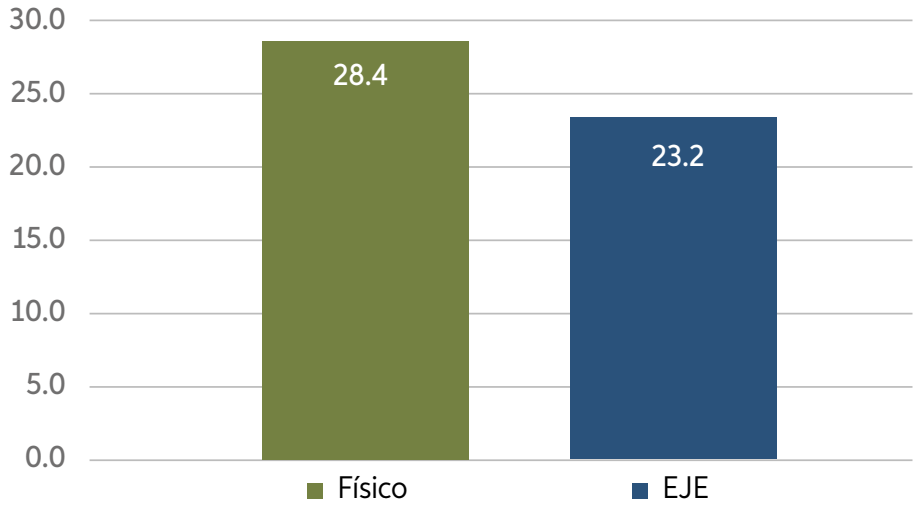

Fecha de actualización: 31 de diciembre de 2020.

Fuente: Gerencia de Informática.

Elaboración: Secretaría Técnica de la Comisión de Trabajo del EJE.

\section{Para otras cortes superiores de justicia}

Este ahorro de tiempo en la calificación de la demanda se observa en la siguiente tabla:

Tabla n. ${ }^{\circ}$ 10. Disminución del tiempo de calificación de la demanda (días hábiles) otras CSJ

\begin{tabular}{|c|c|c|c|c|c|}
\hline $\begin{array}{c}\text { Tipo de } \\
\text { expediente }\end{array}$ & \multicolumn{2}{|c|}{ Físico-EJD } & \multicolumn{2}{c|}{ Electrónico } & \multirow{2}{*}{$\begin{array}{c}\text { Tasa de } \\
\text { variación } \\
\text { promedio }\end{array}$} \\
\hline CSJ & $\begin{array}{c}\text { Demandas } \\
\text { calificadas } \\
\text { promediadas }\end{array}$ & $\begin{array}{c}\text { Días prom. para } \\
\text { descargo }\end{array}$ & $\begin{array}{c}\text { Demandas } \\
\text { calificadas } \\
\text { promediadas }\end{array}$ & $\begin{array}{c}\text { Días prom. para } \\
\text { descargo }\end{array}$ & \\
\hline Provincias & 165052 & 13.5 & 28413 & 8.7 & $-35 \%$ \\
\hline
\end{tabular}

Fecha de actualización: 31 de diciembre de 2020.

Fuente: Gerencia de Informática.

Elaboración: Secretaría Técnica de la Comisión de Trabajo del EJE.

Leyenda: CSJ: Corte Superior de Justicia. 
En la tabla anterior se observa que en las cortes superiores de justicia, en el caso de las demandas físicas ingresadas en los órganos jurisdiccionales, demoraron en promedio 13.5 días para descargar la resolución de calificación. Mientras que, luego de implementarse el Expediente Judicial Electrónico, los mismos órganos jurisdiccionales demoraron en promedio 8.7 días para descargar la citada resolución. Esto muestra una disminución del $35 \%$ en el tiempo de calificación de la demanda, como se puede observar en la siguiente figura:

Figura n. ${ }^{\circ}$ 15. Comparación del tiempo de calificación de la demanda (días hábiles) otras CSJ

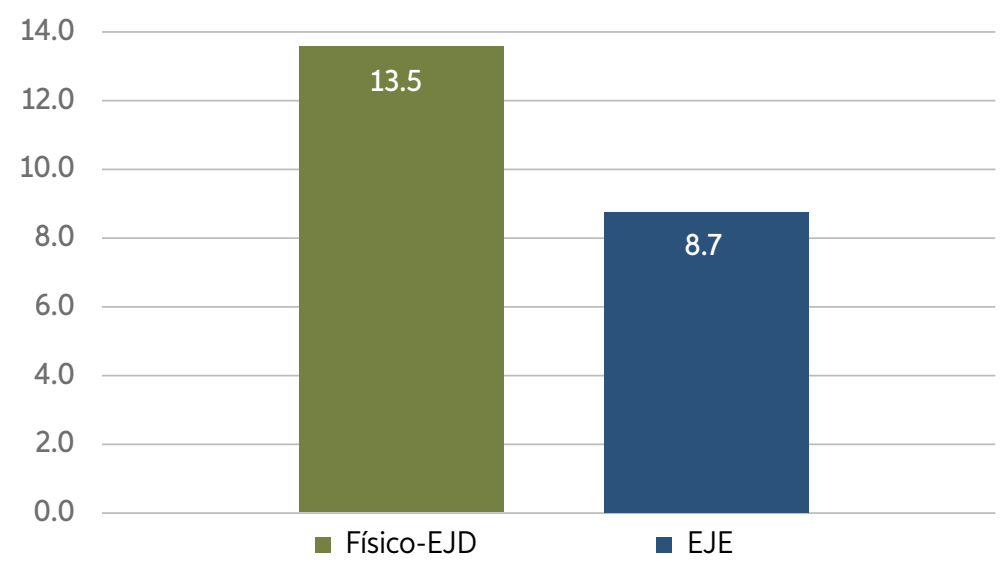

Fecha de actualización: 31 de diciembre de 2020.

Fuente: Gerencia de Informática.

Elaboración: Secretaría Técnica de la Comisión de Trabajo del EJE.

\section{b) Tiempo de proveído de escritos}

Este tiempo se considera desde que ingresa el documento por la mesa de partes hasta que se hace el descargo del proveído. De manera similar como con la demanda, la digitalización de los documentos en el Expediente Judicial Electrónico permite ahorrar tiempos de procesos manuales que antes se realizaban en el expediente físico, tales como la búsqueda y el traslado de documentos para su atención. 


\section{Para la Corte Superior de Justicia de Lima}

Este ahorro de tiempo en el proveído de escritos se observa en la siguiente tabla:

Tabla n. ${ }^{\circ}$ 11. Disminución del tiempo de proveído de escritos (días hábiles) CSJ de Lima

\begin{tabular}{|c|c|c|c|c|c|}
\hline $\begin{array}{c}\text { Tipo de } \\
\text { expediente }\end{array}$ & \multicolumn{2}{|c|}{ Físico } & \multicolumn{2}{c|}{ Electrónico } & Tasa de \\
variación \\
CSJ & $\begin{array}{c}\text { Escritos proveídos } \\
\text { promediados }\end{array}$ & $\begin{array}{c}\text { Días prom. } \\
\text { para descargo }\end{array}$ & $\begin{array}{c}\text { Escritos proveídos } \\
\text { promediados }\end{array}$ & $\begin{array}{c}\text { Días prom. } \\
\text { para descargo }\end{array}$ & promedio \\
\hline Lima & 564415 & 30.1 & 419041 & 25.2 & $-16 \%$ \\
\hline
\end{tabular}

Fecha de actualización: 31 de diciembre de 2020.

Fuente: Gerencia de Informática.

Elaboración: Secretaría Técnica de la Comisión de Trabajo del EJE.

Leyenda: CSJ: Corte Superior de Justicia.

En la tabla anterior se observa que en la Corte Superior de Justicia de Lima, en el caso de los escritos que ingresaron a los expedientes judiciales físicos en los órganos jurisdiccionales, demoraron en promedio 30.1 días para descargar el proveído correspondiente. Mientras que, luego de implementarse el Expediente Judicial Electrónico, los mismos órganos jurisdiccionales demoraron en promedio 25.2 días para descargar el proveído respectivo. Ello muestra una disminución del $16 \%$ en el tiempo de proveído de escritos, como se puede observar en la siguiente figura:

Figura n. ${ }^{\circ}$ 16. Comparación del tiempo de proveído de escritos (días hábiles) CSJ de Lima

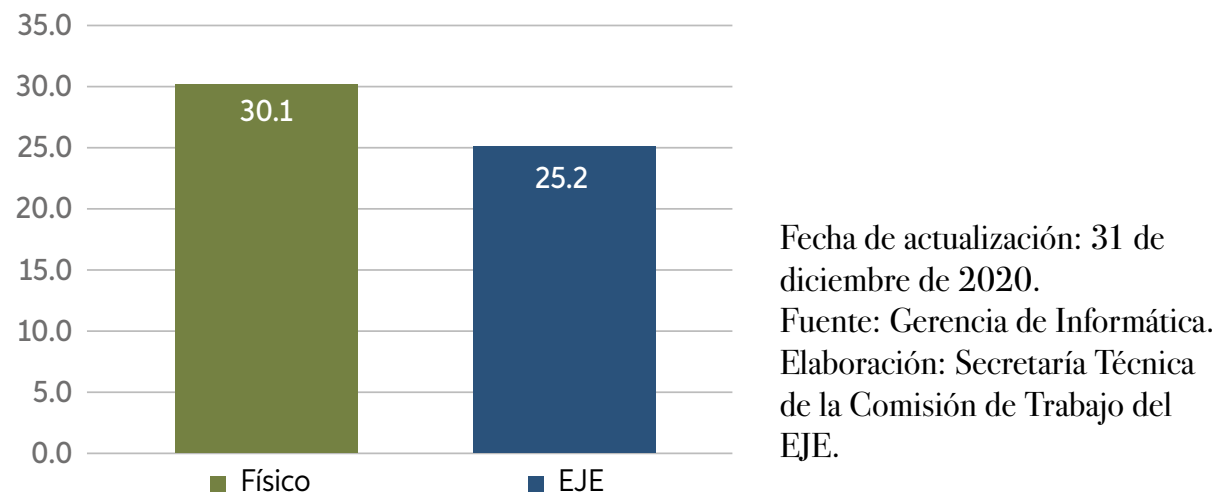

Expediente Judicial Electrónico 


\section{Para otras cortes superiores de justicia}

Este ahorro de tiempo en el proveído de escritos se observa en la siguiente tabla:

Tabla n. ${ }^{\circ}$ 12. Disminución del tiempo de proveído de escritos (días hábiles) otras CSJ

\begin{tabular}{|c|c|c|c|c|c|}
\hline $\begin{array}{c}\text { Tipo de } \\
\text { expediente }\end{array}$ & \multicolumn{2}{|c|}{ Físico-EJD } & \multicolumn{2}{c|}{ Electrónico } & Tasa de \\
\hline CSJ & $\begin{array}{c}\text { Escritos } \\
\text { proveídos } \\
\text { promediados }\end{array}$ & $\begin{array}{c}\text { Días prom. } \\
\text { para descargo }\end{array}$ & $\begin{array}{c}\text { Escritos } \\
\text { proveídos } \\
\text { promediados }\end{array}$ & $\begin{array}{c}\text { Días prom. } \\
\text { para descargo }\end{array}$ & $\begin{array}{c}\text { promedio } \\
\text { Provincias }\end{array}$ \\
781971 & 17.5 & 22181 & 10.2 & $-42 \%$ \\
\hline
\end{tabular}

Fecha de actualización: 31 de diciembre de 2020.

Fuente: Gerencia de Informática.

Elaboración: Secretaría Técnica de la Comisión de Trabajo del EJE.

Leyenda: CSJ: Corte Superior de Justicia.

En la tabla anterior se observa que en las cortes superiores de justicia, en el caso de los escritos físicos ingresados para los expedientes físicos en los órganos jurisdiccionales, demoraron en promedio 17.5 días para descargar el proveído. Mientras que, luego de implementarse el Expediente Judicial Electrónico, los mismos órganos jurisdiccionales demoraron en promedio 10.2 días para descargar el proveído, lo cual muestra una disminución del $42 \%$ en el tiempo de proveído de escritos, como se puede observar en la siguiente figura:

Figura n. ${ }^{\circ}$ 17. Comparación del tiempo de proveído de escritos (días hábiles) otras CSJ

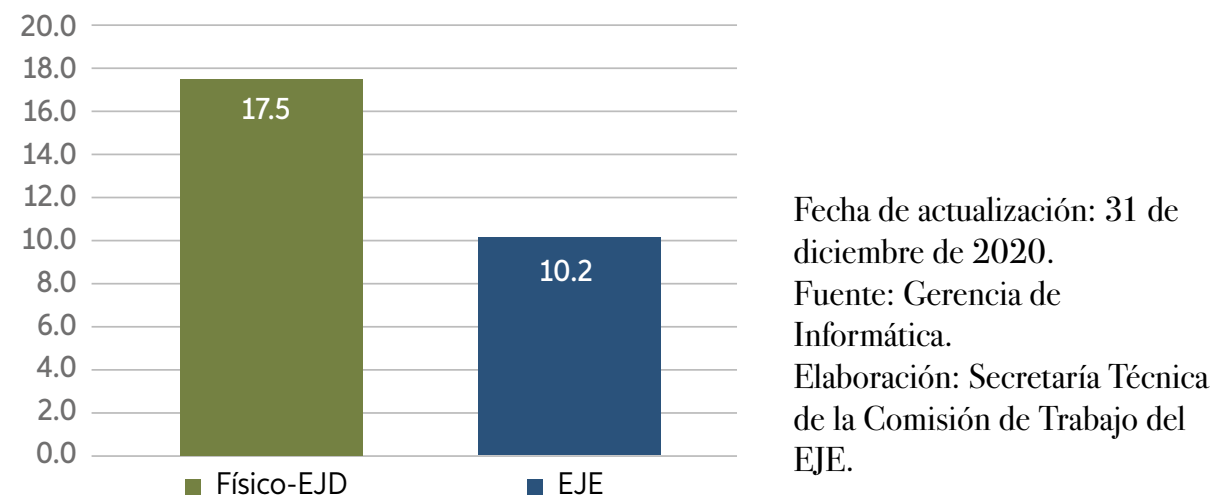




\section{c) Tiempo de duración del proceso en primera instancia}

Este tiempo se considera desde que ingresa la demanda por la mesa de partes hasta que se hace el descargo de la resolución que pone fin a esta instancia. La digitalización de los documentos en el Expediente Judicial Electrónico permite ahorrar tiempos de procesos manuales que antes se realizaban en el expediente físico, como la búsqueda y el traslado de documentos para su atención.

\section{Para la Corte Superior de Justicia de Lima}

Este ahorro de tiempo en la duración del proceso en primera instancia se observa en la siguiente tabla:

Tabla n. ${ }^{\circ}$ 13. Disminución del tiempo de duración del proceso en primera instancia (días hábiles) CSJ de Lima

\begin{tabular}{|c|c|c|c|c|c|}
\hline $\begin{array}{c}\text { Tipo de } \\
\text { expediente }\end{array}$ & \multicolumn{2}{|c|}{ Físico } & \multicolumn{2}{c|}{ Electrónico } & Tasa de \\
\hline CSJ & $\begin{array}{c}\text { Demandas } \\
\text { promediadas }\end{array}$ & $\begin{array}{c}\text { Días prom. para } \\
\text { descargo }\end{array}$ & $\begin{array}{c}\text { Demandas } \\
\text { promediadas } \\
\text { promedio }\end{array}$ & $\begin{array}{c}\text { Días prom. para } \\
\text { descargo }\end{array}$ & promedion \\
\hline Lima & 88180 & 215.5 & 55500 & 182.7 & $-15 \%$ \\
\hline
\end{tabular}

Fecha de actualización: 31 de diciembre de 2020.

Fuente: Gerencia de Informática.

Elaboración: Secretaría Técnica de la Comisión de Trabajo del EJE.

Leyenda: CSJ: Corte Superior de Justicia.

En la tabla anterior se observa que en la Corte Superior de Justicia de Lima, en el caso de los expedientes físicos ingresados en los órganos jurisdiccionales, demoraron en promedio 215.5 días para descargar la resolución que pone fin a la instancia. Mientras que, luego de implementarse el Expediente Judicial Electrónico, los mismos órganos jurisdiccionales demoraron en promedio 182.7 días para descargar la citada resolución, mostrando con ello una disminución del $15 \%$ en el tiempo de duración del proceso en primera instancia, como se puede observar en la siguiente figura: 
Figura n. ${ }^{\circ}$ 18. Comparación del tiempo de duración del proceso en primera instancia (días hábiles) CSJ de Lima

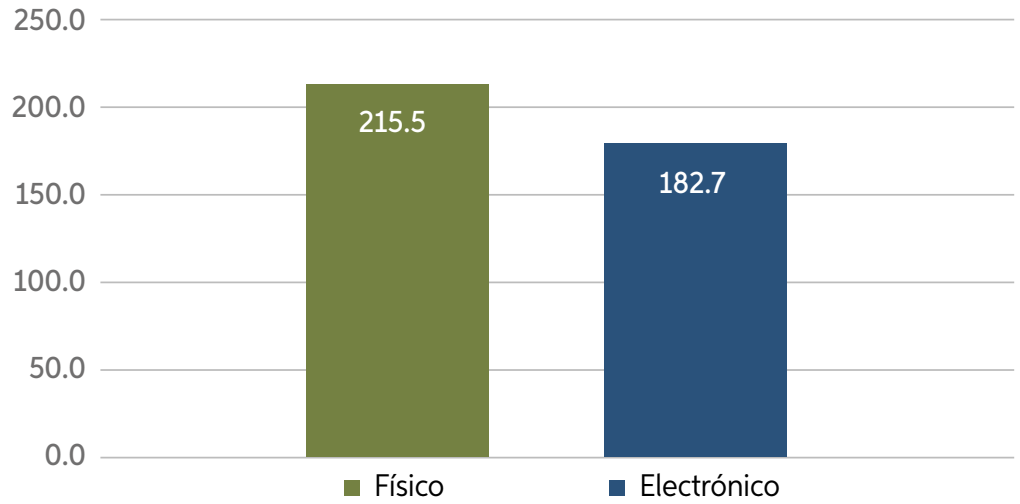

Fecha de actualización: 31 de diciembre de 2020.

Fuente: Gerencia de Informática.

Elaboración: Secretaría Técnica de la Comisión de Trabajo del EJE.

\section{Para otras cortes superiores de justicia}

Este ahorro de tiempo en la duración del proceso en primera instancia se observa en la siguiente tabla:

Tabla n. ${ }^{\circ}$ 14. Disminución del tiempo de duración del proceso en primera instancia (días hábiles) otras CSJ

\begin{tabular}{|c|c|c|c|c|c|}
\hline $\begin{array}{c}\text { Tipo de } \\
\text { expediente }\end{array}$ & \multicolumn{2}{|c|}{ Físico-EJD } & \multicolumn{2}{c|}{ Electrónico } & Tasa de \\
variación \\
CSJ & $\begin{array}{c}\text { Demandas } \\
\text { promediadas }\end{array}$ & $\begin{array}{c}\text { Días prom. } \\
\text { para descargo }\end{array}$ & $\begin{array}{c}\text { Demandas } \\
\text { promediadas }\end{array}$ & $\begin{array}{c}\text { Días prom. } \\
\text { para descargo }\end{array}$ & promedion \\
\hline Provincias & 195928 & 125.7 & 18115 & 62.2 & $-50 \%$ \\
\hline
\end{tabular}

Fecha de actualización: 31 de diciembre de 2020.

Fuente: Gerencia de Informática.

Elaboración: Secretaría Técnica de la Comisión de Trabajo del EJE.

Leyenda: CSJ: Corte Superior de Justicia.

En la tabla anterior se observa que en las cortes superiores de justicia, en el caso de los expedientes físicos ingresados en los órganos jurisdiccionales, demoraron en promedio 125.7 días para descargar 
la resolución que pone fin a la instancia. Mientras que, luego de implementarse el Expediente Judicial Electrónico, los mismos órganos jurisdiccionales demoraron en promedio 62.2 días para descargar la citada resolución, mostrando una disminución del $50 \%$ en el tiempo de duración del proceso en primera instancia, como se puede observar en la siguiente figura:

Figura n. ${ }^{0}$ 19. Comparación del tiempo de duración del proceso en primera instancia (días hábiles) otras CSJ

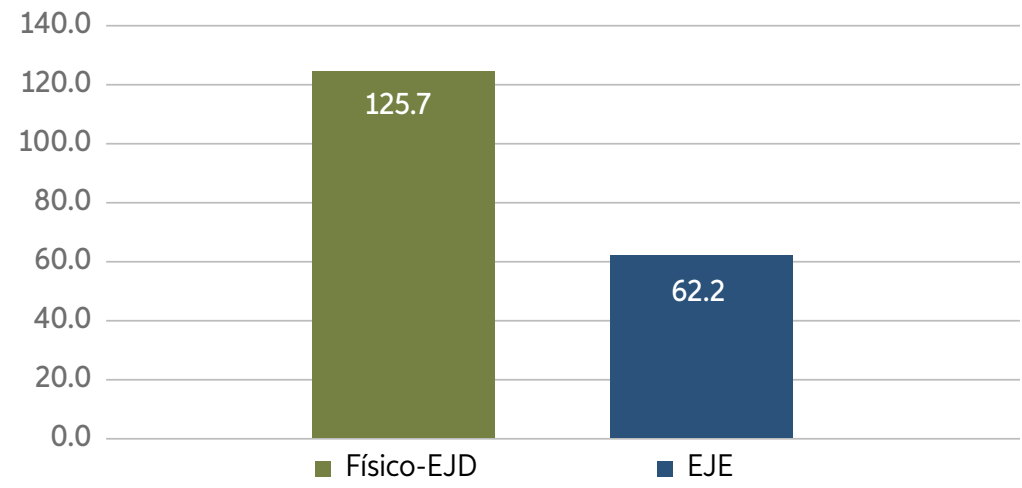

Fecha de actualización: 31 de diciembre de 2020.

Fuente: Gerencia de Informática.

Elaboración: Secretaría Técnica de la Comisión de Trabajo del EJE.

\section{d) Tiempo de duración del proceso en segunda instancia}

Este tiempo se considera desde que ingresa la apelación hasta que se hace el descargo de la resolución que pone fin a esta instancia. La digitalización de los documentos en el Expediente Judicial Electrónico permite ahorrar tiempos de procesos manuales que antes se realizaban en el expediente físico, tales como la búsqueda y el traslado de documentos para su atención.

\section{Para la Corte Superior de Justicia de Lima}

Este ahorro de tiempo en la duración del proceso en segunda instancia se observa en la siguiente tabla: 
Tabla n. ${ }^{\circ}$ 15. Disminución del tiempo de duración del proceso en segunda instancia (días hábiles) CSJ de Lima

\begin{tabular}{|c|c|c|c|c|c|}
\hline Tipo de & \multicolumn{2}{|c|}{ Físico } & \multicolumn{2}{|c|}{ Electrónico } & \multirow{2}{*}{$\begin{array}{c}\text { Tasa de } \\
\text { variación } \\
\text { promedio }\end{array}$} \\
\hline CSJ & $\begin{array}{l}\text { Apelaciones } \\
\text { promediadas }\end{array}$ & $\begin{array}{l}\text { Días prom. } \\
\text { para descargo }\end{array}$ & $\begin{array}{l}\text { Apelaciones } \\
\text { promediadas }\end{array}$ & $\begin{array}{l}\text { Días prom. } \\
\text { para descargo }\end{array}$ & \\
\hline Lima & 19179 & 173.8 & 5183 & 124.7 & $-28 \%$ \\
\hline
\end{tabular}

Fecha de actualización: 31 de diciembre de 2020.

Fuente: Gerencia de Informática.

Elaboración: Secretaría Técnica de la Comisión de Trabajo del EJE.

Leyenda: CSJ: Corte Superior de Justicia.

En la tabla anterior se observa que en la Corte Superior de Justicia de Lima, en el caso de las apelaciones ingresadas en los órganos jurisdiccionales, demoraron en promedio 173.8 días para descargar la resolución que pone fin a la instancia. Mientras que, luego de implementarse el Expediente Judicial Electrónico, los mismos órganos jurisdiccionales demoraron en promedio 124.7 días para descargar la citada resolución. Ello muestra una disminución del $28 \%$ en el tiempo de duración del proceso en segunda instancia, como se puede observar en la siguiente figura:

Figura n. ${ }^{\circ}$ 20. Comparación del tiempo de duración del proceso en segunda instancia (días hábiles) CSJ de Lima

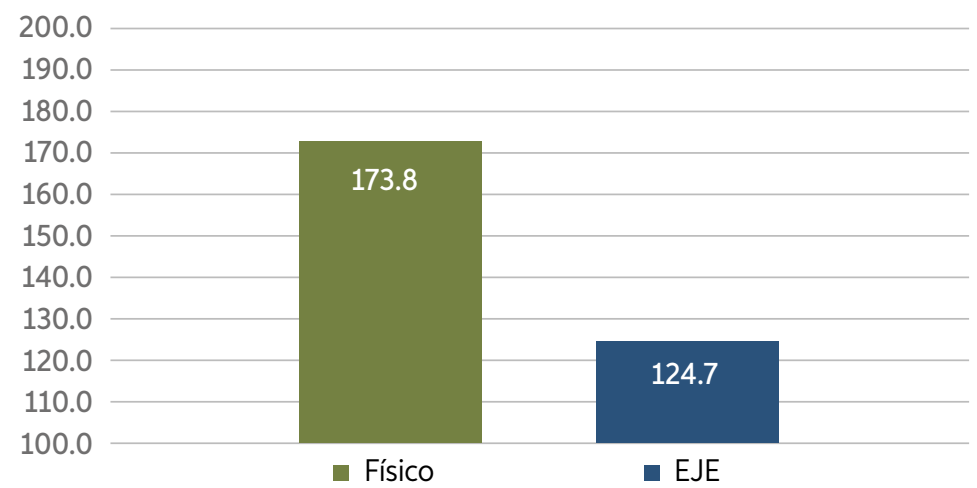

Fecha de actualización: 31 de diciembre de 2020.

Fuente: Gerencia de Informática.

Elaboración: Secretaría Técnica de la Comisión de Trabajo del EJE. 


\section{Para otras cortes superiores de justicia}

Este ahorro de tiempo en la duración del proceso en segunda instancia se observa en la siguiente tabla:

Tabla n. ${ }^{\circ}$ 16. Disminución del tiempo de duración del proceso en segunda instancia (días hábiles) otras CSJ

\begin{tabular}{|c|c|c|c|c|c|}
\hline $\begin{array}{c}\text { Tipo de } \\
\text { expediente }\end{array}$ & \multicolumn{2}{|c|}{ Físico-EJD } & \multicolumn{2}{c|}{ Electrónico } & \multirow{2}{*}{$\begin{array}{c}\text { Tasa de } \\
\text { variación } \\
\text { promedio }\end{array}$} \\
\hline CSJ & $\begin{array}{c}\text { Apelaciones } \\
\text { promediadas }\end{array}$ & $\begin{array}{c}\text { Días prom. } \\
\text { para descargo }\end{array}$ & $\begin{array}{c}\text { Apelaciones } \\
\text { promediadas }\end{array}$ & $\begin{array}{c}\text { Días prom. } \\
\text { para descargo }\end{array}$ & promenn \\
\hline Provincias & 2453 & 162.2 & 721 & 53.4 & $-67 \%$ \\
\hline
\end{tabular}

Fecha de actualización: 31 de diciembre de 2020.

Fuente: Gerencia de Informática.

Elaboración: Secretaría Técnica de la Comisión de Trabajo del EJE.

Leyenda: CSJ: Corte Superior de Justicia.

En la tabla anterior se observa que en las cortes superiores de justicia, en el caso de las apelaciones físicas ingresadas en los órganos jurisdiccionales, demoraron en promedio 162.2 días para descargar la resolución que pone fin a la instancia. Mientras que, luego de implementarse el Expediente Judicial Electrónico, los mismos órganos jurisdiccionales demoraron en promedio 53.4 días para descargar la citada resolución. Lo que muestra una disminución del $67 \%$ en el tiempo de duración del proceso en segunda instancia, como se puede observar en la siguiente figura:

Figura n. ${ }^{\circ} 21$. Comparación del tiempo de duración del proceso en segunda instancia (días hábiles) otras CSJ
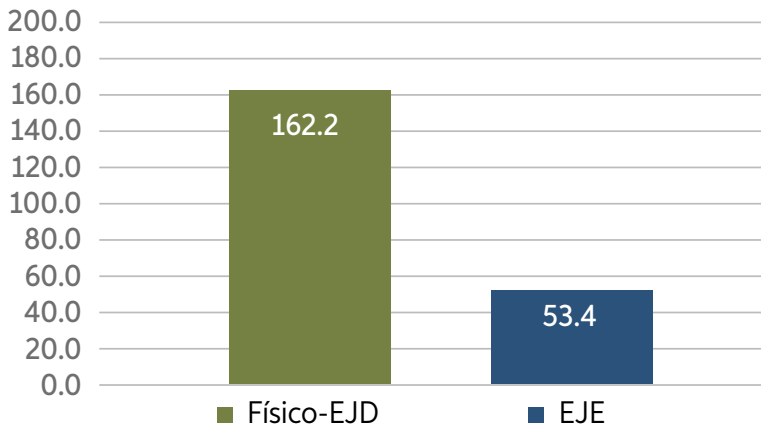

Fecha de actualización: 31 de diciembre de 2020.

Fuente: Gerencia de Informática.

Elaboración: Secretaría

Técnica de la Comisión de Trabajo del EJE.

Expediente Judicial Electrónico 


\subsubsection{Reducción de costos e impacto ecológico}

La implementación paulatina del Expediente Judicial Electrónico ha tenido como consecuencia la reducción en el uso de suministros de impresión y papel, la Mesa de Partes Electrónica es el componente generador de esta externalidad positiva.

Desde la implementación del Expediente Judicial Electrónico hasta el 31 de diciembre de 2020, el Poder Judicial viene contribuyendo a la conservación del medio ambiente, ya que han dejado de usarse un aproximado de 120.4 millones de hojas, lo que equivale a salvar 15054 árboles completamente crecidos. Para ello debe tenerse en cuenta que un expediente consta en promedio de 650 hojas y que un árbol sirve para producir 8000 hojas de papel.

\section{Ahorro de papel en beneficio de la conservación del medio ambiente}

El uso indiscriminado del papel tiene impacto sobre el medio ambiente, pues la gran cantidad de celulosa (que procede de la madera) utilizada en su fabricación trae consigo efectos negativos.

En los actuales tiempos existe una dinámica de cambios en todos los campos y sectores a consecuencia del avance de la tecnología, lo que ha cambiado nuestro modo de vivir.

La tecnología es determinante en la transformación digital: los procesos manuales se realizan ahora de forma digital; con ello se ha agilizado el trabajo y se han mejorando tanto la experiencia como los resultados.

Cabe resaltar que estos conceptos se enlazan también con la preocupación por el cambio climático y el cuidado del ambiente, por lo cual se fomenta la innovación en las operaciones tradicionales de las instituciones tanto públicas como privadas.

En el caso del papel, la problemática se da desde el primer momento, puesto que su proceso de fabricación es una gran fuente de contaminación: se consumen grandes cantidades de madera, agua y energía; se producen gases de efecto invernadero que aceleran el cambio climático; y, por último, su distribución se realiza en transporte a gran escala, que suma otra fuente contaminante. 
Ante esto, la transición del empleo de medios físicos en papel en los procesos al uso de medios virtuales, además de la reducción de costes generados por la adquisición de importantes cantidades de papel e insumos de impresión, así como la disminución de los espacios físicos destinados a los archivos de papel, hace posible la preservación del medio ambiente.

Esquema n. ${ }^{\circ}$ 17. Ahorro de papel en beneficio de la conservación del medio ambiente

Ingresos electrónicos

185286

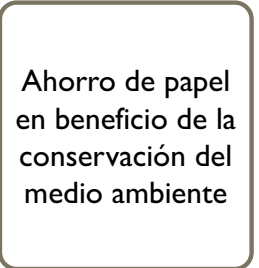

Fojas promedio por expediente
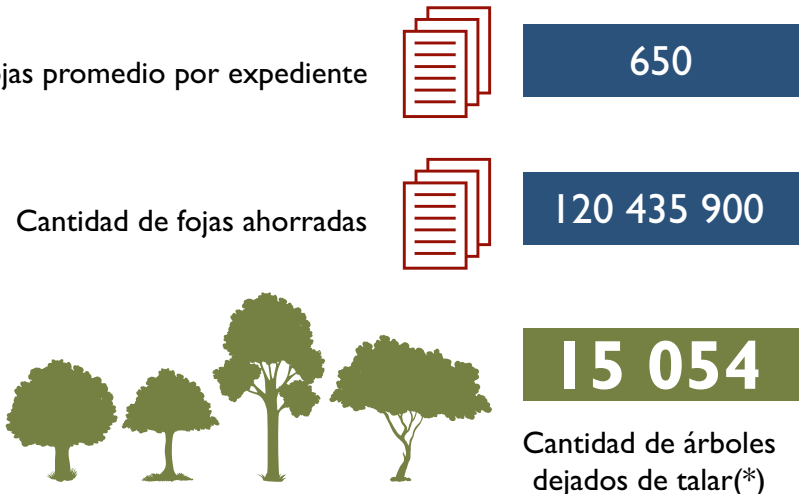

\section{0}

\section{4}

Cantidad de árboles dejados de $\operatorname{talar}(*)$

(*) Un árbol sirve para producir 8000 hojas de papel

Elaboración: Secretaría Técnica de la Comisión de Trabajo del EJE.

\subsubsection{Predictibilidad del sistema}

El Expediente Judicial Electrónico y sus componentes fortalecen la institucionalidad y la predictibilidad del sistema de justicia, expresadas en términos de seguridad jurídica y respeto a los derechos fundamentales. Esto concuerda con la propuesta de transformación digital y representa una de las tareas institucionales que, por un lado, aproxima el servicio de justicia a los ciudadanos, apoyado en una constante transformación que busca disminuir las brechas tecnológicas, culturales y económicas; y, por otro, dentro de esta dinámica preserva la seguridad jurídica. Esta dualidad de objetivos consolida el sistema democrático. 
Esquema n. ${ }^{\circ}$ 18. Fortalecimiento de la institucionalidad nacional y la predictibilidad

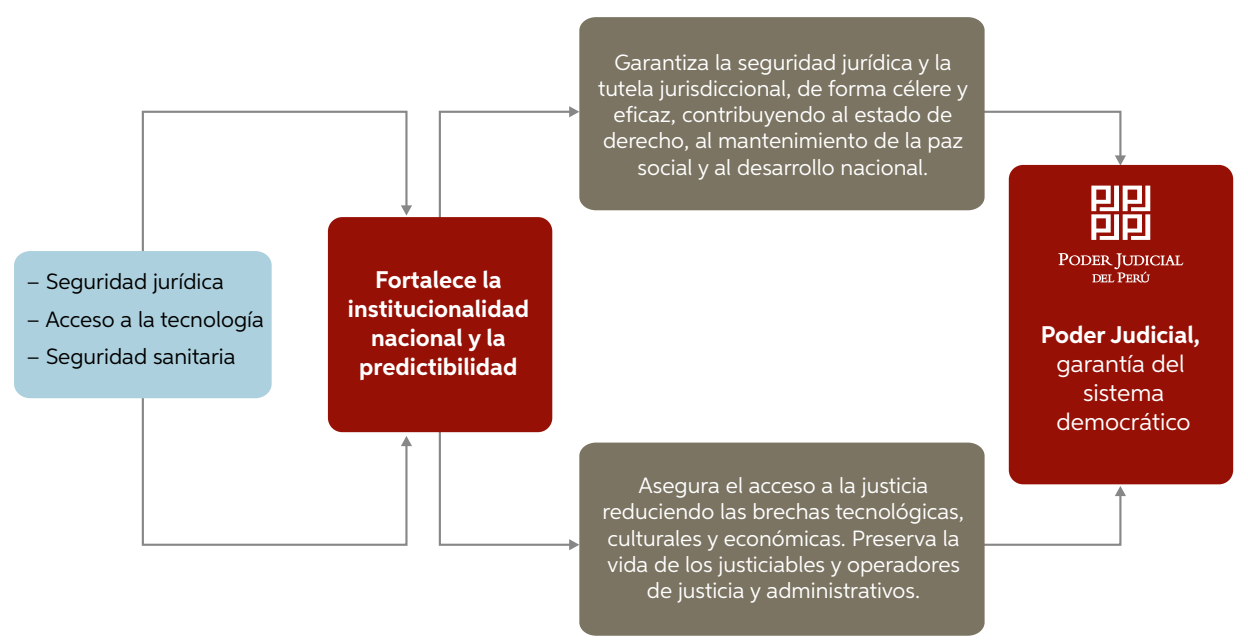

Elaboración: Secretaría Técnica de la Comisión de Trabajo del EJE.

\subsubsection{Visor}

El Expediente Judicial Electrónico y la propuesta de ampliar sus beneficios de proceso digital permite el ilimitado e inmediato acceso a la integridad de los actuados y las decisiones procesales en tiempo real. Así, gracias al Visor, componente del EJE, se puede superar la necesidad del justiciable de acudir a la sala de lectura de las sedes judiciales.

\subsubsection{Videoconferencias}

A través de las videoconferencias, las partes procesales participan en la celebración de audiencias virtuales. Las cortes superiores de justicia que más audiencias generaron fueron Lima con 71 885, Lambayeque con 47 206, La Libertad con 42374 y Cusco con 39 624. Más del $82 \%$ de las audiencias realizadas se concentran en 21 cortes superiores de justicia.

En la siguiente figura se muestra el número de audiencias virtuales por corte superior de justicia desde el 16 de marzo de 2020 al 31 de diciembre de 2020, las cuales hicieron un total de 731574 audiencias vía Hangouts Meet. 
Figura n. ${ }^{\circ} 22$. Videoconferencias desarrolladas en época de pandemia por CSJ

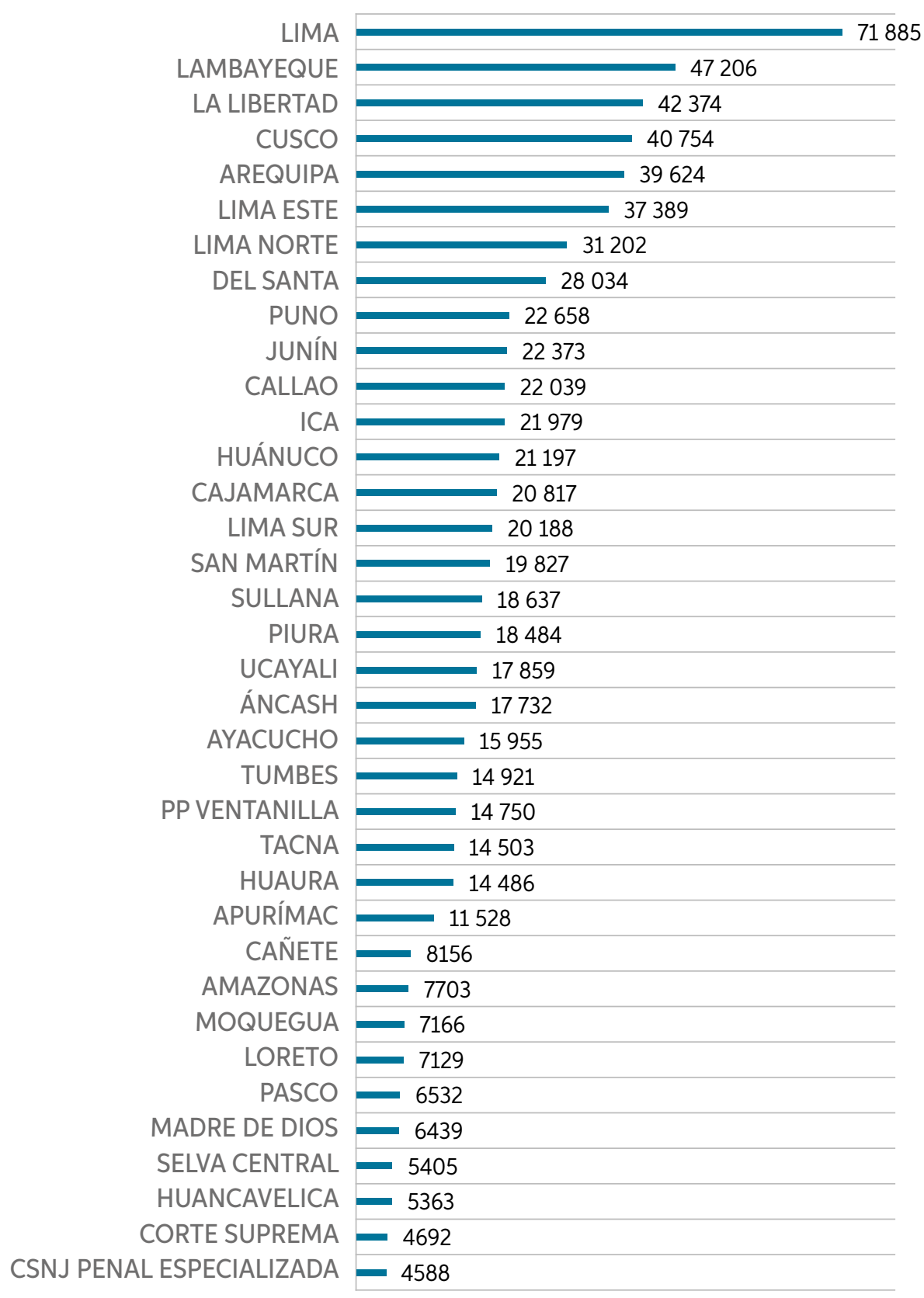

Fuente: Gerencia de Informática.

Elaboración: Secretaría Técnica de la Comisión de Trabajo del EJE. 
La operatividad del Expediente Judicial Electrónico promueve el principio de publicidad y transparencia al permitir el seguimiento y oportunidad en que se generan las decisiones jurisdiccionales. De este modo se acerca a la ciudadanía al funcionamiento o desarrollo del proceso, donde buscan la atención de sus derechos. Se promueve, asimismo, el control ciudadano, lo cual tiene un impacto positivo en la legitimidad de las decisiones judiciales, ya que puede observarse el avance y la culminación de los procesos.

\subsubsection{Sistema de Notificaciones}

La notificación de las resoluciones es un acto procesal inherente al proceso judicial, es uno de los principales actos procesales que sirve para la prosecución del proceso, garantiza el debido proceso y permite tener informados a las partes y a los sujetos procesales de todos los actos que se deciden por el juez, y las pretensiones procesales y materiales de los justiciables. En el Expediente Judicial Electrónico se tienen tres aplicaciones para realizar las notificaciones: el Sistema de Notificación Judicial (Sinoj), el Servicio de Notificaciones (Sernot) y el Sistema de Notificaciones Electrónicas (Sinoe).

Las aplicaciones operan con el Sistema Integrado Judicial (SIJ) y sirven para elaborar la cédula de notificación, con los datos de la parte procesal de destino, la resolución objeto de la notificación, el domicilio procesal, el domicilio real, la casilla electrónica y los anexos si los hubiera. Cuando se trata de notificaciones físicas (modo presencial), estas se realizan a través de las centrales de notificación u oficinas descentralizadas con las aplicaciones Sinoj o en su defecto a través del Sernot. Mientras que en el caso de las notificaciones electrónicas (modo no presencial), estas se realizan a través cédulas que se entregan a las casillas electrónicas de los abogados patrocinantes de las partes procesales; para este tipo de notificaciones hay una conexión con el Sinoe.

En el presente documento nos referimos al Sistema de Notificación Electrónica (Sinoe), sus principales componentes y las estadísticas, dada su estrecha vinculación con el Expediente Judicial Electrónico (EJE). 
Los componentes del Sinoe son los siguientes:

- Casillas electrónicas, que son las cuentas de los repositorios de espacio virtual que se asignan a los usuarios de acuerdo con los perfiles: abogado, auxiliar, fiscal, magistrado, institución y postor.

- Cédulas de notificación electrónica, documentos que son entregados a los usuarios en sus respectivas cuentas.

Cabe señalar que el periodo de obtención de datos se inició el 2 de abril de 2009, fecha de puesta en producción del aplicativo web Sistema de Notificaciones Electrónicas (Sinoe).

\section{a) Casillas electrónicas}

Son un componente del Sistema de Notificaciones Electrónicas creado por el Poder Judicial para que los abogados, los defensores públicos, los postores y las instituciones puedan recibir notificaciones respecto a las decisiones jurisdiccionales de forma íntegra, confiable y célere.

La cuenta de casilla electrónica es la llave para poder acceder a los servicios del entorno del Expediente Judicial Electrónico tales como Mesa de Partes Electrónica (MPE), Visor de Expediente Electrónico (VEE), etc.

Las estadísticas respecto a la creación de casillas electrónicas muestran que la mayor parte de abogados y funcionarios relacionados con el sector justicia disponen de una cuenta de casilla electrónica. Esto en el contexto normativo establecido desde la dación de la Ley n. ${ }^{\circ} 30229$, del 27 de junio de 2014, que adecúa el uso de las tecnologías de información y comunicaciones en el sistema de remates judiciales y en los servicios de notificaciones de las resoluciones judiciales, y que modifica la Ley Orgánica del Poder Judicial, el Código Procesal Civil, el Código Procesal Constitucional y la Ley Procesal del Trabajo (publicada en el diario El Peruano el 12 de julio de 2014).

Con relación al volumen de casillas electrónicas aperturadas, debemos indicar que tiene que ver directamente con el número de abogados registrados en cada región, los auxiliares jurisdiccionales y administrativos del Poder Judicial, los magistrados del Poder Judicial, 
las instituciones como el Ministerio Público, los estudios jurídicos y empresas vinculadas al sector justicia, y a los postores para el caso de los remates judiciales.

Tabla n. ${ }^{\circ}$ 17. Casillas electrónicas por año (2009-2020)

\begin{tabular}{|c|c|}
\hline Año & Cantidad de casillas \\
\hline 2009 & 120 \\
\hline 2010 & 2499 \\
\hline 2011 & 3616 \\
\hline 2012 & 2771 \\
\hline 2013 & 4347 \\
\hline 2014 & 7628 \\
\hline 2015 & 25103 \\
\hline 2016 & 24010 \\
\hline 2017 & 16484 \\
\hline 2018 & 10715 \\
\hline 2019 & 10796 \\
\hline 2020 & 9467 \\
\hline Total & 117556 \\
\hline & \\
\hline
\end{tabular}

Fecha de actualización: Del 2009 al 31 de diciembre de 2020.

Fuente: Gerencia de Informática.

Elaboración: Secretaría Técnica de la Comisión de Trabajo del EJE.

En la tabla se muestran los datos totalizados por ańo desde abril de 2009 al 31 de diciembre de 2020, que hacen un total de 117556 casillas aperturadas a igual número de usuarios.

Para acceder a los servicios de notificaciones electrónicas, mesa de partes electrónica y al sistema de remates virtuales, se requiere contar con una cuenta de casilla electrónica, que ahora se gestiona y tramita en línea. 
Figura n. ${ }^{\circ} 23$. Casillas electrónicas aperturadas por año (2009-2020)

30000

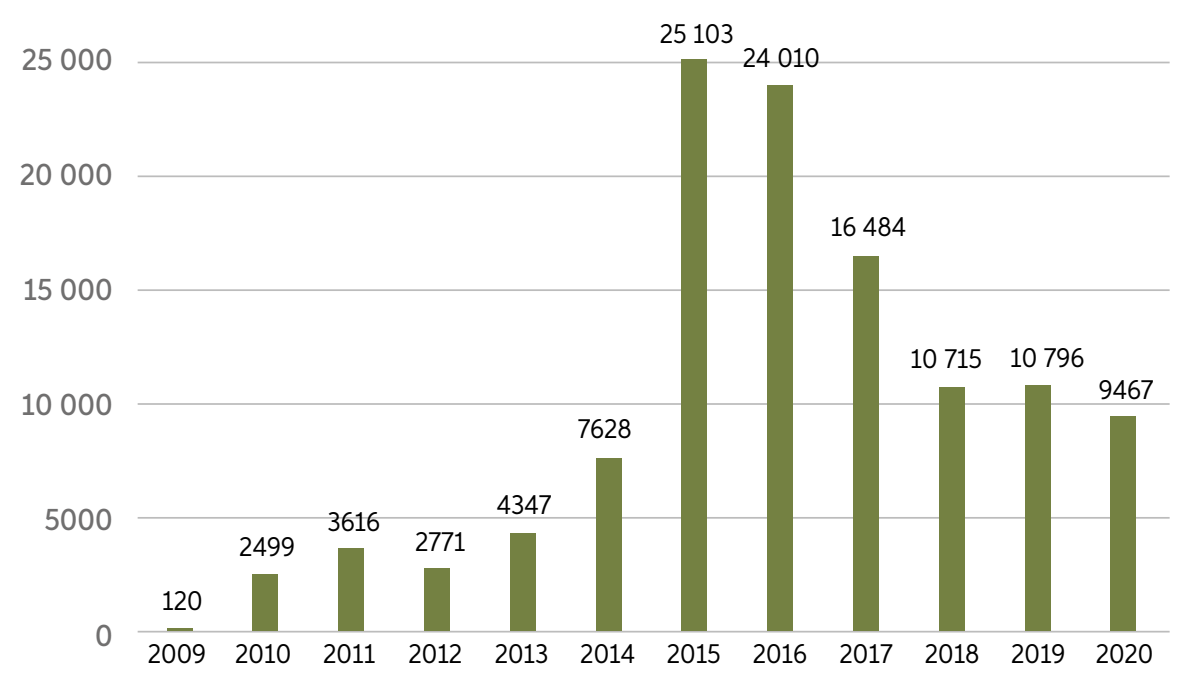

Fecha de actualización: Del 2009 al 31 de diciembre de 2020.

Fuente: Gerencia de Informática.

Elaboración: Secretaría Técnica de la Comisión de Trabajo del EJE.

El gráfico muestra el número de casillas por año. Estas se pusieron en producción en el año 2009, el pico más alto se registró en el 2015 por la expedición de la Ley n. ${ }^{\circ} 30229$, de fecha 14 de julio de 2014, norma que incluye la notificación judicial a través de medios electrónicos.

\section{- Casillas electrónicas por tipo de usuario}

Las casillas electrónicas se otorgan a los usuarios de acuerdo con los perfiles de abogado de quien patrocina un caso judicial; auxiliar trabajador o empleado del Poder Judicial para comunicarse ante un trámite administrativo; fiscal representante de la fiscalía en los casos en que es parte el Ministerio Público; instituciones de la administración pública para comunicación judicial; jueces del Poder Judicial para la comunicación de trámites administrativos y judiciales; perfil de postor, ciudadano que va a participar en una subasta pública. 
Tabla n. ${ }^{\circ}$ 18. Casillas aperturadas por tipo de usuario (2009-2020)

\begin{tabular}{|c|c|}
\hline Tipo de usuario & Cantidad de casillas \\
\hline Abogado & 83134 \\
\hline Auxiliar & 9535 \\
\hline Fiscal & 5547 \\
\hline Institución & 4652 \\
\hline Magistrado & 11662 \\
\hline Postor & 3026 \\
\hline TOTAL & 117556 \\
\hline
\end{tabular}

Fecha de actualización: Del 2009 al 31 de diciembre de 2020. Fuente: Gerencia de Informática. Elaboración: Secretaría Técnica de la Comisión de Trabajo del EJE.

En la tabla se muestra el total de casillas electrónicas aperturadas por perfil de usuario desde abril de 2009 al 31 de diciembre de 2020.

Tabla n. ${ }^{0}$ 19. Casillas aperturadas por tipo de usuario y año (2009-2020)

\begin{tabular}{|c|c|c|c|c|c|c|c|}
\hline \multirow{2}{*}{ Año } & \multicolumn{7}{|c|}{ Tipo de usuario } \\
\cline { 2 - 9 } & Abogado & Auxiliar & Fiscal & Institución & Magistrado & Postor & Total \\
\hline 2009 & 120 & 0 & 0 & 0 & 0 & 0 & 120 \\
\hline 2010 & 2412 & 0 & 0 & 85 & 2 & 0 & 2499 \\
\hline 2011 & 3550 & 0 & 2 & 54 & 10 & 0 & 3616 \\
\hline 2012 & 2718 & 0 & 7 & 39 & 7 & 0 & 2771 \\
\hline 2013 & 4121 & 17 & 86 & 71 & 52 & 0 & 4347 \\
\hline 2014 & 3568 & 1059 & 131 & 73 & 2797 & 0 & 7628 \\
\hline 2015 & 13962 & 4329 & 598 & 216 & 5957 & 41 & 25103 \\
\hline 2016 & 19391 & 1104 & 1672 & 811 & 974 & 58 & 24010 \\
\hline 2017 & 12057 & 1577 & 952 & 549 & 1132 & 217 & 16484 \\
\hline 2018 & 8020 & 552 & 770 & 398 & 290 & 685 & 10715 \\
\hline 2019 & 7604 & 501 & 662 & 715 & 247 & 1067 & 10796 \\
\hline 2020 & 5611 & 396 & 667 & 1641 & 194 & 958 & 9467 \\
\hline Total & 83134 & 9535 & 5547 & 4652 & 11662 & 3026 & 117556 \\
\hline & & & & & & & \\
\hline
\end{tabular}

Fecha de actualización: Del 2009 al 31 de diciembre de 2020.

Fuente: Gerencia de Informática.

Elaboración: Secretaría Técnica de la Comisión de Trabajo del EJE. 
En la tabla se muestra el total de casillas electrónicas aperturadas por perfil de usuario, que asciende a un total de 117556 cuentas de casilla aperturadas desde abril de 2009 al 31 de diciembre de 2020.

Figura n. ${ }^{\circ} 24$. Casillas aperturadas por tipo de usuario (2009-2020)

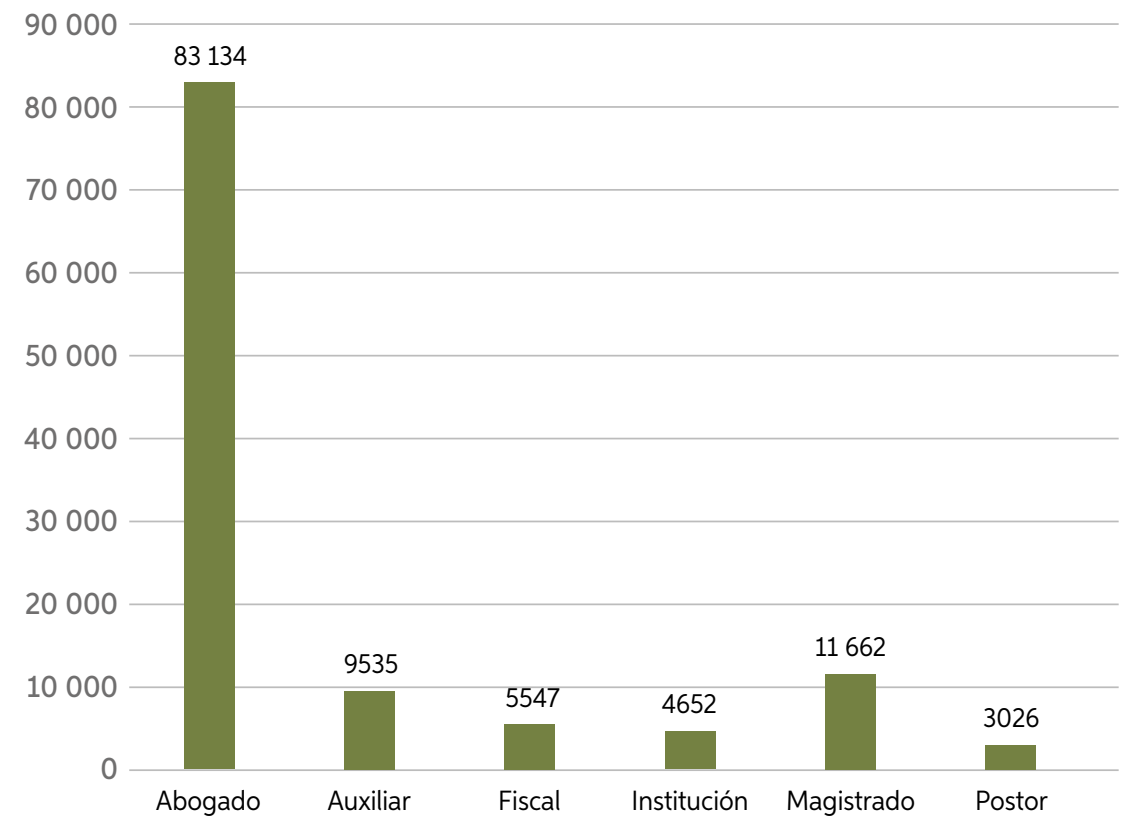

Fecha de actualización: Del 2009 al 31 de diciembre de 2020.

Fuente: Gerencia de Informática.

Elaboración: Secretaría Técnica de la Comisión de Trabajo del EJE.

El gráfico muestra las casillas aperturadas por tipo de usuario, el tipo de usuario abogado es el que registra mayor demanda del servicio, con 83134 casillas electrónicas, mientras que las más baja es el tipo de usuario postor con 3026 casillas aperturadas. 
Figura n. ${ }^{\circ} 25$. Casillas aperturadas por año y tipo de usuario (2009-2020)

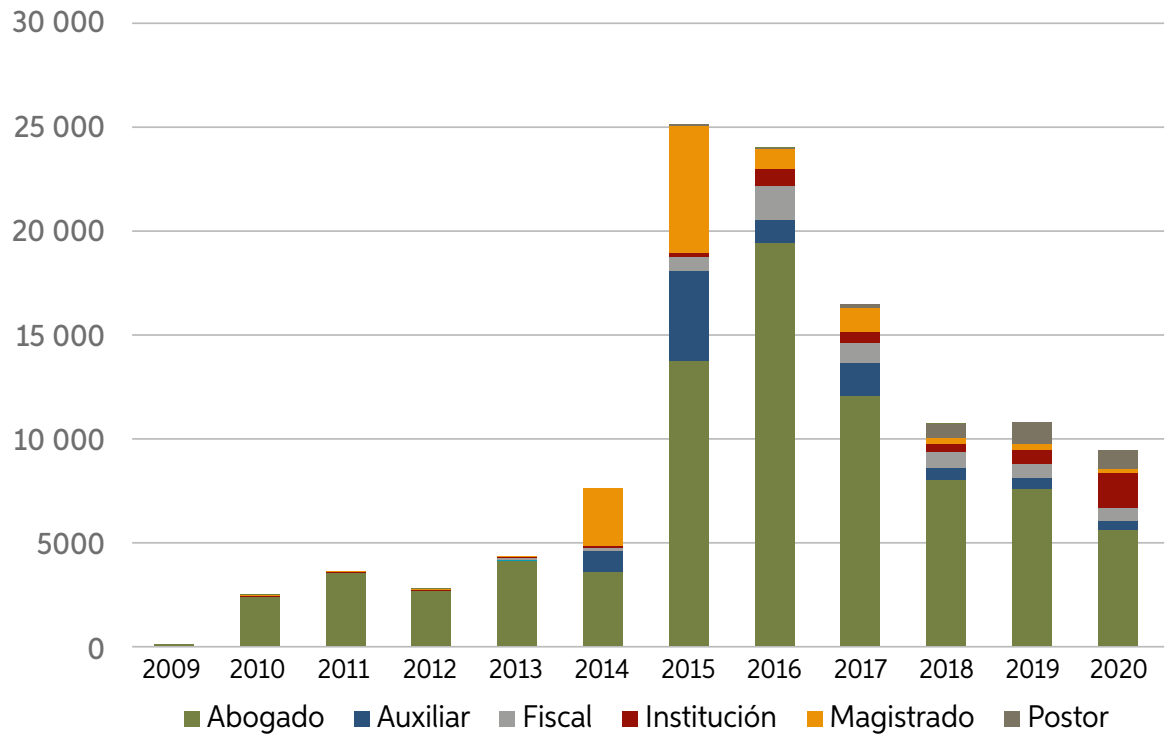

Fecha de actualización: Del 2009 al 31 de diciembre de 2020.

Fuente: Gerencia de Informática.

Elaboración: Secretaría Técnica de la Comisión de Trabajo del EJE.

El gráfico muestra datos de casillas aperturadas por año y tipo de usuario, predomina la columna del ańo 2015, y destacan los abogados y los magistrados.

\section{- Casillas electrónicas por corte}

Es importante considerar que al incorporar usuarios a la plataforma del Sinoe para asignarles casillas electrónicas, se logra el acceso a la justicia con todos los beneficios que representa una comunicación digital al ciudadano. Este proceso de asignación de casillas gratuitas es descentralizado, debido a que en cada distrito judicial, en cada sede judicial o subsede judicial, la Gerencia de Servicios Judiciales y Recaudación de la Gerencia General del Poder Judicial ha puesto en funcionamiento oficinas administrativas para gestionar la entrega de las credenciales a los usuarios a nivel nacional. 
Figura n. ${ }^{\circ}$ 26. Casillas aperturadas por corte superior de justicia (2009-2020)

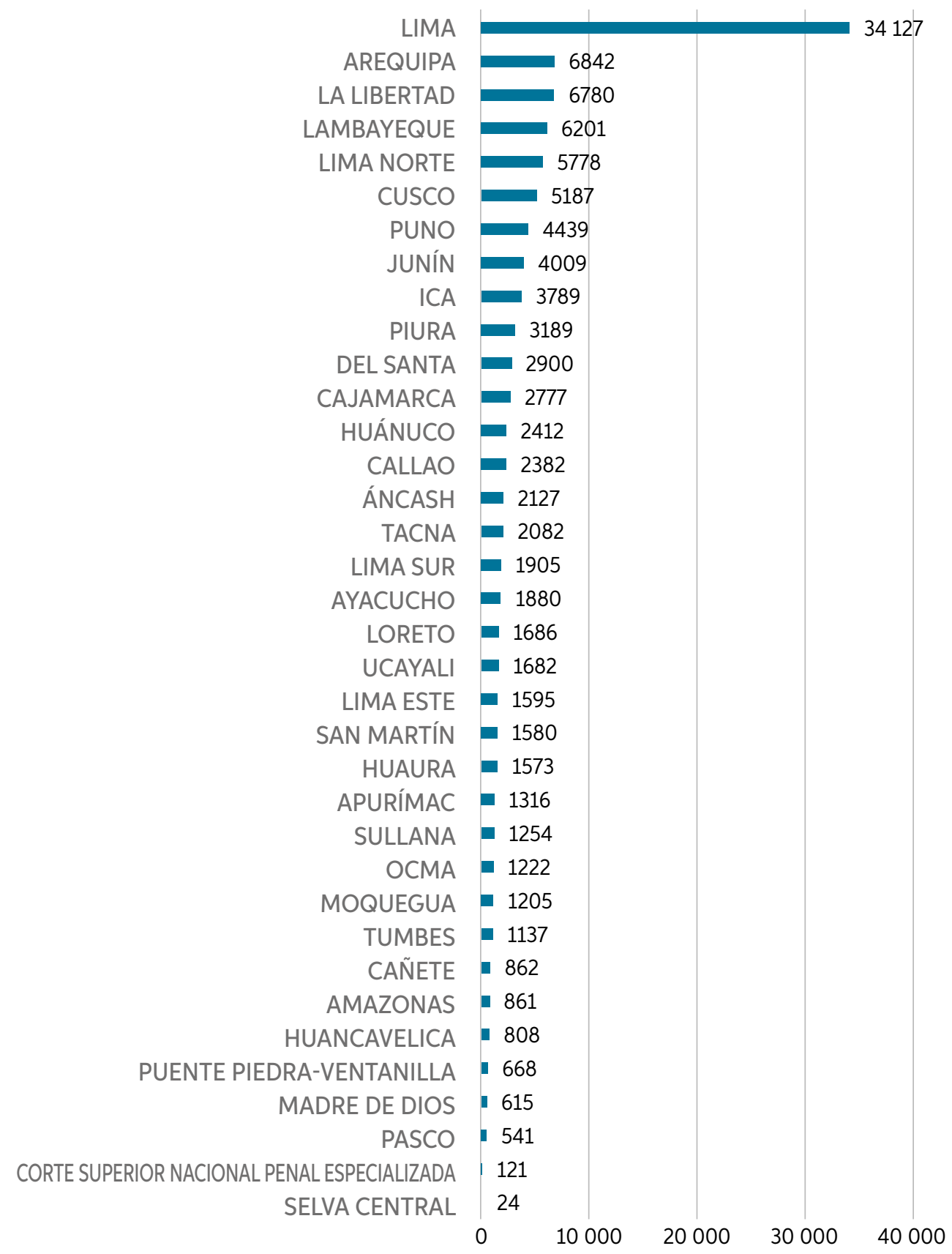

Fecha de actualización: Del 2009 al 31 de diciembre de 2020.

Fuente: Gerencia de Informática.

Elaboración: Secretaría Técnica de la Comisión de Trabajo del EJE.

98 Expediente Judicial Electrónico 
El gráfico muestra las casillas aperturadas por corte, en orden creciente. Para obtener una casilla electrónica, el procedimiento regular se inicia con la inscripción del usuario vía web, se genera un cargo que le permite recoger, de manera presencial, las credenciales luego de la entrega de los documentos físicos, en la oficina zonal de la residencia del interesado, y obtiene así la cuenta de la casilla electrónica.

Con motivo de la pandemia, la Gerencia de Servicios Judiciales y Recaudación reformuló la estrategia de apertura de las casillas electrónicas al implementar un servicio gratuito de apertura de casillas en línea, es decir, se activó el modelo de apertura de casillas no presencial.

\section{b) Cédulas de notificación físicas y electrónicas}

Las notificaciones se realizan para comunicar a las partes y a los sujetos procesales el contenido de las resoluciones y de sus anexos o recaudos si los tuviera. Este acto procesal es realizado por la administración de justicia con la elaboración de la cédula de notificación por parte de los asistentes de notificación y es autorizado por los especialistas de causa, secretarios de juzgado o secretarios de sala, según corresponda.

La Ley Orgánica del Poder Judicial en su artículo 155-A señala:

La notificación electrónica es un medio alternativo a la notificación por cédula y se deriva a casilla electrónica de manera obligatoria en todos los procesos contenciosos y no contenciosos tramitados ante los órganos jurisdiccionales del Poder Judicial. La notificación electrónica debe contar con firma digital y debe ser utilizada en el marco de la Ley 27269, Ley de Firmas y Certificados Digitales, su reglamento, así como la normativa relacionada.

La misma norma establece en qué casos se hace la notificación por cédula de modo físico, artículo 155-E:

Sin perjuicio de la notificación electrónica, las siguientes resoluciones judiciales deben ser notificadas solo mediante cédula: 1 . La que contenga el emplazamiento de la demanda, la declaración de rebeldía y la medida cautelar. 2. La sentencia o auto que pone fin al proceso en cualquier instancia. La resolución notificada por cédula surte efecto desde el día siguiente de notificada. 
Con este marco normativo las notificaciones son físicas (presenciales) y electrónicas (no presencial). Esta última es la que se gestiona a través del Sistema de Notificaciones Electrónicas (Sinoe).

Mediante el R. A. n. ${ }^{\circ}$ 000189-2020-CE-PJ, del 16 de julio de 2020, el Poder Judicial resuelve crear el «Registro de Casillas Electrónicas Institucionales para fines de Emplazamientos Judiciales o Citación con la Demanda (RECEI)».

Esquema n. ${ }^{0}$ 19. Modelo de notificación judicial

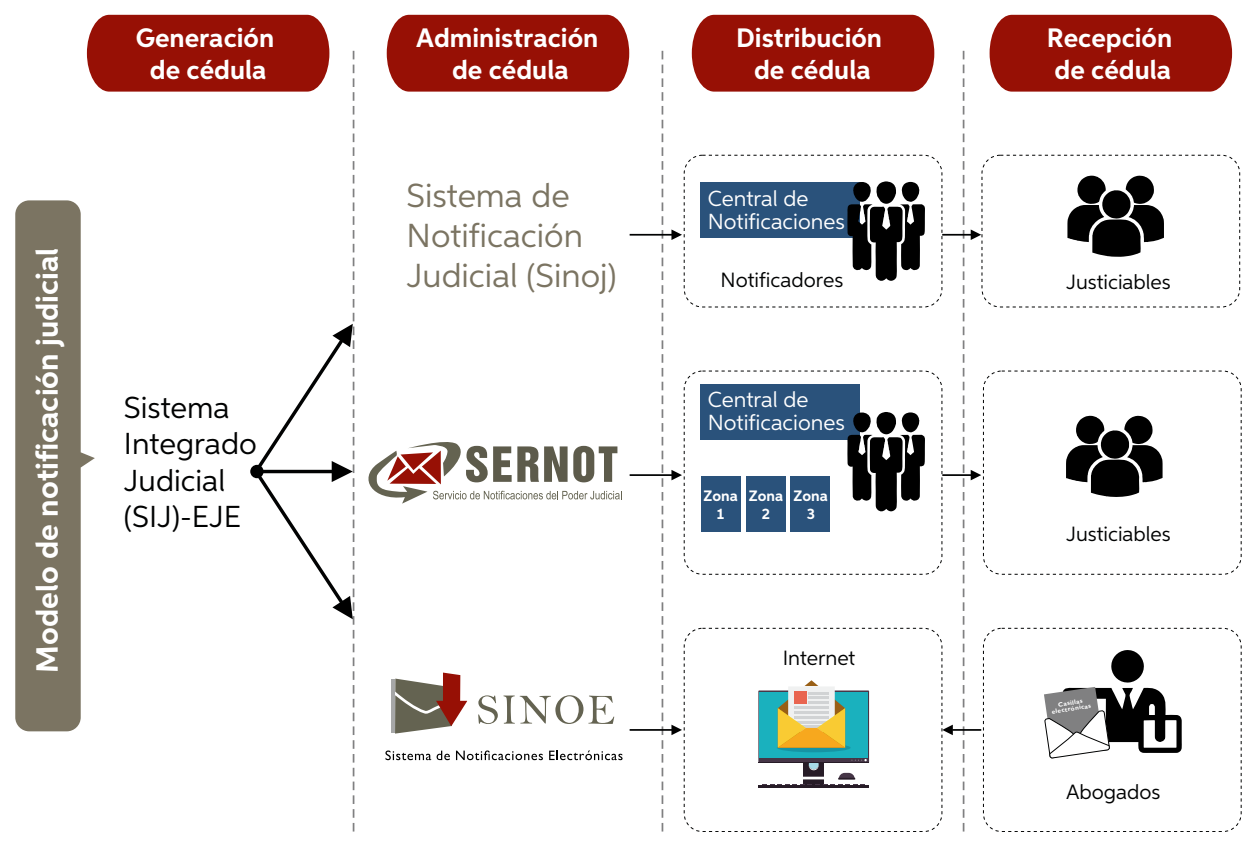

Elaboración: Secretaría Técnica de la Comisión de Trabajo del EJE.

Con lo expresado sobre las notificaciones presentamos las estadísticas de las notificaciones físicas y las notificaciones electrónicas. 
Tabla n. ${ }^{\circ} 20$. Cédulas de notificación físicas y electrónicas por año $(2009-2020)$

\begin{tabular}{|c|c|c|c|}
\hline \multirow{2}{*}{ Año } & \multicolumn{2}{|c|}{ Tipo de cédulas } & \multirow{2}{*}{ Total } \\
\cline { 2 - 3 } & Físicas & Electrónicas & \\
\hline 2009 & 8683301 & 2 & 8683303 \\
\hline 2010 & 10916653 & 608 & 10917261 \\
\hline 2011 & 13750354 & 28645 & 13778999 \\
\hline 2012 & 14128861 & 113769 & 14242630 \\
\hline 2013 & 16932777 & 355215 & 17287992 \\
\hline 2014 & 16788713 & 574823 & 17363536 \\
\hline 2015 & 19837498 & 1256160 & 21093658 \\
\hline 2016 & 16774811 & 3795253 & 20570064 \\
\hline 2017 & 15133651 & 9743217 & 24876868 \\
\hline 2018 & 15218001 & 12990298 & 28208299 \\
\hline 2019 & 13392528 & 15165210 & 28557738 \\
\hline 2020 & 5603556 & 9910722 & 15514278 \\
\hline Total & 167160704 & 53933922 & 221094626 \\
\hline
\end{tabular}

Fecha de actualización: Del 2009 al 31 de diciembre de 2020.

Fuente: Gerencia de Informática.

Elaboración: Secretaría Técnica de la Comisión de Trabajo del EJE.

En la tabla se observa que en once años de vigencia las cédulas de notificación electrónica han tenido un comportamiento creciente y sostenido en el tiempo. Para el análisis estadístico se tiene un total de 221094626 de cédulas. Las notificaciones se han estado realizando siempre y a medida que se incorpora progresivamente la tecnología para algunos procesos como el caso del Sinoj, luego el Sernot y ahora el Sinoe.

Para efectos metodológicos, se toma en cuenta la fecha de la puesta en producción del Sinoe, esto es, abril de 2009 hasta el 31 de diciembre de 2020. Si bien el Sinoe está desarrollado en una arquitectura web, debemos mencionar que es una aplicación que administra y gestiona las casillas electrónicas y que en cada una de estas los usuarios pueden recibir las notificaciones únicamente electrónicas, así como descargarlas y visualizarlas. 
Figura n. ${ }^{\circ} 27$. Cédulas físicas y electrónicas por año (2009-2020)

25000000

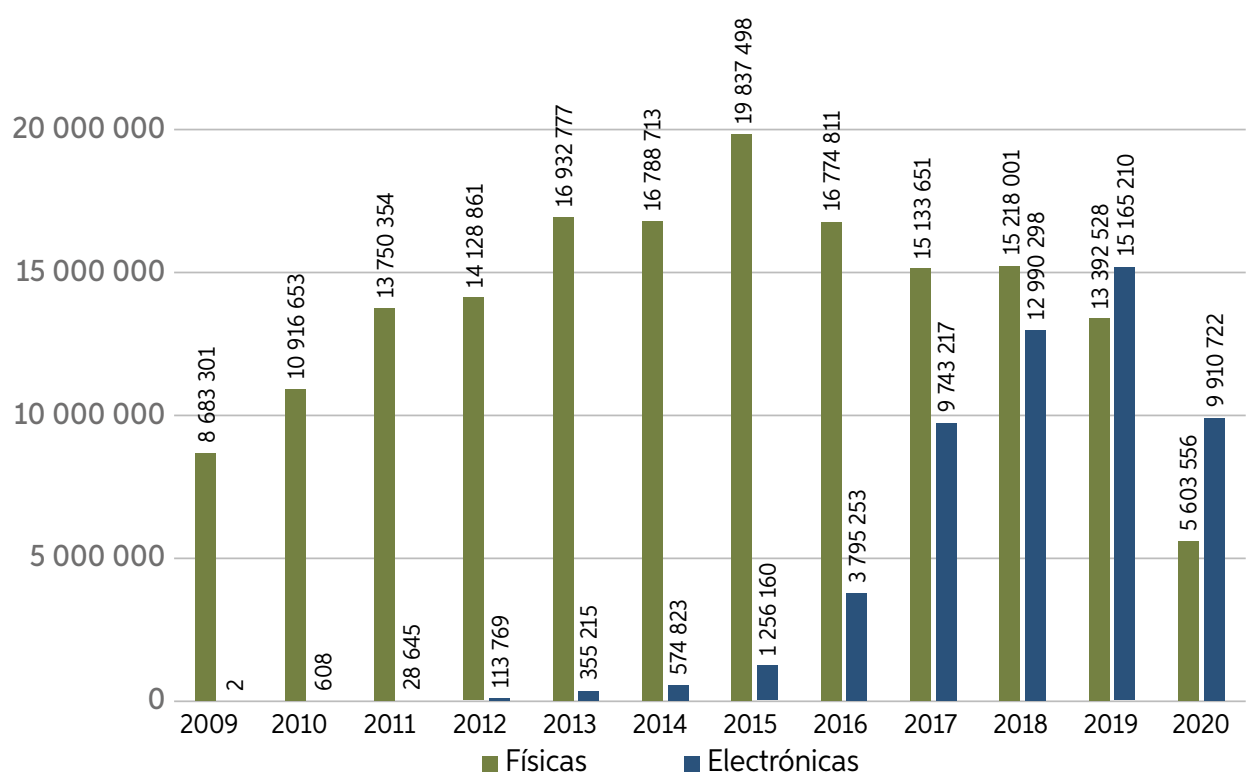

Fecha de actualización: Del 2009 al 31 de diciembre de 2020.

Fuente: Gerencia de Informática.

Elaboración: Secretaría Técnica de la Comisión de Trabajo del EJE.

En el gráfico se observa una tendencia creciente en los once años de vigencia del Sinoe y se debe a tres factores:

a) El despliegue progresivo del componente del aplicativo Notificación Electrónica como parte del Sistema Integrado Judicial (aplicativo de escritorio) para la elaboración de la cédula de notificación electrónica.

b) El uso por parte del usuario interno del aplicativo web Sistema de Notificación Electrónica (Sinoe) para enviar a la casilla electrónica del usuario final.

c) La incorporación progresiva de los abogados debido a la obtención voluntaria de las casillas electrónicas. Consideramos que el emprendimiento del Expediente Judicial Electrónico será el que va a impulsar el incremento de nuevas cuentas de casillas electrónicas, así como el crecimiento de las cédulas de notificación que interactúan recíprocamente en la plataforma. 


\section{- Cédulas de notificación físicas y electrónicas por corte superior de justicia}

Figura n. ${ }^{\circ} 28$. Cédulas de notificación físicas y electrónicas por corte superior de justicia (2009-2020)

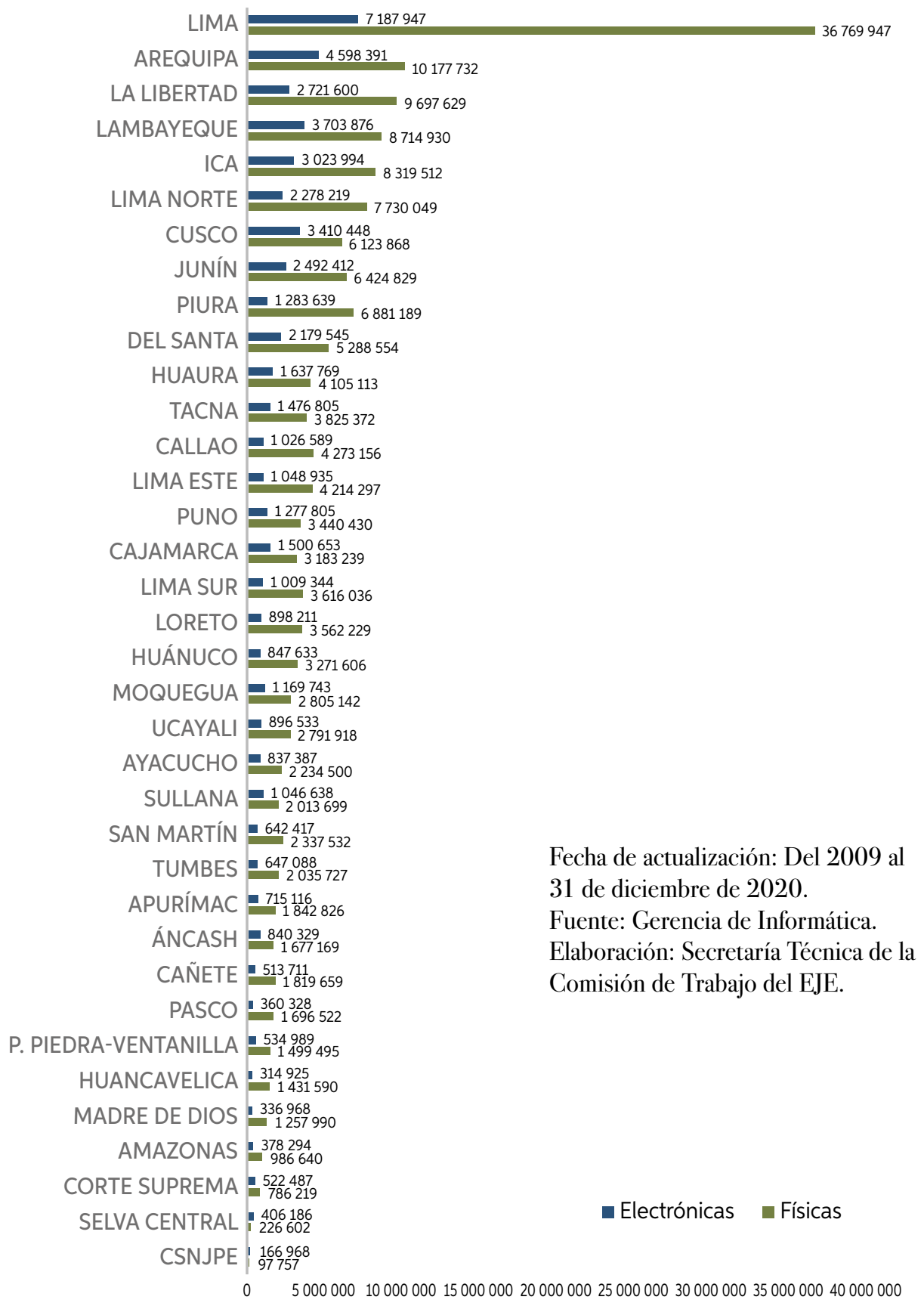

Fecha de actualización: Del 2009 al 31 de diciembre de 2020.

Fuente: Gerencia de Informática. Elaboración: Secretaría Técnica de la Comisión de Trabajo del EJE. 
En el gráfico se muestran las cédulas de notificación físicas y electrónicas por corte y en forma creciente. Lima cuenta con 36769947 cédulas de notificación física y 7187947 electrónicas; Arequipa con 10177732 cédulas de notificación física y 4598391 electrónicas; La Libertad con 9697629 cédulas de notificación física y 2721600 electrónicas; Lambayeque con 8714930 cédulas de notificación física y 3703876 electrónicas respectivamente. Con menor volumen están la Corte de la Selva Central con 226602 cédulas de notificación física y 406186 electrónicas y la nueva Corte Superior Nacional de Justicia Penal Especializada (CSNJPE) con 97757 cédulas de notificación física y 166968 electrónicas. Esta última corte es nueva e integra los sistemas de Justicia Penal Especializada en Crimen Organizado y Corrupción de Funcionarios.

\section{- Cédulas físicas y electrónicas por nivel del órgano jurisdiccional}

Figura n. ${ }^{\circ}$ 29. Cédulas físicas y electrónicas por nivel del órgano

(2009-2020)

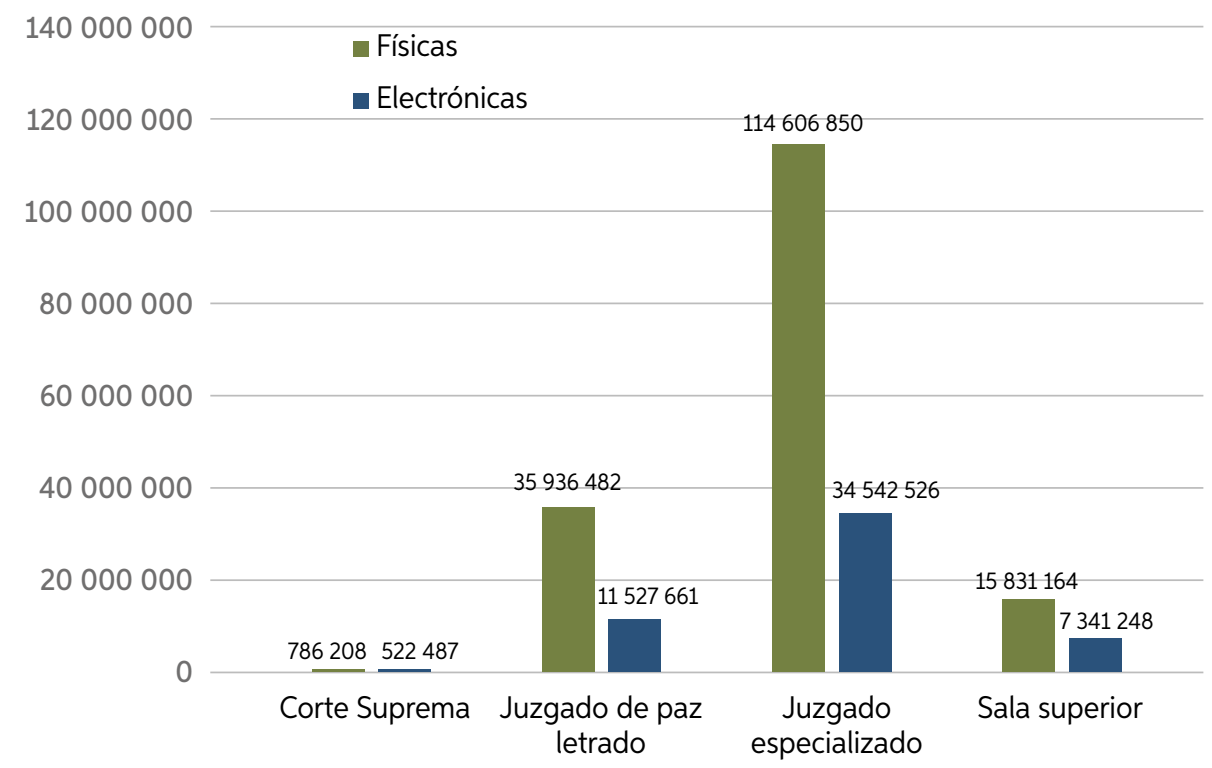

Fecha de actualización: Del 2009 al 31 de diciembre de 2020.

Fuente: Gerencia de Informática.

Elaboración: Secretaría Técnica de la Comisión de Trabajo del EJE. 
El gráfico muestra que la producción de las cédulas de notificación físicas y electrónicas más relevantes es en el nivel de juzgados especializados, seguida de los juzgados de paz letrado, luego las salas superiores y finalmente la Corte Suprema.

\section{- Cédulas electrónicas por especialidad}

Figura n. ${ }^{\circ} 30$. Cédulas electrónicas por especialidad (2009-2020)

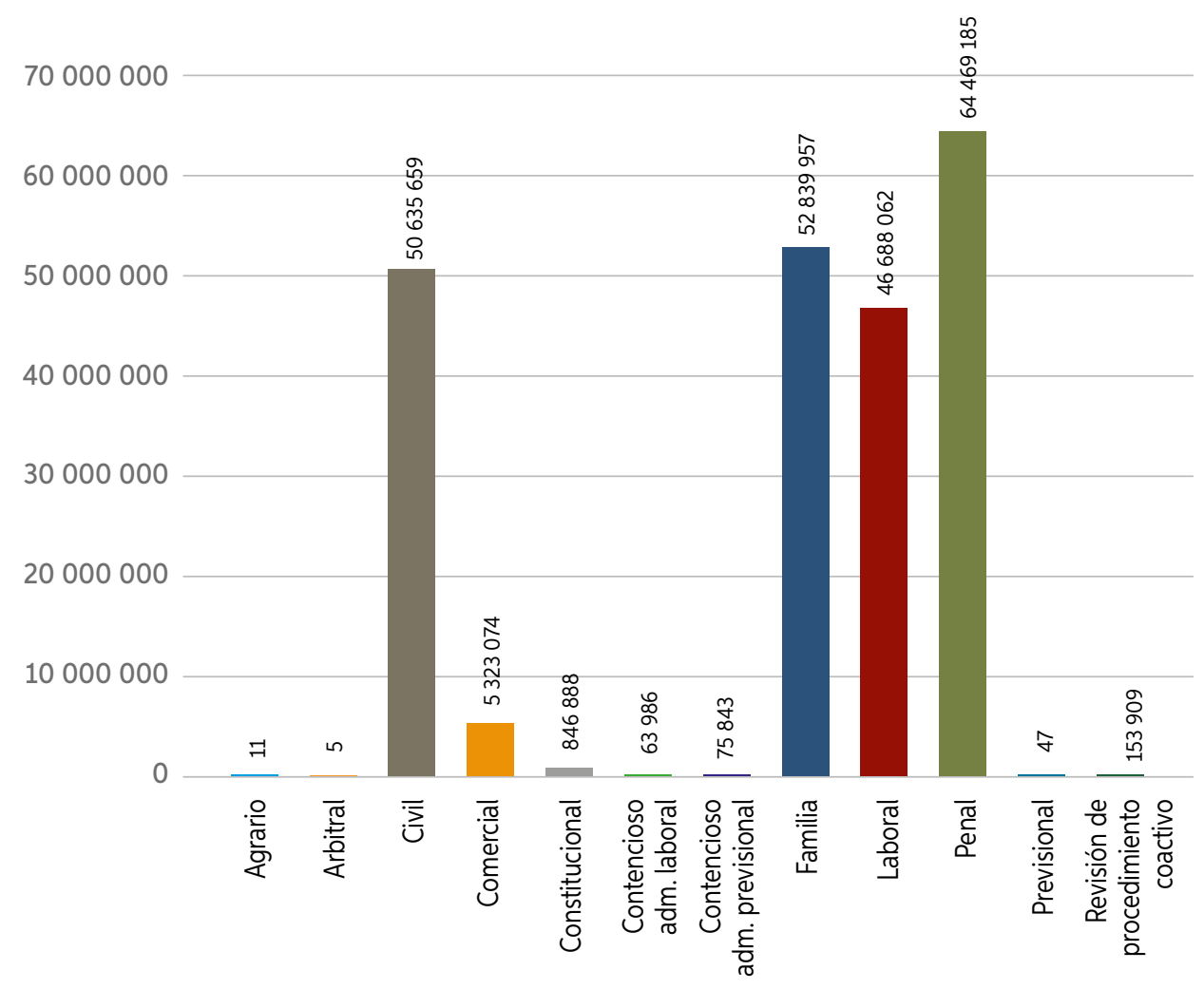

Fecha de actualización: Del 2009 al 31 de diciembre de 2020.

Fuente: Gerencia de Informática.

Elaboración: Secretaría Técnica de la Comisión de Trabajo del EJE.

En el gráfico de barras observamos que la más relevante es la especialidad penal, que cuenta con 64469185 cédulas; seguida por la especialidad civil, que cuenta con 50633659 cédulas; luego la especialidad laboral, que cuenta con 46688062 cédulas y finalmente la especialidad familia civil cuenta con 49081723 cédulas. 


\subsubsection{Equidad del sistema}

Esta medida permite ampliar y facilitar a los ciudadanos el acceso al servicio de justicia, con la implementación de un nuevo canal de atención vía web, generando así transparencia al brindar total acceso al expediente y seguimiento del mismo, lo cual fortalece la independencia y la imparcialidad.

El acceso a la justicia es el principio básico sobre el cual descansa el Estado de derecho. Es el derecho fundamental e internacionalmente reconocido que actúa como fundamento para la exigibilidad del goce de todos los derechos humanos de las personas, como el derecho a la libertad, a la salud, a la educación, al trabajo. En consecuencia, el Estado no solo es responsable por su cumplimiento, sino que debe generar mecanismos viables para que una persona pueda presentarse ante una autoridad para hacer valer sus derechos. De esta forma el Poder Judicial, al potenciar las actividades y el despliegue del Expediente Judicial Electrónico y la Mesa de Partes Electrónica consolida estas soluciones tecnológicas que atienden la necesidad de acceso a la justicia.

\subsubsection{Uso de la Mesa de Partes Electrónica para la presentación de demandas}

Uno de los beneficios del Expediente Judicial Electrónico es la Mesa de Partes Electrónica (MPE), que permite a los justiciables presentar demandas sin tener que desplazarse a la sede judicial para realizar este trámite, como se observa en la siguiente tabla detallada por corte superior de justicia y especialidad desde la implementación del componente MPE (año 2018): 
Tabla n. ${ }^{\circ}$ 21. Uso de la Mesa de Partes Electrónica (MPE) para la presentación de las demandas

\begin{tabular}{|c|c|c|c|c|c|c|}
\hline N. ${ }^{\circ}$ & CSJ & Especialidad & $\begin{array}{l}\text { Demandas } \\
\text { presentadas } \\
\text { por Mesa de } \\
\text { Partes Física }\end{array}$ & $\begin{array}{l}\text { Demandas } \\
\text { presentadas por } \\
\text { Mesa de Partes } \\
\text { Electrónica }\end{array}$ & $\begin{array}{l}\text { Total de } \\
\text { demandas } \\
\text { presentadas }\end{array}$ & $\begin{array}{l}\% \text { de } \\
\text { demandas } \\
\text { presentadas } \\
\text { por la MPE }\end{array}$ \\
\hline \multirow{4}{*}{1} & \multirow{4}{*}{ Lima } & $\begin{array}{l}\text { Civil con } \\
\text { subespecialidad } \\
\text { comercial }\end{array}$ & 43488 & 6321 & 49809 & $12.69 \%$ \\
\hline & & $\begin{array}{l}\text { Cont. adm. con } \\
\text { subespecialidad } \\
\text { tributaria y } \\
\text { aduanera }\end{array}$ & 2670 & 424 & 3094 & $13.70 \%$ \\
\hline & & $\begin{array}{l}\text { Cont. adm. con } \\
\text { subespecialidad en } \\
\text { temas de mercado }\end{array}$ & 4245 & 584 & 4829 & $12.09 \%$ \\
\hline & & Laboral-NLPT & 45607 & 9424 & 55031 & $17.12 \%$ \\
\hline 2 & Lima Norte & Laboral-NLPT-EJE & 13502 & 2091 & 15593 & $13.41 \%$ \\
\hline 3 & Cajamarca & Laboral-NLPT & 1684 & 728 & 2412 & $30.18 \%$ \\
\hline 4 & $\begin{array}{l}\text { Puente } \\
\text { Piedra- } \\
\text { Ventanilla }\end{array}$ & Laboral-NLPT & 431 & 690 & 1121 & $61.55 \%$ \\
\hline 5 & Tacna & Laboral-NLPT & 559 & 371 & 930 & $39.89 \%$ \\
\hline 6 & Callao & Laboral-NLPT & 162 & 1719 & 1881 & $91.39 \%$ \\
\hline 7 & Cusco & Laboral-NLPT & 162 & 707 & 869 & $81.36 \%$ \\
\hline 8 & Arequipa & Laboral-NLPT & 221 & 2124 & 2345 & $90.58 \%$ \\
\hline 9 & Junín & Laboral-NLPT & 89 & 489 & 578 & $84.60 \%$ \\
\hline 10 & Lima Sur & Laboral-NLPT & 272 & 1642 & 1914 & $85.9 \%$ \\
\hline 11 & La Libertad & Laboral-NLPT & 249 & 1560 & 1809 & $86.24 \%$ \\
\hline 12 & Lambayeque & Laboral-NLPT & 41 & 765 & 806 & $94.91 \%$ \\
\hline 13 & Lima Este & Laboral-NLPT & 307 & 2362 & 2669 & $88.50 \%$ \\
\hline 14 & Puno & Laboral-NLPT & 9 & 239 & 248 & $96.37 \%$ \\
\hline 15 & Piura & Laboral-NLPT & 5 & 630 & 635 & $99.21 \%$ \\
\hline \multirow{2}{*}{16} & \multirow{2}{*}{ Santa } & Laboral-NLPT & 10 & 326 & 336 & $97.02 \%$ \\
\hline & & Civil-litigación oral & 0 & 17 & 17 & $100 \%$ \\
\hline 17 & Ica & Laboral-NLPT & 7 & 174 & 181 & $96.13 \%$ \\
\hline \multicolumn{3}{|c|}{ Total } & 113720 & 33387 & 147107 & $22.70 \%$ \\
\hline
\end{tabular}

Fecha de actualización: 31 de diciembre de 2020.

Fuente: Gerencia de Informática.

Elaboración: Secretaría Técnica de la Comisión de Trabajo del EJE.

Leyenda: CSJ: Corte Superior de Justicia, NLPT: Nueva Ley Procesal del Trabajo. 
Este beneficio del Expediente Judicial Electrónico ha sido aprovechado por las cortes superiores de justicia. Los porcentajes del uso de la Mesa de Partes Electrónica para la presentación de demandas se observan en la siguiente figura:

Figura n. ${ }^{\circ}$ 31. Porcentaje de uso de la Mesa de Partes Electrónica (MPE) para la presentación de las demandas

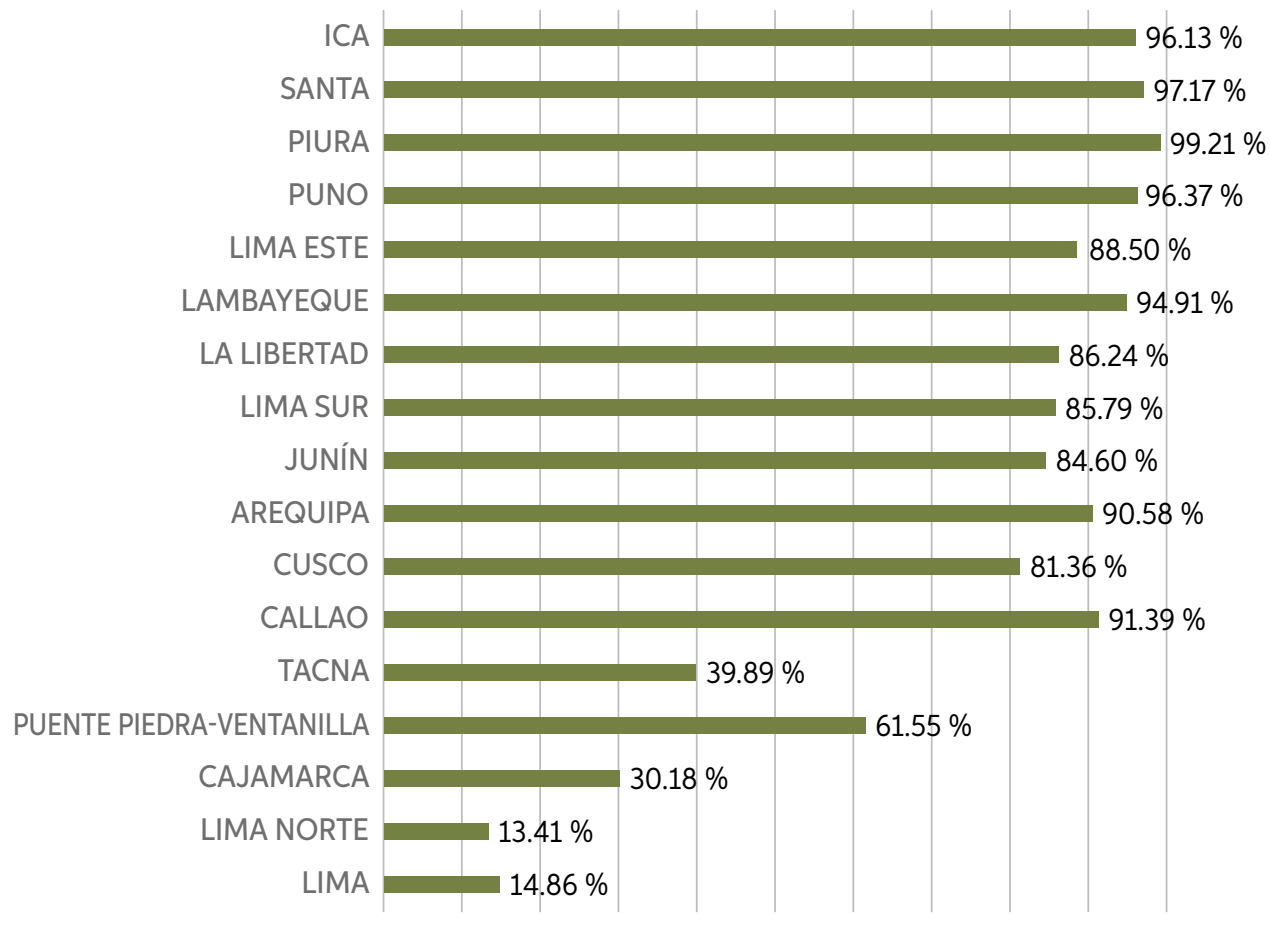

Fecha de actualización: 31 de diciembre de 2020.

Fuente: Gerencia de Informática.

Elaboración: Secretaría Técnica de la Comisión de Trabajo del EJE.

\section{Durante el año 2020}

Considerando la emergencia sanitaria presentada en el país, se observa el impacto en la variación del porcentaje de uso de la Mesa de Partes Electrónica en las cortes superiores de justicia. Esto se observa en la siguiente tabla: 
Respecto a las demandas ingresadas durante el año 2020, se obtiene la información del porcentaje de uso de la Mesa de Partes Electrónica que se muestra en la tabla y la figura siguientes:

Tabla n. ${ }^{\circ}$ 23. Porcentaje de uso de la Mesa de Partes Electrónica (MPE) para la presentación de las demandas en el año 2020

\begin{tabular}{|c|c|c|c|c|c|c|c|c|c|c|c|c|}
\hline $\begin{array}{l}\text { Demandas } \\
\text { ingresadas }\end{array}$ & 壱 & $\dot{0}$ & $\dot{\tilde{\pi}}$ & 荌 & $\stackrel{\vec{\pi}}{\Sigma}$ & $\stackrel{\Xi}{\Xi}$ & $\dot{\Xi}$ & $\dot{8}$ & $\dot{\ddot{n}}$ & $\dot{0}$ & $\dot{\vec{z}}$ & $\dot{\ddot{\theta}}$ \\
\hline $\begin{array}{l}\text { Por la Mesa } \\
\text { de Partes } \\
\text { Física- } \\
\text { CDG }\end{array}$ & 5157 & 2908 & 1595 & 6 & 29 & 93 & 425 & 893 & 825 & 881 & 1439 & 1107 \\
\hline $\begin{array}{l}\text { Por la Mesa } \\
\text { de Partes } \\
\text { Electrónica- } \\
\text { MPE }\end{array}$ & 84 & 55 & 20 & 8 & 111 & 565 & 2175 & 2855 & 2874 & 3341 & 8958 & 11591 \\
\hline Total & 5241 & 2963 & 1615 & 14 & 140 & 658 & 2600 & 3748 & 3699 & 4222 & 10397 & 12698 \\
\hline $\begin{array}{l}\text { Porcentaje } \\
\text { del uso de } \\
\text { la MPE }\end{array}$ & $1.6 \%$ & $1.9 \%$ & $1.2 \%$ & $57.1 \%$ & $79.3 \%$ & $85.9 \%$ & $83.7 \%$ & $76.2 \%$ & $77.7 \%$ & $79.1 \%$ & $86.2 \%$ & $91.3 \%$ \\
\hline
\end{tabular}

Fecha de actualización: 31 de diciembre de 2020.

Fuente: Gerencia de Informática.

Elaboración: Secretaría Técnica de la Comisión de Trabajo del EJE. 
Figura n. ${ }^{\circ} 32$. Porcentaje de uso de la Mesa de Partes Electrónica

(MPE) para la presentación de las demandas durante el año 2020

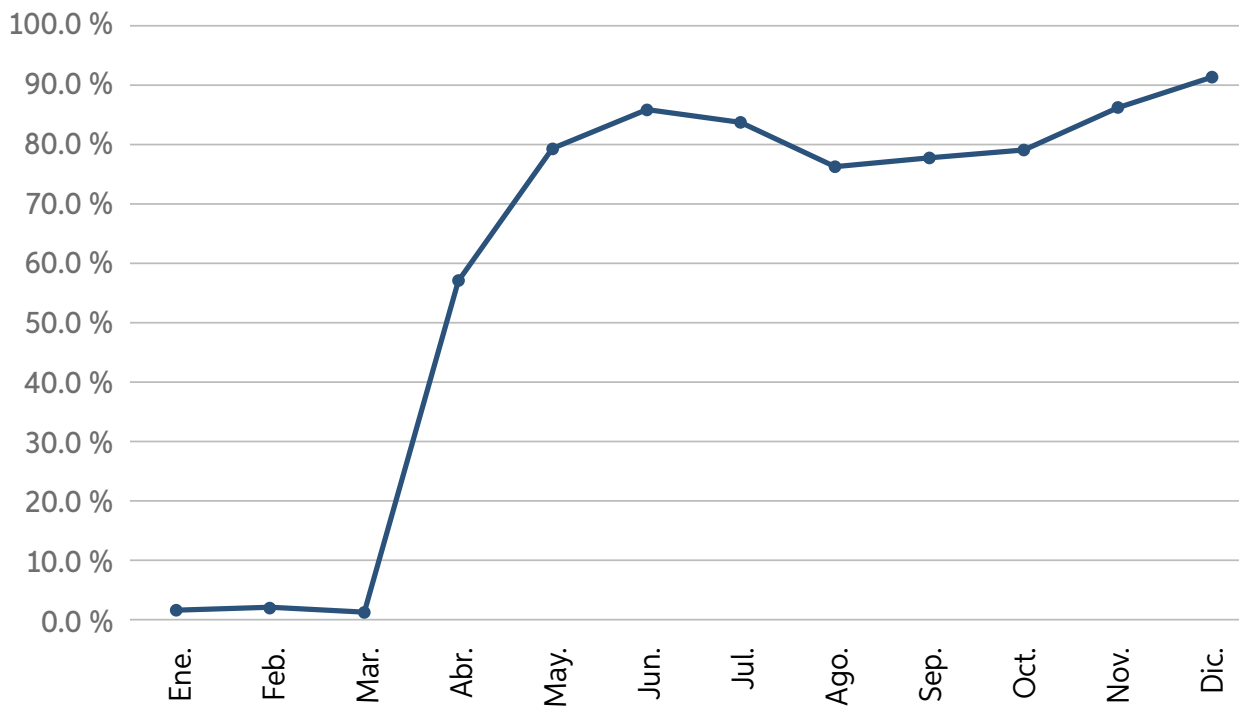

Fecha de actualización: 31 de diciembre de 2020.

Fuente: Gerencia de Informática.

Elaboración: Secretaría Técnica de la Comisión de Trabajo del EJE.

Como se puede observar en la figura anterior, el beneficio de la Mesa de Parte Electrónica fue muy bien utilizado durante la emergencia sanitaria en favor del litigante.

\subsubsection{Uso de la Mesa de Partes Electrónica para la presentación de escritos}

Al 31 de diciembre de 2020 han ingresado 508472 escritos en los Expedientes Judiciales Electrónicos, de los cuales el $34 \%$ ha sido presentado por la Mesa de Partes Electrónica. Esto puede verse en la siguiente tabla detallada por corte superior de justicia y especialidad desde la implementación del componente MPE (año 2018): 


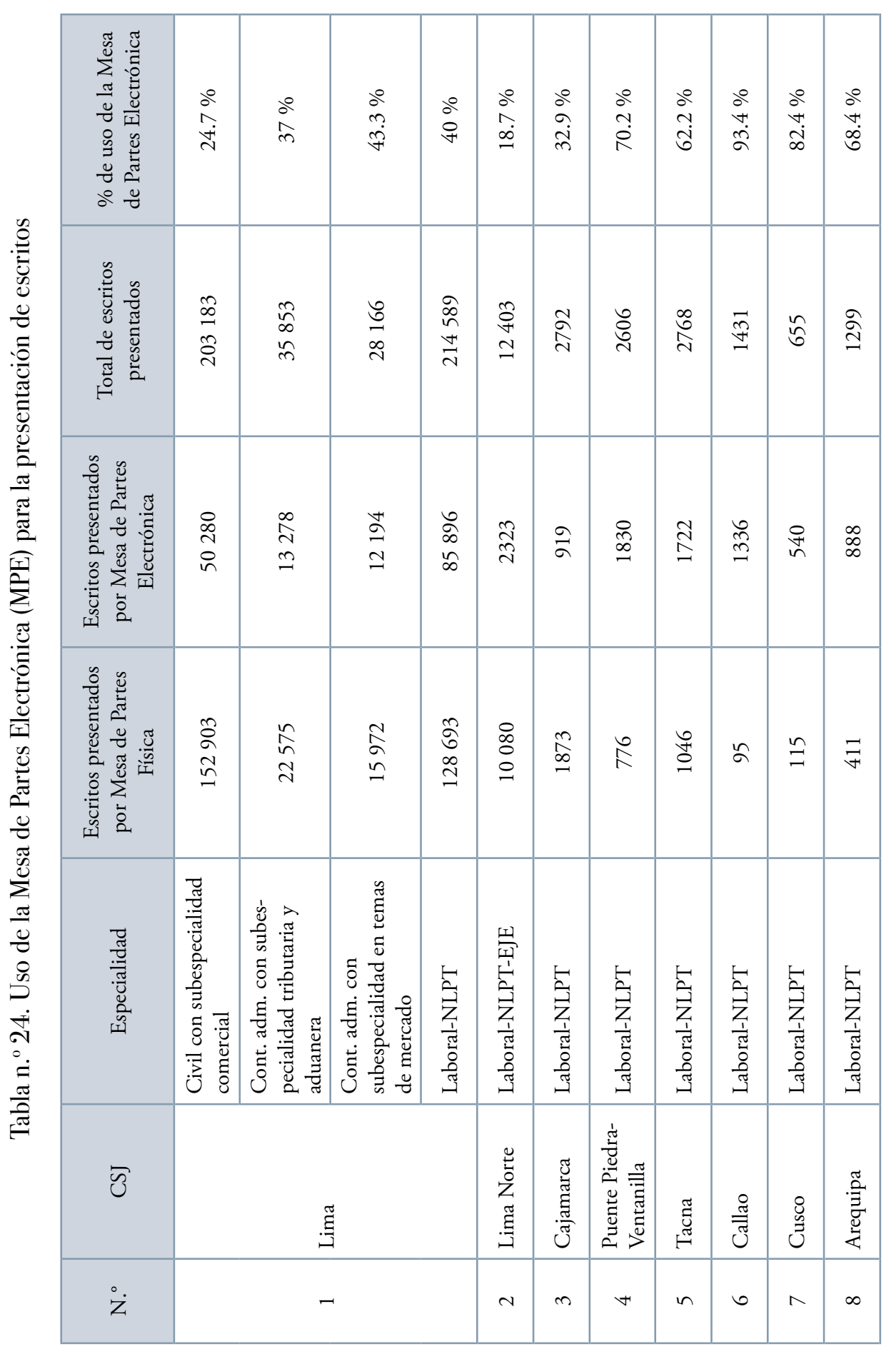




\begin{tabular}{|c|c|c|c|c|c|c|c|c|c|c|}
\hline $\begin{array}{l}\stackrel{\circ}{2} \\
\stackrel{v}{\circ} \\
\stackrel{0}{\circ}\end{array}$ & $\begin{array}{l}\stackrel{0}{ } \\
\infty \\
\infty \\
\infty\end{array}$ & 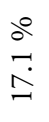 & $\begin{array}{l}\stackrel{0}{ } \\
\text { ஸे } \\
\curvearrowright\end{array}$ & 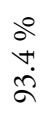 & $\begin{array}{l}\dot{0}^{2} \\
\tilde{n} \\
i n\end{array}$ & 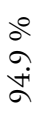 & $\begin{array}{l}\stackrel{0}{ } \\
\text { ஸे } \\
\stackrel{\infty}{0}\end{array}$ & $\begin{array}{l}\text { ஓ } \\
\stackrel{8}{\circ}\end{array}$ & $\begin{array}{l}\stackrel{0}{n} \\
i\end{array}$ & $\begin{array}{l}d^{\circ} \\
\text { mे }\end{array}$ \\
\hline$\frac{n}{\sigma}$ & $\begin{array}{l}\infty \\
\stackrel{\infty}{N}\end{array}$ & $\overrightarrow{\tilde{0}}$ & 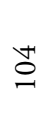 & $\vec{\infty}$ & $\tilde{n}$ & ฉે & $\stackrel{\circ}{\simeq}$ & $N$ & $\checkmark$ & \begin{tabular}{l}
$\stackrel{N}{f}$ \\
\multirow{1}{\infty}{} \\
$\stackrel{0}{\circ}$
\end{tabular} \\
\hline$\stackrel{尺}{\stackrel{f}{f}}$ & $\stackrel{n}{\approx}$ & $\stackrel{゚}{\beth}$ & 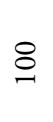 & $\stackrel{0}{n}$ & 우 & హ゙ & $\stackrel{m}{n}$ & $\sim$ & $n$ & $\begin{array}{l}\underset{N}{ } \\
\infty \\
N \\
N\end{array}$ \\
\hline$\stackrel{n}{ \pm}$ & $\tilde{n}$ & $\tilde{\infty}$ & 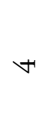 & $\approx$ & $\stackrel{n}{=}$ & n & $\stackrel{\odot}{ }$ & 0 & - & 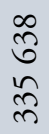 \\
\hline 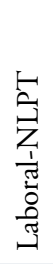 & 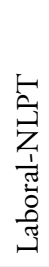 & 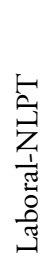 & 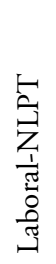 & 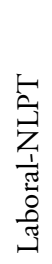 & 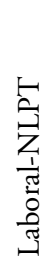 & 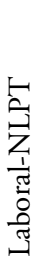 & 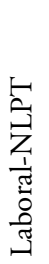 & 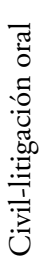 & 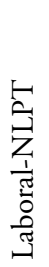 & \\
\hline 哥 & 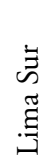 & 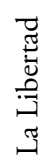 & 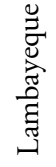 & 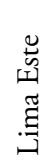 & $\stackrel{\varrho}{\Xi}$ & $\stackrel{\widetilde{G}}{\leftrightarrows}$ & & & $\stackrel{\widetilde{\mathscr{C}}}{ }$ & \\
\hline$a$ & $\stackrel{0}{-}$ & $\Xi$ & $\simeq$ & $\dddot{2}$ & 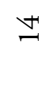 & $\stackrel{\sim}{\sim}$ & & & 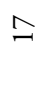 & $\stackrel{\pi}{0}$ \\
\hline
\end{tabular}

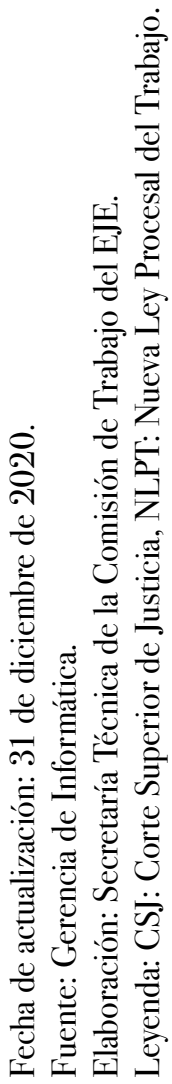

Beneficios y resultados del EJE 113 
Este beneficio del Expediente Judicial Electrónico ha sido aprovechado por las cortes superiores de justicia. Ello se refleja en los porcentajes de uso de la Mesa de Partes Electrónica que se observan en la siguiente figura:

Figura n. ${ }^{\circ}$ 33. Porcentaje de uso de la Mesa de Partes Electrónica (MPE) para la presentación de escritos

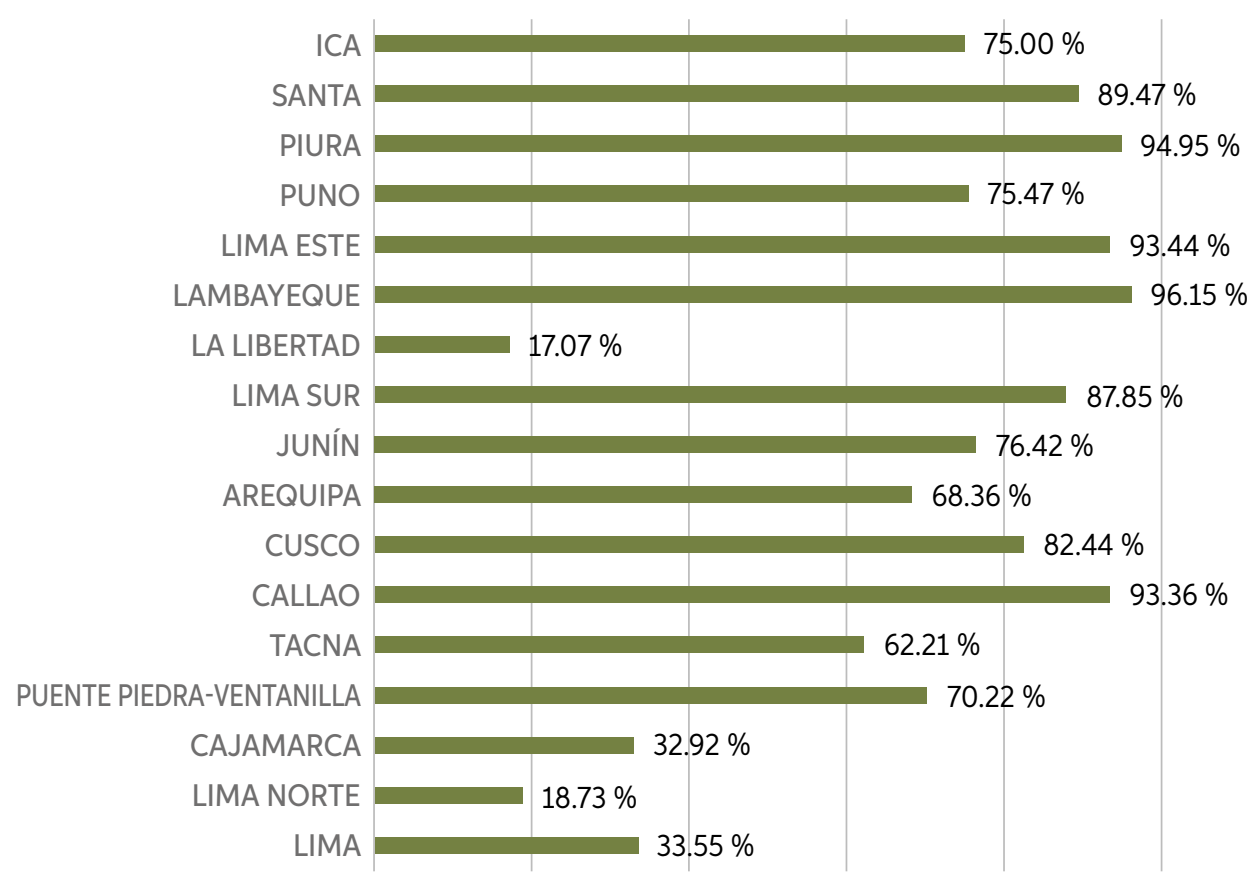

Fecha de actualización: 31 de diciembre de 2020.

Fuente: Gerencia de Informática.

Elaboración: Secretaría Técnica de la Comisión de Trabajo del EJE.

\section{Durante el ańo 2020}

Considerando la emergencia sanitaria presentada en el país, se observa el impacto en la variación del porcentaje de uso de la Mesa de Partes Electrónica en las cortes superiores de justicia para la presentación de escritos. Esto se observa en la siguiente tabla: 


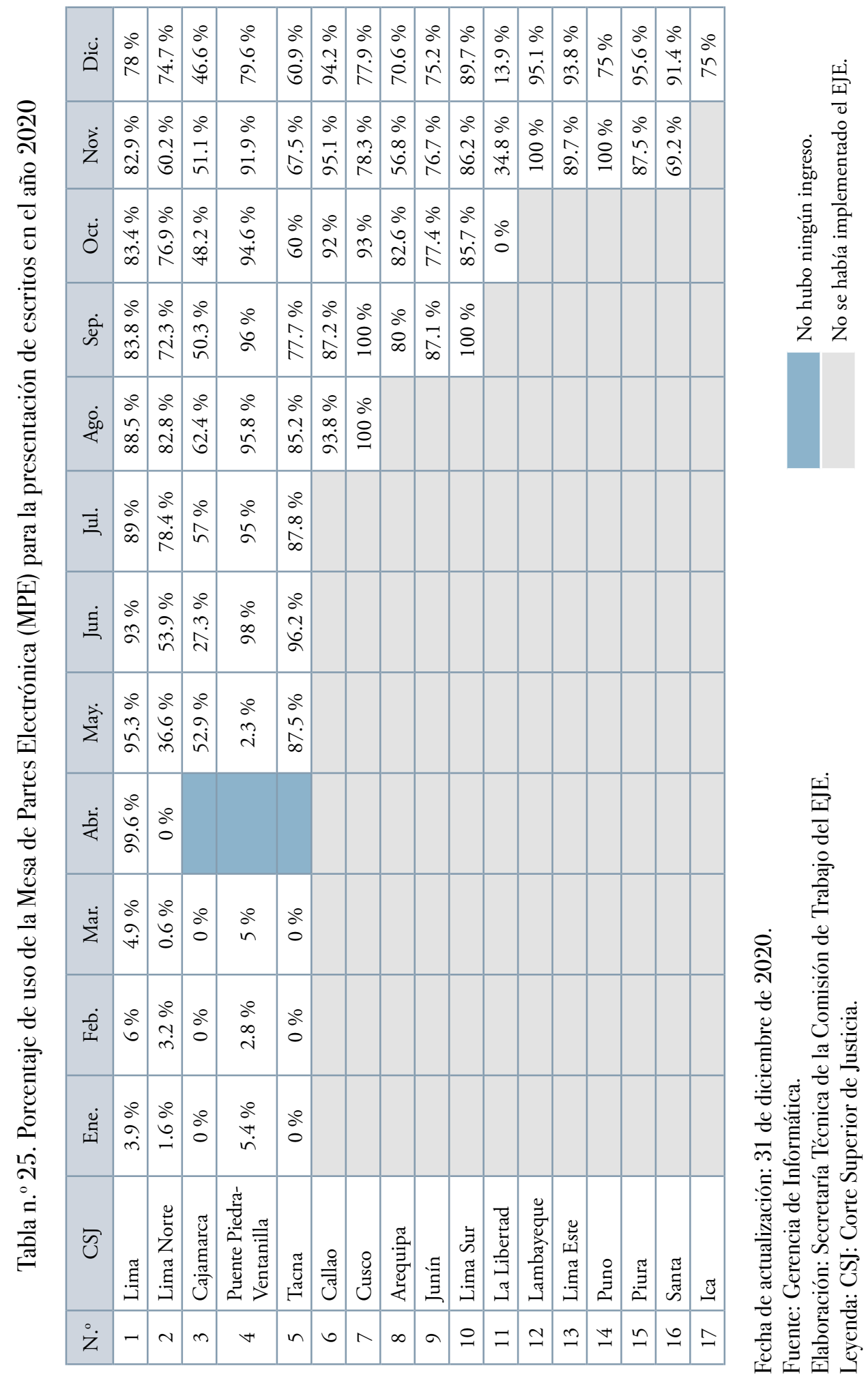


De los escritos ingresados durante el año 2020, se obtiene la información sobre el porcentaje de uso de la Mesa de Partes Electrónica que se muestra en la tabla y la figura siguientes:

Tabla n. ${ }^{\circ}$ 26. Porcentaje de uso de la Mesa de Partes Electrónica (MPE) para la presentación de escritos en el año 2020

\begin{tabular}{|c|c|c|c|c|c|c|c|c|c|c|c|c|}
\hline $\begin{array}{l}\text { Escritos } \\
\text { ingresados }\end{array}$ & घี & $\dot{0}$ & 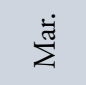 & 荌 & $\sum_{i}^{ \pm}$ & $\stackrel{\Xi}{\Xi}$ & $\dot{\Xi}$ & $\dot{8}$ & ڤें & 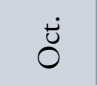 & $\dot{\vec{z}}$ & $\stackrel{\dot{\theta}}{0}$ \\
\hline $\begin{array}{l}\text { Por la Mesa } \\
\text { de Partes } \\
\text { Física-CDG }\end{array}$ & 20251 & 9558 & 7818 & 8 & 684 & 576 & 2767 & 3603 & 5288 & 5375 & 5530 & 7499 \\
\hline $\begin{array}{l}\text { Por la Mesa } \\
\text { de Partes } \\
\text { Electrónica- } \\
\text { MPE }\end{array}$ & 799 & 592 & 392 & 939 & 2046 & 6246 & 21777 & 27056 & 26377 & 25742 & 24454 & 23822 \\
\hline Total & 21050 & 10150 & 8210 & 947 & 2730 & 6822 & 24544 & 30659 & 31665 & 31117 & 29984 & 31321 \\
\hline $\begin{array}{l}\text { Porcentaje } \\
\text { del uso de la } \\
\text { MPE }\end{array}$ & $3.8 \%$ & $5.8 \%$ & $4.8 \%$ & $99.2 \%$ & $74.9 \%$ & $91.6 \%$ & $88.7 \%$ & $88.2 \%$ & $83.3 \%$ & $82.7 \%$ & $81.6 \%$ & $76.1 \%$ \\
\hline
\end{tabular}

Fecha de actualización: 31 de diciembre de 2020.

Fuente: Gerencia de Informática.

Elaboración: Secretaría Técnica de la Comisión de Trabajo del EJE. 
Figura n. ${ }^{\circ}$ 34. Porcentaje de uso de la Mesa de Partes Electrónica

(MPE) para la presentación de escritos durante el año 2020

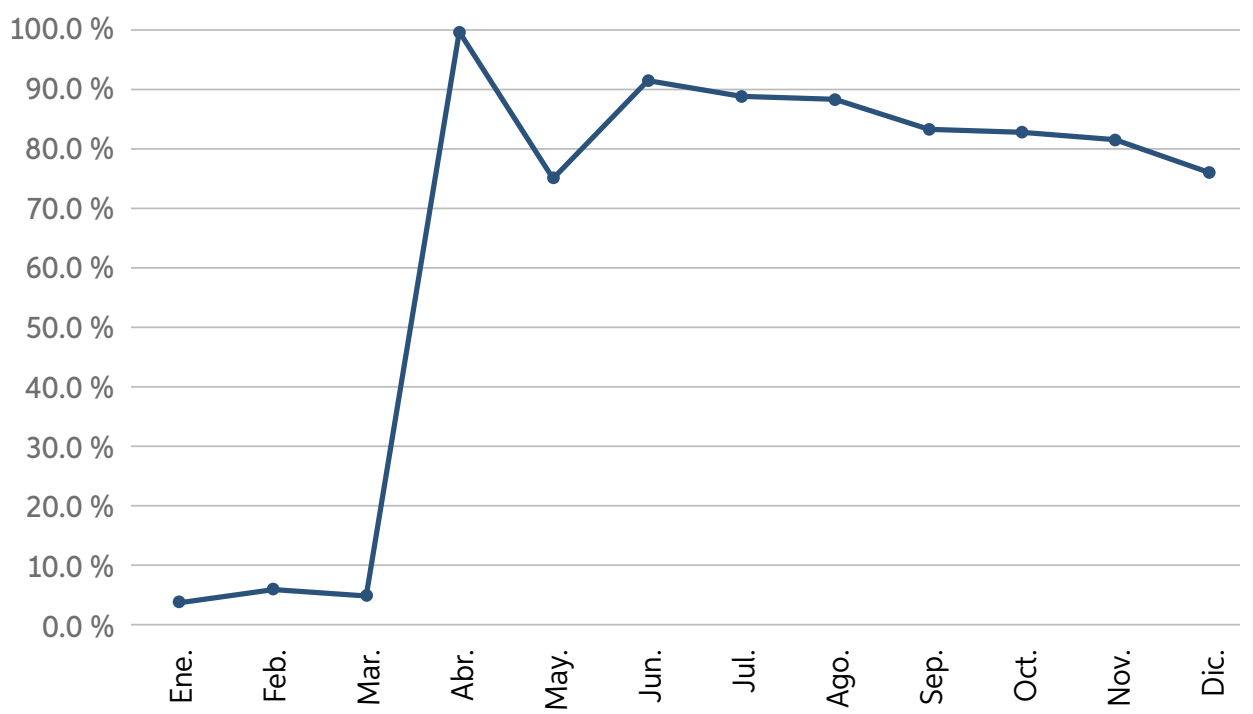

Fecha de actualización: 31 de diciembre de 2020.

Fuente: Gerencia de Informática.

Elaboración: Secretaría Técnica de la Comisión de Trabajo del EJE.

Como se puede observar en la figura anterior, el beneficio de la Mesa de Partes Electrónica para la presentación de escritos fue muy bien utilizado durante la emergencia sanitaria en favor del litigante.

\subsubsection{Uso de la Mesa de Partes Electrónica en el marco de la Resolución Administrativa n. ${ }^{\circ}$ 133-2020-CE-PJ}

La Mesa de Partes Electrónica, componente del Expediente Judicial Electrónico, ha representado una respuesta eficaz para enfrentar la situación de pandemia, amplió sus servicios a todas las especialidades judiciales y estableció una modalidad de acceso para continuar con la gestión de expediente físicos según el siguiente detalle: 
Esquema n. ${ }^{\circ}$ 20. Con la R. A. n. ${ }^{\circ}$ 133-2020-CE-PJ se habilita la MPE para diversas especialidades

Resolución Administrativa n. ${ }^{\circ}$ 133-2020-CE-PJ (7 de mayo de 2020) aprueba para el uso de las diversas especialidades:

"Proyecto de Mesa de Partes Electrónica y digitalización de expedientes físicos» «Protocolo para el uso de la Mesa de Partes Electrónica del Poder Judicial y digitalización o escaneo de expedientes físicos para el periodo de reinicio de actividades»

Si se cuenta con firma electrónica:

Escritos y anexos firmados electrónicamente, originales en poder del presentante hasta el levantamiento del periodo de emergencia.
Si se cuenta con firma electrónica:

Excepcionalmente escritos y anexos firmados electrónicamente, el personal jurisdiccional los imprimirá. Son considerados originales, no requieren confirmación por parte del presentante.

\section{Si no se cuenta con firma} electrónica:

Excepcionalmente los escritos y anexos serán firmados gráficamente y escaneados, estarán sujetos a confirmación por parte del presentante hasta el levantamiento del periodo de emergencia.

Para acceder a la MPE, solo se debe contar con casilla electrónica.

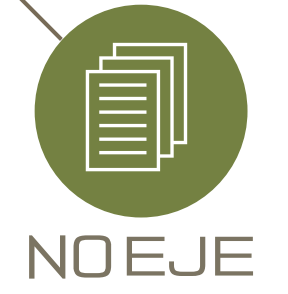

Si no se cuenta con firma electrónica:

Excepcionalmente los escritos y anexos serán firmados gráficamente y escaneados, estarán sujetos a confirmación por parte del presentante hasta el levantamiento del periodo de emergencia.

Elaboración: Secretaría Técnica de la Comisión de Trabajo del EJE.

Al respecto se diseñó un plan de implantación de este canal de acceso a la justicia en el que se establecieron etapas progresivas para brindar este medio de acceso a la justicia. 
Esquema n. ${ }^{\circ}$ 21. Etapas de implementación de la Mesa de Partes

Electrónica a nivel nacional

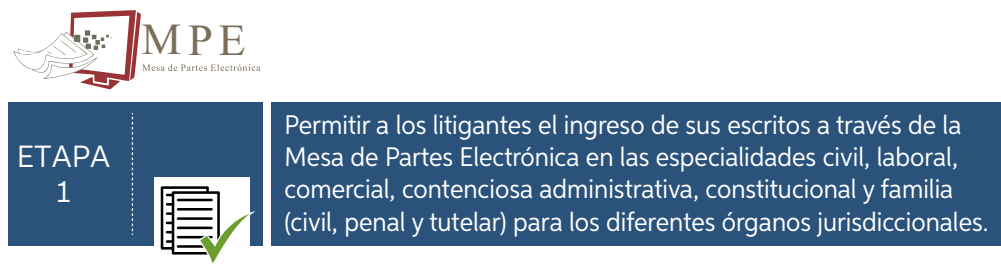

\section{Plazo de ejecución}

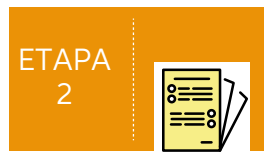

Permitir el ingreso de las demandas a través de la Mesa de Partes Electrónica en las especialidades civil, laboral comercial, contenciosa administrativa, constitucional y familia (civil, penal y tutelar) para los diferentes órganos.

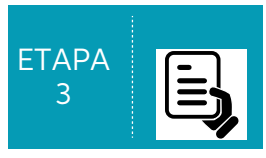

Permitir a los litigantes el ingreso de los escritos a través de la Mesa de Partes Electrónica (MPE) en la especialidad penal (tradicional y NCPP).

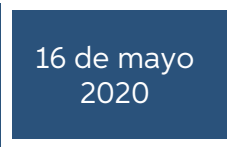

16 de mayo 2020

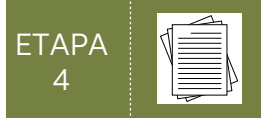

Permitir el ingreso de las denuncias y requerimientos a través de la Mesa de Partes Electrónica en la especialidad penal (tradicional y NCPP).

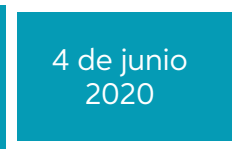

30 de junio 2020

Elaboración: Secretaría Técnica de la Comisión de Trabajo del EJE.

El componente de la Mesa de Partes Electrónica ha recibido un impulso importante con las recientes medidas establecidas en la Resolución Administrativa n. ${ }^{\circ}$ 133-2020-CE-PJ, que amplía la cobertura de este servicio a otras especialidades e incluye los procesos tramitados en expedientes físicos. Esta decisión ha tenido un impacto favorable en los justiciables, pues les permite un mayor y fácil acceso a la justicia.

Este nuevo canal de acceso ha tenido resultados significativos: desde el inicio de la entrada en vigor de la Resolución Administrativa n. ${ }^{\circ} 133-2020-C E-P J$, a partir del 7 de mayo de 2020, se ha registrado el ingreso de documentos de las diversas especialidades en un volumen de 2227 775. Esto pone en evidencia la capacidad de reacción del Poder Judicial para no detener la preservación de los derechos de los ciudadanos y simultáneamente asegurar el derecho a la vida y la salud de los ciudadanos que acceden al servicio de justicia. Cabe precisar que las especialidades que emplearon este medio digital fueron laboral con el $27 \%$, familia civil $23 \%$, civil $19 \%$ y penal $16 \%$. 
Figura n. ${ }^{\circ}$ 35. Uso de la Mesa de Partes Electrónica (MPE) según tipo de ingreso en aplicación de la R. A. n. ${ }^{\circ}$ 133-2020-CE-PJ al 31-12-2020

Volumen de documentos ingresados por la MPE según tipo de ingreso al 31-12-2020

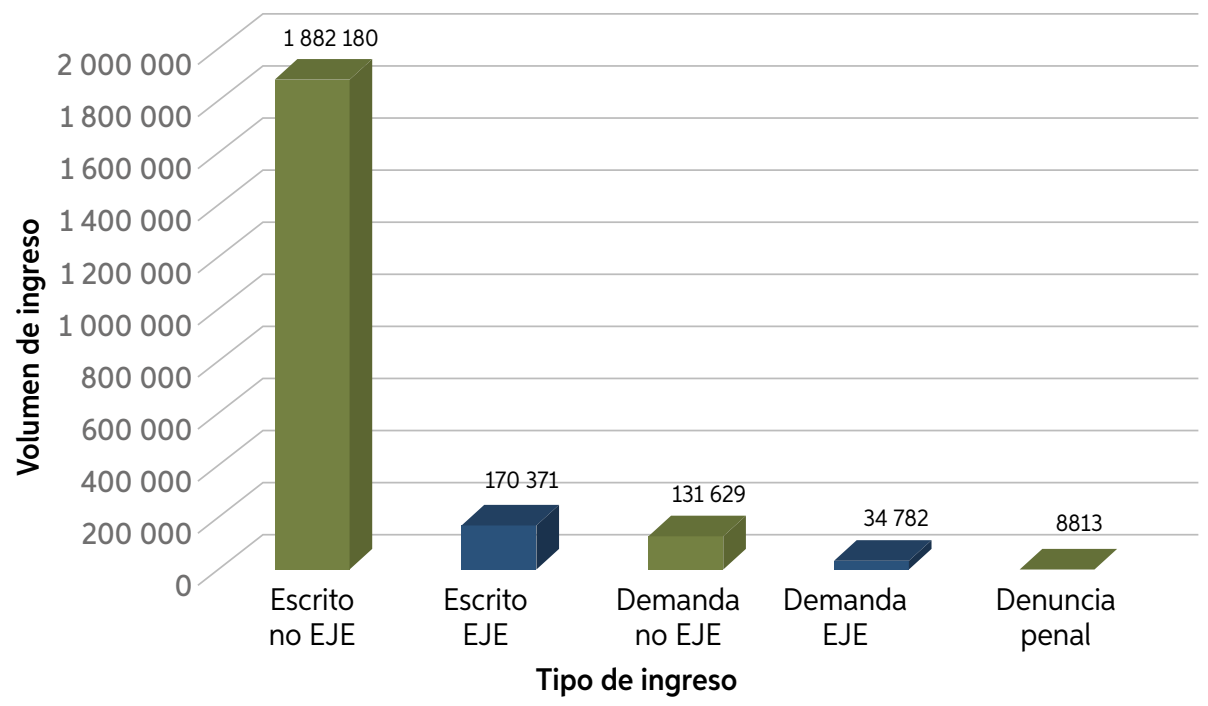

\section{Documentos ingresados a la Mesa de Partes Electrónica por especialidad durante la pandemia al 31-12-2020}

Derecho

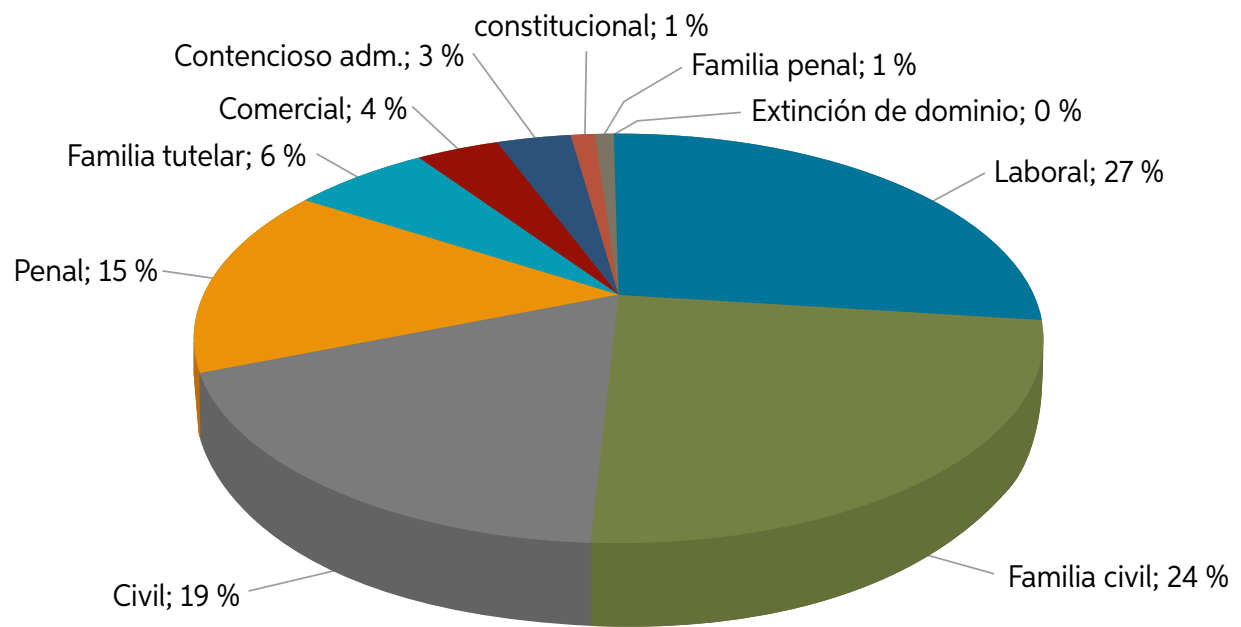

\section{Total de ingresos de documentos a nivel nacional: 2227775}

Fecha de actualización: 31 de diciembre de 2020.

Fuente: Gerencia de Informática.

Elaboración: Secretaría Técnica de la Comisión de Trabajo del EJE. 
Por otro lado, se han generado 339516 citas electrónicas, de tal forma que se atenderán mediante todos los medios las necesidades de los justiciables.

Los distritos judiciales que más la usan son Lima con $38 \%$, Loreto con 10 \%, Lima Este con 10 \%, Lima Norte con 6 \% y Lima Sur con $4 \%$.

Figura n. ${ }^{\circ} 36$. Citas electrónicas por sede judicial generadas al $31-12-2020$

\begin{tabular}{|c|c|}
\hline AMAZONAS & 1273 \\
\hline ÁNCASH & 57 \\
\hline APURÍMAC & 1418 \\
\hline AREQUIPA & 20397 \\
\hline AYACUCHO & 34 \\
\hline CAJAMARCA & 8199 \\
\hline CALLAO & 7920 \\
\hline CAÑETE & - 3589 \\
\hline CUSCO & 6836 \\
\hline DEL SANTA & 1643 \\
\hline HUÁNUCO & 365 \\
\hline HUAURA & - 2780 \\
\hline ICA & 5263 \\
\hline JUNÍN & 5637 \\
\hline LA LIBERTAD & 7513 \\
\hline LAMBAYEQUE & 7563 \\
\hline LIMA & 121257 \\
\hline LIMA ESTE & 31046 \\
\hline LIMA NORTE & 18760 \\
\hline LIMA SUR & 13990 \\
\hline LORETO & 30864 \\
\hline MADRE DE DIOS & 601 \\
\hline MOQUEGUA & - 2415 \\
\hline PASCO & 286 \\
\hline PIURA & 7259 \\
\hline PUNO & 5284 \\
\hline SAN MARTÍN & 5271 \\
\hline SELVA CENTRAL & 335 \\
\hline SULLANA & 1422 \\
\hline TACNA & - 4518 \\
\hline TUMBES & 3307 \\
\hline UCAYALI & 12414 \\
\hline
\end{tabular}

Fecha de actualización: 31 de diciembre de 2020.

Fuente: Gerencia de Informática.

Elaboración: Secretaría Técnica de la Comisión de Trabajo del EJE. 



\section{Capítulo IV}

\section{EVENTOS Y CAPACITACIONES}

\subsection{Congresos internacionales del EJE}

La Comisión de Trabajo del Expediente Judicial Electrónico realizó en el 2019 y el 2020 el I y II Congreso Internacional del EJE, respectivamente. El objetivo de estos congresos fue que se tomara conocimiento de las buenas prácticas y experiencias que se aplican en otros países en el uso de los medios electrónicos en la administración de justicia; asimismo, se buscaba generar un espacio de diálogo y debate entre los operadores de justicia, que permita unificar criterios para impartir justicia, impulsando el cambio de cultura hacia la aplicación de la tecnología como herramienta de apoyo en la labor jurisdiccional y el trámite de los procesos al servicio de los justiciables y la ciudadanía.

Del mismo modo, los eventos permitieron explicar que la transición hacia un expediente judicial electrónico plantea diversos desafíos, que incluyen a los usuarios, quienes tienen que comprender que los expedientes físicos ya no tendrán que ser utilizados en la presentación de una demanda o escrito, lo que permitirá crear sociedades modernas.

Ambos congresos fueron dirigidos a magistrados, personal jurisdiccional y administrativo del Poder Judicial, y a usuarios externos a nivel nacional.

\subsubsection{Congreso Internacional}

El primer congreso, realizado los días 5 y 6 de diciembre de 2019, consideró prioritario optimizar la formación de los actores de la reforma de justicia digital, a fin de fortalecer sus conocimientos, habilidades y destrezas en el marco de la implementación; así como uniformizar criterios respecto a la tramitación virtual del proceso judicial. Contó con la participación de ponentes de Argentina, Chile, Costa Rica y Paraguay. 
En ese sentido, el evento generó espacios de diálogo y debate respecto a la nueva gestión del proceso judicial, en la que se consignan todas las actuaciones procesales a través de medios electrónicos seguros, con la finalidad de adoptar acuerdos para optimizar la prestación del servicio de justicia.

El primer día se desarrollaron los siguientes temas:

- Justicia digital en el Poder Judicial de Paraguay Expositor: Alberto Joaquín Martínez Simón, ministro de la Corte Suprema de Justicia de la República de Paraguay.

- Implementación del Expediente Judicial Electrónico en el Poder Judicial del Perú

Expositor: Héctor Enrique Lama More, juez supremo de la Corte Suprema de Justicia de la República y presidente de la Comisión de Trabajo del EJE.

- Inteligencia artificial y justicia

Expositor: Juan Gustavo Corvalán, director del Laboratorio de Innovación e Inteligencia Artificial de la Facultad de Derecho de la Universidad de Buenos Aires, Argentina.

- Tramitación electrónica de los procesos judiciales en Chile Expositor: Roberto Villalobos Yánez, jefe de proyectos en la Corporación Administrativa del Poder Judicial de Chile.

- Tecnología de Información y Comunicaciones en los procesos judiciales de Costa Rica

Expositora: Vivian Rimola Soto, jefa de Desarrollo de Sistemas del Poder Judicial de Costa Rica.

- Tecnologías emergentes en el sector justicia Expositor: Fidel Ricardo Rey de Castro de Mesa, consultor de sistemas de información. 
- Innovación tecnológica para la mejora del servicio de administración de justicia: el Expediente Judicial Electrónico en el Poder Judicial del Perú

Expositor: Guillermo Pérez Silva, gerente de Informática de la Gerencia General del Poder Judicial del Perú.

En el segundo día, jueces, personal jurisdiccional y administrativo, quienes tramitan procesos con el EJE en las Cortes Superiores de Justicia de Lima, Lima Norte, Cajamarca, Puente Piedra-Ventanilla y Tacna, intercambiaron experiencias y compartieron buenas prácticas con esta herramienta digital. Ellos participaron en un taller en el que hubo ponencias de magistrados que aplican el EJE, seguido de un panel de debate a cargo de invitados internacionales, y el desarrollo de temas propuestos en las mesas de trabajo.

La labor en las mesas de trabajo consistió en identificar las buenas prácticas sobre la base de las experiencias en sus funciones, se mencionaron principalmente las siguientes:

- Búsqueda rápida de datos en el expediente electrónico, pues el formato OCR lo permite.

- Capacitación a abogados para el uso de la MPE.

- Celeridad, transparencia, reducción de plazos procesales en la tramitación de procesos.

- Dentro de la bandeja el juez controla eficientemente cada expediente en el estado correspondiente.

- Disminución del tiempo real en dar respuesta efectiva a las solicitudes planteadas por los litigantes.

- La parte procesal puede acceder al EJE en cualquier momento a la hora de solicitar la lectura del expediente.

- Entregas de sentencias en el plazo máximo fijado por la ley.

- Monitoreo constante de demandas por calificar, escritos y sentencias pendientes de publicación, con el uso del sistema del EJE.

- No hay pérdida de expedientes, ya que todo está digitalizado. 
Los temas de los talleres fueron los siguientes:

- Gestión del despacho judicial con el EJE Expositora: Patricia Lazarte Villanueva, jueza del 19. ${ }^{\circ}$ Juzgado Contencioso Administrativo con Subespecialidad Tributario y Aduanero.

- El EJE como herramienta en la labor jurisdiccional Expositora: Ana Prado Castańeda, jueza de la $1 .{ }^{a}$ Sala Civil con Subespecialidad Comercial.

- Gestión administrativa con el EJE Expositora: Yuliana Contreras Portugal, administradora del Módulo Corporativo Laboral-NLPT.

Tabla n. ${ }^{\circ}$ 27. Participantes del taller de intercambio de experiencias

\begin{tabular}{|c|c|}
\hline Cargos de los participantes & N. ${ }^{\circ}$ de participantes \\
\hline Jueces superiores & 22 \\
\hline Jueces especializados & 41 \\
\hline Jueces de paz letrados & 6 \\
\hline Personal jurisdiccional & 23 \\
\hline Administradores & 11 \\
\hline Jefe de Mesa de Partes & 8 \\
\hline Total & 111 \\
\hline
\end{tabular}

Elaboración: Secretaría Técnica de la Comisión de Trabajo del EJE.

\subsubsection{Congreso Internacional}

Aprobada con Resolución Corrida n. ${ }^{\circ}$ 001011-2020-P-CE-PJ, la segunda edición del congreso se realizó de manera virtual los días 17 y 18 de diciembre de 2020, debido a la coyuntura a causa de la COVID-19. Contó con la participación de ponentes de Argentina, Chile, Brasil y Espańa. 
En este congreso se buscó conocer las buenas prácticas y experiencias aplicadas en otros países en el uso de los medios digitales en la administración de justicia; del mismo modo, se buscó generar el diálogo y el debate entre los operadores de justicia para unificar criterios en la impartición de justicia, apoyados con el uso de las TIC.

Los temas desarrollados fueron los siguientes:

- Experiencias en la justicia digital del Poder Judicial de Espańa Expositor: Antonio Dorado Picón, consejero del Consejo Consultivo de Andalucía (España).

- La tramitación electrónica en el Poder Judicial de Chile Expositor: Sergio Muñoz Gajardo, ministro de la Corte Suprema de Justicia de Chile.

- Inteligencia artificial para transformar la administración de justicia

Expositor: Juan Gustavo Corvalán, director del Laboratorio de Innovación e Inteligencia Artificial de la Facultad de Derecho de la Universidad de Buenos Aires, Argentina.

- Implementación de las TIC en el Sistema Judicial de Brasil Expositor: José Eduardo de Resende Chaves Júnior, presidente de la Unión Iberoamericana de Jueces.

- Avances en la implementación del Expediente Judicial Electrónico en la justicia peruana

Expositor: Héctor Enrique Lama More, juez supremo de la Corte Suprema de Justicia de la República y presidente de la Comisión de Trabajo del EJE.

- Buenas prácticas en la implementación del Expediente Judicial Electrónico y su impacto en la gestión del despacho Expositor: Percy Salas Ferro, juez especializado de la Corte Superior de Justicia de Lima. 
Tabla n. ${ }^{\circ} 28$. Participantes y alcance del congreso

\begin{tabular}{|l|c|}
\hline \multicolumn{1}{|c|}{ Descripción } & Total \\
\hline Participantes & 976 \\
\hline Preinscritos & 4300 \\
\hline $\begin{array}{l}\text { Reproducciones (transmisión por la fan page del canal } \\
\text { Justicia TV) }\end{array}$ & 17400 \\
\hline $\begin{array}{l}\text { Cantidad de compartidos (transmisión por la fan page } \\
\text { del canal Justicia TV) }\end{array}$ & 210 \\
\hline Total & 22886 \\
\hline
\end{tabular}

Elaboración: Secretaría Técnica de la Comisión de Trabajo del EJE.

\subsection{Capacitaciones externas}

Durante el 2019 y el 2020 se realizaron diversas capacitaciones externas a los usuarios o justiciables con el fin de promover una labor eficaz en los órganos jurisdiccionales en cuanto al uso del sistema EJE y sus alcances normativos, así como para potenciar el conocimiento de los beneficios del cambio tecnológico conducentes a la mejora de la imagen institucional del Poder Judicial, que garantice un oportuno acceso a la justicia.

Las capacitaciones estuvieron a cargo de la Secretaría Técnica de la Comisión de Trabajo del Expediente Judicial Electrónico, la Gerencia de Informática y la Gerencia de Servicios Judiciales y Recaudación.

\subsubsection{Actividades de capacitación externa realizadas durante el año 2019}

A continuación, detallamos las actividades de capacitación realizadas en el 2019. 


\subsubsection{Talleres teórico-prácticos}

La Comisión de Trabajo del EJE capacitó a 708 usuarios externos por esta modalidad. Los talleres estuvieron dirigidos al público externo: abogados, procuradores y estudios jurídicos de la especialidad comercial, tributario y de mercado, y laboral-Nueva Ley Procesal del Trabajo. Asimismo, se capacitó a usuarios de las Cortes Superiores de Justicia de Lima Norte, Cajamarca, Ventanilla y Tacna.

Los capacitados pudieron conocer acerca del ingreso de las demandas y escritos mediante la MPE, que les permite convertir la documentación en un expediente judicial electrónico.

Tabla n. ${ }^{\circ}$ 29. Participantes en los talleres teórico-prácticos

\begin{tabular}{|c|c|c|c|c|}
\hline N. & Semestre & CSJ & $\begin{array}{c}\text { N. }{ }^{\circ} \text { de } \\
\text { capacitaciones }\end{array}$ & $\begin{array}{c}\text { N. }{ }^{\circ} \text { de } \\
\text { capacitados }\end{array}$ \\
\hline 1 & $\begin{array}{c}\text { Enero- } \\
\text { junio }\end{array}$ & $\begin{array}{c}\text { Lima, Lima Norte, } \\
\text { Puente Piedra-Ventanilla, } \\
\text { Cajamarca y Tacna }\end{array}$ & 26 & 350 \\
\hline 2 & $\begin{array}{c}\text { Julio- } \\
\text { diciembre }\end{array}$ & $\begin{array}{c}\text { Lima, Lima Norte, } \\
\text { Puente Piedra-Ventanilla, } \\
\text { Cajamarca y Tacna }\end{array}$ & 31 & 708 \\
\hline
\end{tabular}

Elaboración: Secretaría Técnica de la Comisión de Trabajo del EJE.

\subsubsection{Conferencias}

Exposiciones brindadas por especialistas, centradas en la presentación del EJE como herramienta de modernización del Poder Judicial. Se desarrollaron en dos submodalidades:

\section{a) Conferencias para abogados}

Se realizaron cinco (5) conferencias dirigidas a profesionales del derecho de instituciones públicas y privadas, en Lima, Cajamarca y Tacna. Se capacitó en total a 710 personas. 
Tabla n. ${ }^{\circ}$ 30. Abogados participantes en las conferencias

\begin{tabular}{|c|c|c|}
\hline N. $^{\circ}$ & CSJ & N. ${ }^{\circ}$ de participantes \\
\hline 1 & Cajamarca & 127 \\
\hline 2 & Cajamarca & 147 \\
\hline 3 & Tacna & 247 \\
\hline 4 & Lima & 85 \\
\hline 5 & Tacna & 104 \\
\hline & Total & 710 \\
\hline
\end{tabular}

Elaboración: Secretaría Técnica de la Comisión de Trabajo del EJE.

\section{b) Conferencias para estudiantes de Derecho}

La conferencia magistral «Expediente Judicial Electrónico (EJE): tecnología y justicia en beneficio de la ciudadanía» estuvo dirigida a los estudiantes de los últimos ciclos de la carrera profesional de Derecho de las universidades Alas Peruanas (UAP), César Vallejo (UCV), San Martín de Porres (USMP), Inca Garcilaso de la Vega (UIGV), San Ignacio de Loyola (USIL), Lima (ULIMA) y San Marcos (UNMSM).

La capacitación itinerante tuvo como objetivos brindar información sobre la importancia del EJE y promover la utilización de la Mesa de Partes Electrónica (MPE). Estuvo a cargo de la secretaria técnica de la Comisión de Trabajo del EJE, Edith Elena Sicha Juárez; el presidente de la Corte Superior de Justicia de Lima, Miguel Ángel Rivera Gamboa; el presidente de la Corte Superior de Justicia de Lima Norte, Vicente Amador Pinedo Coa; y el gerente de Informática, Guillermo Pérez Silva.

Los temas que se desarrollaron fueron «Experiencias positivas de la implementación del EJE en el despacho judicial», «EJE, innovación tecnológica al servicio de la justicia» $\mathrm{y}$ "Avances de la implementación del Expediente Judicial Electrónico y experiencias en otros países». Fueron capacitados 1020 estudiantes. 
Tabla n. ${ }^{\circ}$ 31. Estudiantes participantes en las conferencias

\begin{tabular}{|c|c|c|}
\hline N. ${ }^{\circ}$ & Universidad & N. ${ }^{\circ}$ de capacitados \\
\hline 1 & UAP & 148 \\
\hline 2 & UNMSM & 135 \\
\hline 3 & USMP & 217 \\
\hline 4 & UIGV & 157 \\
\hline 5 & ULIMA & 91 \\
\hline 6 & USIL & 50 \\
\hline 7 & UCV & 222 \\
\hline & Total & 1020 \\
\hline
\end{tabular}

Elaboración: Secretaría Técnica de la Comisión de Trabajo del EJE.

\subsubsection{Visitas guiadas}

El EJE tuvo la visita de 163 personas, entre público interno y externo, personal de las cortes de Lima y provincias, instituciones públicas y universidades.

Tabla n. ${ }^{\circ} 32$. Participantes en visitas guiadas

\begin{tabular}{|c|c|c|}
\hline N. & Institución & N. ${ }^{\circ}$ de participantes \\
\hline 1 & Corte Superior de Justicia de Moquegua & 5 \\
\hline 2 & Corte Superior de Justicia de Lima Sur & 6 \\
\hline 3 & Corte Superior de Justicia de Puente Piedra-Ventanilla & 5 \\
\hline 4 & Corte Superior de Justicia de Tacna & 7 \\
\hline 5 & Corte Superior de Justicia de Cajamarca & 28 \\
\hline 6 & Universidad Nacional José Faustino Sánchez Carrión (Huacho) & 38 \\
\hline 7 & Universidad Nacional Mayor de San Marcos & 23 \\
\hline 8 & Universidad Nacional Federico Villarreal & 18 \\
\hline 9 & Indecopi & 11 \\
\hline 10 & C. E. Santa María de Magdalena & 163 \\
\hline
\end{tabular}

Elaboración: Secretaría Técnica de la Comisión de Trabajo del EJE. 


\subsubsection{Charlas al público en general}

Se realizaron charlas informativas al público en general sobre el EJE en la Corte Superior de Justicia de Tacna.

Tabla n. ${ }^{\circ} 33$. Número de capacitados en las charlas al público en general

\begin{tabular}{|c|c|c|}
\hline N. ${ }^{\circ}$ & CSJ & N. ${ }^{\circ}$ de capacitados \\
\hline 1 & Tacna & 157 \\
\hline
\end{tabular}

Elaboración: Secretaría Técnica de la Comisión de Trabajo del EJE

\subsubsection{Taller in-bouse}

Se realizó un taller in-house para la empresa ElectroPerú, que fue dirigido a los abogados del área de Asesoría Legal.

Tabla n. ${ }^{\circ} 34$. Número de capacitados en el taller in-house

\begin{tabular}{|c|c|c|}
\hline $\mathrm{N} .{ }^{\circ}$ & Institución & N. ${ }^{\circ}$ de capacitados \\
\hline 1 & ElectroPerú & 10 \\
\hline
\end{tabular}

Elaboración: Secretaría Técnica de la Comisión de Trabajo del EJE.

\subsubsection{Actividades de capacitación externa realizadas durante el año 2020}

A continuación, detallamos las actividades de capacitación realizadas en el 2020:

\subsubsection{Videoconferencias}

Se organizaron dos videoconferencias virtuales para informar, a nivel nacional, sobre el uso de la Mesa de Partes Electrónica.

Las acciones de capacitación en el uso del EJE y la MPE, según lo dispuesto en la R. A. n. ${ }^{\circ}$ 133-2020-CE-P, permitieron capacitar a 2524 usuarios externos o justiciables. 


\section{a) Uso de la Mesa de Partes Electrónica (MPE) en el contexto del estado de emergencia nacional}

La actividad organizada por la Comisión de Trabajo del EJE y la Secretaría Técnica de la Comisión de Trabajo del EJE sirvió para impulsar a los operadores de justicia a nivel nacional a usar las herramientas tecnológicas en la presentación de demandas y escritos al Poder Judicial, mediante la MPE en expedientes EJE (electrónicos) y físicos (no EJE).

La exposiciones estuvieron a cargo del juez supremo Héctor Lama More, presidente de la Comisión de Trabajo del EJE (tema: «El Expediente Judicial Electrónico y el uso de la Mesa de Partes Electrónica en la contribución de la modernización de la justicia peruana en tiempos del COVID-19»); Guillermo Pérez Silva, gerente de Informática (tema: «Presentación de demandas y escritos por la MPE»); y Adler Horna Araujo, gerente de Servicios Judiciales y Recaudación (tema: «Casillas electrónicas: registro y uso de casillas electrónicas, visualización de las notificaciones electrónicas»).

Tabla n. ${ }^{\circ}$ 35. Participantes de la videoconferencia

\begin{tabular}{|c|l|c|}
\hline CSJ & \multicolumn{1}{|c|}{ Nombre del evento } & N. ${ }^{\circ}$ capacitados \\
\hline Nivel nacional & $\begin{array}{l}\text { Uso de la Mesa de Partes Electrónica (MPE) en el } \\
\text { contexto del estado de emergencia nacional }\end{array}$ & 2524 \\
\hline
\end{tabular}

Elaboración: Secretaría Técnica de la Comisión de Trabajo del EJE.

\section{b) Reactivación del Poder Judicial y uso de la Mesa de Partes Electrónica como herramienta preventiva ante la COVID-19}

En la actividad académica organizada por las cortes superiores de justicia de las regiones que presentan más casos por coronavirus y coordinada con la Secretaría Técnica de la Comisión de Trabajo del EJE, se informó respecto a las medidas adoptadas para el reinicio de actividades en los órganos jurisdiccionales y se concientizó sobre el uso continuo de la MPE, que permite rapidez y transparencia en los procesos.

Las exposiciones estuvieron a cargo del juez supremo Héctor Lama More, presidente de la Comisión de Trabajo del EJE (tema: 
«Reactivación de los órganos jurisdiccionales y uso de herramientas implementadas por el Poder Judicial para el regreso a la nueva convivencia, priorizadas en regiones con alto índice de COVID-19»); y Guillermo Pérez Silva, gerente de Informática (tema: «Herramientas tecnológicas implementadas por el Poder Judicial para la nueva convivencia»).

Tabla n. ${ }^{\circ} 36$. Alcance de la videoconferencia

\begin{tabular}{|c|c|c|c|}
\hline CSJ & \multicolumn{1}{|c|}{ Nombre del evento } & $\begin{array}{c}\text { N. de visualizaciones } \\
\text { (Facebook Live) }\end{array}$ & $\begin{array}{c}\text { N. }{ }^{\circ} \text { de reproducciones } \\
\text { (Facebook Live) }\end{array}$ \\
\hline $\begin{array}{c}\text { Nivel } \\
\text { nacional }\end{array}$ & $\begin{array}{l}\text { Videoconferencia: «Reactivación del } \\
\text { Poder Judicial y uso de la Mesa de } \\
\text { Partes Electrónica como herramienta } \\
\text { preventiva ante el COVID-19» }\end{array}$ & 240900 & 44800 \\
\hline
\end{tabular}

Elaboración: Secretaría Técnica de la Comisión de Trabajo del EJE.

\subsubsection{Capacitaciones virtuales}

\section{a) Capacitación antes de la implementación}

Las actividades de capacitación por la ampliación e implementación del EJE en las Cortes Superiores de Justicia del Callao, Cusco, Arequipa, Junín y Lima Sur, aprobada mediante la R. A. n. ${ }^{\circ}$ 000142-2020-CE-PJ, permitieron capacitar a 1209 usuarios externos.

Tabla n. ${ }^{\circ}$ 37. Cantidad de capacitados antes de la implementación según la R. A n. ${ }^{\circ}$ 000142-2020-CE-PJ

\begin{tabular}{|c|c|c|}
\hline Nombre del evento & CSJ & N. ${ }^{\circ}$ de capacitados \\
\hline \multirow{5}{*}{$\begin{array}{l}\text { Capacitación virtual } \\
\text { implementación del Expediente } \\
\text { Judicial Electrónico (EJE): } \\
\text { herramientas tecnológicas del Poder } \\
\text { Judicial }\end{array}$} & Cusco & 135 \\
\hline & Callao & 306 \\
\hline & Arequipa & 310 \\
\hline & Junín & 265 \\
\hline & Lima Sur & 193 \\
\hline \multicolumn{2}{|l|}{ Total } & 1209 \\
\hline
\end{tabular}

Elaboración: Secretaría Técnica de la Comisión de Trabajo del EJE. 
Similar actividad de capacitación fue realizada para la implementación del EJE en las Cortes Superiores de Justicia de La Libertad, Lambayeque, Piura, Puno, Lima Este, Santa e Ica, aprobada a través de

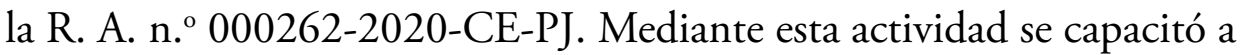
1330 usuarios externos.

Tabla n. ${ }^{\circ}$ 38. Cantidad de capacitados antes de la implementación según la R. A. n. ${ }^{\circ}$ 000262-2020-CE-PJ

\begin{tabular}{|l|c|c|}
\hline \multicolumn{1}{|c|}{ Nombre del evento } & CSJ & N. ${ }^{\circ}$ de capacitados \\
\hline \multirow{3}{*}{$\begin{array}{l}\text { Capacitación virtual } \\
\text { implementación del Expediente }\end{array}$} & La Libertad & 153 \\
\cline { 2 - 3 } $\begin{array}{l}\text { Judicial Electrónico (EJE): } \\
\text { herramientas tecnológicas del } \\
\text { Poder Judicial }\end{array}$ & Lambayeque & 228 \\
\cline { 2 - 3 } & Lima Este & 382 \\
\cline { 2 - 3 } & Puno & 111 \\
\cline { 2 - 3 } & Piura & 143 \\
\cline { 2 - 3 } & Santa & 177 \\
\hline Total & Ica & 136 \\
\hline
\end{tabular}

Elaboración: Secretaría Técnica de la Comisión de Trabajo del EJE.

\section{b) Capacitación de reforzamiento}

De acuerdo con el Plan de Actividades de la Comisión de Trabajo del EJE, aprobado con la R. A. n. ${ }^{\circ}$ 000152-2020-CE-PJ, se realizaron capacitaciones de reforzamiento para los usuarios externos de los distritos judiciales que cuentan con el EJE (Lima, Lima Norte, Cajamarca, Puente Piedra-Ventanilla y Tacna). De esta manera, fueron capacitadas 747 personas. Las capacitaciones fueron realizadas mediante Google Hangouts Meet. 
Tabla n. ${ }^{\circ}$ 39. Cantidad de capacitados según la R. A.

n. ${ }^{\circ}$ 000152-2020-CE-PJ

\begin{tabular}{|c|c|c|}
\hline Nombre del evento & CSJ & N. ${ }^{\circ}$ de capacitados \\
\hline \multirow{5}{*}{$\begin{array}{l}\text { Capacitación virtual: } \\
\text { "Uso de la Mesa de } \\
\text { Partes Electrónica y otras } \\
\text { herramientas tecnológicas } \\
\text { como medida preventiva } \\
\text { ante el COVID-19» }\end{array}$} & Lima & 376 \\
\hline & Lima Norte & 156 \\
\hline & $\begin{array}{l}\text { Puente Piedra- } \\
\text { Ventanilla }\end{array}$ & 153 \\
\hline & Tacna & 30 \\
\hline & Cajamarca & 32 \\
\hline \multicolumn{2}{|c|}{ Total } & 747 \\
\hline
\end{tabular}

Elaboración: Secretaría Técnica de la Comisión de Trabajo del EJE.

\section{c) Capacitación a usuarios del Distrito Judicial de Huánuco}

La Corte Superior de Justicia de Huánuco, en coordinación con la Secretaría Técnica, realizó una inducción virtual a 84 abogados externos del mencionado distrito judicial. La capacitación fue realizada según lo dispuesto en la R. A. n. ${ }^{\circ}$ 133-2020-CE-PJ.

Tabla n. ${ }^{\circ}$ 40. Cantidad de capacitados según la R. A.

n. ${ }^{\circ}$ 000133-2020-CE-PJ

\begin{tabular}{|l|c|c|}
\hline \multicolumn{1}{|c|}{ Nombre del evento } & CSJ & N. ${ }^{\circ}$ capacitados \\
\hline $\begin{array}{l}\text { Capacitación virtual: } \\
\text { «Mesa de Partes Electrónica (MPE) y otras } \\
\text { herramientas tecnológicas del Poder Judicial» }\end{array}$ & Huánuco & 84 \\
\hline
\end{tabular}

Elaboración: Secretaría Técnica de la Comisión de Trabajo del EJE.

\subsubsection{II Congreso Internacional}

El 2020 se realizó el II Congreso Internacional del Expediente Judicial Electrónico, evento que se desarrolló de manera virtual, como se señaló en el punto 4.1.2., y participaron 976 personas. 
Tabla n. ${ }^{\circ}$ 41. Número de participantes en el II Congreso Internacional

\begin{tabular}{|c|c|c|}
\hline N. ${ }^{\circ}$ & Descripción & N. ${ }^{\circ}$ participantes \\
\hline 1 & II Congreso Internacional & 976 \\
\hline
\end{tabular}

Elaboración: Secretaría Técnica de la Comisión de Trabajo del EJE.

En la siguiente tabla se muestra el total de capacitados externos en los años 2019 y 2020 :

Tabla n. ${ }^{\circ} 42$. Cantidad de capacitados externos durante el 2019 y el 2020

\begin{tabular}{|c|c|c|}
\hline Año & N. ${ }^{\circ}$ capacitados & Variación \\
\hline 2019 & 2768 & \\
\hline 2020 & 6870 & $148 \%$ \\
\hline Total de capacitados & 9638 & \\
\hline
\end{tabular}

Elaboración: Secretaría Técnica de la Comisión de Trabajo del EJE.

De la información mostrada se observa que la cantidad de capacitados externos, respecto al ańo anterior, se incrementó en $148 \%$ durante el 2020.

Figura n. ${ }^{\circ} 37$. Cantidad de capacitados externos durante el 2019 y el 2020

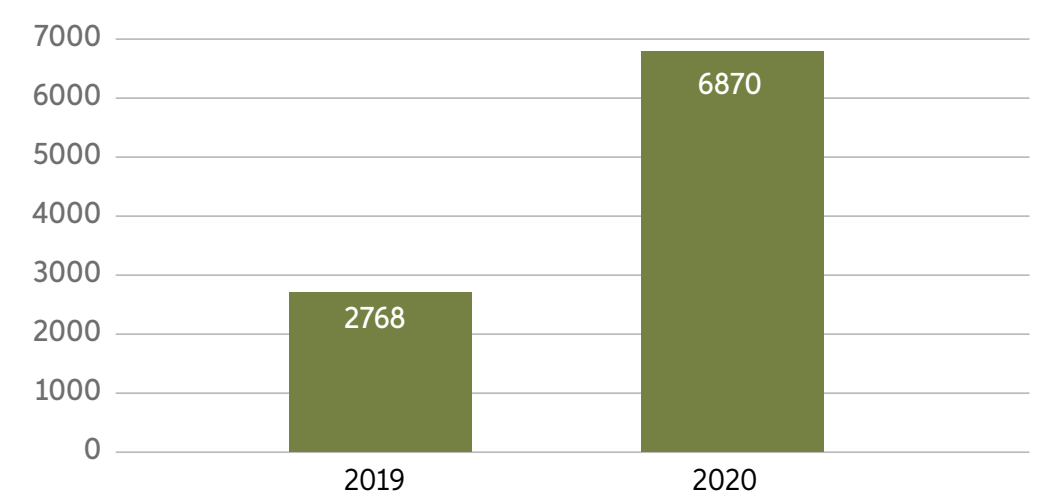

Fecha de actualización: 31 de diciembre de 2020.

Elaboración: Secretaría Técnica de la Comisión de Trabajo del EJE. 


\subsection{Capacitaciones internas}

En el 2019 y el 2020 se realizaron diversas capacitaciones internas dirigidas al personal jurisdiccional y administrativo que aplica el Expediente Judicial Electrónico, a fin de promover una labor eficaz en los despachos judiciales, potenciando el conocimiento de los beneficios del cambio tecnológico como mecanismo de modernización de la justicia peruana.

Las capacitaciones estuvieron a cargo de la Secretaría Técnica de la Comisión de Trabajo del EJE, la Gerencia de Servicios Judiciales y Recaudación y la Gerencia de Informática.

\subsubsection{Actividades de capacitación interna realizadas durante el año 2019}

A continuación, detallamos las actividades de capacitación interna realizadas en el 2019.

\subsubsection{Participación del EJE en charlas de inducción}

En coordinación con la Subgerencia de Capacitación de la Gerencia General del Poder Judicial y el Área de Capacitación de la Corte Suprema de Justicia, se dieron charlas de inducción a los nuevos colaboradores, con la finalidad de acercarlos al EJE. En total, se capacitó a 221 personas.

Tabla n. ${ }^{\circ}$ 43. Cantidad de capacitados en charlas de inducción

\begin{tabular}{|c|c|c|c|}
\hline N. ${ }^{\circ}$ & Lugar & Mes & N. ${ }^{\circ}$ de capacitados \\
\hline 1 & Gerencia General & Junio & 48 \\
\hline 2 & Corte Suprema & Julio & 29 \\
\hline 3 & Corte Suprema & Agosto & 28 \\
\hline 4 & Corte Suprema & Septiembre & 23 \\
\hline 5 & Corte Suprema & Octubre & 31 \\
\hline 6 & Corte Suprema & Noviembre & 38 \\
\hline 7 & Corte Suprema & Diciembre & 24 \\
\hline & Total & & 221 \\
\hline
\end{tabular}

Elaboración: Secretaría Técnica de la Comisión de Trabajo del EJE. 


\subsubsection{Charla a personal del Poder Judicial}

La Secretaría Técnica de la Comisión de Trabajo del EJE capacitó a 60 personas que laboran en la Oficina Desconcentrada de Control de la Magistratura (Odecma).

Tabla n. ${ }^{\circ} 44$. Número de capacitados en charla a personal de la Odecma

\begin{tabular}{|c|c|c|}
\hline N. $^{\circ}$ & CSJ & N. ${ }^{\circ}$ de capacitados \\
\hline 1 & Lima (Odecma) & 60 \\
\hline
\end{tabular}

Elaboración: Secretaría Técnica de la Comisión de Trabajo del EJE.

\subsubsection{I Congreso Internacional}

El 2019 se realizó el I Congreso Internacional del Expediente Judicial Electrónico, como se detalló en el punto 4.1.1. Participaron 111 personas entre personal administrativo y jurisdiccional de las sedes en las cuales está implementado el EJE.

Tabla n. ${ }^{\circ}$ 45. Número de capacitados en el I Congreso Internacional

\begin{tabular}{|c|c|c|}
\hline N. $^{\circ}$ & Lugar & N. ${ }^{\circ}$ de capacitados \\
\hline 1 & Hotel Meliá & 111 \\
\hline
\end{tabular}

Elaboración: Secretaría Técnica de la Comisión de Trabajo del EJE.

\subsubsection{Actividades de capacitación interna realizadas durante el año 2020}

A continuación, detallamos las actividades de capacitación interna realizadas en el 2020.

\subsubsection{Capacitaciones de reforzamiento}

Estas capacitaciones se realizaron con base en la Resolución Administrativa n. ${ }^{\circ}$ 00060-2020-P-CE-PJ, del 20 de abril de 2020, mediante la cual el Consejo Ejecutivo del Poder Judicial aprobó el proyecto denominado «Plan de Capacitación y Difusión en Forma Virtual, 
dirigido a los Operadores de Justicia que vienen aplicando el Expediente Judicial Electrónico (EJE)».

La Comisión de Trabajo del EJE capacitó a 955 operadores de justicia de las Cortes Superiores de Justicia de Lima, Lima Norte, Puente Piedra-Ventanilla, Cajamarca y Tacna, como se detalla en la siguiente tabla:

Tabla n. ${ }^{\circ}$ 46. Cantidad de capacitados según la R. A.

n. ${ }^{\circ}$ 00060-2020-P-CE-PJ

\begin{tabular}{|c|l|c|c|c|}
\hline N. $^{\circ}$ & \multicolumn{1}{|c|}{ Nombre del evento } & CSJ & Especialidad & N. ${ }^{\circ}$ de capacitados \\
\hline 1 & $\begin{array}{l}\text { Curso virtual del Expediente } \\
\text { Judicial Electrónico (EJE) }\end{array}$ & Lima & Laboral-NLPT & 379 \\
\hline 2 & $\begin{array}{l}\text { Curso virtual del Expediente } \\
\text { Judicial Electrónico (EJE) }\end{array}$ & Lima & Comercial & 191 \\
\hline 3 & $\begin{array}{l}\text { Curso virtual del Expediente } \\
\text { Judicial Electrónico (EJE) }\end{array}$ & Lima & $\begin{array}{c}\text { Tributario y de } \\
\text { mercado }\end{array}$ & 149 \\
\hline 4 & $\begin{array}{l}\text { Curso virtual del Expediente } \\
\text { Judicial Electrónico (EJE) }\end{array}$ & $\begin{array}{c}\text { Puente Piedra- } \\
\text { Ventanilla }\end{array}$ & Laboral-NLPT & 75 \\
\hline 5 & $\begin{array}{l}\text { Curso virtual del Expediente } \\
\text { Judicial Electrónico (EJE) }\end{array}$ & Cajamarca & Laboral-NLPT & 50 \\
\hline 6 & $\begin{array}{l}\text { Curso virtual del Expediente } \\
\text { Judicial Electrónico (EJE) }\end{array}$ & Lima Norte & Laboral-NLPT & 76 \\
\hline 7 & $\begin{array}{l}\text { Curso virtual del Expediente } \\
\text { Judicial Electrónico (EJE) }\end{array}$ & Tacna & Laboral-NLPT & 35 \\
\hline \multicolumn{2}{|l|}{ Total } & 955 \\
\hline
\end{tabular}

Elaboración: Secretaría Técnica de la Comisión de Trabajo del EJE.

\subsubsection{Capacitaciones antes de la implementación}

\section{a) Capacitación virtual en cinco nuevas cortes}

Esta capacitación se realizó con base en la Resolución Administrativa n. ${ }^{\circ}$ 000142-2020-CE-PJ, del 11 de mayo de 2020, mediante la cual el Consejo Ejecutivo del Poder Judicial aprobó la ampliación del proyecto Expediente Judicial Electrónico-EJE Piloto en el área laboral en las Cortes Superiores de Justicia de Arequipa, Cusco, Callao, Junín y Lima Sur. 
La Comisión de Trabajo del EJE capacitó a 352 operadores de justicia en la especialidad laboral-NLPT en las referidas cortes, como se precisa a continuación:

Tabla n. ${ }^{\circ}$ 47. Cantidad de capacitados antes de la implementación según la R. A. n. ${ }^{\circ} 000142-2020-$ CE-PJ

\begin{tabular}{|c|l|c|c|c|}
\hline N. & \multicolumn{1}{|c|}{ Nombre de la actividad } & CSJ & Especialidad & N. ${ }^{\circ}$ de capacitados \\
\hline 1 & $\begin{array}{l}\text { Curso virtual del Expediente } \\
\text { Judicial Electrónico (EJE) }\end{array}$ & Cusco & Laboral-NLPT & 44 \\
\hline 2 & $\begin{array}{l}\text { Curso virtual del Expediente } \\
\text { Judicial Electrónico (EJE) }\end{array}$ & Callao & Laboral-NLPT & 65 \\
\hline 3 & $\begin{array}{l}\text { Curso virtual del Expediente } \\
\text { Judicial Electrónico (EJE) }\end{array}$ & Arequipa & Laboral-NLPT & 91 \\
\hline 4 & $\begin{array}{l}\text { Curso virtual del Expediente } \\
\text { Judicial Electrónico (EJE) }\end{array}$ & Junín & Laboral-NLPT & 60 \\
\hline 5 & $\begin{array}{l}\text { Curso virtual del Expediente } \\
\text { Judicial Electrónico (EJE) }\end{array}$ & Lima Sur & Laboral-NLPT & 92 \\
\hline \multicolumn{2}{|l}{ Total } & & 352 \\
\hline
\end{tabular}

Elaboración: Secretaría Técnica de la Comisión de Trabajo del EJE.

\section{b) Capacitación virtual en siete nuevas cortes}

Realizada con base en la Resolución Administrativa n. ${ }^{\circ}$ 000262-2020CE-PJ, del 18 de septiembre de 2020, mediante la cual el Consejo Ejecutivo del Poder Judicial aprobó la ampliación de la implantación del Expediente Judicial Electrónico-EJE Piloto en la especialidad laboral-Nueva Ley Procesal del Trabajo en las Cortes Superiores de Justicia de La Libertad, Puno, Lambayeque, Lima Este, Piura, Santa e Ica.

Fueron capacitados 535 operadores de justicia en la especialidad laboral-NLPT. 
Tabla n. ${ }^{\circ}$ 48. Cantidad de capacitados antes de la implementación según la R. A. n. ${ }^{\circ}$ 000262-2020-CE-PJ

\begin{tabular}{|c|l|c|c|c|}
\hline N. & \multicolumn{1}{|c|}{ Nombre de la actividad } & CSJ & Especialidad & N. ${ }^{\circ}$ de capacitados \\
\hline 1 & $\begin{array}{l}\text { Curso virtual del Expediente } \\
\text { Judicial Electrónico (EJE) }\end{array}$ & La Libertad & Laboral-NLPT & 121 \\
\hline 2 & $\begin{array}{l}\text { Curso virtual del Expediente } \\
\text { Judicial Electrónico (EJE) }\end{array}$ & Lambayeque & Laboral-NLPT & 70 \\
\hline 3 & $\begin{array}{l}\text { Curso virtual del Expediente } \\
\text { Judicial Electrónico (EJE) }\end{array}$ & Lima Este & Laboral-NLPT & 83 \\
\hline 4 & $\begin{array}{l}\text { Curso virtual del Expediente } \\
\text { Judicial Electrónico (EJE) }\end{array}$ & Puno & Laboral-NLPT & 61 \\
\hline 5 & $\begin{array}{l}\text { Curso virtual del Expediente } \\
\text { Judicial Electrónico (EJE) }\end{array}$ & Piura & Laboral-NLPT & 57 \\
\hline 6 & $\begin{array}{l}\text { Curso virtual del Expediente } \\
\text { Judicial Electrónico (EJE) }\end{array}$ & Santa & Laboral-NLPT & 95 \\
\hline 7 & $\begin{array}{l}\text { Curso virtual del Expediente } \\
\text { Judicial Electrónico (EJE) }\end{array}$ & Ica & Laboral-NLPT & 48 \\
\hline \multicolumn{1}{|c|}{ Total } & & 535 \\
\hline
\end{tabular}

Elaboración: Secretaría Técnica de la Comisión de Trabajo del EJE.

\section{c) Capacitación virtual en la especialidad civil-litigación oral}

Esta capacitación se realizó con base en la Resolución Administrativa n. ${ }^{\circ}$ 000379-2020-CE-PJ, del 24 de diciembre de 2020, mediante la cual el Consejo Ejecutivo del Poder Judicial aprobó la implementación del Expediente Judicial Electrónico (EJE) y la Mesa de Partes Electrónica (MPE) en los órganos jurisdiccionales pertenecientes al Módulo Civil Corporativo de Litigación Oral y las salas civiles de la Corte Superior de Justicia del Santa.

La Comisión de Trabajo del EJE capacitó a 70 operadores de justicia en el sistema EJE en la referida corte, como se precisa a continuación: 
Tabla n. ${ }^{\circ}$ 49. Cantidad de capacitados antes de la implementación según la R. A. n. ${ }^{0}$ 000379-2020-CE-PJ

\begin{tabular}{|l|c|c|c|}
\hline \multicolumn{1}{|c|}{ Nombre del evento } & CSJ & Especialidad & N. ${ }^{\circ}$ capacitados \\
\hline $\begin{array}{l}\text { Curso virtual del Expediente Judicial } \\
\text { Electrónico (EJE) }\end{array}$ & Santa & Oralidad civil & 70 \\
\hline
\end{tabular}

Elaboración: Secretaría Técnica de la Comisión de Trabajo del EJE.

\section{d) Capacitación virtual en la especialidad penal-NCPP}

Esta capacitación se realizó con base en la Resolución Administrativa n. ${ }^{\circ}$ 000138-2020-P-CE-PJ, del 28 de diciembre de 2020, mediante la cual el Consejo Ejecutivo del Poder Judicial aprobó la implementación del Expediente Judicial Electrónico (EJE) y la Mesa de Partes Electrónica-MPE (etapa intermedia) en la Corte Superior Nacional de Justicia Penal Especializada.

La Comisión de Trabajo del EJE capacitó a 94 operadores de justicia de la referida corte, como se detalla en la siguiente tabla:

Tabla n. ${ }^{\circ}$ 50. Cantidad de capacitados antes de la implementación según la R. A. n. ${ }^{\circ}$ 000138-2020-CE-PJ

\begin{tabular}{|l|l|l|c|}
\hline \multicolumn{1}{|c|}{ Nombre del evento } & \multicolumn{1}{|c|}{ CSJ } & Especialidad & N. ${ }^{\circ}$ capacitados \\
\hline $\begin{array}{l}\text { Curso del EJE } \\
\text { (implementación) }\end{array}$ & $\begin{array}{l}\text { Corte Superior Nacional de } \\
\text { Justicia Penal Especializada }\end{array}$ & $\begin{array}{l}\text { Penal-etapa } \\
\text { intermedia }\end{array}$ & 94 \\
\hline
\end{tabular}

Elaboración: Secretaría Técnica de la Comisión de Trabajo del EJE.

\subsubsection{Personal del Poder Judicial fue capacitado en el uso de la Mesa de Partes Electrónica}

Del 6 al 10 de julio de 2020, el personal del área de Informática y responsables de Imagen Institucional de todas las cortes superiores de justicia del Poder Judicial fue capacitado en el uso de la Mesa de Partes Electrónica (MPE), en el marco de la R. A. n. ${ }^{\circ}$ 133-2020-CE-PJ, que aprobó el Proyecto de Mesa de Partes Electrónicas y digitalización de expedientes físicos en todas las especialidades. 
La capacitación fue coorganizada por la Secretaría Técnica de la Comisión de Trabajo del EJE y la Gerencia de Informática.

Tabla n. ${ }^{\circ}$ 51. Cantidad de capacitados en el uso de la Mesa de Partes Electrónica

\begin{tabular}{|l|l|l|c|}
\hline \multicolumn{1}{|c|}{ Nombre del evento } & \multicolumn{1}{|c|}{ CSJ } & \multicolumn{1}{c|}{ Especialidad } & N. ${ }^{\circ}$ capacitados \\
\hline $\begin{array}{l}\text { Uso de la Mesa de Partes Electrónica } \\
\text { (MPE) en el marco de la R. A. } \\
\text { n. }{ }^{\circ} \text { 133-2020-CE-PJ }\end{array}$ & $\begin{array}{l}\text { A nivel } \\
\text { nacional }\end{array}$ & $\begin{array}{l}\text { Áreas de Informática e } \\
\text { Imagen Institucional }\end{array}$ & 70 \\
\hline
\end{tabular}

Elaboración: Secretaría Técnica de la Comisión de Trabajo del EJE.

\subsubsection{II Congreso Internacional}

El 2020 se realizó el II Congreso Internacional del Expediente Judicial Electrónico. El evento se desarrolló de manera virtual, como se detalló en el punto 4.1.2, y fueron capacitadas 140 personas, entre magistrados $\mathrm{y}$ autoridades.

Tabla n. ${ }^{\circ}$ 52. Cantidad de capacitados en el II Congreso Internacional

\begin{tabular}{|c|c|c|}
\hline N. ${ }^{\circ}$ & Descripción & N. ${ }^{\circ}$ capacitados \\
\hline 1 & II Congreso Internacional & 140 \\
\hline
\end{tabular}

Elaboración: Secretaría Técnica de la Comisión de Trabajo del EJE.

El total de capacitados internos en los años 2019 y 2020 se puede ver en la siguiente tabla:

Tabla n. ${ }^{\circ}$ 53. Cantidad de capacitados internos durante el 2019 y el 2020

\begin{tabular}{|c|c|c|}
\hline Año & N. ${ }^{\circ}$ capacitados & Variación \\
\hline 2019 & 392 & \\
\hline 2020 & 2216 & $465 \%$ \\
\hline Total de capacitados & 2608 & \\
\hline
\end{tabular}

Elaboración: Secretaría Técnica de la Comisión de Trabajo del EJE. 
De la información mostrada se observa que la cantidad de capacitados internos, respecto al año anterior, se incrementó en $465 \%$ durante el 2020.

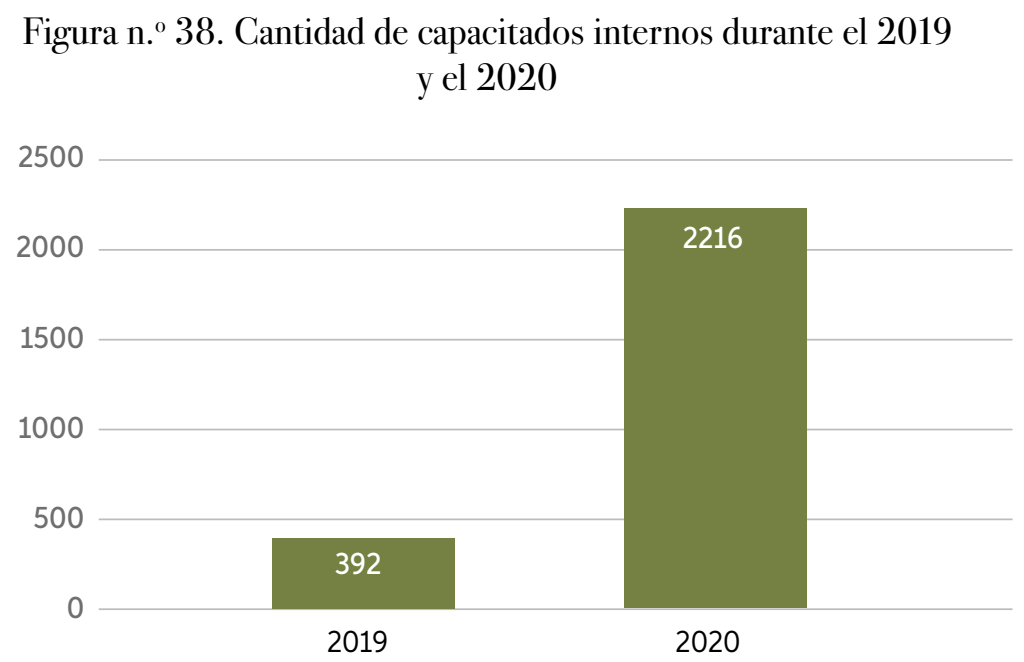

Fecha de actualización: 31 de diciembre de 2020.

Elaboración: Secretaría Técnica de la Comisión de Trabajo del EJE. 



\section{Capítulo V}

\section{PROYECCIONES}

El Ministerio de Economía y Finanzas y el Banco Mundial suscribieron un convenio en el último trimestre del 2019. En este se concede un préstamo para ejecutar el proyecto "Mejoramiento de los servicios de justicia no penales a nivel nacional en el Poder Judicial» a través del Expediente Judicial Electrónico. El objetivo principal es la transformación del expediente judicial de papel a uno electrónico de forma progresiva y que estará presente en los 35 distritos judiciales del país.

Actualmente, se encuentra en proceso el inicio de las actividades que forman parte de este proyecto. Esto se dará en función de las lecciones aprendidas en el proceso de planeamiento y metodología del desarrollo de actividades de implantación que viene desarrollando el Expediente Judicial Electrónico.

A continuación transcribimos la nota de prensa del Ministerio de Economía y Finanzas (2019) respecto a este convenio:

El Gobierno del Perú, representado por el Ministerio de Economía y Finanzas, y el Banco Mundial suscribieron un convenio de préstamo por hasta US\$ 85 millones para la implementación del programa: «Mejoramiento de los servicios de justicia no penales a través de la implementación del Expediente Judicial Electrónico (EJE)», el cual permitirá la interoperabilidad de los sistemas vinculados a la administración de justicia en el país, tales como: el Poder Judicial, la Academia de la Magistratura, la Junta Nacional de Justicia, el Tribunal Constitucional y del Ministerio de Justicia y Derechos Humanos.

El programa apunta a modernizar y dar celeridad a los servicios de justicia, disminuyendo los gastos de los ciudadanos para acceder a los sistemas de justicia del país. La inversión total de este programa es un monto equivalente a US\$ 158.13 millones, que será financiado con los US $\$ 85$ millones otorgados por el Banco Mundial, y la diferencia será cubierta mediante una contrapartida nacional. 
Este componente ayuda a los ciudadanos vulnerables a acceder al apoyo para resolver disputas legales y conflictos, al igual que manejando reclamos administrativos con el Estado. Asimismo, apoya al mejoramiento y ampliación de programas existentes que proveen servicios de justicia a población vulnerable, en particular los Centros de Asistencia Legal Gratuita (ALEGRA).

La ministra de Economía y Finanzas, María Antonieta Alva, sostuvo que «el gobierno a través de este programa busca mejorar la eficiencia, el acceso, la transparencia y la satisfacción del usuario en la entrega de los servicios de justicia a través de la adecuada implementación del Expediente Judicial Electrónico no penal, un servicio crítico para generar un país con más oportunidades». Además, la ministra señaló que la prioridad que ha dado este Gobierno a la reforma de justicia se materializa en hechos concretos, así el presupuesto público del próximo año incluye un aumento de 986 millones para seguir avanzando en esta dirección. Este aumento beneficiará, entre otros, al Ministerio de Justicia y Derechos Humanos, al Poder Judicial y a la Fiscalía. Asimismo, este programa, que se ejecutará en los siguientes cinco años, contará con US\$73 millones adicionales financiados por el tesoro público.

Por su parte, la directora del Banco Mundial para Bolivia, Chile, Ecuador y Perú, Marianne Fay, expresó que «el Banco Mundial apoya al Perú en sus esfuerzos para mejorar el acceso a servicios de justicia de calidad para todas las personas, en especial, para aquellas en una mayor situación de vulnerabilidad. El uso de nuevas tecnologías de la información junto con la implementación de medidas clave para fortalecer la gestión permitirá derribar barreras de acceso y aumentar la eficiencia de los servicios, a la vez que se reducen los costos y aumenta la transparencia».

Asimismo, la ministra de Justicia y Derechos Humanos, Ana Teresa Revilla, resaltó que gracias al esfuerzo del gobierno y la ayuda del Banco Mundial, más peruanos y peruanas tendrán acceso a los sistemas de justicia del país. Por ello, este proyecto se constituye en un importante esfuerzo de coordinación y voluntad de las entidades participantes a fin de abordar la solución de problemas que atañen a la justicia en nuestro país. Además, representa la confianza de uno de los organismos internacionales más importantes, como es el Banco Mundial, en el mejoramiento de nuestro sistema de justicia, y debe de servir para lograr la aspiración de la ciudadanía de contar con una justicia célere, oportuna, transparente y libre de corrupción.

148 Expediente Judicial Electrónico 


\section{Mejores servicios de justicia}

El programa «Mejoramiento de los servicios de justicia no penales a través de la implementación del Expediente Judicial Electrónico (EJE)» demanda el despliegue de una serie de componentes como la mejora institucional del sistema de administración de justicia en materia no penal; la mayor producción, análisis y transmisión de la información de los operadores de justicia; la disminución de barreras socioeconómicas, culturales y geográficas que limitan el acceso a la justicia de la población vulnerable; y una mayor eficiencia de los operadores de justicia en la prestación del servicio de justicia al ciudadano.

La mejora institucional del sistema de administración de justicia en materia no penal tiene como objetivo otorgar servicios más eficientes y transparentes en el Poder Judicial, en la Junta Nacional de Justicia y en el Tribunal Constitucional. Con este objetivo se revisarán y rediseñarán los procesos jurisdiccionales y administrativos existentes y se implementará el sistema de información EJE a nivel nacional.

Asimismo, como parte de la mayor producción, análisis y transmisión de la información de los operadores de justicia, se realizará el fortalecimiento de los mecanismos de monitoreo y control del desempeño en el Poder Judicial, el Tribunal Constitucional y la Junta Nacional de Justicia.

Respecto a la disminución de barreras socioeconómicas, culturales y geográficas que limitan el acceso a la justicia de la población vulnerable, el programa apunta a mejorar y ampliar los programas e iniciativas existentes que proveen servicios de justicia a población vulnerable, en particular de los Centros de Asistencia Legal Gratuita (ALEGRA).

Para los próximos cinco años se contempla llevar a cabo las siguientes acciones:

- Diseño general de los procesos jurisdiccionales y de la gestión de despacho.

- Desarrollo aplicativo informático.

- Implementación de programas de capacitación.

- Implementación del marco jurídico.

- Realización de evaluaciones de impacto y encuestas de satisfacción. 
- Implementación de estrategia para mejorar la transparencia y acceso a la información del Poder Judicial.

- Implementación de mecanismos de monitoreo.

- Implementación de justicia itinerante.

En este contexto, existen resultados de la transformación digital que se encuentran en proceso. Adicionalmente, mediante la Resolución Administrativa n. ${ }^{\circ}$ 484-2019-CE-PJ se estableció la Comisión Nacional de Gestión e Innovación Tecnológica del Poder Judicial, que tendrá como funciones:

a) La implementación de nuevas tecnologías en el trámite de los expedientes judiciales.

b) La reorganización de los despachos judiciales.

c) Una reforma en el soporte de gestión administrativa.

También debemos anotar que se encuentran en proceso de consolidación algunos de los resultados obtenidos:

Esquema n. ${ }^{\circ} 22$. Resultados de la transformación digital de la justicia peruana

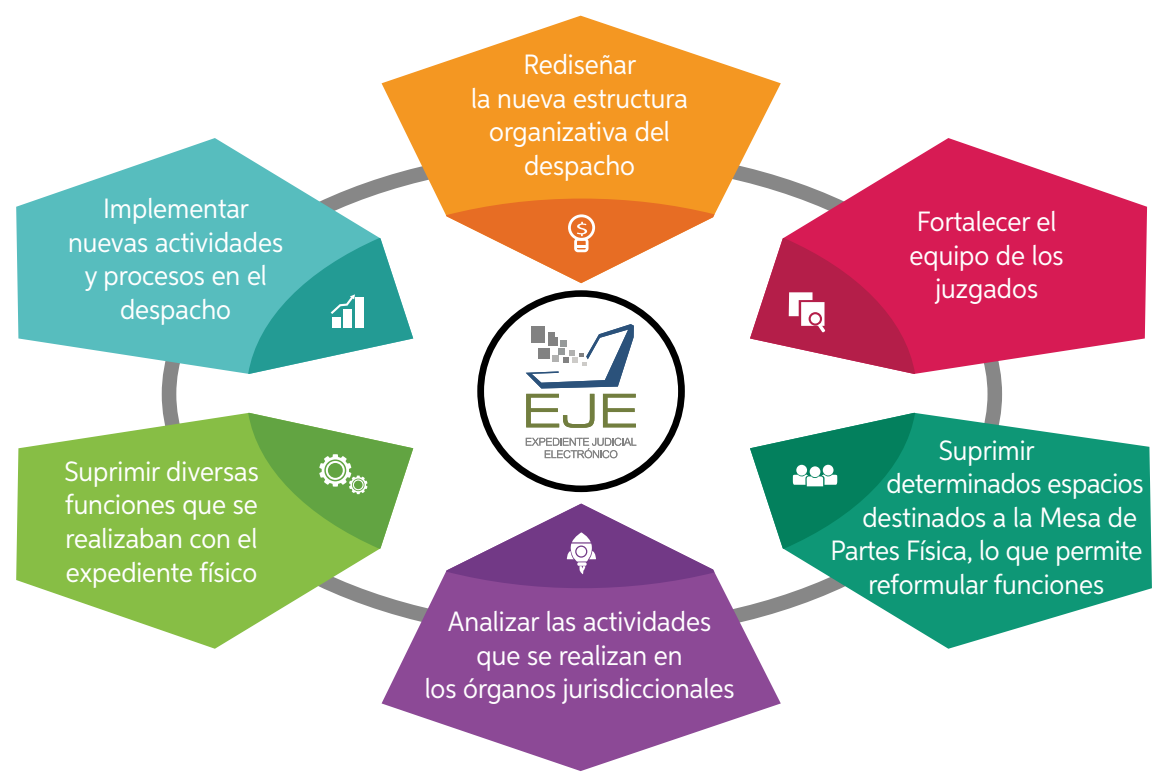

Elaboración: Secretaría Técnica de la Comisión de Trabajo del EJE. 


\section{Con tal fin:}

la implementación y uso de las Tecnologías de Información y Comunicaciones, en el servicio de administración de justicia, implican necesariamente un cambio de modelo de los despachos judiciales; así como un cambio de diseńo del soporte administrativo, acciones que no pueden ser aisladas, sino coordinadas, integradas y entrelazadas entre sí, dado que el éxito de una depende de las otras (Consejo Ejecutivo del Poder Judicial, 2019d, décimo considerando).

En vista de ello, se han identificado algunas tareas desarrolladas en el proceso de modernización del Poder Judicial según el siguiente esquema:

Esquema n..$^{\circ}$ 23. Tareas desarrolladas por los componentes de las actividades del Poder Judicial en el proceso de modernización de los servicios de justicia en el aspecto tecnológico en tiempos de la COVID-19

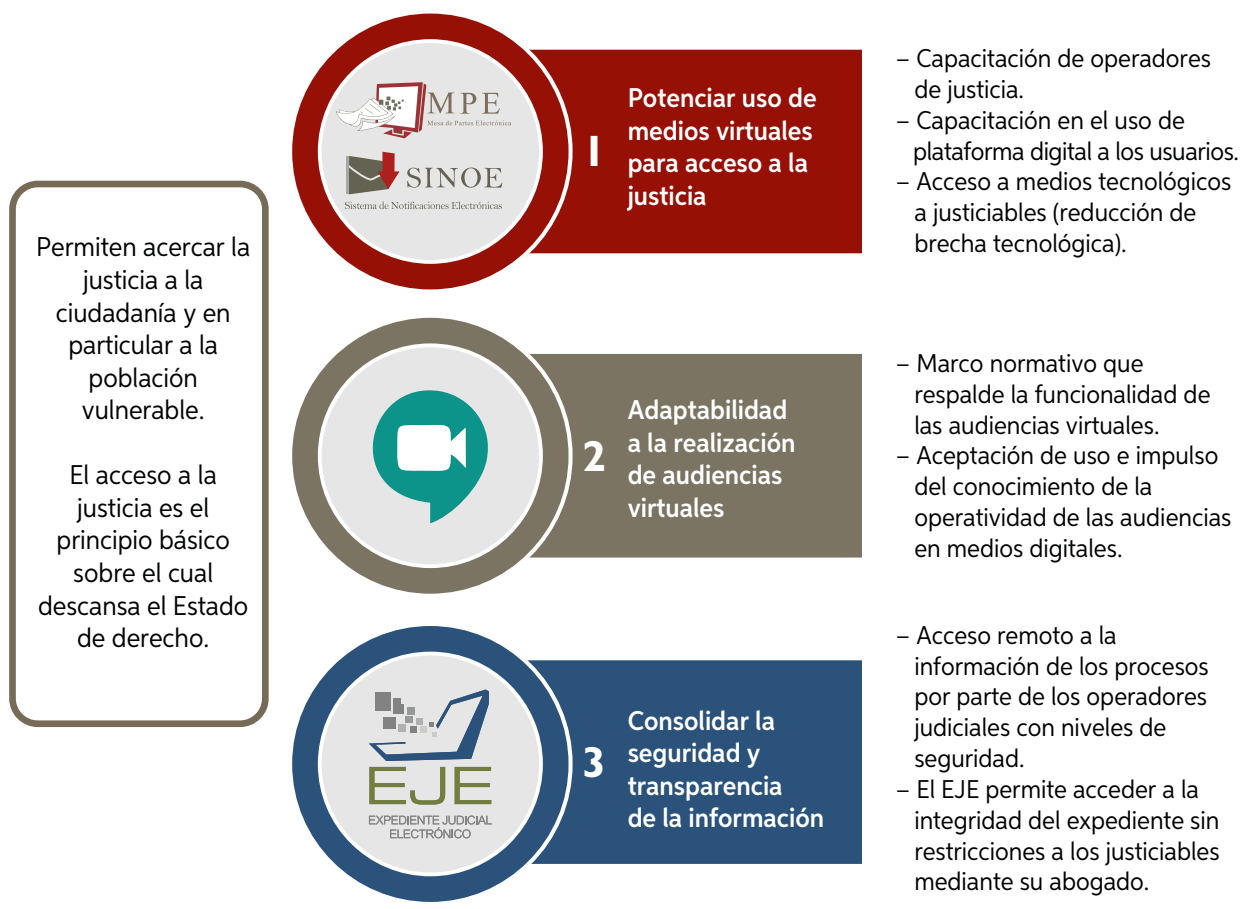

Elaboración: Secretaría Técnica de la Comisión de Trabajo del EJE. 
El Consejo Ejecutivo, como uno de los órganos de dirección del Poder Judicial, en ejercicio de sus funciones de llevar a cabo las acciones tendientes al mejoramiento de la administración de justicia, y con la facultad de designar comisiones de asesoramiento, investigación y estudio, consideró necesario constituir al interior del Poder Judicial un ente rector que se encargue de la función de proponer, coordinar, dirigir, integrar, supervisar y monitorear las acciones derivadas de la ejecución del programa «Mejoramiento de los servicios de justicia no penales a través de la implementación del Expediente Judicial Electrónico (EJE)». De este modo, se creó la Comisión Nacional de Gestión e Innovación Tecnológica del Poder Judicial, que estará conformada por:

a) El Presidente del Poder Judicial y del Consejo Ejecutivo del Poder Judicial.

b) El consejero responsable del Equipo Técnico Institucional de la Nueva Ley Procesal del Trabajo.

c) El consejero responsable de la Unidad de Gestión de Despacho Judicial.

d) El presidente de la Comisión de Trabajo del Expediente Judicial Electrónico (EJE).

e) El gerente general del Poder Judicial. 
Esquema n. ${ }^{\circ}$ 24. Conformación de la Comisión Nacional de Gestión e Innovación Tecnológica del Poder Judicial

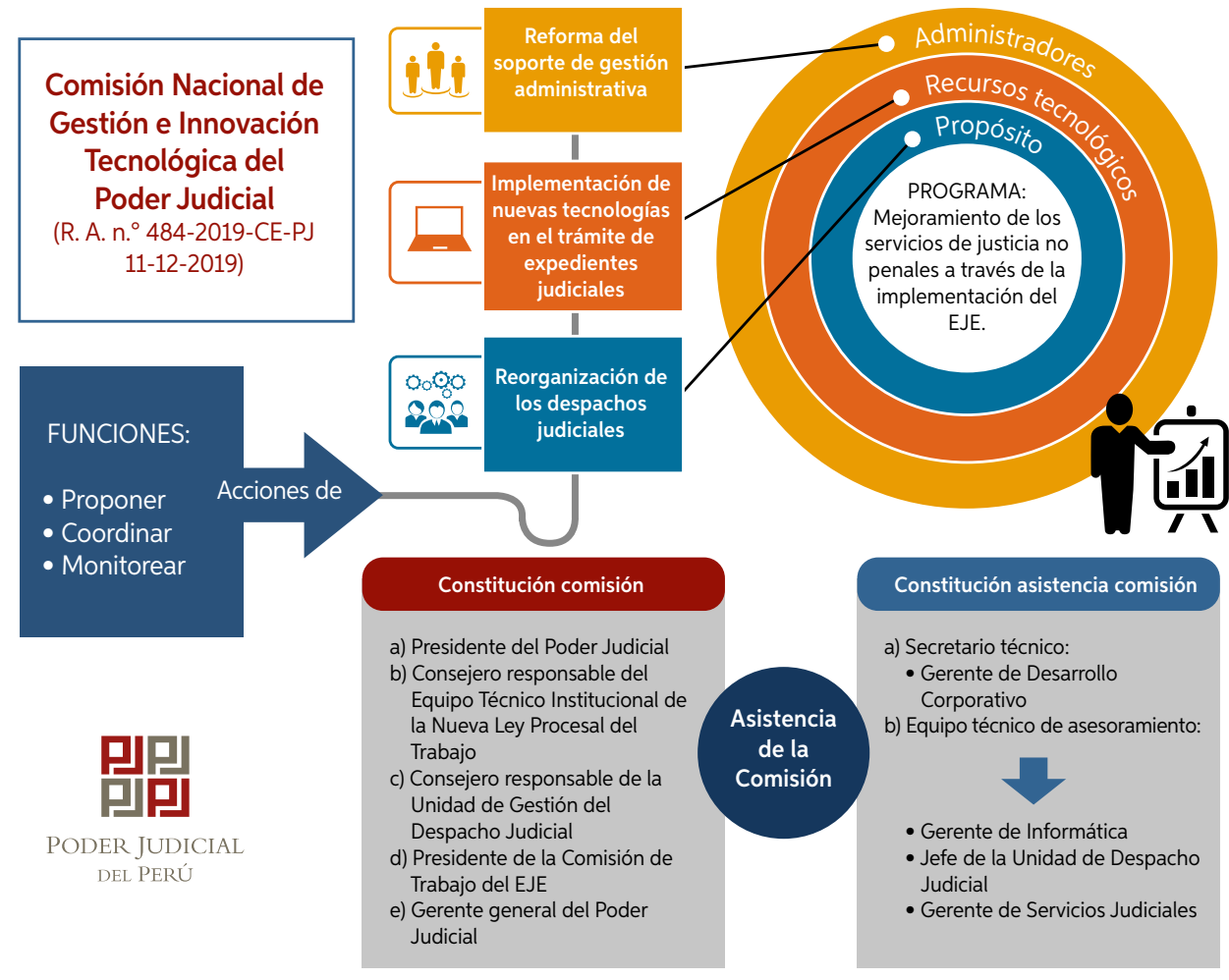

Elaboración: Secretaría Técnica de la Comisión de Trabajo del EJE.

\subsection{Desafíos y retos}

La existencia de una brecha, potencial o presente, que dificulte el acceso a la justicia digital no puede frenar su implementación. Sería como dejar de bregar por un derecho ante la insatisfacción total de otro. El camino es simple y obvio, el Estado debe luchar por todos los derechos, consciente de que su satisfacción plena no llegará al mismo tiempo.

En el Poder Judicial, y en especial en el equipo de implementación del EJE, sabemos que existe una brecha digital que debemos superar. Por ello nuestros esfuerzos se focalizan no solo en el desarrollo del EJE en sí mismo, sino en el diseño y aplicación de las estrategias institucionales para disminuir esa brecha, que podrá ser superada no 
solo con nuestro concurso, sino con políticas públicas sostenidas, generalizadas y transversales, en todo el Estado, a fin de lograr una verdadera alfabetización digital y acercar las ventajas de la tecnología a todos los peruanos tanto en un nivel conceptual como material. 


\section{LISTA DE ESQUEMAS}

Esquema n. ${ }^{\circ}$ 1. Antecedentes de iniciativas de transformación digital en el sistema de justicia en el Perú, previo al EJE

Esquema n. ${ }^{\circ}$ 2. Componentes de la modernización del despacho judicial

Esquema n. ${ }^{\circ}$ 3. Tecnología en los procesos judiciales

Esquema n. ${ }^{\circ}$ 4. Componentes del Expediente Judicial Electrónico (EJE)

Esquema n. ${ }^{\circ}$ 5. Evolución del proceso de implementación del EJE en las cortes superiores de justicia

Esquema n. ${ }^{\circ}$ 6. Órganos jurisdiccionales implementados con el EJE

Esquema n. ${ }^{\circ}$ 7. Especialidad de los órganos jurisdiccionales implementados con el EJE

Esquema n. ${ }^{\circ}$ 8. Flujo del proceso de modernización de los servicios de justicia

Esquema n. ${ }^{\circ}$ 9. Plan Estratégico Institucional (PEI) del Poder Judicial para el periodo 2020-2030

Esquema n. ${ }^{\circ}$ 10. Resumen de la metodología de las tareas de implementación del Expediente Judicial Electrónico en la justicia peruana

Esquema n. ${ }^{\circ} 11$. Elementos de motivación del uso del Expediente Judicial Electrónico como elemento de transformación digital en el Poder Judicial 
Esquema n. ${ }^{\circ}$ 12. Medidas del Poder Judicial para enfrentar la pandemia y brindar acceso a la justicia

Esquema n. ${ }^{\circ}$ 13. Aporte de la introducción de las TIC en la administración de justicia

Esquema n. ${ }^{\circ} 14$. Beneficios para la labor jurisdiccional y el justiciable

Esquema n. ${ }^{\circ} 15$. Buenas prácticas en el uso del Expediente Judicial Electrónico en el despacho judicial

Esquema n. ${ }^{\circ}$ 16. Resultado del Expediente Judicial Electrónico

Esquema n. ${ }^{\circ}$ 17. Ahorro de papel en beneficio de la conservación del medio ambiente

Esquema n. ${ }^{\circ}$ 18. Fortalecimiento de la institucionalidad nacional y la predictibilidad

Esquema n. ${ }^{\circ}$ 19. Modelo de notificación judicial

Esquema n. ${ }^{\circ}$ 20. Con la R. A. n. ${ }^{\circ}$ 133-2020-CE-PJ se habilita la MPE para diversas especialidades

Esquema n. ${ }^{\circ}$ 21. Etapas de implementación de la Mesa de Partes Electrónica a nivel nacional

Esquema n. ${ }^{\circ} 22$. Resultados de la transformación digital de la justicia peruana

Esquema n. ${ }^{\circ}$ 23. Tareas desarrolladas por los componentes de las actividades del Poder Judicial en el proceso de modernización de los servicios de justicia en el aspecto tecnológico en tiempos de la COVID-19

Esquema n. ${ }^{\circ}$ 24. Conformación de la Comisión Nacional de Gestión e Innovación Tecnológica del Poder Judicial 


\section{LISTA DE FIGURAS}

Figura n. ${ }^{\circ}$ 1. Órganos jurisdiccionales implementados con el EJE por tipo de órgano jurisdiccional

Figura n. ${ }^{\circ}$ 2. Órganos jurisdiccionales implementados con el EJE por año

Figura n. ${ }^{\circ}$ 3. Órganos jurisdiccionales implementados con el EJE por especialidad

Figura n. ${ }^{\circ}$ 4. Avance del EJE respecto a las 27 cortes superiores de justicia que aplican la NLPT

Figura n. ${ }^{\circ}$ 5. Cantidad de demandas EJE ingresadas por especialidad y tipo de órgano jurisdiccional

Figura n. ${ }^{\circ}$ 6. Cantidad de demandas EJE ingresadas por tipo de órgano jurisdiccional

Figura n. ${ }^{\circ}$ 7. Cantidad de demandas EJE ingresadas por tipo de órgano jurisdiccional

Figura n. ${ }^{\circ}$ 8. Demandas EJE ingresadas por especialidad y tipo de órgano jurisdiccional

Figura n. ${ }^{\circ}$ 9. Demandas EJE ingresadas por tipo de órgano jurisdiccional en la especialidad laboral-NLPT

Figura n. ${ }^{\circ} 10$. Cantidad de EJE que terminaron su proceso de primera instancia por tipo de órgano jurisdiccional

Figura n. ${ }^{\circ} 11$. Cantidad de expedientes judiciales electrónicos apelados por tipo de órgano jurisdiccional 
Figura n. ${ }^{\circ}$ 12. Cantidad de EJE que terminaron su proceso de segunda instancia por tipo de órgano jurisdiccional

Figura n. ${ }^{\circ} 13$. EJE elevados a la Corte Suprema de Justicia de la República por tipo de órgano jurisdiccional

Figura n. ${ }^{\circ}$ 14. Comparación del tiempo de calificación de la demanda (días hábiles) CSJ de Lima

Figura n. ${ }^{\circ}$ 15. Comparación del tiempo de calificación de la demanda (días hábiles) otras CSJ

Figura n. ${ }^{\circ} 16$. Comparación del tiempo de proveído de escritos (días hábiles) CSJ de Lima

Figura n. ${ }^{\circ} 17$. Comparación del tiempo de proveído de escritos (días hábiles) otras CSJ

Figura n. ${ }^{\circ}$ 18. Comparación del tiempo de duración del proceso en primera instancia (días hábiles) CSJ de Lima

Figura n. ${ }^{\circ}$ 19. Comparación del tiempo de duración del proceso en primera instancia (días hábiles) otras CSJ

Figura n. ${ }^{\circ}$ 20. Comparación del tiempo de duración del proceso en segunda instancia (días hábiles) CSJ de Lima

Figura n. ${ }^{\circ}$ 21. Comparación del tiempo de duración del proceso en segunda instancia (días hábiles) otras CSJ

Figura n. ${ }^{\circ}$ 22. Videoconferencias desarrolladas en época de pandemia por CSJ

Figura n. ${ }^{\circ}$ 23. Casillas electrónicas aperturadas por año (20092020)

Figura n. ${ }^{\circ}$ 24. Casillas aperturadas por tipo de usuario (20092020)

Figura n. ${ }^{\circ}$ 25. Casillas aperturadas por año y tipo de usuario (2009-2020) 
Figura n. ${ }^{\circ}$ 26. Casillas aperturadas por corte superior de justicia (2009-2020)

Figura n. ${ }^{\circ}$ 27. Cédulas físicas y electrónicas por año (20092020)

Figura n. ${ }^{\circ} 28$. Cédulas de notificación físicas y electrónicas por corte superior de justicia (2009-2020)

Figura n. ${ }^{\circ} 29$. Cédulas físicas y electrónicas por nivel del órgano (2009-2020)

Figura n. ${ }^{\circ}$ 30. Cédulas electrónicas por especialidad (20092020)

Figura n. ${ }^{\circ}$ 31. Porcentaje de uso de la Mesa de Partes Electrónica (MPE) para la presentación de las demandas

Figura n. ${ }^{\circ} 32$. Porcentaje de uso de la Mesa de Partes Electrónica (MPE) para la presentación de las demandas durante el año 2020

Figura n. ${ }^{\circ} 33$. Porcentaje de uso de la Mesa de Partes Electrónica (MPE) para la presentación de escritos

Figura n. ${ }^{\circ}$ 34. Porcentaje de uso de la Mesa de Partes Electrónica (MPE) para la presentación de escritos durante el ańo 2020

Figura n. ${ }^{\circ} 35$. Uso de la Mesa de Partes Electrónica (MPE) según tipo de ingreso en aplicación de la R. A. n. ${ }^{\circ}$ 133-2020-CE-PJ al 31-12-2020

Figura n. ${ }^{\circ} 36$. Citas electrónicas por sede judicial generadas al 31-12-2020

Figura n. ${ }^{\circ}$ 37. Cantidad de capacitados externos durante el 2019 y el 2020

Figura n. ${ }^{\circ}$ 38. Cantidad de capacitados internos durante el 2019 y el 2020 



\section{LISTA DE TABLAS}

Tabla n. ${ }^{\circ}$ 1. Órganos jurisdiccionales implementados con el EJE

Tabla n. ${ }^{\circ}$ 2. Cantidad de demandas EJE ingresadas al Poder Judicial

Tabla n. ${ }^{\circ}$ 3. Demandas EJE ingresadas por especialidad y tipo de órgano jurisdiccional

Tabla n. ${ }^{\circ}$ 4. Demandas EJE ingresadas por tipo de órgano jurisdiccional en la especialidad laboral-NLPT

Tabla n. ${ }^{\circ}$ 5. Cantidad de EJE que terminaron su proceso de primera instancia

Tabla n. ${ }^{\circ}$ 6. Cantidad de expedientes judiciales electrónicos apelados

Tabla n. ${ }^{\circ}$ 7. Cantidad de EJE que terminaron su proceso de segunda instancia

Tabla n. ${ }^{\circ}$ 8. Cantidad de elevaciones a las salas de la Corte Suprema de Justicia de la República

Tabla n. ${ }^{\circ}$ 9. Disminución del tiempo de calificación de la demanda (días hábiles) CSJ de Lima

Tabla n. ${ }^{\circ}$ 10. Disminución del tiempo de calificación de la demanda (días hábiles) otras CSJ

Tabla n. ${ }^{\circ} 11$. Disminución del tiempo de proveído de escritos (días hábiles) CSJ de Lima 
Tabla n. ${ }^{\circ}$ 12. Disminución del tiempo de proveído de escritos (días hábiles) otras CSJ

Tabla n. ${ }^{\circ} 13$. Disminución del tiempo de duración del proceso en primera instancia (días hábiles) CSJ de Lima

Tabla n. ${ }^{\circ} 14$. Disminución del tiempo de duración del proceso en primera instancia (días hábiles) otras CSJ

Tabla n. ${ }^{\circ} 15$. Disminución del tiempo de duración del proceso en segunda instancia (días hábiles) CSJ de Lima

Tabla n. ${ }^{\circ}$ 16. Disminución del tiempo de duración del proceso en segunda instancia (días hábiles) otras CSJ

Tabla n. ${ }^{\circ}$ 17. Casillas electrónicas por año (2009-2020)

Tabla n. ${ }^{\circ}$ 18. Casillas aperturadas por tipo de usuario (20092020)

Tabla n. ${ }^{\circ}$ 19. Casillas aperturadas por tipo de usuario y año (2009-2020)

Tabla n. ${ }^{\circ} 20$. Cédulas de notificación físicas y electrónicas por año (2009-2020)

Tabla n. ${ }^{\circ}$ 21. Uso de la Mesa de Partes Electrónica (MPE) para la presentación de las demandas

Tabla n. ${ }^{\circ}$ 22. Porcentaje de uso de la Mesa de Partes Electrónica (MPE) para la presentación de las demandas en el año 2020

Tabla n. ${ }^{\circ}$ 23. Porcentaje de uso de la Mesa de Partes Electrónica (MPE) para la presentación de las demandas en el año 2020

Tabla n. ${ }^{\circ} 24$. Uso de la Mesa de Partes Electrónica (MPE) para la presentación de escritos

Tabla n. ${ }^{\circ} 25$. Porcentaje de uso de la Mesa de Partes Electrónica (MPE) para la presentación de escritos en el año 2020

Tabla n. ${ }^{\circ}$ 26. Porcentaje de uso de la Mesa de Partes Electrónica (MPE) para la presentación de escritos en el año 2020 
Tabla n..$^{\circ}$ 27. Participantes del taller de intercambio de experiencias

Tabla n. ${ }^{\circ} 28$. Participantes y alcance del congreso

Tabla n. ${ }^{\circ} 29$. Participantes en los talleres teórico-prácticos

Tabla n. ${ }^{\circ} 30$. Abogados participantes en las conferencias

Tabla n. ${ }^{\circ} 31$. Estudiantes participantes en las conferencias

Tabla n. ${ }^{\circ} 32$. Participantes en visitas guiadas

Tabla n. ${ }^{\circ} 33$. Número de capacitados en las charlas al público en general

Tabla n. ${ }^{\circ}$ 34. Número de capacitados en el taller in-house

Tabla n. ${ }^{\circ} 35$. Participantes de la videoconferencia

Tabla n. ${ }^{\circ} 36$. Alcance de la videoconferencia

Tabla n. ${ }^{\circ} 37$. Cantidad de capacitados antes de la implementación según la R. A n. ${ }^{\circ} 000142-2020-C E-P J$

Tabla n. ${ }^{\circ} 38$. Cantidad de capacitados antes de la implementación según la R. A. n. ${ }^{\circ}$ 000262-2020-CE-PJ

Tabla n. ${ }^{\circ}$ 39. Cantidad de capacitados según la R. A. n. $000152-$ 2020-CE-PJ

Tabla n. ${ }^{\circ} 40$. Cantidad de capacitados según la R. A. n. ${ }^{\circ} 000133-$ 2020-CE-PJ

Tabla n. ${ }^{\circ}$ 41. Número de participantes en el II Congreso Internacional

Tabla n. ${ }^{\circ}$ 42. Cantidad de capacitados externos durante el 2019 y el 2020

Tabla n. ${ }^{\circ}$ 43. Cantidad de capacitados en charlas de inducción

Tabla n. ${ }^{\circ} 44$. Número de capacitados en charla a personal de la Odecma 
Tabla n. ${ }^{\circ}$ 45. Número de capacitados en el I Congreso Internacional

Tabla n. ${ }^{\circ}$ 46. Cantidad de capacitados según la R. A. n. ${ }^{\circ} 00060-$ 2020-P-CE-PJ

Tabla $n .^{\circ}$ 47. Cantidad de capacitados antes de la implementación según la R. A. n. ${ }^{\circ}$ 000142-2020-CE-PJ

Tabla n. ${ }^{\circ}$ 48. Cantidad de capacitados antes de la implementación según la R. A. n. ${ }^{\circ}$ 000262-2020-CE-PJ

Tabla n. ${ }^{\circ}$ 49. Cantidad de capacitados antes de la implementación según la R. A. n. ${ }^{\circ}$ 000379-2020-CE-PJ

Tabla . $^{\circ}$ 50. Cantidad de capacitados antes de la implementación según la R. A. n. ${ }^{\circ}$ 000138-2020-CE-PJ

Tabla n. ${ }^{\circ}$ 51. Cantidad de capacitados en el uso de la Mesa de Partes Electrónica

Tabla n. ${ }^{\circ}$ 52. Cantidad de capacitados en el II Congreso Internacional

Tabla n. ${ }^{\circ}$ 53. Cantidad de capacitados internos durante el 2019 y el 2020 


\section{REFERENCIAS}

Aspis, A. (2010). Las TICs y el rol de la justicia en Latinoamérica. Derecho \& Sociedad, (35), 327-340. http://revistas.pucp.edu.pe/ index.php/derechoysociedad/article/view/13311

Consejo Ejecutivo del Poder Judicial (2017a). Resolución Administrativa n. ${ }^{\circ}$ 228-2017-CE-PJ. Lima: 26 de julio de 2017. https://www.pj.gob.pe/wps/wcm/connect/9eb4450042 15f841a08ff2b3be91b58f/RA_228_2017_CE_PJ+-+26_ 06_2017_OK.pdf?MOD=AJPERES\&CACHEID $=9 \mathrm{eb} 44500$ 4215f841a08ff2b3be91b58f (2017b). Resolución Administrativa n. ${ }^{\circ}$ 345-2017-CE-PJ. Lima: 19 de diciembre de 2017. https://www.pj.gob.pe/wps/wcm/ connect/f74 a 4a 8046dc0a 5 e 8 aebdb5d3cd 1c288/RA _345_2017_CE_PJ\%20-\%2019_12_2017.pdf? MOD= AJPERES

(2018a). Resolución Administrativa n. ${ }^{\circ}$ 067-2018-CE-PJ. Lima: 6 de marzo de 2018. https://www.pj.gob.pe/wps/wcm/ connect/d7cfc8804505e47d926fda01a4a5d4c4/PEI-+PJ +APROBADO+2019-2021_OKOK.pdf?CACHEID $=\mathrm{d} 7 \mathrm{cfc} 8804505 \mathrm{e} 47 \mathrm{~d} 926 \mathrm{fda} 01 \mathrm{a} 4 \mathrm{a} 5 \mathrm{~d} 4 \mathrm{c} 4 \& \mathrm{MOD}=\mathrm{AJPERES}$ (2018b). Resolución Administrativa n. ${ }^{\circ}$ 198-2018-CE-PJ. Lima: 4 de julio de 2018. https:/www.pj.gob.pe/wps/wcm/ connect/b7980b004644ebadb6a2fe04d51e568e/RA_198 _2018_CE_PJ+-+04_07_2018.pdf?MOD=AJPERES \& CACHEID=b7980b004644ebadb6a2fe04d51e568e 
(2018b). Resolucion Administrativa n. ${ }^{\circ}$ 194-2018-P-CE-PJ. Lima: 29 de octubre de 2018. https://www.pj.gob.pe/wps/wcm/ connect/2f56c000478a61ec 8 d 088 f1612471008/ $\mathrm{RES}+194-2018-\mathrm{P}-\mathrm{CE}-\mathrm{PJ} \cdot \mathrm{pdf}$ ? MOD = A J PERES \& $\mathrm{CACHEID=2f56c000478a61ec8d088f1612471008}$ (2018c). Resolucion Administrativa n. ${ }^{\circ} 328-2018-C E-P J$. Lima: 19 de diciembre de 2018. https:/www.pj.gob.pe/wps/ $\mathrm{wcm} /$ connect/e65dc000486a5a9fb571bda38f54faeb/ RA_328_2018_CE_PJ+-+19_12_2018.pdf?MOD=AJPERES $\&$ CACHEID $=$ e65dc000486a5a9fb571bda38f54faeb (2019a). Resolución Administrativa n. ${ }^{\circ}$ 070-2019-CE-PJ. Lima: 13 de febrero de 2019. http://eje.pe/wps/wcm/connect/ b2d6dd804b95296587598791cd134a09/RA_070_2019_ CE_PJ.pdf?MOD=AJPERES\&CACHEID=b2d6dd $804 \mathrm{~b} 9$ 5296587598791cd134a09

(2019b). Resolución Administrativa n. ${ }^{\circ}$ 114-2019-CE-PJ. Lima: 13 de marzo de 2019. https://www.pj.gob.pe/wps/wcm/ connect/cf 1 f9b0049b8e986a065f3466 bedd $180 /$ RA_114_2019_CE_PJ+-+13_03_2019.pdf?MOD=AJPERES $\&$ CACHEID $=$ cf1f9b0049b8e986a065f3466bedd 180 (2019c). Resolución Administrativa n. ${ }^{\circ}$ 470-2019-CE-PJ. Lima: 27 de noviembre de 2019. http://eje.pe/wps/wcm/connect/ 42fa60804cbb53f1a968ebe93f7fa794/RA-470-2019-CE-PJ. pdf?MOD=AJPERES $\&$ CACHEID $=42 \mathrm{fa} 60804 \mathrm{cbb} 53 \mathrm{f} 1 \mathrm{a} 968 \mathrm{e}$ be93f7fa794

(2019d). Resolución Administrativa n. ${ }^{\circ}$ 484-2019-CE-PJ. Lima: 11 de diciembre de 2019. http://eje.pe/wps/wcm/connect/ 270f52804cbb5ab4aae7ebe93f7fa794/RA-484-2019-CE-PJ. pdf?MOD=AJPERES\&CACHEID=270f52804cbb5ab4aae7 ebe93f7fa794 (2020a). Resolución Administrativa n. ${ }^{\circ}$ 142-2020-CE-PJ. Lima: 11 de mayo de 2020. https://busquedas.elperuano.pe/normas legales/aprueban-la-ampliacion-del-proyecto-expediente -judicial-elec-resolucion-administrativa-n-000142-2020-ce-pj $-1866666-4 /$ 
(2020b). Resolución Administrativa n. ${ }^{\circ}$ 000206-2020-CE-PJ. Lima: 6 de agosto de 2020. https://busquedas.elperuano.pe/ normaslegales/disponen-la-implementacion-del-expediente -judicial-electroni-resolucion-administrativa-no-000206-2020 -ce-pj-1875717-2/

(2020c). Resolución Administrativa n. ${ }^{\circ}$ 000235-2020-CE-PJ. Lima: 31 de agosto de 2020. https://busquedas.elperuano.pe/ normaslegales/disponen-implementacion-del-expediente-judicial -electronico-resolucion-administrativa-no-000235-2020-ce -pj-1886647-4/

(2020d). Resolución Administrativa n. ${ }^{\circ}$ 251-2020-CE-PJ. Lima: 9 de septiembre de 2020. https://www.pj.gob.pe/wps/wcm/ connect/0017b8804fce90c1ba7ebf6976768c74/RA-251-2020 -CE-PJ.pdf?MOD=AJPERES\&CACHEID=0017b8804fce 90 c1ba7ebf6976768c74

(2020e). Resolución Administrativa n. ${ }^{\circ}$ 000262-2020-CE-PJ. Lima: 18 de septiembre de 2020. http://eje.pe/wps/wcm/ connect/16c427004fd7a78b99e0bd6976768c74/RA-000262 -2020-CE-PJ.pdf?MOD=AJPERES \&CACHEID = $16 c 42$ 7004fd7a78b99e0bd6976768c74

(2020f). Resolución Administrativa n. 309-2020-CE-PJ. Lima: 28 de octubre de 2020. https://www.pj.gob.pe/wps/wcm/connect/ e0538d80405b7940b95fbd6976768c74/RESOLUCION +ADMINISTRATIVA-000309-2020-CE.pdf?MOD=AJPERES $\&$ CACHEID $=\mathrm{e} 0538 \mathrm{~d} 80405 \mathrm{~b} 7940 \mathrm{~b} 95 \mathrm{fbd} 6976768 \mathrm{c} 74$

(2020g). Resolución Administrativa n. ${ }^{\circ}$ 320-2020-CE-PJ. Lima: 4 de noviembre de 2020. https://www.pj.gob.pe/wps/ wcm/connect/4d34ba0040b19c59bd24bd6976768c74/ RESOLUCION+ADMINISTRATIVA-000320-2020-CE.pdf? $\mathrm{MOD}=\mathrm{AJPERES} \& \mathrm{CACHEID}=4 \mathrm{~d} 34 \mathrm{ba} 0040 \mathrm{~b} 19 \mathrm{c} 59 \mathrm{bd} 24 \mathrm{~b}$ d6976768c74

(2020h). Resolución Administrativa n. ${ }^{\circ}$ 326-2020-CE-PJ. Lima: 11 de noviembre de 2020. https://www.pj.gob.pe/wps/ $\mathrm{wcm} /$ connect/82ce0d0040b1d4febf46bf6976768c74/ RESOLUCION+ADMINISTRATIVA-000326-2020-CE.pdf? $\mathrm{MOD}=\mathrm{AJPERES} \& \mathrm{CACHEID}=82 \mathrm{ce} 0 \mathrm{~d} 0040 \mathrm{~b} 1 \mathrm{~d} 4 \mathrm{febf} 46 \mathrm{~b}$ f6976768c74 
(2020i). Resolución Administrativa n. ${ }^{\circ}$ 338-2020-CE-PJ. Lima: 18 de noviembre de 2020. https://busquedas.elperuano. $\mathrm{pe} /$ normaslegales/disponen-la-implantacion-del-expediente -judicial-electronico-resolucion-administrativa-no-000338 -2020-ce-pj-1905082-1/

(2020j). Resolución Administrativa n. ${ }^{\circ}$ 343-2020-CE-PJ. Lima: 25 de noviembre de 2020. https://busquedas.elperuano.pe/ normaslegales/disponen-la-implantacion-del-expediente -judicial-electronico-resolucion-administrativa-no-000343 -2020-ce-pj-1906797-3/

(2020k). Resolución Administrativa n. ${ }^{\circ}$ 355-2020-CE-PJ. Lima: 2 de diciembre de 2020. https://busquedas.elperuano.pe/normas legales/disponen-la-implantacion-del-expediente-judicial -electronico-resolucion-administrativa-no-000355-2020-ce -pj-1908632-1/

(20201). Resolución Administrativa n. ${ }^{\circ}$ 379-2020-CE-PJ. Lima: 24 de diciembre de 2020. https://www.pj.gob.pe/ wps/wcm/connect/acbb3e804119b74a970cbf5aa55ef1d3/ RESOLUCION+ADMINISTRATIVA-000379-2020-CE.pdf? $\mathrm{MOD}=\mathrm{AJPERES} \& \mathrm{CACHEID}=\mathrm{acbb} 3 \mathrm{e} 804119 \mathrm{~b} 74 \mathrm{a} 970 \mathrm{cb}$ f5aa55ef1d3

(2020m). Resolución Administrativa n. ${ }^{\circ}$ 138-2020-P-CE-PJ. Lima: 28 de diciembre de 2020. http://eje.pe/wps/wcm/ connect/de7550004103be0e85f2bd5aa55ef1d3/RA-000138 -2020-P-CE-PJ.pdf? MOD=AJPERES \&CACHEID=de 7550004103be0e85f2bd5aa55ef1d3

Corte Superior de Justicia de Lima Norte (2019). Resolucion Administrativa n. ${ }^{\circ}$ 147-2019-P-CSJLIMANORTE/PJ. Independencia: 5 de febrero de 2019. https://busquedas.elperuano.pe/normas legales/autorizan-implementacion-del-expediente-judicial -electronico-resolucion-administrativa-no-147-2019-p-csjlima nortepj-1743176-2/ 
Ministerio de Economía y Finanzas (2019). El Gobierno del Perú y el Banco Mundial suscribieron convenio para modernizar y darle celeridad a los servicios de justicia en el país. Lima: 27 de noviembre de 2019. https://www.mef.gob.pe/en/?option=com_ content $\&$ language $=$ en $-\mathrm{GB} \&$ Itemid $=101108 \& \mathrm{view}=$ article $\&$ cat id $=0 \&$ id $=6231$ \&lang $=$ en $-G B$

Pozobón, P. (2012, 3 de noviembre). Carlos G. Gregorio - Investigador argentino habla sobre las TICs y la justicia. Las TICS en la justicia. https://ticsyjusticia.blogspot.com/2012/11/carlos-g-gregorio -investigador.html 



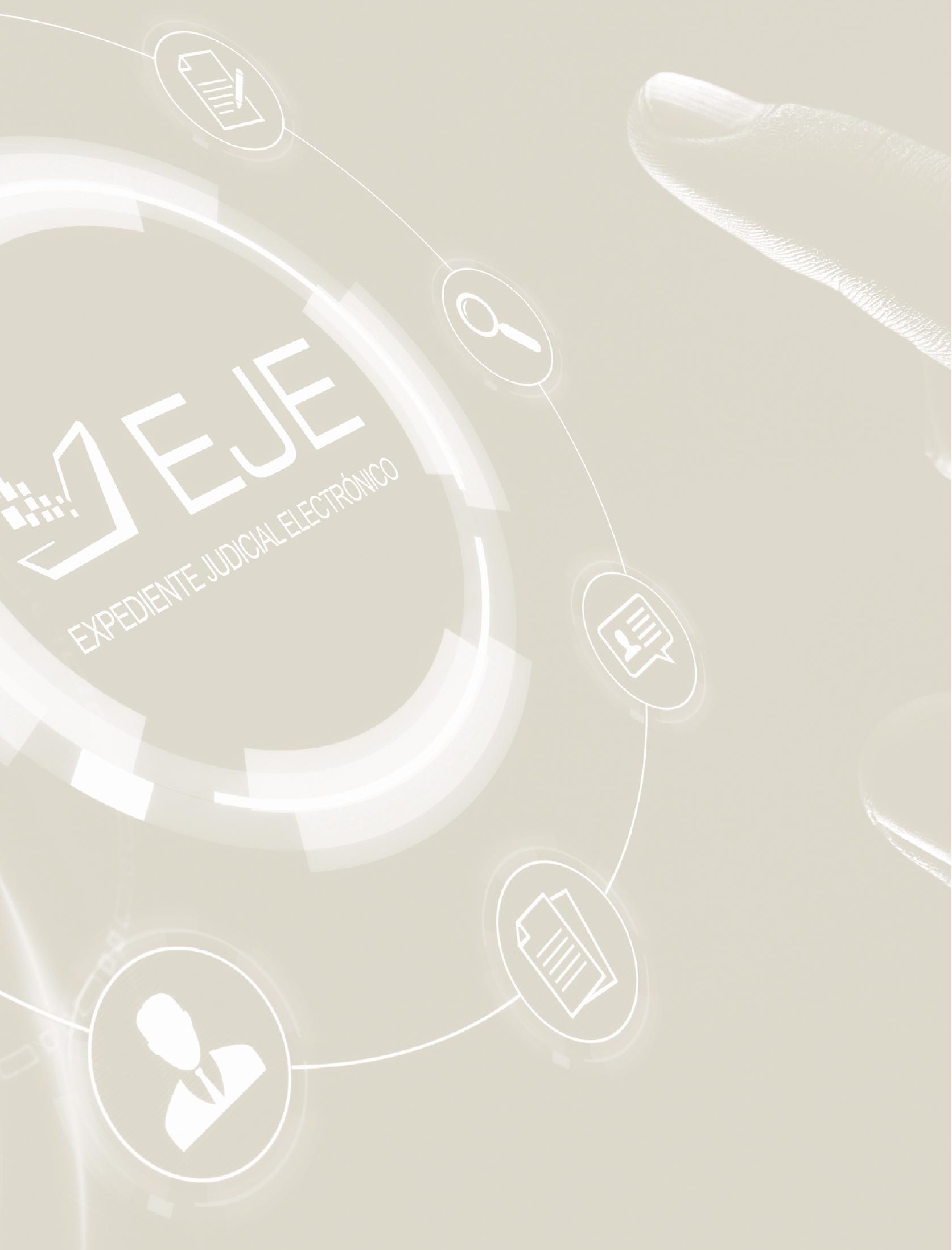




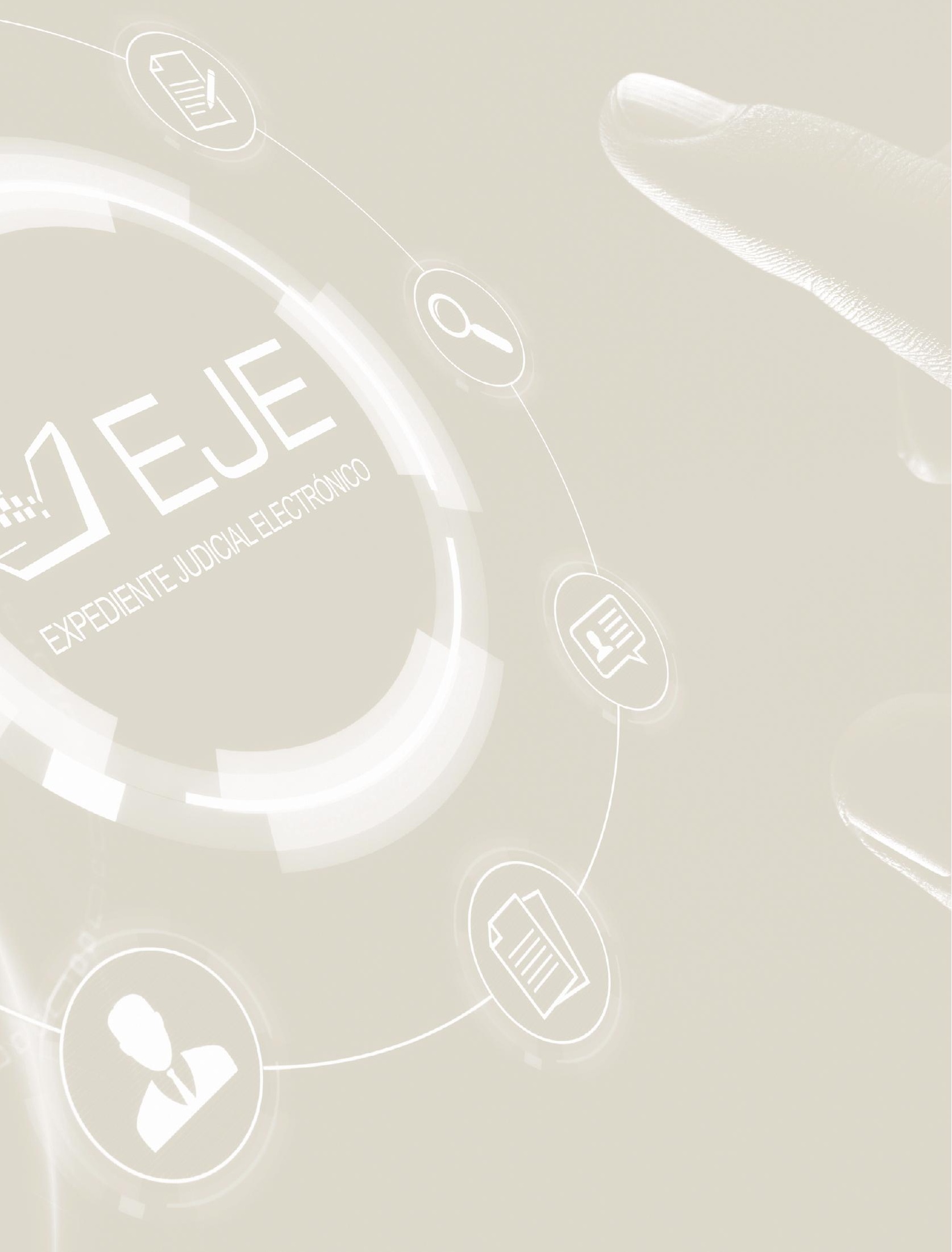


El Expediente Judicial Electrónico (EJE), que se implementó desde el año 2017 en diversas cortes superiores de justicia del país, ha sido determinante en la iniciativa de modernización del Poder Judicial. Con este se busca dejar de lado el uso de papel, el archivamiento antiguo y las notificaciones tradicionales presenciales, para cambiarlos por procesos judiciales digitales, que brinden soluciones céleres y eficaces para el acceso al servicio de justicia de la ciudadanía en el contexto de confinamiento por la COVID-19.

La transformación digital de este Poder del Estado supone la modernización del sistema de justicia, en lo referido a las facilidades de acceso del ciudadano de modo virtual o remoto, así como en el uso de la tecnología y plataformas informáticas en la tramitación de los procesos judiciales. Justamente la publicación de este libro muestra cómo se viene implementando el camino hacia la transformación digital dentro del Poder Judicial del Perú.

Héctor Enrique Lama More

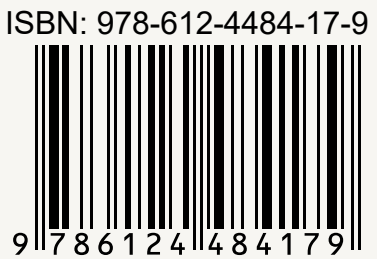

